REACTIVE PROCESSING OF SILICA-REINFORCED TIRE RUBBER

NEW INSIGHT INTO THE TIME- AND TEMPERATURE-DEPENDENCE OF SILICA RUBBER INTERACTION 


\section{YOKOHAMA}

The research described in this thesis was financially supported by the Yokohama Rubber Co., LTD.

Reactive Processing of Silica-Reinforced Tire Rubber:

New Insight into The Time- And Temperature-Dependence of Silica Rubber Interaction

By Satoshi Mihara

Ph.D thesis, University of Twente, Enschede, the Netherlands, 2009.

With references - With summary in English and Dutch.

Copy right (c) Satoshi Mihara, 2009.

All right reserved.

Cover design by Satoshi Mihara

Printed at Print Partners, Ipskamp, P. O. Box 333, $7500 \mathrm{AH}$, Enschede, the Netherlands.

ISBN: 978-90-365-2839-9 


\title{
REACTIVE PROCESSING OF SILICA-REINFORCED TIRE RUBBER
}

\author{
NEW INSIGHT INTO THE TIME- AND TEMPERATURE- \\ DEPENDENCE OF SILICA RUBBER INTERACTION
}

DISSERTATION

to obtain

the degree of doctor at the University of Twente, on the authority of the rector magnificus, prof.dr. H. Brinksma, on account of the decision of the graduation committee, to be publicly defended on Friday, 8of May at 15:00.

by

Satoshi Mihara

born on 5th March 1973

in Kumamoto, Japan 
This dissertation has been approved by:

Promoter : prof. dr. ir. J. W. M. Noordermeer

: dr. R. N. Datta 


\section{TABLE OF CONTENTS}

$\begin{array}{lll}\text { Chapter } 1 & \text { Introduction }\end{array}$

Chapter 2 Literature survey: overview of filler reinforcement

and silane chemistry

Chapter 3 Comparison study of silica:

determining factors of physical properties

of silica reinforced rubber

Chapter 4 Insight into the kinetics of silica flocculation in

silica reinforced rubber compounds

Chapter $5 \quad$ Ultra small-angle X-ray scattering study of

silica flocculation in filled rubber

Chapter 6 Reinforcement mechanism of silica with

alternatives for DPG: Part 1

Effect of $\mathrm{pKa}$ value of amines on the silaniziation

kinetics in model olefin experiments

Chapter $7 \quad$ Reinforcement mechanism of silica with

alternatives for DPG: Part 2 effect of amines

on silane chemistry in rubber processing 
Chapter 8

Reinforcement mechanism of silica with

alternatives for DPG: Part 3

Evaluation of quinuclidine and 3-quinuclidinol

in rubber compounds

Chapter $9 \quad$ Conclusions

Samenvatting

Symbols and abbreviations

Bibliography

Curriculum vitae

165

Acknowledgements 


\section{Chapter 1}

\section{INTRODUCTION}

\subsection{Historical overview of rubber technology}

The start of rubber history is the use of natural rubber (NR), made from a fluid known as latex. This material was discovered by the natives from Haiti to provide them with a material for a ball game and for water proofing of clothing. ${ }^{[1]}$ This fluid was commonly tapped from one of their local trees and then condensed. The tree, from which they tapped the latex, was called "caa-o-chu", meaning weeping tree ${ }^{[2]}$. It is well known that Columbus was the first person who saw rubber amongst the Europeans.

This material was brought to the Academy of Science in Paris in 1736 from Peru upon which scientists discovered an important application of this material, the rubber eraser. "Rubber" is derived from rubbing out of pencil marks with a small cube of rubber and later on, this material brought from Peru was given the name "rubber". [2]

The most important invention in rubber technology was vulcanization, which is named after the Roman God of Fire, Vulcan. This process was discovered by Charles Goodyear and even now, is one of key processes in rubber technology. ${ }^{[2,3]}$

After the invention of vulcanization, the demand of rubber rapidly increased especially due to the invention and development of automobiles. It's not too much to say that tire technology most contributed to the development of rubber technology. The first tire was solid composed of a rubber sheet covered with fabric. ${ }^{[4]}$ Later on, the concept of an air-filled tire was developed by Andre Michelin, but it took a long time to solve the problem of flat tires. Finally, J.B. Dunlop successfully managed to introduce the pneumatic tires to vehicles. ${ }^{[4]}$

The latest major development in rubber technology is the replacement of carbon black by silica as reinforcing filler, with the advantage of reduced rolling resistance of tires, consequently reduced fuel consumption of vehicles. Precipitated silica was first introduced in 1948 by the Columbian Chemical Division of the Pittsburgh Plate Glass Co., LTD. ${ }^{[5]}$ Several precipitated silicas were developed in the next decade, however their reinforcing properties were relatively low as compared to carbon black. In the late 60's of last century a silane coupling agent such as 3-mercapto propyltrimethoxyl silane was applied in silica filled rubber to improve the reinforcing properties. ${ }^{[6-8]}$ This silane had a scorch problem: the tendency to prematurely 
vulcanize during processing. Therefore, a new silane bis-(3-triethoxysilylpropyl)tetrasulfide (TESPT) was introduced by Degussa in 1972. ${ }^{[6-8]}$ This new silane system achieved a better performance of the winter tire in 1974. In the early 90's the "Green Tire Technology" was introduced by Michelin. ${ }^{[9]}$ This technology contributes a vehicle fuel saving of 3-4\% as compared to tread compounds with carbon black, corresponding to a reduction of the rolling resistance of the tire of approximately $20 \%$. This environmental and economical advantage of the silica technology is most important, even though it encompasses many problems, such as higher production costs and difficulties in processing.

\subsection{Aim of this thesis}

The aim of the investigations in the present thesis is to aid the understanding of the reinforcing mechanism in silica filled rubber. Better reinforcing properties result from an enhanced reaction between the silane coupling agent and the silica or the rubber matrix. It is known that an amine such as 1,3-diphenylguanidine (DPG) is capable of accelerating the coupling reaction between the silane and the silica, the so-called silanization. However, DPG is a toxic substance; therefore, DPG alternatives will be required in the near future.

Another important element is how to disperse the silica properly in the rubber matrix. For silica filled rubber, silica flocculation (demixing) takes place during rubber processing because of the polarity difference between the silica and the polymers. This silica flocculation can affect the reinforcing properties and the physical properties of the resulting compounds.

\subsection{Structure of this thesis}

The studies described in the present thesis focus on the reinforcing mechanism of silica filled rubber, as well as the silane chemistry during processing. Chapter 2 gives an overview of the mechanisms involved in rubber reinforcement, and in particular with silica, and the role of silane chemistry therein.

This thesis encompasses 6 experimental chapters.

Chapter 3: The focus is on the determining factors of the physical properties of silica reinforced rubber. Bound rubber is measured to estimate the bound rubber thickness and its effect on the physical properties.

Chapter 4: In this chapter the flocculation process of silica during the heating process involved in vulcanization is monitored by using a Rubber Process Analyzer (RPA2000). By monitoring the shear modulus at $0.56 \%$ strain during heating, the rate constant of the silica flocculation is estimated. Further, an Arrhenius plot is applied in this study to calculate the activation energy of the silica flocculation.

Chapter 5: A further study regarding the flocculation process of the silica is done by 
Introduction

using the USAXS technique. For the USAXS measurements, the Spring-8 (Super Photon ring-8, Beam line BL19B2, Japan Atomic Energy Research Institute) which is the world's largest third-generation synchrotron radiation facility was applied. In this study the morphological structure of the silica in the rubber matrix is detailed.

Chapter 6: The kinetic parameters of the silanization reaction in the presence of amines such as DPG and DPG alternatives are investigated in model olefin systems. In this study the effect of amines on the silanization kinetics are described.

Chapter 7: The side reactions during the silanization are investigated by using LC-MS. The silane chemistry is complicated due to these side reactions. Therefore, a study of the side reactions during the silanization reaction is important to further understand the reinforcing mechanism of silica filled rubber.

Chapter 8: The DPG alternatives quinuclidine and 3-quinuclidinol which have similar pKa values to DPG are evaluated in silica filled rubber. In this chapter the possibility of replacing DPG by the DPG alternatives is discussed.

Chapter 9 contains the overall conclusions of this thesis.

\subsection{References}

1. J.A. Brydson, "Rubbery Materials and their Compounds", Elsevier Science Publishers Ltd., Essex (1988)

2. H.F. Mark, "Rubber Technology handbook", Hanser Publishers: Munich (1996)

3. C.M. Blow, C. Hepburn, "Rubber Technology and Manufacture", Butterworths, London, second edition, (1982)

4. www.yokohamatire.jp/check-de-smile/sp_history/index.html

5. H.D. Luginsland, Educational symposium of the Rubber Division, American Chemical Society, Savannah, Georgia, April 29 - May 1 (2002)

6. F. Thum, S. Wolff, Kautsch. Gummi Kunstst. 28, 733 (1975)

7. S. Wolff, Kautsch. Gummi Kunstst. 34, 280 (1981)

8. S. Wolff, Rubber Chem. Technol. 69, 325 (1996)

9. R. Rauline, EP patent 0 501227A1, to Michelin \& Cie, (Febuary 12, 1992) 
Chapter 1 


\section{Chapter 2}

\section{OVERVIEW OF FILLER REINFORCEMENT AND SILANE CHEMISTRY}

Rubbers can not be used in pure form because of their low mechanical properties. Therefore, fillers are generally applied in rubber compounds to improve the mechanical properties of rubber. The fillers used in rubber compounds are characterized by their reinforcing properties, depending on surface activity and size of the fillers.

Carbon blacks have been used as versatile reinforcing fillers since the early 1900's. However, silicas have been widely applied in tire tread compounds since the "Green Tire Technology" was introduced in 1992 by Michelin. Silica is capable of significantly improving the rolling resistance and wet traction of tire tread compounds compared to carbon black. Indeed, by using silica in a tire tread compound, 3-4\% fuel can be saved, corresponding to a reduction of rolling resistance of about $20 \%$.

However, silica-filled rubber provides difficulties such as a high Mooney viscosity due to polarity differences between polymer and silica. Therefore, a silane coupling agent is commonly applied in silica-filled rubber. Using a silane coupling agent, the physical properties and processability are significantly improved.

Silane chemistry during rubber processing is complicated due to the chemical reactions to take place during rubber mixing. Actually, several chemical reactions involving the silane coupling agent take place during rubber processing, for instance the silica-silane reaction: the so-called "silanization", silane-rubber coupling, and crosslinking between polymers. Many researchers have contributed to an understanding of these complicated reactions. However, the mechanism of silane chemistry and silica reinforcement are still not fully understood. For silica-filled rubber, the following parameters are important:

Material parameters: silica, silane, polymer and additives;

Processing parameters: mixing, extrusion and curing with accurate temperature control;

Machine parameters: use of intermeshing internal mixers

In the present chapter, a literature review is made outlining these parameters. 


\subsection{Dynamic mechanical properties of filler reinforced rubber}

For tire performance, several parameters are required: high (wet and dry) traction, high wear resistance, low rolling resistance and high steering performance under handling situations. These performances depend on the physical properties of tire tread compounds, tire construction including structure and tread profile, and the road condition. In particular, three important properties, such as wet traction, wear resistance and rolling resistance, are described as the "magic triangle" of properties, and they need to be well balanced. ${ }^{[1-3]}$

Wet traction of a tire requires a high loss tangent at lower temperature, which means lower elastic properties of the rubber. The rolling resistance is defined as the energy consumption per unit distance during driving. This energy consumption is converted into the heat energy of tread compounds. In fact, the unit of the rolling resistance is $[\mathrm{J} / \mathrm{m}]$, which is equal to $[\mathrm{N}]{ }^{[2]}$ Wear resistance relates to the glass transition temperature $T_{g}$ of tread compounds and filler dispersion. The use of a polymer with lower $\mathrm{Tg}$ can improve the wear resistance.

The majority of tire performances strongly depends on the viscoelastic properties of filler-filled rubber, hence understanding basic viscoelastic theory is required. Rubber is a viscoelastic material: As it deforms, a part of the energy is elastically stored, whereas the rest of the energy is dissipated as heat, defined as hysteresis loss. The hysteric loss of a tire, as well as the aerodynamic drag and friction in the contact path and within the rim, are not recoverable, contributing to the total drag force on a moving vehicle.

The behavior of visco-elastic materials can be modeled using a sinusoidal shear deformation $\gamma(\mathrm{t})$ with angular frequency $\omega$.

$$
\gamma(t)=\gamma_{0} \sin (\omega t)
$$

where $\gamma_{0}$ and $t$ are maximum strain and time, respectively.

In this deformation the shear stress response $\sigma(t)$ is also sinusoidal, but out of phase with strain:

$$
\sigma(t)=\sigma_{o} \sin (\omega t+\delta)=\left(\sigma_{o} \cos \delta\right) \sin \omega t+\left(\sigma_{o} \sin \delta\right) \cos \omega t
$$

where $\delta$ is the phase angle.

The phase angle is graphically depicted in Figure 2.1. The shear stress signal $\sigma(t)$ can be separated into two contributions: one in phase with strain $\sigma_{0} \cos \delta$, and one $90^{\circ}$ out of phase $\sigma_{0} \sin \delta$. 


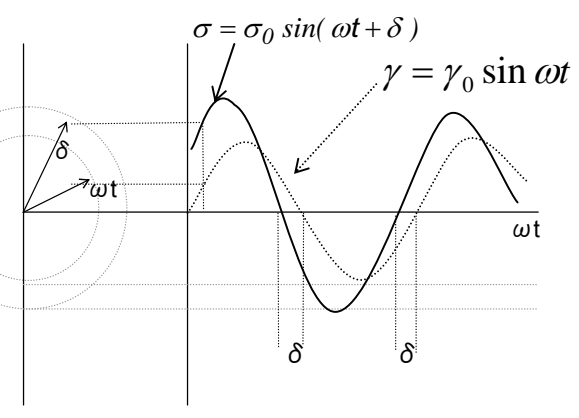

Figure 2.1 : Illustration of the phase angle for delay of stress response on sinusoidal deformation

The shear modulus ' $G^{\prime}$ is the component in phase and the loss or viscous modulus G" is the component out of phase with the oscillatory strain.

$$
\begin{aligned}
& \sigma(t)=\gamma_{0}\left[G^{\prime} \sin \omega t+G^{\prime \prime} \cos \omega t\right] \\
& \mathbf{G}^{\prime}=\frac{\sigma_{0}}{\gamma_{0}} \cos \delta \\
& \mathbf{G}^{\prime \prime}=\frac{\sigma_{0}}{\gamma_{0}} \sin \delta
\end{aligned}
$$

When the shear modulus $G^{*}$ is written in the complex form, the shear modulus is described by the real and imaginary part, respectively.

$$
\begin{aligned}
& G^{*}=G^{\prime}+i G^{\prime \prime} \\
& G^{*^{2}}=G^{\prime 2}+G^{\prime 2}
\end{aligned}
$$

The phase angle is represented as follows:

$$
\tan \delta=\frac{G^{\prime \prime}}{G^{\prime}}
$$

These moduli G' and G" have a dependence on temperature and frequency. A typical frequency dependence of these moduli of a viscoelastic material is shown in Figure 2.2. 


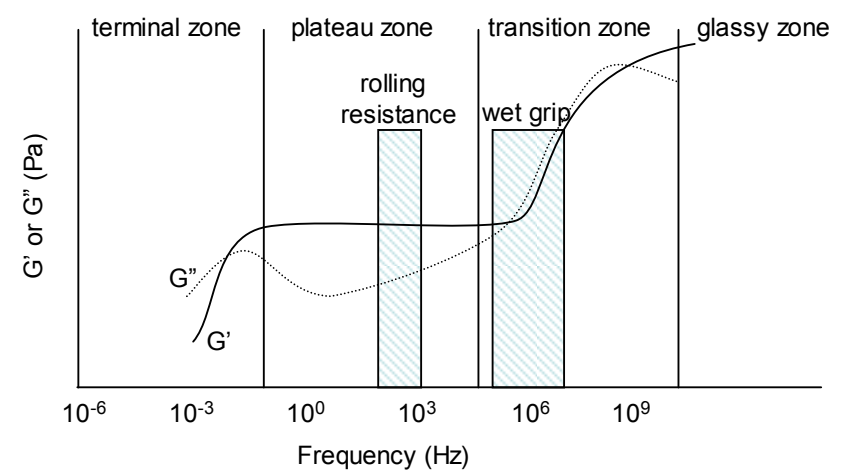

Figure 2.2 : Frequency dependence of shear modulus G' and loss modulus G" for a typical visco-elastic polymer ${ }^{[4]}$

This frequency dependence of moduli results from the chain and the segment mobility in rubber compounds. ${ }^{[4]}$ At low frequency all the polymer chains in rubber compounds are capable of following deformation without delay and energy loss during one cycle of deformation. As the frequencies of strain increase, the entanglements of polymers are no longer able to follow to strain during one cycle of deformation. As a result, the entanglements act as crosslink points. It is well known that this crosslink density derived from entanglement of polymers is related to the plateau region. In this region a constant shear modulus and the minimum loss modulus can be seen; all other movements are still possible and elastic behavior is still taking place. After the rubber plateau region, with further increasing frequency, rubber compounds reach to the transition state between the rubber state and the glassy state, corresponding to a further decrease of polymer mobility. Finally, rubber compounds reach to the glassy state in which the modulus becomes high because of the rigidity of polymer chains at such high frequencies. In this region polymer chains are unable to move flexibly enough to follow the applied strain, except for small local polymer chain motions, and the energy dissipation is very high. ${ }^{[4]}$

The rolling resistance is related to the loss tangent of rubber compounds at the low frequency region within the rubbery state. This low frequency region corresponds to the angular velocity of a rolling tire. It is generally known that a lower loss tangent at low frequency leads to lower rolling resistance. On the other hand, wet traction is related to the loss tangent at high frequency. In general, a higher loss tangent at high frequency leads to high wet traction ${ }^{[5,6]}$

According to the temperature-time equivalence principle, a low frequency and high frequency can be interchanged with high temperature and low temperature, respectively. The temperature dependences of the loss tangent, shear modulus and loss modulus are shown in Figure 2.3. 


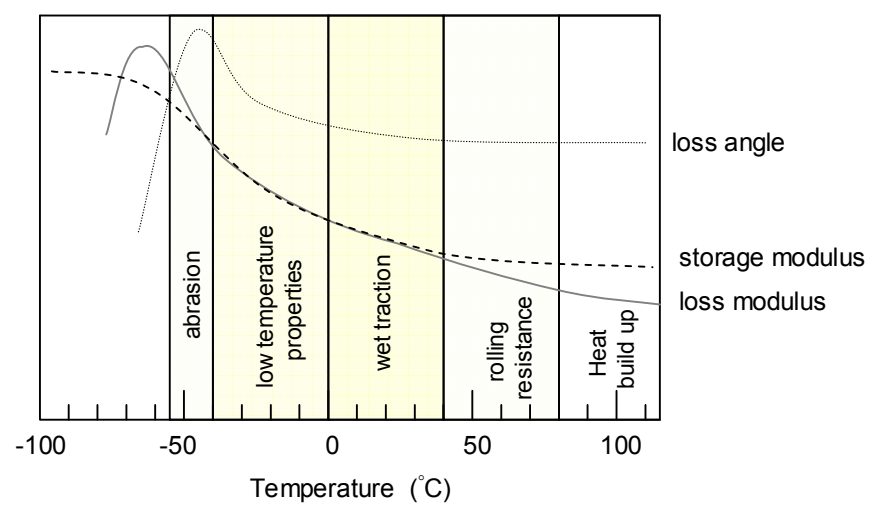

Figure 2.3 : Temperature dependence of shear modulus G', loss modulus G" and phase angle $\tan \delta^{[5,6]}$

At lower temperature around the glass transition temperature, the polymer is in the glassy state with high moduli, and the loss angle shows a maximum value. In tire technology a correlation between the glass transition temperature and abrasion resistance is generally accepted. ${ }^{[1,5,6]}$ At the temperature range from $0^{\circ} \mathrm{C}$ to ambient temperature, the loss angle correlates with the skid behavior and traction of the tire. Especially for wet skid performance of a tire, a high loss angle at a temperature around $0^{\circ} \mathrm{C}$ is required. ${ }^{[5-8]}$ In the next temperature region around $60^{\circ} \mathrm{C}$, the loss angle correlates with the rolling resistance of a tire. With further increase of temperature, rubber compounds start to degrade and reach the limits of driving safety. In this temperature region the loss angle indicates the heat buildup properties. ${ }^{[7]}$

The dynamic properties of rubber compounds are strongly influenced by adding fillers. In particular, the filler-polymer interaction significantly impacts the dynamic properties of filled rubbers. The effect of fillers on the dynamic properties, for example the loss tangent, depends on the particle size of the filler, surface activity, and the amount of filler in the rubber compounds. ${ }^{\left[{ }^{[-12]}\right.}$ These properties are related to breakdown and reformation of agglomerates, the slip between polymer chains and filler particles, and the presence of bound rubber on the filler surface. ${ }^{[13]}$

Carbon blacks have been commonly used as the reinforcing fillers for a long time. Recently, silica is widely used in tire tread compounds since its introduction by Michelin. Figure 2.4 shows the temperature dependence of the loss tangent of carbon black and silica filled compounds, respectively. ${ }^{[6]}$ 


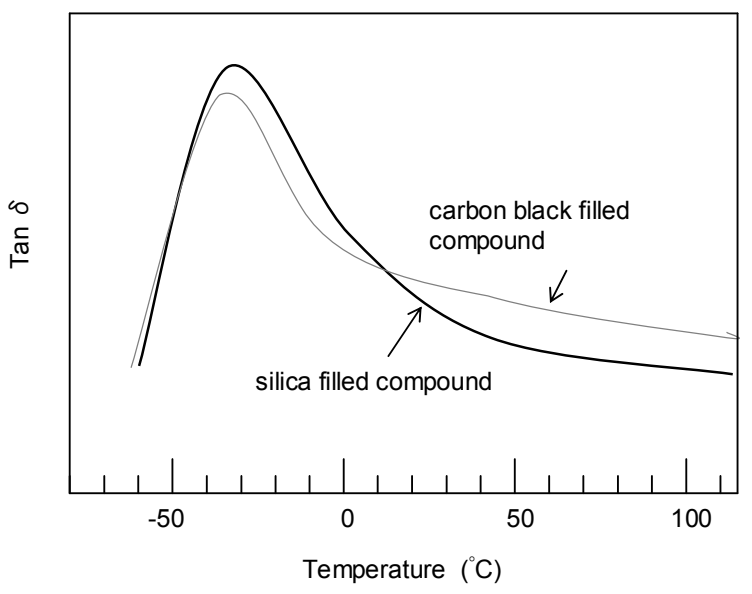

Figure 2.4 : Temperature dependence of phase angle $\tan \delta$ for carbon black filled and silica filled rubber ${ }^{[6]}$

Comparing the loss tangent value, a lower loss tangent value for silica filled compounds can be seen at the higher temperature range, which means that the rolling resistance of silica filled rubber is lower compared to that of carbon black filled rubber. On the other hand, the loss tangent of silica filled compounds at lower temperature is higher compared to that of carbon black filled compounds, indicating that the wet traction of silica filled rubber is also higher than that of carbon black filled rubber. These differences between silica and carbon black are due to the differences in surface properties. ${ }^{[6]}$

\subsection{Rubber reinforcement}

\subsubsection{Reinforcing effect}

In general, elastomers are not used in their pure form, but are reinforced by fillers. For carbon black filled rubber, physical bonding between carbon black and polymer plays an important role in rubber reinforcement. On the other hand, for silica-filled rubber, the interaction between silica and polymer is very weak because of their large polarity difference. Besides filler-polymer interaction, filler-filler interaction affects the material characteristics as described by Payne. ${ }^{[14]}$ The strainindependent contributions to rubber reinforcement, such as the hydrodynamic effect, the polymer network contribution and the filler-polymer interaction, and the strain-dependent filler-filler interaction, the so-called "Payne effect", are described in Figure 2.5. ${ }^{[15]}$ 


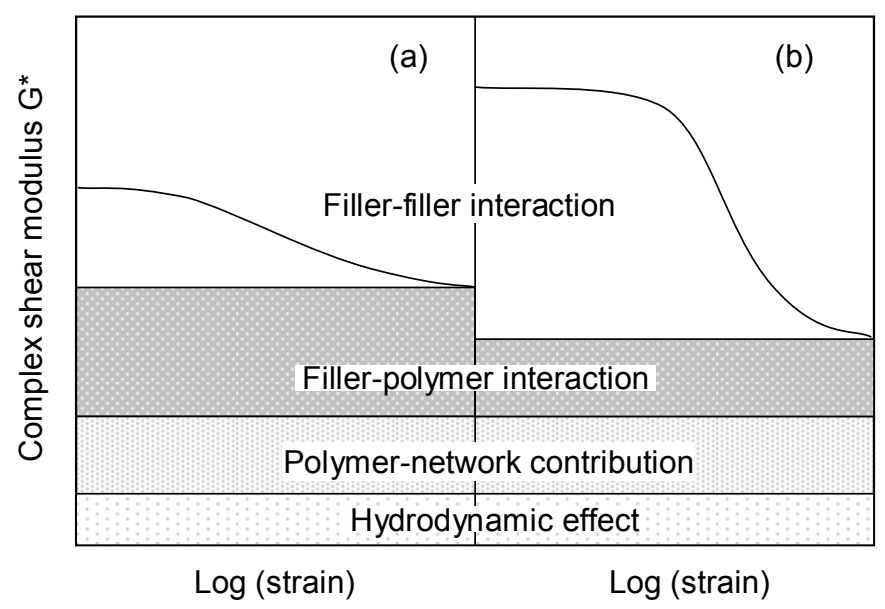

Figure 2.5 : Parameters contributing to shear modulus ${ }^{[15]}$ (a) Carbon black filled rubber ; (b) Silica filled rubber

\subsubsection{Hydrodynamic effect :}

The hydrodynamic effect is based on the viscosity increase of viscous fluids by the addition of particles. ${ }^{[16,17]}$ This phenomenon was modeled by Einstein about one hundred years ago and described as the viscosity increase of a suspension liquid by dispersed rigid spherical particles. The viscosity change was described as follow: ${ }^{16,17]}$

$$
\eta=\eta_{o}\left(1+k_{e} \phi\right)
$$

where $\eta$ is the suspension viscosity, $\eta_{0}$ is viscosity of the pure liquid, $k_{e}$ is 2.5 for spherical particle and $\phi$ is the volume fraction of particles.

This equation means that when a filler of volume fraction $\phi$ is dispersed into a fluid, the viscosity of the liquid suspension becomes $\eta$. This equation is basically true only when the concentration of particles is dilute, the spherical particles are uniform, there are no interactions between the particles, and the wetting of the particles is complete. However, these conditions do not match actual filled-rubber systems. Therefore, based on practical experience and Einstein's theory, Guth and Gold have described rubber reinforcement as follows: ${ }^{[18]}$

$$
\eta=\eta_{o}\left(1+2.5 \phi+14.1 \phi^{2}\right)
$$

In this equation $\phi^{2}$ accounts for the effect of interaction between particles in a dense suspension liquid. In addition, Guth developed the following equation by considering the geometrical effect of a filler: ${ }^{[19]}$

$$
G^{\prime}=G^{\prime}{ }_{o}\left(1+0.67 a \phi+1.62 a^{2} \phi^{2}\right)
$$


where $G^{\prime}$ and G'$_{0}$ are the shear moduli of the filled and unfilled system, respectively; $a$ is the ratio of length/width of the particles.

Young's modulus of filler-filled rubber generally depends on the volume fraction of filler, the interaction between fillers and the size of the particles.

\subsubsection{Polymer-network effect :}

The polymer network formed during vulcanization is also one of the strainindependent contributions to the modulus. The shear modulus is described as a function of concentration of elastically active network chains, the absolute temperature and the Boltzmann constant.

$$
G_{o}=v \times K \times T
$$

where $v$ is the concentration of elastically active chains per unit volume $\left[\mathrm{cm}^{3}\right], \mathrm{K}$ is Bolzmann's constant and $\mathrm{T}$ is the absolute temperature.

\subsubsection{Filler-polymer interaction :}

It has been experimentally demonstrated that the storage modulus G' drastically increases as the filler loading increases, resulting from filler-polymer interaction, so-called bound rubber.

Several bound rubber models have been developed by many researchers. One of the bound rubber models is the occluded rubber model proposed by Medalia and Kraus. ${ }^{[20,21]}$ In this model, rubber is partly trapped in the filler aggregates as shown in Figure 2.6, depending on the aggregate or agglomerate geometry of a filler. This occluded rubber does not contribute to the elastic behavior of the rubber matrix at lower strain; consequently the filler aggregates with trapped rubber act as large particles.

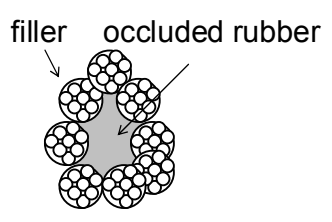

occluded rubber

(a)

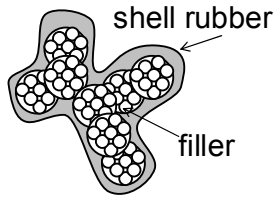

shell rubber

(b)

Figure 2.6 : Schematic bound rubber model

(a) : Occluded rubber model[20,21] (b) : Shell rubber model ${ }^{[22,23]}$

Smith and Pliskin proposed the shell rubber model, resulting from chemical adsorption of polymer on the filler surface. ${ }^{[22,23]}$ In this model a rubber layer can exist on the filler surface as shown in Figure 2.6(b).

O'Brien et al. have developed the advanced bound rubber model based on the shell rubber model. ${ }^{[24]}$ According to this model, a double layer structure of polymer, 
composed of a glass-state layer and a rubber-state layer, is formed on the carbon black particles as shown in Figure 2.7.

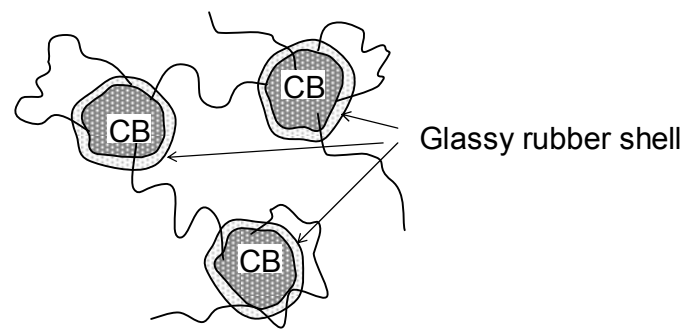

Figure 2.7 : O'Brien model of bound rubber ${ }^{[24]}$

\subsubsection{Filler-filler interaction :}

According to Payne's interpretation, filler-filler interaction contributes to the straindependence of the modulus, the so-called Payne effect, as shown in Figure 2.5. Payne experimentally demonstrated that the storage modulus of filled rubber drastically decreases as the strain increases, and additionally the loss modulus has a local maximum value at the strain where the storage modulus changes most. This results from filler-filler interaction due to van der Waals forces and hydrogen bonds. ${ }^{[14,25]}$

Kraus proposed a filler-filler network model based on the attractive van der Waals forces and repulsive Leonnard-Jones forces. The filler particle acts as a large multifunctional crosslink site, resulting in non-affine deformation. ${ }^{[26,27]}$ In this model the contacts between fillers are periodically broken and reformed under a periodic sinusoidal strain $\gamma$. The rate of breakage $R_{\text {break }}$ is described as a function of the maximum strain amplitude $\gamma_{0}$, the number of remaining contacts $N_{c}$ and the rate constant of breakage $\mathrm{k}_{\mathrm{bre}}$ :

$$
\boldsymbol{R}_{\text {break }}=\boldsymbol{k}_{\text {bre }} \gamma_{o}^{m} N_{c}
$$

where $\mathrm{m}$ is the model fitting parameter.

The rate of agglomeration $\mathrm{R}_{\text {agg }}$ is described as follows:

$$
R_{\text {agg }}=k_{\text {agg }} \gamma_{o}^{-m}\left(N_{o}-N_{c}\right)
$$

where $\mathrm{k}_{\mathrm{agg}}$ is the rate constant of the agglomeration process, $\mathrm{N}_{\mathrm{o}}$ is the number of elastically active filler contacts at zero deformation, and $\mathrm{N}_{\mathrm{c}}$ is again the number of remaining contacts at a given strain.

According to the quantitative model of the Payne effect proposed by Kraus, the shear modulus G' and loss modulus G" of the aggregate network at specific strain can be described as follows: 


$$
\begin{gathered}
\frac{G-G(\infty)}{G(0)-G(\infty)}=\frac{1}{1+\left(\frac{\gamma_{o}}{\gamma_{c}}\right)^{2 m}} \\
\frac{G^{\prime \prime}-G^{\prime \prime}(\infty)}{G^{\prime \prime}(0)-G^{\prime \prime}(\infty)}=\frac{2\left(\frac{\gamma_{o}}{\gamma_{c}}\right)^{m}}{1+\left(\frac{\gamma_{0}}{\gamma_{c}}\right)^{2 m}}
\end{gathered}
$$

where $G^{\prime}(\infty)$ and $G^{\prime \prime}(\infty)$ are moduli at the high strain amplitudes, and $G^{\prime}(0)$ and G"(0) are moduli at zero strain amplitude. $\gamma_{c}$ is the strain half-width amplitude and can be described as follow:

$$
\gamma_{c}=\left(\frac{k_{\text {agg }}}{k_{\text {bre }}}\right)^{m / 2}
$$

$\gamma_{c}$ depends not only on the filler types and concentrations, but also on the types of polymer in a rubber matrix. The constant $m$ depends on the surface structure of the filler. Combining eq. 2.7 and eq. 2.8, the loss tangent is then described as follow:

$$
\tan \delta=\frac{G^{\prime \prime}(\infty)\left[\left(\frac{\gamma_{0}}{\gamma_{c}}\right)^{m / 2}-\left(\frac{\gamma_{0}}{\gamma_{c}}\right)^{-m / 2}\right]^{2}+2 G^{\prime \prime}(0)}{G^{\prime}(\infty)\left(\frac{\gamma_{0}}{\gamma_{c}}\right)^{m}+G^{\prime}(0)\left(\frac{\gamma_{o}}{\gamma_{c}}\right)^{-m}}
$$

Several alternative models of the Payne effect have been developed. One of the extended models, proposed by Klüppel, is based on the percolation and kinetic cluster-cluster aggregation theory. ${ }^{[28]}$ 


\subsection{Silica reinforcement}

\subsubsection{Classification of fillers}

The fillers can be classified on basis of their chemical composition and influence on rubber properties. The effect of filler types on rubber properties is typically classified in three categories: non-reinforcing, semi-reinforcing and reinforcing. The classification of fillers strongly depends on the size of the filler particles as shown in Figure 2.8. ${ }^{[13]}$

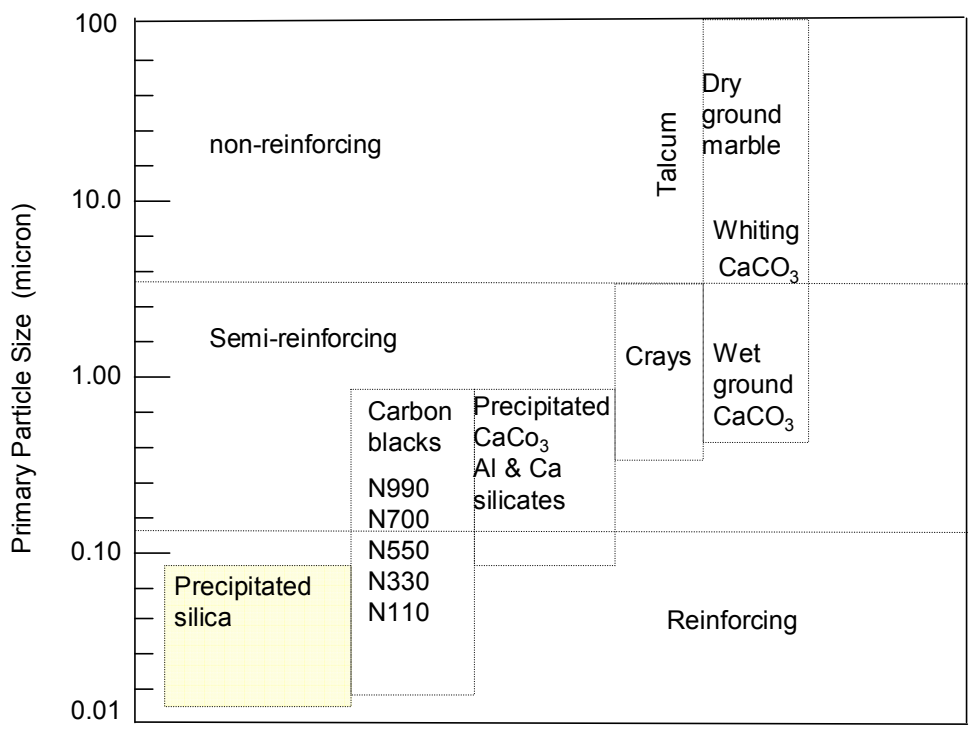

Figure 2.8 : Classification of fillers based on the size of the primary filler particle ${ }^{[28]}$

Amorphous silica is one of the fillers with small particle size, generally classified into the semi-reinforcing and reinforcing filler classifications, the same as carbon black. Various types of silica are produced using conditions as shown in Table 2.1. ${ }^{[29-31]}$

Table 2.1: Effect of precipitation conditions of silica ${ }^{[29]}$

\begin{tabular}{llll}
\hline $\mathrm{pH}$ & Drying & Dispersibility & category \\
\hline High $\mathrm{pH}$ & long time & poor & Conventional silica \\
Lower $\mathrm{pH}$ & long time & medium & Semi Highly Dispersible silica \\
High $\mathrm{pH}$ & short time & good & HD silica \\
Optimized & short time & excellent & HD silica \\
\hline
\end{tabular}




\subsubsection{Aggregate size of silica}

The morphological structure of silica plays an important role in the physical properties of filled rubber. During processing of silica, many primary particles remain condensed into aggregates of typical dimensions of $100-200 \mathrm{~nm}$, which are the real reinforcing species in rubber compounds. When the particles are close together, an interaction between the primary particles can take place. The degree of condensation in aggregates, commonly designated by structure, determines the inter-particle void volume and pore diameter within the aggregates. The measurement of this "structure" is based on the adsorption of dibutylphthalate, socalled DBP. Conventional silica has a DBP value of typically $175 \mathrm{~g} / 100 \mathrm{~g}$; especially for the HD silicas, the DBP value is typically $200 \mathrm{~g} / 100 \mathrm{~g}$ or above. ${ }^{[32]}$

It was found by the so-called crushed DBP measurements that the HD silicas show a high structural level and are less fragile compared to those of the CV silicas. In addition, aggregates of the HD silicas have a more branched structure with 3-4 major branches on average. ${ }^{[33]}$ This means that the HD silica is highly capable of dispersing due to shear forces during the mixing process.

For both types of silica, the HD silica and the CV silica, the typical size distribution of aggregates is shown in Figure 2.9. The aggregate sizes show bimodal

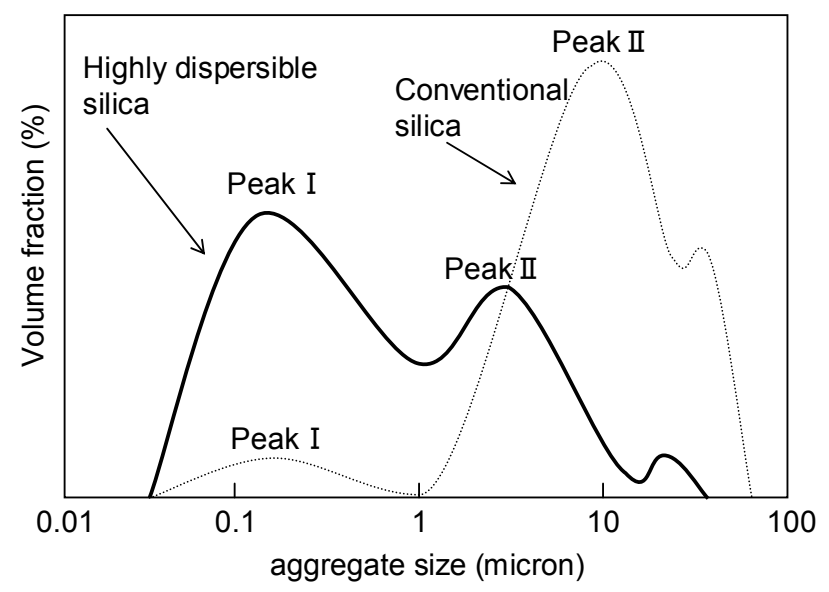

Figure 2.9 : Size distribution of silica aggregates for highly dispersible silica (solid line) and conventional silica (broken line) ${ }^{[32]}$

distributions. For the HD silica, the amount of small aggregates is relatively high compared to that of the CV silica. 


\subsubsection{Specific surface area of silica}

The specific surface area of silica is generally determined by using two methods: the $\mathrm{N}_{2}$-adsorption, so-called Brunauer - Emmett - Teller method (BET), and the adsorption of $\mathrm{N}$-cetyl-N,N,N'-trimethylammonium-bromide, so-called CTAB.

The BET method measures the overall surface area of particle including the micro pores as shown in Figure 2.10 (a). Therefore, this method has a potential to overestimate the accessible surface for coupling agents or polymers due to inability to penetrate in the pores. The BET values may vary in the range of $50-$ $350 \mathrm{~m}^{2} / \mathrm{g}$. Especially for HD silica the BET value is $170 \mathrm{~m}^{2} / \mathrm{g}$ or above.

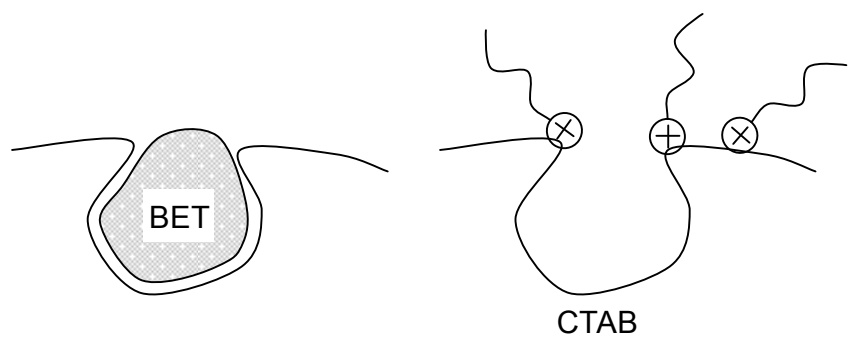

(a)

(b)

Figure 2.10 : Characterization of filler surface ${ }^{[28]}$

(a) BET ; (b) CTAB

The CTAB measurement is commonly used in the determination of the specific surface area of silica. CTAB molecules are so larger that they can not penetrate into the micro pores as shown in Figure 2.10(b). Therefore, it is possible to measure the external surface area of the particle. The standard values of CTAB may vary in range of $100-200 \mathrm{~m}^{2} / \mathrm{g}$; especially for HD silica the standard value of CTAB is around $160 \mathrm{~m}^{2} / \mathrm{g}$ or above. ${ }^{[34,35]}$ CTAB values show a good correlation with the primary particle size. Therefore, the physical properties of the filled rubbers strongly correlate with the CTAB surface area, better than with the BET surface area.

\subsubsection{Characterization of the silica surface}

The silica surface is composed of siloxane and silanol groups. The chemical characteristics of the silica surface are mainly determined by the amount of silanol groups, the degree of hydration, the amount of adsorbed water and the surface acidity. Three types of surface silanol hydroxyls have been identified by using SiNMR-experiments or infrared spectroscopy. ${ }^{[36-38]}$ Figure 2.11 shows the three types of hydroxyls: ${ }^{[32]}$

$>$ Isolated a single hydroxyl group on a silicon atom

$>$ Vicinal

two hydroxyl groups on adjacent silicon atoms

$>$ Geminal

two hydroxyl groups on the same silicon atom 


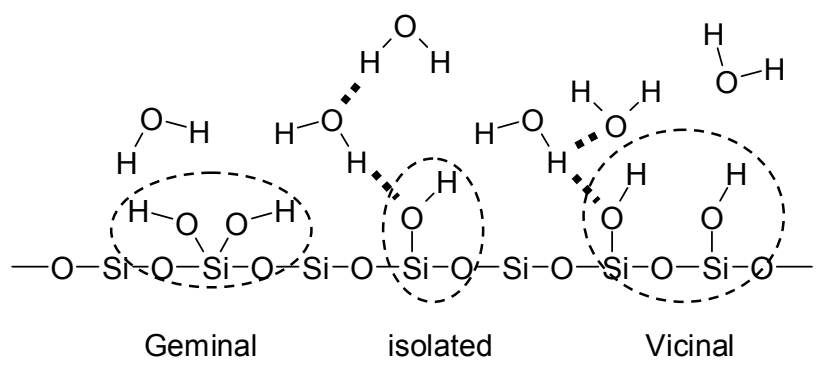

Figure 2.11: Types of hydroxyl groups on the silica surface ${ }^{[32]}$

Depending on the precipitation conditions, these three different types of hydroxyl groups can be formed. Adjacent silanols such as the geminal type of silanol groups are highly capable of absorbing water. For highly dispersible silica, it is found that the geminal silanol content is about less than about $20 \%$.

\subsubsection{Surface chemistry of silica}

Filler-polymer interaction in rubber compounds strongly impacts on the reinforcing property as mentioned before. The silica surface is covered by a large number of silanol and siloxane groups and can be characterized by the surface energy. ${ }^{[36-38]}$ The surface energy depends on dipole-dipole interactions, van der Waals forces, hydrogen bonding and electrostatic interactions. The surface energy of a filler can be described by the following equation, which is composed of dispersive and specific components: ${ }^{[39]}$

$$
\gamma_{s}=\gamma_{S}^{d}+\gamma_{S}^{s p} \quad\left[J / m^{2}\right]
$$

where $\gamma_{S}{ }^{d}$ is the dispersive component, indicating the tendency of adhesion to an organic matrices such as a rubber polymer, and $\gamma_{s}{ }^{\text {sp }}$ is the polar component, indicating the tendency of interaction with itself.

The specific component $\gamma_{s}{ }^{\text {sp }}$ of silica is relatively high compared to that of carbon black because of the large number of polar groups on the silica surface. ${ }^{[40]}$ The dispersive component, responsible for the degree of wetting of fillers by polymers depends on the difference of the solubility parameters. ${ }^{[41]}$ The solubility parameters of some polymers and silica are summarized in Table 2.2. ${ }^{[42]}$ As shown in Table 2.2, silica shows a very high solubility parameter value compared to the polymers, which means that these two materials are difficult to blend. 
Table 2.2 : Solubility parameters of rubbers and fillers ${ }^{[42]}$

\begin{tabular}{ll}
\hline Material & $\begin{array}{l}\text { Hildebrand } \\
\text { solubility parameter }\left(\mathrm{MPa}^{1 / 2}\right)\end{array}$ \\
\hline NBR & $19.3-20.3$ \\
SBR & $16.6-18.3$ \\
NR, BR, IIR & $16.2-16.6$ \\
PE, EPM, EPDM & 16.2 \\
\hline \hline Silica & $28.4-36.5$ \\
Carbon black & $24.4-30.5$ \\
\hline
\end{tabular}

The compatibility between silica and model compounds with resemblance to the molecular structures of polymers can be investigated by the Inverse Gas Chromatography (IGC) technique. ${ }^{[43,44]}$ According to these studies, the compatibility of polymers with silica can be classified as follows:

(High compatibility with silica) : NBR $>\mathrm{SBR}>\mathrm{NR}>\mathrm{BR}>$ high vinyl $\mathrm{BR}>\mathrm{EP}(\mathrm{D}) \mathrm{M}$ $>$ IIR

This tendency corresponds to the solubility parameter of each polymer.

\subsubsection{Temperature induced flocculation of silica filled compounds}

It is well known that for silica-filled rubber, the storage modulus at low strain amplitude increases during the heating process involved in vulcanization. ${ }^{[44]}$ This increase of storage modulus can be due to some silica flocculation: demixing. For

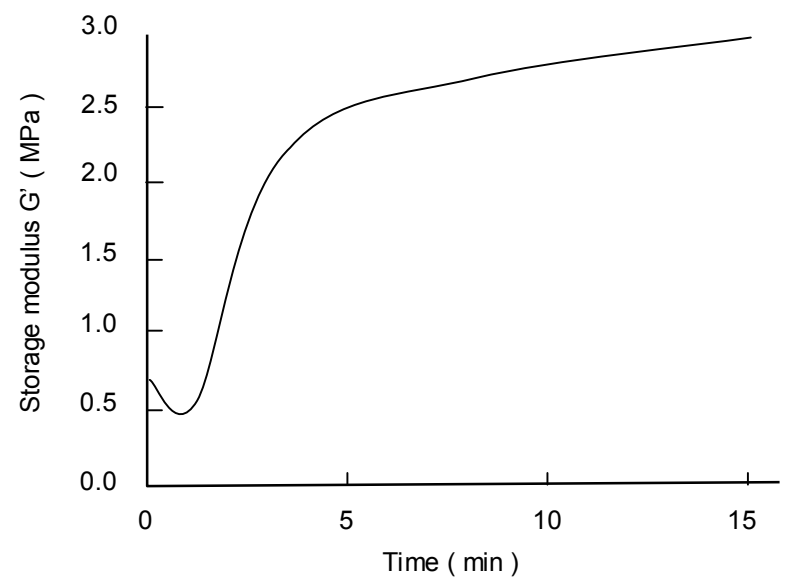

Figure 2.12 : Increase of the storage modulus at $0.56 \%$ strain during the heating process in silica-filled rubber ${ }^{[44]}$

silica-filled compounds, Luginsland et al. experimentally demonstrated that the Payne effect also increases during the heating process as shown in Figure 2.12. 
Both result from the polarity differences between silica and rubber as shown in Table 2.2.

\subsubsection{Bound rubber model of silica filled rubber}

As various chemical reactions take place during processing of silica-filled rubber, a new advanced bound rubber model has been developed. It is well known that bound rubber of silica-filled rubber is mainly composed of two components: occluded rubber in the silica aggregates and crosslinked polymer due to polymer chain scission and recoupling. ${ }^{[4]}$

Luginsland et al. proposed a simple model of silica/silane reinforcement based on the hydrodynamic-occlusion-interaction theory as proposed by Medalia. ${ }^{[4]} \mathrm{A}$ schematic representation is shown in Figure 2.13.
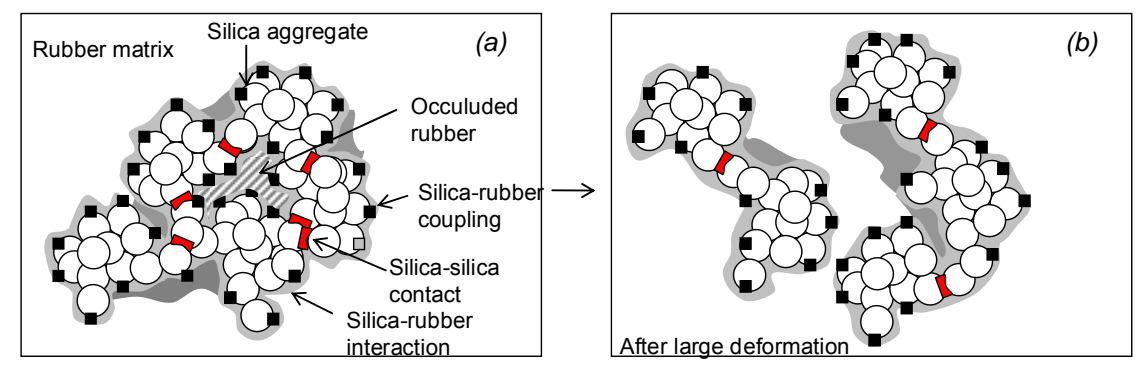

Figure 2.13: Simple model of silica/silane reinforcement ${ }^{[44]}$ (a): No deformation : (b): after larqe deformation

Due to the large polarity differences between silica and polymer, the filler-filler network can easily form and as a result part of the rubber matrix is occluded in this filler network. This means that the occluded rubber is physically and chemically immobilized within the filler network. However, under high deformation this filler network partially breaks open. Therefore, with increasing deformation of rubber, the occluded rubber is reduced or released and then follows the matrix deformation. However, due to a chemical bonding via the silane coupling agent, the occluded rubber and the rubber on the silica surface remain grossly immobilized, and therefore still contribute to the modulus even at high deformations. This chemically immobilized rubber is defined as "in-rubber structure". 


\subsubsection{Use of modified S-SBR}

Bound rubber in silica-filled rubber plays an important role in the viscoelastic properties, depending on the degree of interaction between polymer and silica.

Solution Styrene-Butadiene rubber (S-SBR) is a random copolymer synthesized by
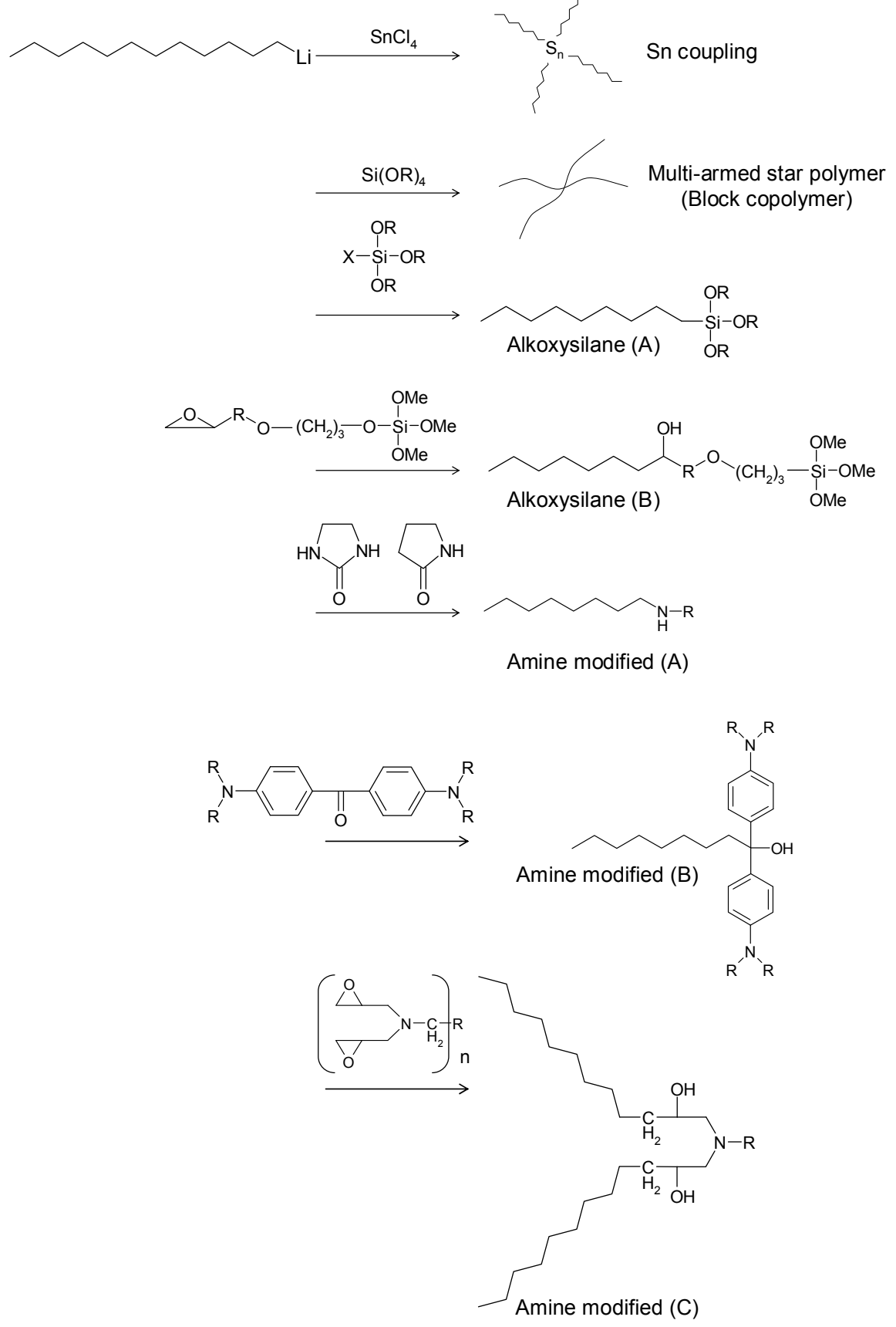

Figure 2.14 : Various types of functionalized S-SBR ${ }^{[45-47]}$ 
living anionic polymerization.

This polymerization method is able to synthesize block copolymers and functionalized polymers. Recently, S-SBR with Sn-coupling or a functionalized terminal group is commonly used to improve the polymer-filler interaction. In addition, new types of S-SBR with di-modified terminal or block copolymers have been developed as shown in Figure 2.14. ${ }^{[45-47]}$ These functionalized S-SBR basically have polar groups which can directly react with silica. Multi-armed star polymers such as SBR-IR and IR/SBR/IR can also be synthesized. ${ }^{[46]}$

\subsection{Silane chemistry}

\subsubsection{Types of silane coupling agents}

As the compatibility between silica and polymers is low, a reduction of the polarity differences is required. This can be done by silane coupling agents such as Bis(triethoxysilylpropyl)tetrasufide (TESPT), which is capable of reacting with the silica surface and the polymer, and is commonly applied in silica-filled rubber. ${ }^{[48-52]}$. TESPT is composed of a poly-sulfide part which can react with the polymer and ethoxysilyl-groups on the silicon atom which can react with the hydroxyl groups present on the silica. The average sulfur rank of the poly-sulfide is 3.86 . The polysulfide part of TESPT releases reactive sulfur moieties in silica-filled compounds during rubber processing due to splitting of the TESPT. Therefore, TESPT is unstable at high shear or high temperature conditions, resulting in a sulfur donor effect of TESPT. ${ }^{[53,54]}$

An alternative silane bis(triethoxysilylpropyl)disulfide (TESPD: Si266/Si75) has also been introduced. ${ }^{[55]}$ TESPD is actually not a pure disulfide but rather a mixtures of polysulfides. The average sulfur rank is close to 2 . The advantage of TESPD is higher stability at high shear conditions or high temperatures compared to that of TESPT and therefore less scorch sensitivity. However, due to its sulfur content, additional elemental sulfur is required to achieve comparable reinforcement to TESPT. ${ }^{[56]}$

Recently, a reduction of the emission of volatile organic compounds such as ethanol during the mixing process or tire lifetime is required. New types of silane coupling agents were introduced as shown in Figure 2.15. 
<smiles>CCCCCCCC(=O)SCCC[Si](OCC)(OCC)OCC</smiles>

Structure A :NXT

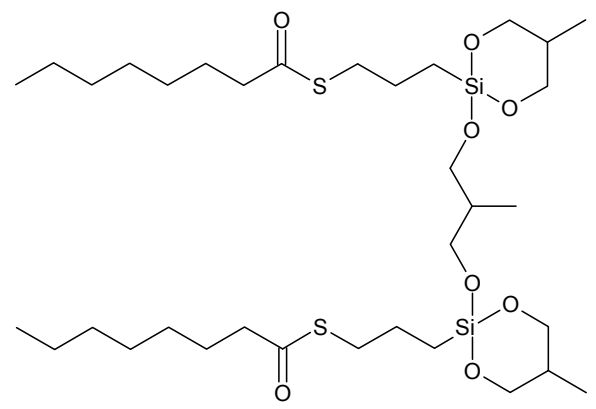

Structure C: NXT Ultra low V<smiles>CCCCCCCC(=O)SCCC[Si]1(OCC)OCC(C)CO1</smiles>

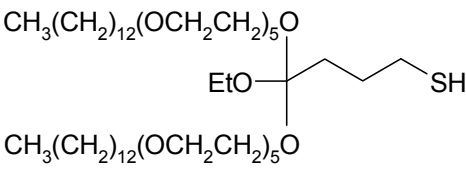

Structure D: VP Si363

Figure 2.15: New types of silanes

In the blocked silane coupling agent NXT the sulfur atom is blocked by esterification with octanethionic acid (Structure A) ${ }^{[57-62]}$ NXT silane prevents sulfur donation during rubber processing, but the sulfur atom has to be "unblocked" by de-esterification with e.g. an alcohol in order to make it available for reaction with rubber polymers. Various NXT alternatives have also been developed to reduce the volatile organic compounds as shown in Structures B and C.

Another new silane Si363 has been developed, composed of a free mercapto group, one ethoxy group and polymeric, amphiphilic substituents as shown in Figure 2.15 (Structure D). It is reported that Si363 is capable of reducing rolling resistance even further, about $10 \%$ more compared to the conventional silane coupling agent TESPT. ${ }^{[62]}$

\subsubsection{Mechanism of silanization reaction}

The silane chemistry is complicated because of the two reactive sites, such as the ethoxy groups and the poly-sulfide in TESPT. The reaction between silane and silica, the so-called silanization, has been studied by many researchers. ${ }^{[54,63-66]}$

The reaction mechanism of silanization is schematically summarized in Figures 2.16(a) and (b). The primary step is the reaction of the first alkoxy group of the silane with silanol groups on the silica surface. Two possible mechanisms are reported as shown in Figure 2.16(a): Direct reaction of the silanol groups on the silicon with the alkoxy group of TESPT, and hydrolysis of the alkoxy group to form a reactive silanol with the release of ethanol. 


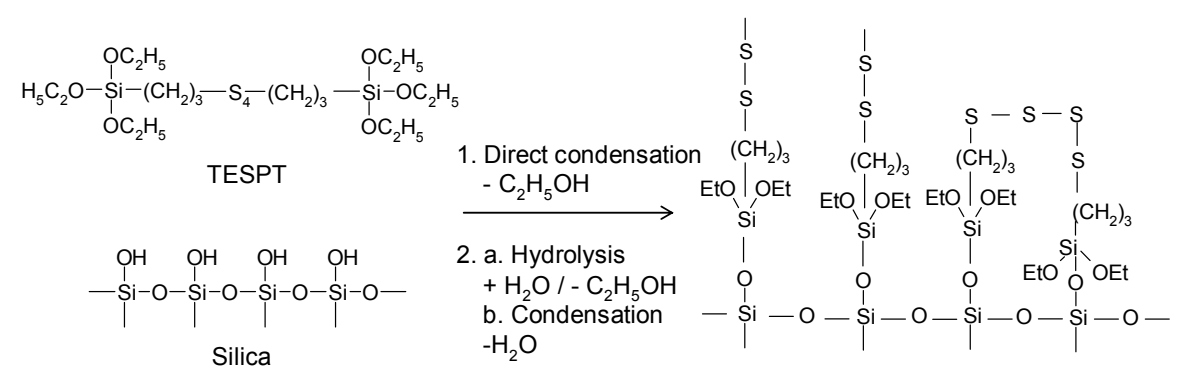

(a) : Primary reaction of silica with TESPT

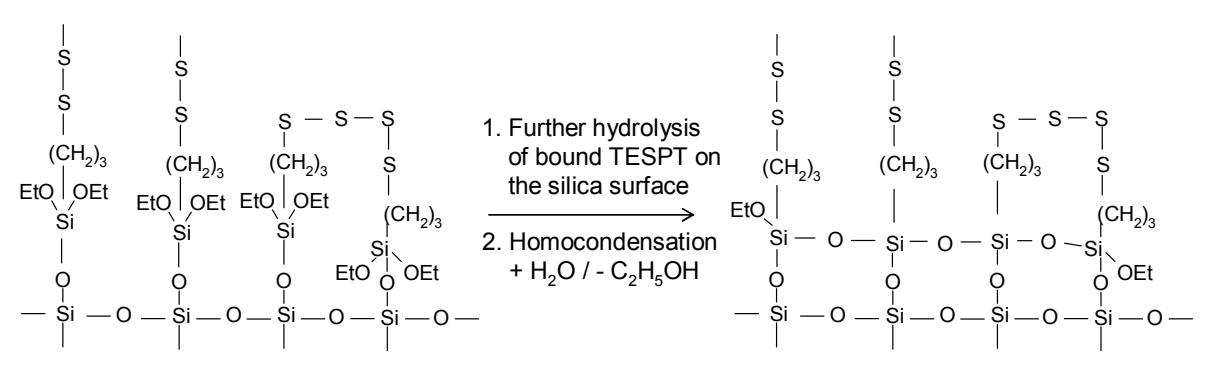

(b) : Secondary reaction of silica with TESPT

Figures 2.16 : Reaction mechanism of silanization[56]

These reactions occur slowly on the silica surface in the presence of water. ${ }^{[67,68]}$ The rate constant of hydrolysis increases with increasing temperature, and additionally using a catalytic agent such as an acidic or alkaline medium. After the hydrolysis, the activated silane is capable of reacting with silanol groups on the silica. The rate constant of this reaction is relatively fast compared to hydrolysis. This means that the hydrolysis reaction is the rate-determine step for the silanization.

After the primary reaction, an intermolecular condensation between silanes on the silica surface, the so-called secondary reaction takes place as shown in Figure $16(b)$, caused by unreacted ethoxy groups of the silanes.

The reaction rate of the secondary reaction is rather slow compared to that of the primary reaction. The secondary reaction is also accelerated by water and an increase of temperature. ${ }^{[69,70]}$ A low degree of intermolecular condensation is required, if any, to achieve an optimal reinforcing property. 


\subsubsection{Kinetics parameters of the silanization reaction}

In order to understand the mechanism of silanization, a study related to silanization kinetics has been carried out by Görl et. al. ${ }^{[6]}$ The kinetic parameters of the silanization can be estimated by quantitative analysis of the amount of released ethanol during rubber processing. Based on the assumption that the primary reaction is a first order reaction, the kinetic parameters were estimated as follow:

$$
\begin{aligned}
& -\frac{d[\text { TESPT }]}{d t}=k_{1}[\text { TESPT }]=\frac{d[E t O H]}{d t} \\
& \ln k_{1}=\ln A-\frac{E_{a 1}}{R T}
\end{aligned}
$$

where $t$ is time, $k_{1}$ is rate constant of the primary reaction, $E_{a 1}$ is the activation energy, $\mathrm{R}$ is gas constant and $\mathrm{T}$ is the absolute temperature.

For TESPT the kinetic parameters are summarized in Table 2.3. ${ }^{[6,71]}$ As mentioned above, the rate of the primary reaction increases with increasing reaction temperature. The activation energy was calculated to be $47 \mathrm{~kJ} / \mathrm{mol}$, according to the Arrhenius equation.

Table 2.3 : Rate constants for the primary reaction $k_{1}$ and the secondary reaction $k_{2}{ }^{[66,71]}$

\begin{tabular}{llll}
\hline Temp. $\left({ }^{\circ} \mathrm{C}\right)$ & 120 & 140 & 160 \\
\hline $\mathrm{k}_{1}\left(\mathrm{~min}^{-1}\right)$ & 0.061 & 0.122 & 0.229 \\
$\mathrm{k}_{2}\left(\mathrm{~min}^{-1}\right)$ & 0.006 & 0.008 & 0.012 \\
\hline
\end{tabular}

\subsubsection{Silanization acceleration}

The acceleration of silanization depends on the rate of hydrolysis of the alkoxysilanes. In the presence of moisture on the silica surface as well as in the presence of an acid- or base- catalyst, hydrolysis can be accelerated. ${ }^{[72]}$ It was proposed that the promotion of silanization in the presence of acid- or basecatalysts is according to a bimolecular $\mathrm{S}_{\mathrm{N}} 2$ type reaction as shown in Figure $2.17 .{ }^{[73]}$ 


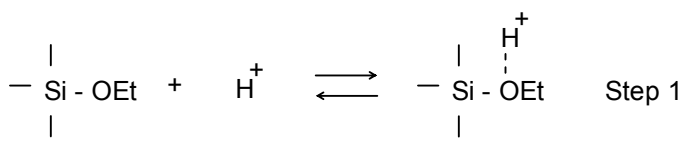

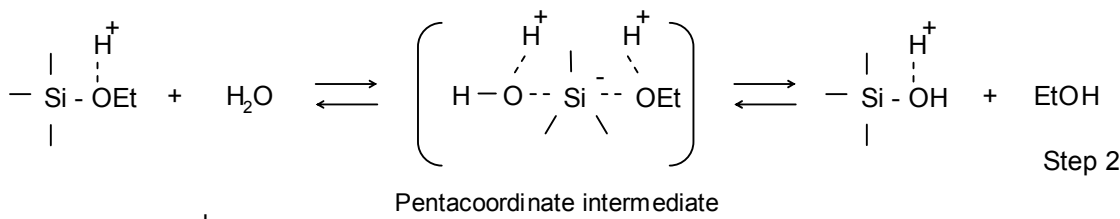

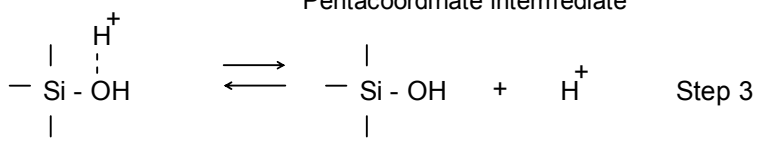

(a) Acid catalyzed hydrolysis

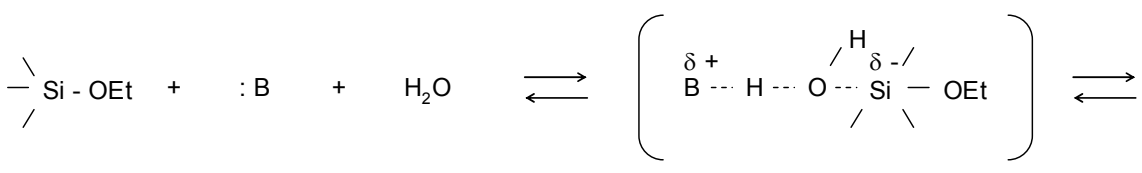

$$
\begin{aligned}
& \mathrm{B}: \cdots \mathrm{H}^{+}+\left(\begin{array}{c}
\mathrm{I}- \\
\mathrm{H}-\mathrm{O}-\mathrm{Si}-\mathrm{OEt} \\
\text { Pentacoordinate }
\end{array}\right) \rightleftarrows\left(\begin{array}{ccc}
\backslash \delta- & \mathrm{Et} & \delta+ \\
\mathrm{H}-\mathrm{O}-\mathrm{Si} \cdots & \mathrm{O} \cdots & \mathrm{H} \cdots \mathrm{B} \\
/ & &
\end{array}\right) \rightleftarrows \\
& \text { intermediate } \\
& -\mathrm{Si}-\mathrm{OH}+: \mathrm{B}+\mathrm{EtOH}
\end{aligned}
$$

(b) Base catalyzed hydrolysis

Figure 2.17 : Hydrolysis mechanism of silane coupling agent ${ }^{[73]}$ (a): Acid catalyzed ; (b): Base catalyzed

Recently, the effect of silanization accelerators such as amines, enamines (-R$\mathrm{C}=\mathrm{C}-\mathrm{NR}_{2}$ ) and aldimines ( $\left.\mathrm{R}-\mathrm{CH}=\mathrm{N}-\mathrm{R}\right)$ has been studied. ${ }^{[74,75]}$ In these studies it has been experimentally demonstrated that the use of these amines in combination with DPG (1,3-diphenylguanidine) significantly improves the degree of silanization. In addition, DPG itself is capable of accelerating the silanization. ${ }^{74,75]}$ 


\subsubsection{Silane-rubber coupling reactions}

\subsubsection{Crosslinking reactions :}

For the activation of silica-rubber coupling, curatives such as elemental sulfur and accelerators play an important role in the silane-rubber reaction. ${ }^{[76-78]}$ It is well known that silane-rubber coupling takes place during the vulcanization process. In the presence of elemental sulfur, the poly-sulfide of the silane is activated due to the insertion of elemental sulfur into the poly-sulfide of the silane. In fact, the silane can act not only as sulfur donor but also as sulfur acceptor during rubber processing. According to Debnath et al., the crosslinking reaction between model olefins in model compound experiments takes place, resulting from the sulfur donor effect of TESPT. ${ }^{[79]}$ The crosslinked product between the model olefins is shown in Figure 2.18.

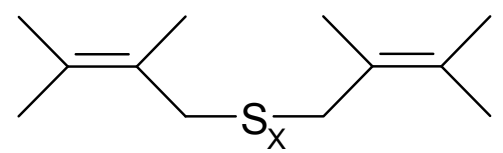

Figure 2.18 : Crosslinked product between model olefins ${ }^{[79]}$

However, in the presence of a constant amount of elemental sulfur, the crosslink density in the rubber matrix decreases with increasing amount of TESPT, resulting from the sulfur acceptor effect of TESPT (Figures 2.19). ${ }^{[56]}$
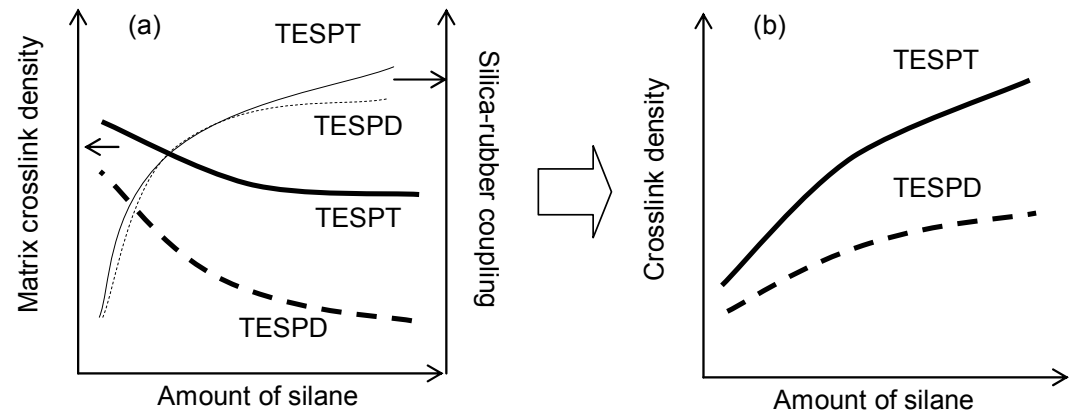

Figure 2.19 : Effect of silane on matrix crosslink density in the presence । constant amount of sulfur[56]

(a): Matrix crosslink density and silica/rubber coupling

(b): Total crosslink density (Matrix crosslinking + silica/rubber coupling)

Finally, the total crosslink density increases with increasing amount of TESPT because the silica-rubber coupling acts as crosslinking points in silica filled compounds. 
2.4.5.2 Acceleration of silane-rubber coupling in the presence of a sulphenamide accelerator (CBS)

As mentioned above, an accelerator such as DPG is capable of accelerating the silanization reaction. $\mathrm{N}$-cyclohexylbenzothiazole-2-sulphenamide (CBS), which is commonly used as primary accelerator in silica-filled rubber, is also capable of accelerating the silane-rubber coupling as shown in Figure 2.20. In this reaction model CBS can react with silane during vulcanization ${ }^{[78]}$.
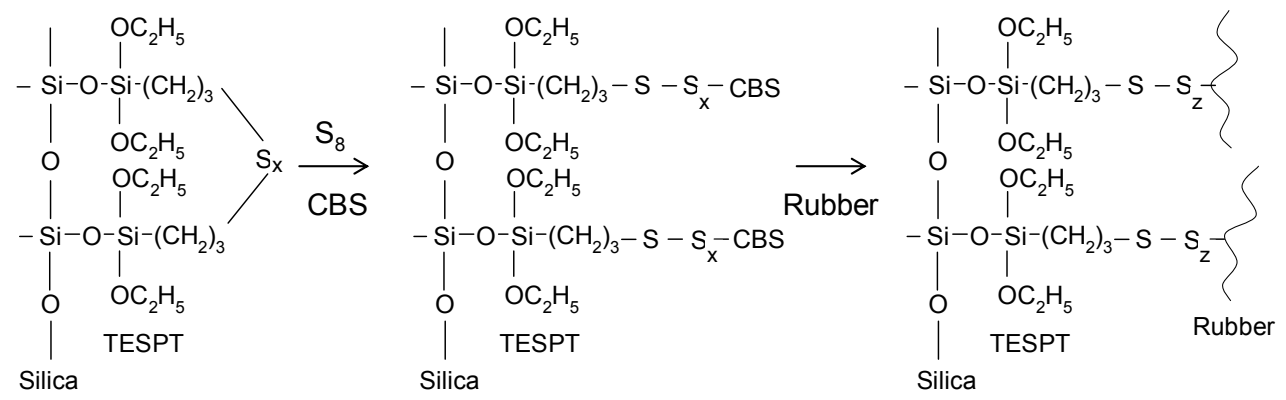

Figure 2.20 : Silane - rubber coupling in the presence of $\mathrm{CBS}^{[78]}$

\subsection{Mixing theory of rubber}

\subsubsection{Mixing with fillers}

The mixing of silica and carbon black with rubber varies widely because of the chemistry involved in silica mixing versus the more dispersive mixing of carbon black. The basic mixing process and theory are discussed to understand the special aspects of silica mixing.

Active fillers are commonly specified by three characteristic sizes: primary particles, aggregates and agglomerates. Figure 2.21 shows the particle size ranging from large agglomerates to primary particles. ${ }^{[80]}$

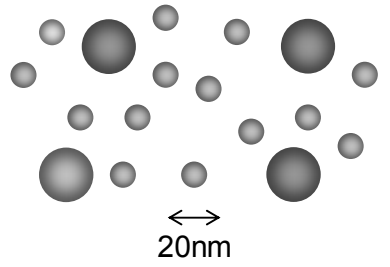

(a)

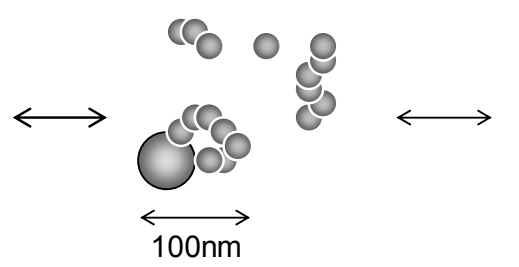

(b)

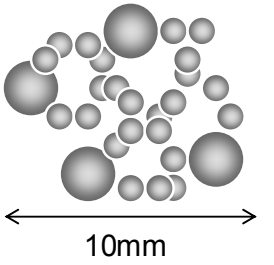

(c)

Figure 2.21 : Characteristic sizes of fillers ${ }^{[80]}$

(a): Primary particle ; (b): Aggregate ; (c): Agglomerate

Mixing defined as "simple mixing", is the process whereby the randomness or entropy of a mixture is increased without affecting the physical state of the 
components. Nakajima and Palmgrem proposed that a number of elementary steps are involved in mixing a batch of rubber as shown in Figure 2.22::[81,82]

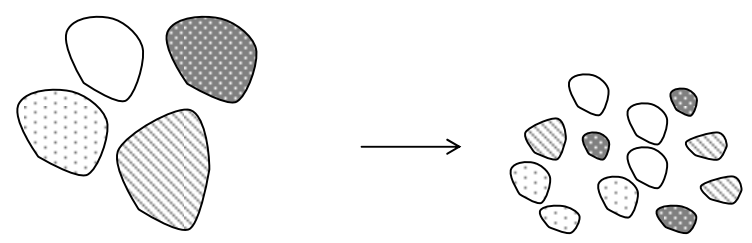

Subdivision

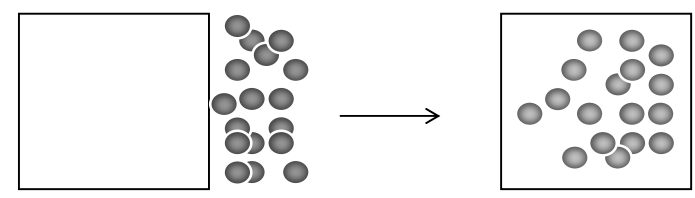

Incorporation
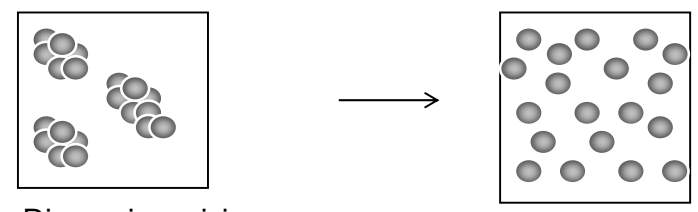

Dispersive mixing
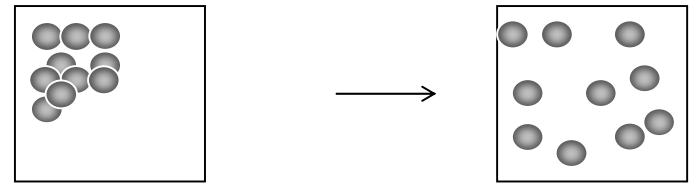

Simple mixing

(Distributive mixing)

Figure 2.22 : Illustration of the different mixing stages for filled rubber ${ }^{[82]}$

Step 1 (Subdivision):

Subdivision is the process that larger lumps or agglomerates are subdivided to smaller ones, suitable for incorporation into the rubber.

Step 2 (Incorporation):

This process involves incorporation of powdered or liquid materials into the rubber to form a coherent mass. Without incorporation the ingredients are tumbled around in the mixer with little energy being spent and practically no mixing taking place.

Step 3 (Dispersion):

The dispersion process involves the reduction of the size of agglomerates to their ultimate size in aggregates. The physical state of the fillers, such as trapped or occluded rubber in the aggregates, also changes during this process.

Step 4 (Simple mixing):

This process means moving a particle from one point to another without changing its physical shape in order to increase randomness, homogeneity or entropy, also called extensive or distributive mixing. 
Mastication and plasticization take place during the whole mixing process. These processes result in a change of the rheological properties of filled rubber, for instance, a decrease of viscosity due to the mechano-chemical breakdown of the polymer and transferring it to a more easily deformable and less elastic state.

A large number of agglomerates exist in rubber compounds at the end of the incorporation process. The agglomerate size decreases due to shear forces in the internal mixer during the dispersion process. Tokita and Pliskin proposed this mechanism and concluded that the agglomerates act like "large particles". The large particles are broken down by shear forces during mixing as shown in Figure $2.23 .^{[83,87]}$.

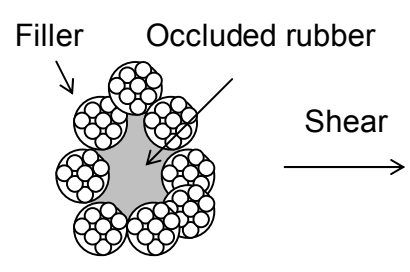

Agglomerate

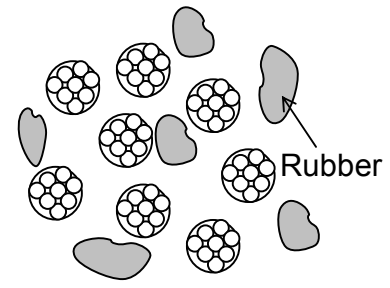

Aggregates

Figure 2.23 : Dispersion process of the agglomerates in filled rubber ${ }^{[83,84]}$

Another advanced dispersion model was developed by Shiga et al. In this model the agglomerates are chipped in the fluid having a velocity gradient; therefore it is called "the onion peel model". ${ }^{[85]}$ In this model the peel force on agglomerates relates to the filler-polymer interaction. 


\subsubsection{Silica mixing}

For silica mixing involving the special chemical reaction of silanization, the following control parameters strongly impact the silanization efficiency. ${ }^{[71,86,87]}$ :

1. geometrical design of mixing chamber and rotors;

2. temperature control;

3. optimum cooling efficiency;

4. fill factor;

5. air injection into the internal mixer;

6. ram pressure (variation of pressure has minor influence);

\subsubsection{Comparison of internal mixer design:}

Basically two types of internal mixers are commonly used in rubber compounding. Figures 2.24(a) and (b) show the schematic figures of a tangential mixer and an intermeshing mixer, respectively. ${ }^{[8]}$

Historically, tangential internal mixers have been used in the tire industry for the
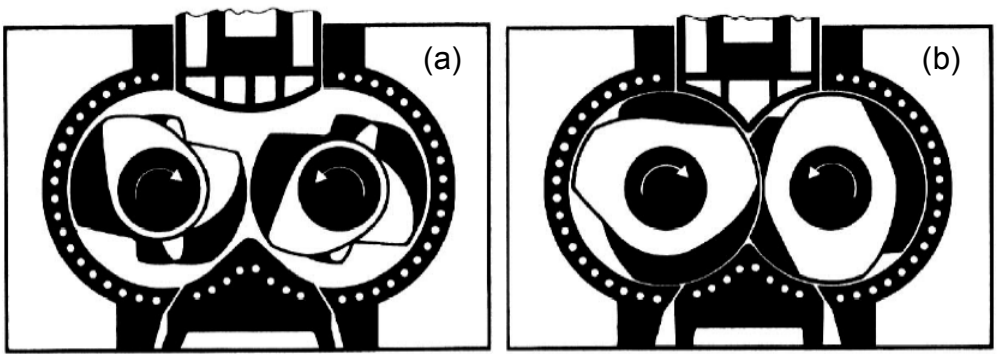

Figures 2.24 : Illustration of rotor geometry[88]

(a) : Tangential rotor ; (b) : Intermeshing rotor

production of tire tread compounds, whereas intermeshing systems were preferred for the production of industrial products. Since the green tire technology has been introduced, intermeshing mixers have become more important because of the accurate temperature control. The characteristics of each mixer are as follows:

Tangential mixers:

There is a lot of space between rotors and axial recesses; additionally the paths of blade tips only just fail to touch. The rubber compounds intensively flow from the two sides to the center of the mixing chamber where the high shear mixing takes place. The tangential mixers provide excellent filling and discharge behavior as well as short mixing times. This mixer type is commonly manufactured with empty volumes in the range from 1 to 650 liters. Various rotor shapes and speed ratios between rotors are available. The effectively employed volumes, the fill factor, during the mixing process generally range from $60 \%$ to $70 \%$ of the empty volumes for reactions of sufficient distributive mixing, which does not happen in a fully filled mixer.

Intermeshing mixers:

The center line of the rotors is less than the rotor diameter, hence the paths of the 
rotor tips cross the working area of the other rotor. Consequently both rotors have to be driven with the same speed. The main high shear mixing takes place between the rotor tips and the mixer walls. There is only a small space between the rotors and this small gap leads to a strong additional mixing effect. The total power consumption per unit time is higher than that of a tangential mixer. In addition, the fill factor of intermeshing mixers is approximately $5 \%$ less than that of tangential mixers because of less void space to allow for sufficient distributive mixing. The intermeshing system is capable of controlling temperature more accurately because of the larger cooling surface inside the mixer, resulting in a higher silanization efficiency. ${ }^{[86,87]}$

\subsubsection{Importance of temperature control during mixing :}

Silanization is a chemical reaction, and therefore accurate temperature control is required to get consistent properties. ${ }^{[71,86,87]}$ Utilizing TESPT in silica mixing, the Payne effect strongly depends on the mixing dump temperature as shown in Figures 2.25(a). ${ }^{[71,86,87]}$ The Payne effect decreases with increasing mixing dump temperature up to around $150^{\circ} \mathrm{C}$ and then slightly increases. On the other hand, the storage modulus at $100 \%$ strain starts to increase at more than $150^{\circ} \mathrm{C}$ dump temperature as shown in Figure 2.25(b), resulting from premature scorch during the mixing process.
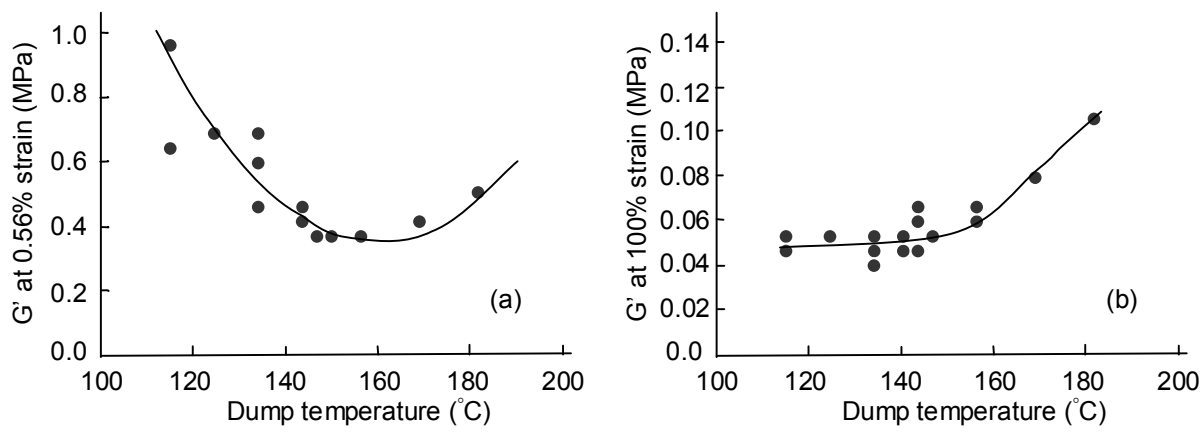

Figure 2.25 : Effect of mixing dump temperature on storage modulus $\mathrm{G}^{\text {,[71] }}$ (a): $0.56 \%$ strain (Payne effect) ; (b): $100 \%$ strain

2.5.2.3 Effect of the cooling efficiency:

As mentioned above, the intermeshing mixer is capable of better controlling temperature, and consequently provides a higher silanization efficiency. The cooling medium temperature in an internal mixer also impacts the silanization efficiency. ${ }^{[86,87]}$ Figure 2.26 shows the effect of the cooling medium temperature in the internal mixer on the Payne effect. 


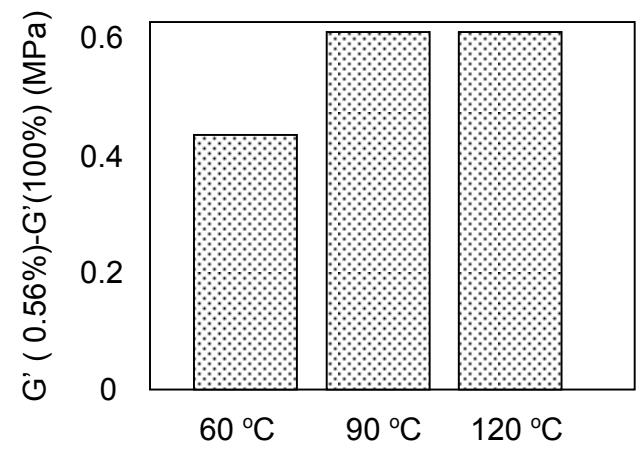

Cooling medium temperature $\left({ }^{\circ} \mathrm{C}\right)$

Figure 2.26 : Effect of the cooling medium temperature in the internal mixer on the Payne effect ${ }^{[87]}$

A lower cooling medium temperature results in a lower Payne effect, resulting from a higher silanization efficiency. No difference is observed any more at a cooling medium temperature above $90^{\circ} \mathrm{C}$ as shown in Figure 2.26 .

\section{2,5.2.4 Effect of fill factor :}

The fill factor also impacts on the silanization efficiency. ${ }^{[87,88]}$ In case of a lower fill factor, the total amount of ethanol generated in the mixing chamber is definitely low compared to the amount generated at higher fill factor. A certain quantity of the compound passes two different positions of gaps during the mixing process: 1) between the rotors; 2 ) between the rotors and the side walls of the internal mixer. For low fill factor, the degree of passes between these gaps increases, which means a higher degree of mixing. In addition, the cooling efficiency during mixing, which means the heat transfer from rubber to cooling water, increases with decreasing fill factor.

As a result, the Payne effect as well as the compound Mooney viscosity decrease with decreasing fill factor as shown in Figure 2.27, indicating of a better silanization.

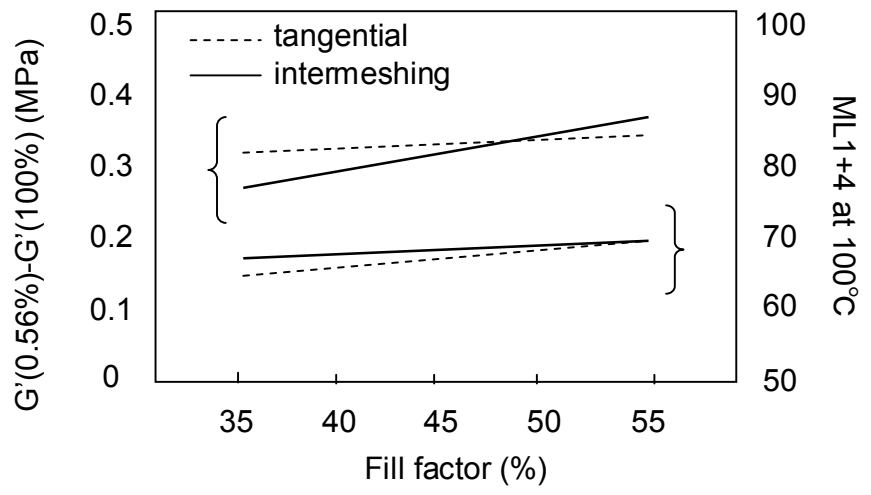

Figure 2.27 : Effect of fill factor on the Payne effect and Mooney viscosity[87] (Solid line) : intermeshing rotor ; (Broken line) : tangential rotor 
mixing

As mentioned above, ethanol is generated during the silanization process. In a production plant, ethanol partly evaporates out of the compounds and then recondences in the mixing chamber. The re-condensation of ethanol results in slippage of the compounds, and consequently the mixing and the cooling efficiency decrease. In addition, high ethanol condensation in the compounds causes a decrease of the silanization rate. To overcome these problems, air injection during the silanization process was applied. As shown in Figure 2.28, the silanization efficiency could significantly be improved in this manner. ${ }^{[86,87]}$

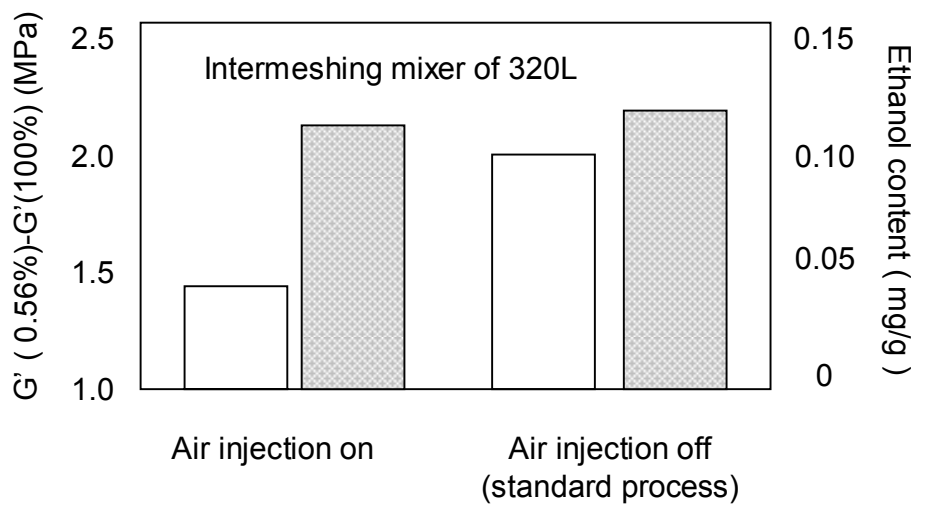

Figure 2.28 : Effect of air injection on the silanization efficiency [87]

( $\square$ ) : G'(0.56\%)-G'(100\%) ; ( $\square$ ): Ethanol content

\subsubsection{Ram pressure-less during mixing:}

The elimination of ethanol during mixing is important to achieve sufficient silanization. Ram pressure-less mixing is one of the ways to eliminate the ethanol during mixing. ${ }^{[87]}$ According to Dierkes, pressure-less mixing enhances the ethanol evaporation during the mixing, resulting in an increase of the silanization efficiency. Figure 2.29 shows the effect of the ram pressure-less mixing on the Payne effect. By using ram pressure-less mixing the Payne effect strongly decreases as shown in Figure 2.29. 


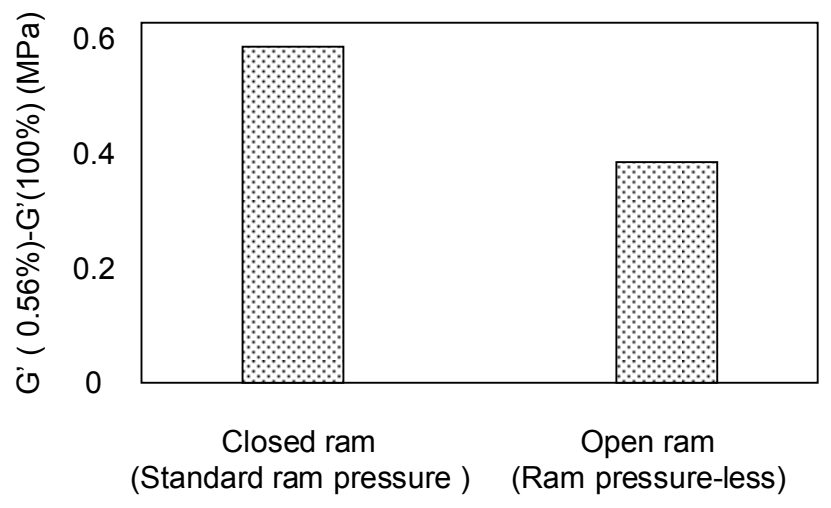

Figure 2.29 : Effect of the ram pressure on the Payne effect ${ }^{[87]}$ Mixer: Intermeshing mixer with $320 \mathrm{~L}$ volume

\subsection{Motivation of the project}

The use of silica in tire tread compounds has advantages in terms of improved tire performance such as low rolling resistance and better wet traction. These advantages result from reinforcement of silica in combination with a silane coupling agent. However, silica filled rubbers still provide a lot of difficulties due to the large polarity differences between silica and the rubber and the complicated silane chemistry.

Recently, various types of silica have been developed, in particular highly dispersible silicas (HD silica). It is well known that the HD silicas show better physical properties compared to conventional silica (CV silica). The reason for this improved physical properties of the HD silicas compared to that of CV silica is not fully understood. The interaction of silica-rubber is one of key factors determining the physical properties of silica filled rubbers.

Due to the large polarity difference between silica and polymer, silica flocculation is observed during storage and during the vulcanization process of silica-filled rubber. This flocculation process also impacts on the physical properties of silica-filled rubber. Therefore, insight into the stability of the morphology of silica in the rubber matrix is required to further understand the mechanism of silica reinforcement.

Acceleration of silanization is another major issue in silica filled rubber. To achieve a better silanization, material parameters, machine parameters and the methods employed are of importance. Amines, such as enamines and aldimines, are capable of accelerating the silanization reaction without creating a scorch problem. 1,3-diphenylguanidine (DPG) acts not only as silanization booster but also as secondary accelerator in silica filled rubber. However, DPG has become suspect for reasons of toxicity. Therefore, alternatives for DPG will be required in future. 
The focus of the project of this thesis will be to provide further understanding the regarding the reinforcing mechanism and the determining factors of the physical properties of silica-filled rubber. And also new types of amines as DPG alternatives will be explored.

This thesis is divided into the following main items:

1. Reinforcing mechanism of silica filled rubber:

- Bound rubber formation;

- Flocculation process;

- Improved reinforcing properties in the presence of alternative amines to replace DPG.

2. Silane chemistry:

- Acceleration of silanization by using various amines;

- Use of alternative amines for DPG;

- Side reactions during the silanization process.

Finally, based on these experiments, a few new alternatives for DPG are depicted and investigated. 


\subsection{References}

1. J.W. Ten Brinke, "Silica Reinforced Tyre Rubber", Thesis: 2002, Dept. of Rubber Technology, Univ. of Twente, Enschede, the Netherlands

2. R. Engehausen, A. Rawlison, J. Trimbach, Tire Technol. Int. Ann. Review, 36, 2001 (2001)

3. W. M. Hess, W.K. Klamp, Rubber Chem. Technol., 56, 390 (1986)

4. D.E. Hall, J.C. Moreland, Am. Chem. Soc., Rubber Div. Meeting. Dallas, Texas, April 4-6, (2000)

5. K.H. Nordsiek, Kautsch. Gummi Kunstst., 38, 178 (1985)

6. M.J Wang, Rubber Chem. Technol., 71, 520 (1998)

7. G. Heinrich, Kautsch. Gummi Kunstst., 45, 173 (1992)

8. F. Thurn, S. Wolff, Kautsch. Gummi Kunstst., 28, 733 (1975)

9. H. Roelig, Rubber Chem. Technol., 12, 284 (1939)

10. W.S.J. Naunton, J.S.R. Warning, Trans. Inst. Rubber Ind., 14, 340 (1939)

11. S.D. Gehman, D.E. Woodford, R.B. Stambaugh, Ind. Eng. Chem, 33, 1032 (1941)

12. R.B. Stambaugh, Ind. Eng. Chem., 34, 1358 (1942)

13. A. Blume, S. Uhrlandt, Am. Chem. Soc., Rubber Div. Meeting, Akron, Ohio (2000)

14. A.R. Payne, Rubber Plast. Age, 963 (1961)

15. A.Y. Coran, J.-B. Donnet, Rubber Chem. Technol., 65, 1016 (1992)

16. A. Einstein, Ann. der Physik, 19, 289 (1906)

17. A. Einstein, Ann. der Physik, 34, 591 (1911)

18. E. Guth, O. Gold, Phy. Rev., 53, 322 (1938)

19. E. Guth, J. Appl. Mech., 16, 20 (1945)

20. A.I. Medalia, J. Interface. Sci., 32, 115 (1970)

21. G. Kraus, Rubber Chem. Technol., 44, 199 (1971)

22. P.P.A. Smit, Rubber Chem. Technol., 41, 1194 (1968)

23. I. Pliskin, N. Tokita, J. Appl. Sci., 16, 473 (1972)

24. J. O'Brien, E. Cashell, G.E. Wardell, V.J. McBrierty, Macromolecules, 9, 653 (1976)

25. A.R. Payne, Rubber Chem. Technol., 44, 440 (1971)

26. G. Kraus, J. Polym. Sci., 39, 75 (1984)

27. G. Kraus, "Reinforcement of Elastomers "Interscience., NY, (1965)

28. M. Klüppel, Kautsch. Gummi Kunstst., 50, 282 (1997)

29. T. A. Okel, Am. Chem. Soc., Rubber Div. Meeting, San Antonio, Texas, May 16-18 (2005)

30. A. Blume, Rubber World, 86, 30 (2002)

31. M.P. Wagner, Rubber Chem. Technol., 49, 703 (1976)

32. H.D. Luginsland, Am. Chem. Soc., Rubber Div. Meeting, Savannah, Georgia, April 29-May 1 (2002)

33. D.W. Schaefer, J. Appl. Crystallography, 33(1), 587 (2000)

34. J. Janzen, Rubber Chem. Technol., 44, 1287 (1971)

35. A. Voet, J.C. Morawski, J.B. Donnet, Rubber Chem. Technol., 50, 342 (1977)

36. G.E. Marcial, D.W. Sindorf, J. Am. Chem. Soc., 102, 7606 (1980)

37. D.W. Sindorf, G.E. Marcial, J. Am. Chem. Soc., 87, 5516 (1986)

38. D.L. Wood, et al., J. Am. Ceramic Soc., 66, 693 (1986)

39. J.L. Leblanc, Prog. Polym. Sci., 2, 627 (2002) 
40. D.R. Bassett, E.A. Boucher, A.C. Zettlemoyer, J. Colloid Interface Sci., 27, 649 (1968)

41. M.J. Wang, Rubber Chem. Technol., 64, 559 (1991)

42. R.F. Grossman, "The Mixing of Rubber", Chapman \& Hall, 25 (1997)

43. M. Castellano, J. Macromol. Sci., 43(3), 451 (2002)

44. H.D. Luginsland, Rubber Chem. Technol., 75, 563 (2002)

45. Y. Ozawa, International Rubber Conference, Nürnberg, Germany, June 30July 3 (2003)

46. S.Muecke, International Rubber Conference, Nürnberg, Germany, June 30July 3 (2003)

47. B. Hsu, A. Halasa, K. Bate, J. Zhou, K.-C. Hua, N. Ogata, International Rubber Conference, Yokohama, Japan, October 26-28 (2005)

48. R. Rauline, EP 0 501227A1, to Michelin Recherche et Technique S.A. (February 12, 1992).

49. S. Wolff, Kautsch. Gummi Kunstst., 33, 1000 (1980)

50. M.J. Moore, Am. Chem. Soc., Rubber Div. Meeting, Cleveland, Ohio, October 16-19 (2001)

51. S. Bandyopadhyay, P.P. De. D. K. Tripathy, S.K. De., Rubber Chem. Technol, 69, 675 (1996)

52. W. Hopkins, W. von Hellens, A. Koshi, J. Rausa, Am. Chem. Soc., Rubber Div. Meeting, Cleveland, Ohio, October 16-19 (2001)

53. R.W. Cruise, M.H. Hofstetter, L.M. Panzer, R.J. Pickwell, Am. Chem. Soc., Rubber Div. Meeting, Louisville, Kentucky, October 8-11 (1996)

54. A. Hunsche, U. Görl, A. Muller, M. Knaak, Kautsch. Gummi Kunstst., 50, 881 (1997)

55. Deggusa AG, Applied Technol., Advanced Filler, Produkt information PI321 and PI335

56. A. Hasse, O. Klockman, A. Wehmeier, H.-D. Luginsland., Kautsch. Gummi Kunstst., 55, 236 (2002)

57. P.G. Joshi, R.W. Cruse, R.J. Pickwell, K.J. Weller, W.E. Sloan, Tire Tech International annual review (2003)

58. D.J. Zanzig, G. Thielen, J. Verthe, EP1400559A1, to GoodYear Tire \& Rubber Company (2004)

59. H.-D. Luginsland, A. Hasse, M. Radcziwill, R. Krafczyk, US 1727339, to Evonik Degussa AG (2004)

60. Z.D. John, US 7262254, to GoodYear Tire \& Rubber Company (2002)

61. P.G. Joshi, R.W. Cruse, R.J. Pickwell, K.J. Weller, M.H. Hofstetter, E.R. Pohl, M.F. Stout, Rubber \& Plastics News, September 9, (2002)

62. O. Klockmann, A. Hasse, Deutsche Kautschuk-Tagung, Nürnberg, Germany, 3-6 July (2006)

63. A. Hunsche, U, Görl, H.G. Koban, Th. Lehmann, Kautsch. Gummi Kunstst., 51, 525 (1998)

64. U. Görl, A. Hunsche, Am. Chem. Soc., Rubber Div. Meeting, Louisville, Kentucky, October 8-11 (1996)

65. U. Görl, J. Munzenberg, H.D. Luginsland, A. Muller, Kautsch. Gummi Kunstst., 52, 588 (1999)

66. U. Görl, A. Hunsche, A. Muller, H.G. Koban., Rubber Chem. Technol., 70, 608 (1997)

67. F. Beari, et al., J. Organometallic Chem., 625, 208 (2001) 
68. M. Brand, et al., Zeitschrift fur Naturforschung 54b, 155 (1999)

69. D.W. Sindorf, G.E. Maciel, J. Phys. Chem., 86, 5208 (1982)

70. D.W. Sindorf, G.E. Maciel, J. Am. Chem. Soc., 105, 3767 (1986)

71. L.A.E.M Reuvekamp, "Reactive mixing of silica and rubber for tires and engine mounts”, Thesis: 2003, Dept. Rubber Technol., Univ. of Twente: Enschede, the Netherlands

72. M.J. Moore, Rubber Plast. News., June 3, 14, (2002)

73. K.J. Kim, Rubber Chem. Technol., 78, 84 (2005)

74. W. David, U.S. Pat. 6.951.897, to Michelin Recherche et Technique S.A., U.S. (23-07-2002)

75. W. Katarzyna, U.S. Pat. 6.984 .689 , to Michelin Recherche et Technique S.A., (23-07-2002)

76. H.-D. Luginsland, Kautsch. Gummi Kunstst., 53, 10 (2000)

77. S. Wolff, Kautsch. Gummi Kunstst., 34, 280 (1981)

78. A. Hasse, O. Klockmann, Kautsch. Gummi Kunstst., 55, 5 (2002)

79. S.C. Debnath, R. N. Datta, J. W. M. Noordermeer, Rubber Chem. Technol., 76, $1311(2003)$

80. Y. Li, M.J. Wang, T. Zhang, Rubber Chem. Technol., 67, 693 (1994)

81. H. Palmgren, Rubber Chem. Technol., 48, 462 (1975)

82. N. Nakajima, Rubber Chem. Technol., 53, 1088 (1980)

83. N. Tokita, I. Pliskin, Rubber Chem. Technol., 46, 1166 (1973)

84. I. Pliskin, Rubber Chem. Technol., 49, 12 (1976)

85. S. Shiga, Nippon Gomu Kyokaishi., 62, 123 (1989)

86. W.K. Dierkes, J.W.M. Noordermeer, Rubber World, 229(6), 33 (2004)

87. W.K. Dierkes, "Economic mixing of silica-rubber compounds", Thesis: 2005, Dept. of Rubber Technology, Univ. of Twente, Enschede, the Netherlands

88. G. Heiss, "Mixing of Silica Compounds", ITEC (2000) 
Chapter 2 


\section{Chapter 3}

\section{COMPARISON STUDY OF SILICA DETERMINING FACTORS OF PHYSICAL PROPERTIES OF SILICA REINFORCED RUBBER}

The interfacial area on the silica surface involved in filler-polymer interaction can be estimated using the bound rubber measurement with an ammonia treatment. The interfacial area on the silica surface, which is chemically active, increases with increasing mixing dump temperature due to higher silanization; hence the Payne effect decreases. The bound rubber thickness can be estimated using the Pliskin-Tokita equation. The bound rubber thickness decreases with increasing CTAB surface area, resulting from a strong filler-filler interaction caused by the polarity differences between the silica and the polymer.

The interfacial area on the silica surface which is chemically accessible to the polymer, defined as the specific bound rubber, and the bound rubber thickness strongly affect the visco-elastic/physical properties of silica filled compounds. With increasing specific chemically bound rubber on the silica surface, the Payne effect and $\tan \delta$ at $60^{\circ} \mathrm{C}$ decrease because of increasing interfacial area between silica and polymer resulting in reduction of the filler-filler interaction. The reinforcing index M300/M100, which is generally used as a measure for rolling resistance for silica reinforced tires, shows a positive correlation with the specific bound rubber $\left(V_{\text {beff }} / C T A B\right)$. Therefore, the chemical interfacial area on the silica surface is highlighted as the dominant factor for the reinforcing index of the silica reinforced rubber.

For both polymers, butadiene rubber and styrene-butadiene rubber, the bonding ability to the silica surface is investigated by using pyrolysis gas chromatography. The bonding ability of butadiene rubber to the silica surface is approximately half of that of styrene butadiene rubber. 


\subsection{Introduction}

Amorphous precipitated silica has been used in rubber as a reinforcing filler for decades. ${ }^{[1,2]}$ However, amorphous precipitated silica still has a number of difficulties due to the polarity differences between silica and rubber polymers. The silica surface is highly polar and hydrophilic due to the presence of hydroxyl groups on the silica surface and consequently a strong silica-silica network is formed in a rubber matrix. ${ }^{[3]}$ As a result, processing difficulties such as an increase of Mooney viscosity take place. ${ }^{[4,5]}$ The filler network is characterized by stress softening with increasing strain, the so-called Payne effect, defined as the difference of the storage modulus at low and high strain $\left(\Delta G^{\prime}\right) .^{[6,7]}$

To reduce the filler-filler interaction, a silane coupling agent is commonly used. Bis(triethoxysilylpropyl)tetrasulphide (TESPT) is widely used as silane coupling agent. ${ }^{[8-10]}$ TESPT can react chemically with the silica surface making it hydrophobic during mixing. In fact, the silane chemistry is complicated because several chemical reactions take place during rubber processing. A number of studies concerning silanization chemistry have been done in the past. ${ }^{[11-16]}$ According to these, the mixing conditions but particularly the mixing dump temperature strongly affect the silane chemistry.

Besides the mixing conditions, the colloidal properties of the silica also affect the silane chemistry and the silica dispersion. ${ }^{[17,18]}$ In general, silica can be classified as conventional, semi dispersible or highly dispersible silica, depending on the particle size distribution. Figure 3.1 shows the aggregate size distribution for the conventional silica (CV silica) and the highly dispersible silica (HD silica). ${ }^{[18]}$

As can be seen, for HD silica the relative amount of small aggregates is high compared to $\mathrm{CV}$ silica. HD silica is commonly used in passenger tire tread

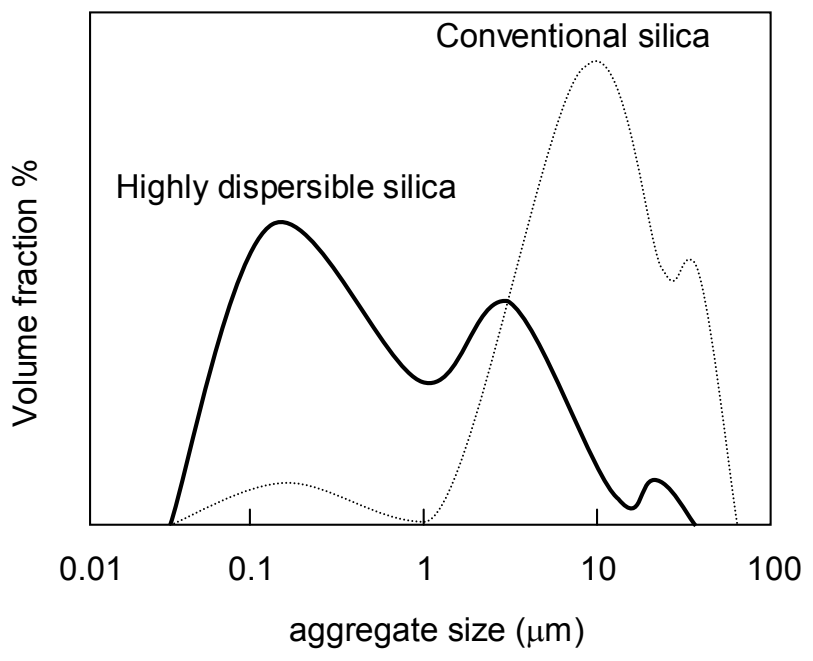

Figure 3.1: Schematic particle distribution of silica

compounds. The aggregates are formed by the primary particles of the silica. The primary particle size of the silica is characterized by the surface area such as BET 
or CTAB based on the adsorption theory. The nitrogen BET method measures the overall surface area of particle including the micro pores. On the other hand, by the cetyl trimethylammonium bromide (CTAB) method it is possible to measure the external surface area of the particle. It is known that TESPT can not penetrate into the micro pores of silica. Therefore, a better correlation to surface area is obtained with the CTAB surface area. ${ }^{[19,20]}$ In typical tire tread applications, $8 \%$ of TESPT for a standard silica with a CTAB-surface of $160 \mathrm{~m}^{2} / \mathrm{g}$ are generally required. ${ }^{[18]}$

One of the problems related to the large polarity-difference between silica and rubber polymers is the tendency of the silica to re-agglomerate or flocculate again after mixing, in spite of the use of silane coupling agents. The silica-polymer interaction plays an important role in the reduction of filler flocculation. Bound rubber (the amount of rubber polymer which can not be dissolved anymore after mixing rubber and silica, before crosslinking) is one of the direct indications for filler-polymer interaction. Several bound rubber models have been proposed. ${ }^{[11-25]}$ Especially in the case of silica filled compounds, due to the strong silica-silica interaction, a rubber polymer is partially trapped in the secondary silica network, which results in an increase in modulus. ${ }^{[7,10,18]}$ In addition, bound rubber in silica filled compounds increases with increasing dump temperature due to a larger interaction of silane coupling agent towards silica and rubber. ${ }^{[17]}$

For an incompatible blend of different rubbers such as styrene-butadiene rubber and butadiene rubber, the polarity difference between the silica and each rubber is also important. Based on model compounds studies, it was suggested that the interaction of a butadiene unit with the silica surface is relatively low compared to that of a styrene-butadiene unit. ${ }^{[26,27]}$

In the present chapter we focus on the interfacial layer between the silica particle and the polymer to understand the nature of the filler-polymer interaction. The determining factors of the physical properties of a silica reinforced rubber will be discussed.

\subsection{Experimental}

\subsubsection{Preparation of samples}

Different types of silica were used in the present study as given in Table 3.1. The silicas are tabled by increasing CTAB value. All experiments were done using a tire tread composition corresponding to the fuel-saving green tire technology as given in Table 3.2. The amount of silane applied in the recipes was adjusted according to equation 3.1, in which the amount of silane was adjusted for various silicas based on the CTAB surface areas. The total amount of active sulfur was adjusted to 2.1 phr, being the sum of the sulfur contained in the silane and in the curatives.

$$
\operatorname{TESPT}(p h r)=5.3 \times 10^{-4} \times(C T A B)_{\text {silica }} \times(p h r)_{\text {silica }}
$$

The compounds were mixed in 3 steps. The first two steps were done using a Brabender Plasticorder lab station internal mixer with $390 \mathrm{ml}$ volume. The mixing procedures in the first two steps are shown in Table 3.3. 
Table 3.1: Analytical data of silicas

\begin{tabular}{llllll}
\hline Silica & Source & Ty pe & $\begin{array}{l}\text { BET } \\
\left(\mathrm{m}^{2} / \mathrm{g}\right)\end{array}$ & $\begin{array}{l}\text { CTAB } \\
\left(\mathrm{m}^{2} / \mathrm{g}\right)\end{array}$ & $\begin{array}{l}\text { DBP } \\
(\mathrm{g} / 100 \mathrm{~g})\end{array}$ \\
\hline Zeosil 1115MP & Rhodia Silices & HD & 109 & 108 & 212 \\
Zeosil 1165MP & Rhodia Silices & HD & 155 & 152 & 196 \\
Ultrasil 7005 & Degussa & HD & 171 & 164 & 260 \\
Ultrasil VN3 & Degussa & CV & 177 & 168 & 183 \\
\hline
\end{tabular}

Table 3.2: Compound formulations

\begin{tabular}{llll}
\hline Component & Product name & Supplier & phr \\
\hline S-SBR $*$ & Buna VSL5025HM-1 & Lanxess & 103 \\
BR & Nipol 1220 & Nippon Zeon & 25.0 \\
Silica & listed in Table 3.1 & listed in Table 3.1 & 80.0 \\
Silane(TESPT) & Si69 & Degussa & variable \\
Aromatic oil & Tudalen 3570A & Hansen \& Rosenthal & 4.40 \\
Zinc oxide & ZnO & Merck & 2.50 \\
Stearic acid & Steraric acid & Merck & 2.50 \\
Curatives: & & & \\
Sulfur & & J.T. Baker & Variable \\
CBS & SantocureCBS & Flexsys & 1.70 \\
DPG & Perkacit DPG & Flexsys & 2.00 \\
\hline
\end{tabular}

※ 37.5phr oil extended

The starting temperature of the mixing chamber was $50^{\circ} \mathrm{C}$. The dump temperature in the first two steps was kept below $160^{\circ} \mathrm{C}$ by changing the rotor speed. The fill factor of the mixer was fixed to $68 \%$. The curatives were mixed on the two roll mill in the third step.

Table 3.3: Mixing procedure

\begin{tabular}{|c|c|c|c|c|}
\hline \multicolumn{2}{|c|}{ Step 1} & \multicolumn{2}{|l|}{ Step 2} & Step 3 \\
\hline Time & Action & Time & Action & Action \\
\hline $\begin{array}{l}0.00 \\
1.00 \\
2.00 \\
4.00 \\
4.20 \\
6.20\end{array}$ & $\begin{array}{l}\text { Add rubber } \\
\text { Add } 1 / 2 \text { silica, } 1 / 2 \text { silane } \\
\text { Add } 1 / 2 \text { silica, } 1 / 2 \text { silane, oil, stearic acid } \\
\text { Ram up, sweep } \\
\text { Ram down } \\
\text { Dump }\end{array}$ & $\begin{array}{l}0.00 \\
1.00 \\
5.00\end{array}$ & $\begin{array}{l}\text { Add master batch } \\
\text { Add } \mathrm{ZnO} \\
\text { Dump }\end{array}$ & $\begin{array}{l}\text { All curatives were mixed on } \\
\text { a two-roll mill. }\end{array}$ \\
\hline
\end{tabular}


Vulcanization was done in a Wickert laboratory press WLP 1600 at $160^{\circ} \mathrm{C}$ and 100 bar for optimal cure time. The optimal cure time was determined using a RPA2000 dynamic rheological tester from Alpha technology. The Rheogram was measured under the following conditions: $160^{\circ} \mathrm{C}, 0.833 \mathrm{~Hz}$ and $2.79 \%$ strain for 30 minutes. The differential curve, as shown Figure 3.2 was calculated from the rheogram.

In the differential curve, the two tangential lines passing through the maximum value (A) and the plateau region (B) were established and then the cross point of these two lines was estimated. The cross point plus 1 minute was used as the optimal vulcanization time.

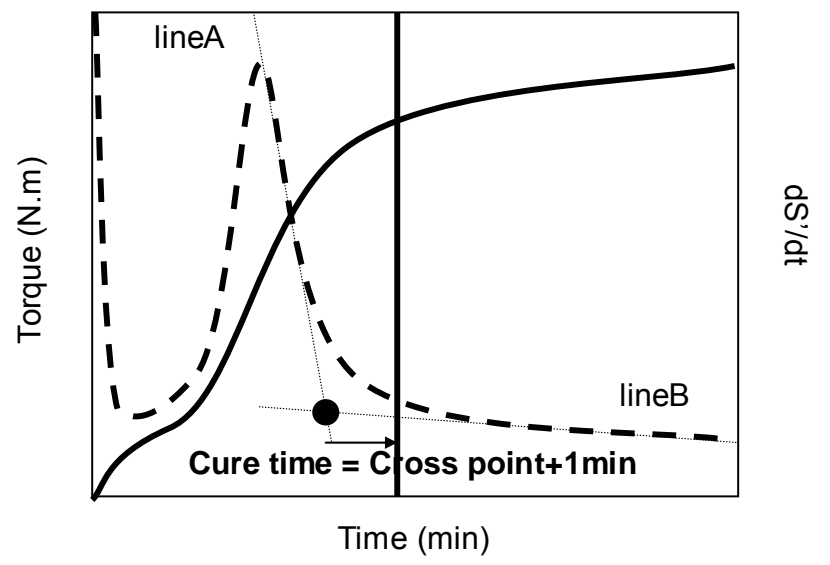

Figure 3.2: Schematic rheogram (- ) and differential curve (---- )

\subsubsection{Sample analysis}

\subsubsection{Payne effect}

Payne effect measurements were done using a Rubber Process Analyzer RPA2000 from Alpha technologies. The storage modulus at $0.56 \%$ strain was measured under the following conditions; temperature: $100^{\circ} \mathrm{C}$ and frequency: $0.5 \mathrm{~Hz}$. This measurement may be used and can be accepted as a measure of the Payne effect.

\subsubsection{Bound rubber measurements}

Bound rubber measurements were done for rubber compounds mixed till different dump temperatures. These values were used to estimate the average thickness of the bound rubber layer on the filler surface. For the present purpose only chemically bound rubber is taken into account. Therefore, an ammonia treatment was done prior to the bound rubber measurements. According to Wolff and Polmanteer, ammonia treatment cleaves physically bound rubber. ${ }^{[21,28]}$ The chemically bound rubber measurement was therefore done in the following way:

\section{0,2 Grams of uncured rubber without curatives was put into a metal cage;}

The sample in the cage was immersed in $100 \mathrm{ml}$ toluene for 72 hours at room temperature.

2. Toluene was renewed every 24 hours;

The sample was removed out of the toluene and dried for 24 hours. 
3. The sample was put into an ammonia atmosphere with toluene for 72 hours in order to cleave physical linkages;

The sample was immersed in $100 \mathrm{ml}$ toluene for 72 hours at room temperature. Toluene was renewed every 24 hours.

4. The sample was dried for 24 hours and weighed.

The effective volume fraction of polymer chemically bound to the silica $V_{\text {beff }}$ was calculated according to equation 3.2:

$$
v_{b e f f}=\frac{W_{f g}-W_{f}}{W_{p}}
$$

where $W_{f g}$ is the weight of silica with the bound rubber attached to it after ammonia treatment; $W_{f}$ is the weight of the silica in the specimen and $W_{p}$ is the weight of the polymer in the specimen.

\subsubsection{Pyrolysis gas chromatography}

The pyrolysis gas chromatographic conditions are shown in Table 3.4. 4-vinyl-1-

Table 3.4: Pyrolysis gas chromatographic conditions

\begin{tabular}{ll}
\hline Pyrolyzer & Japan Analytical Industry, JHP-3S \\
Column & Shimadzu GC-14D \\
Packed Column & Shinwa, SILICON DC-200 \\
Column Temp. & $140^{\circ} \mathrm{C}$ \\
Injection and detector Temp. & $230^{\circ} \mathrm{C}$ \\
Pyrolized condition & $5 \mathrm{~min}$ for $3 \mathrm{sec}$. \\
Sample weight & $0.3 \mathrm{mg}$ \\
Flow rate of $\mathrm{N}_{2}$ & $40 \mathrm{ml} / \mathrm{min}$ \\
Mass spectrometer & Shimadzu, QP-1000
\end{tabular}

cyclohexene from butadiene rubber and styrene from styrene-butadiene rubber were detected under the conditions applied in this study. Those two peaks areas were used as the key peaks in order to determine the quantities of SBR and BR in the bound rubber. ${ }^{[29]}$

\subsubsection{Mechanical properties}

The mechanical properties of the cured compounds were measured using a Zwick Z020 tensile tester according to ISO-37.

\subsubsection{Visco-elastic properties}

The $\tan \delta$ at $60^{\circ} \mathrm{C}$ was measured after vulcanization using a Toyo Seiki viscoelasticity spectrometer under the conditions of a frequency of $20 \mathrm{~Hz}$, an initial elongation strain of $10 \%$ and an amplitude of $\pm 2 \%$. It is generally known that the value of $\tan \delta$ at $60^{\circ} \mathrm{C}$ is correlated with the rolling resistance. 


\subsection{Results}

\subsubsection{Payne effects as a function of the mixing dump temperature}

The storage modulus at low strain $(0.56 \%)$, the so-called Payne effect, after the 2nd mixing step is plotted as a function of the mixing dump temperature in Figure 3.3.

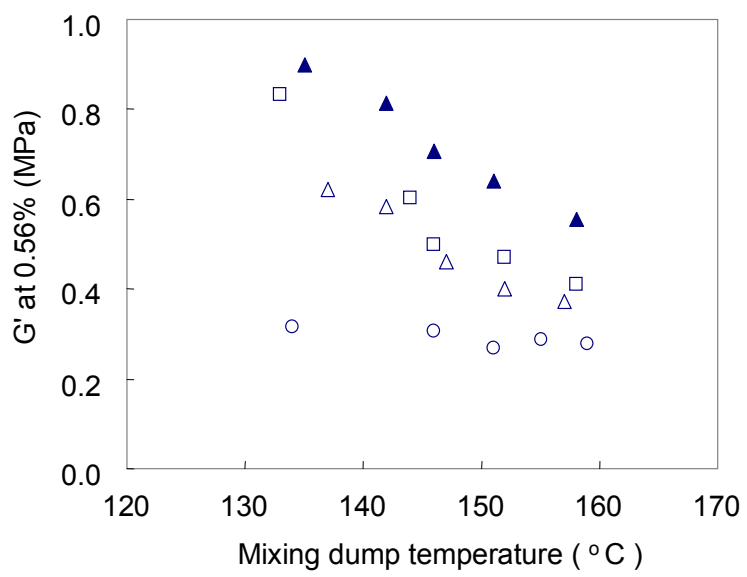

Figure 3.3: Comparison of Payne effect for different types of silica $(\circ)$ : 1115MP ; $(\Delta)$ : 1165MP ; ( $)$ ): 7005 ; ( $\triangle$ ):VN3

All the silicas except 1115MP show a continuous decrease in storage modulus at $0.56 \%$ strain with increasing mixing dump temperature. For $1115 \mathrm{MP}$, no significant decrease of storage modulus at $0.56 \%$ strain can be seen.

\subsubsection{Bound rubber measurement}

Figure 3.4 shows the bound rubber contents as a function of the mixing dump temperature.

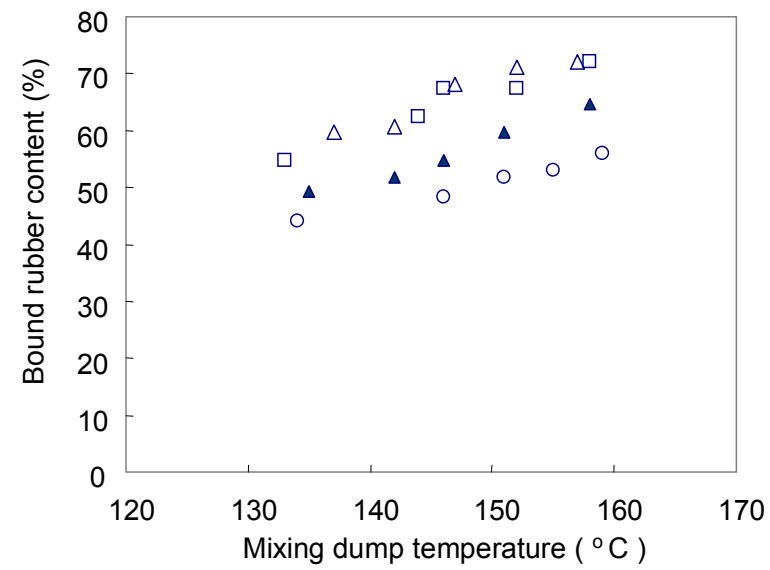

Figure 3.4: Bound rubber content as a function of the mix dump temperature

( $\bigcirc$ ): 1115MP ; $(\Delta)$ : 1165MP ; ( ( ): 7005 ; ( $\triangle$ ): VN3

It is evident that the bound rubber content increases with increasing mixing dump 
temperature due to a higher degree of silanization. For the $1115 \mathrm{MP}$ silica, the bound rubber is relatively low compared to the other silicas.

The bound rubber can be composed of three different types of polymer bonded on the silica surface: chemical-bonding, physical-bonding and occluded rubber. To estimate the amount of physically bonding polymer in the bound rubber, ammonia treatment on the bound rubber was carried out according to the experimental procedure described before. It is well known that by ammonia treatment, it is possible to cleave physical bonds between silica and polymer. ${ }^{[21,28]}$ Figure 3.5 shows the amounts of extracted polymer after ammonia treatment as a function of the mixing dump temperature; so all polymer which is not chemically bonded to the filler surface.

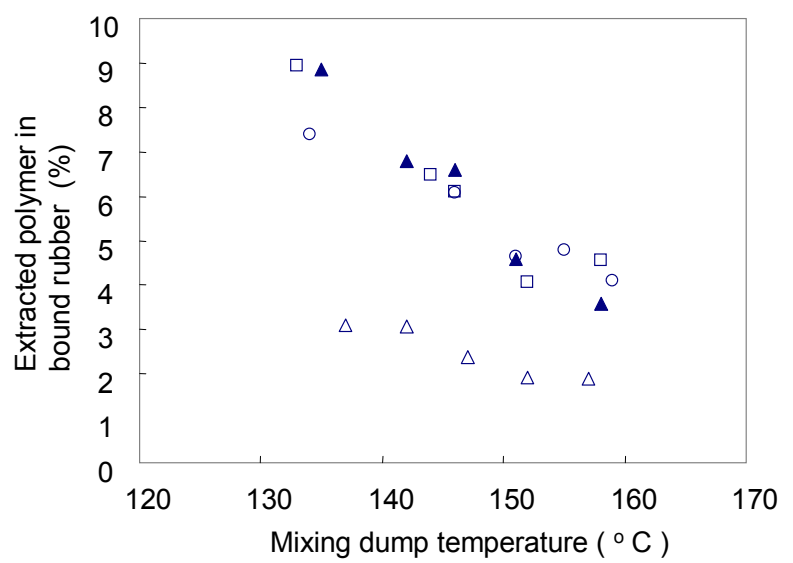

Figure 3.5: Extracted polymer with ammonia treatment as a function of the mixing dump temperature $(\circ)$ : 1115MP ; $(\Delta): 1165 \mathrm{MP} ;(\square)$ : $7005 ;(\Delta)$ : VN3

This extracted polymer amount decreases with increasing mixing dump temperature. This indicates that a higher mixing dump temperature leading to a higher degree of silanization does increase the amount of chemically bonded polymer on the silica surface. For the 1165MP silica, the amount of extracted polymer after ammonia treatment is relatively low, indicating a high amount of chemically bonded polymer on the silica surface. On the other hand, for the other silicas no significant difference can be seen.

In general, it is assumed that the full silica-rubber coupling via the silane coupling agent takes place during the vulcanization. ${ }^{[17,31,32]}$ However, taking the results above into account, it is suggested that at least part of the formation of chemically bonded polymer on the silica surface already takes place during mixing. Therefore, in this study we propose to define the specific bound rubber, which is the chemically bound rubber before vulcanization relative to the accessible silica surface area, by equation 3.3:

$$
\text { Specific bound rubber }=\frac{\text { Bound rubber after ammonia treatment }}{C T A B \text { surface area of silica }}\left[\frac{g}{\mathrm{~m}^{2}}\right]
$$

(eq.3.3) 
Figure 3.6 shows the specific chemically bound rubber before vulcanization as a function of the mixing dump temperature.

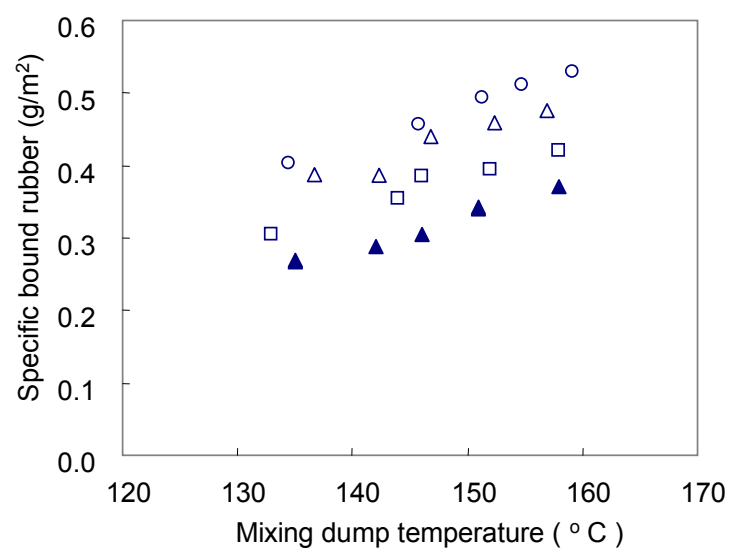

Figure 3.6: Specific bound rubber as a function of the mixing dump temperature

$(\circ)$ : 1115MP ; ( $\Delta$ ): 1165MP ; ( ): 7005 ; ( $\Delta$ ): VN3

The specific bound rubber increases with increasing mixing dump temperature. For the silicas with higher CTAB surface area the specific bound rubber is relatively low. One possible interpretation for the lower specific bound rubber could be a reduced effectiveness of the silica surface to form chemically bonded polymer, as a result of strong silica-silica interaction due to the polarity differences between polymer and silica.

Figure 3.7 shows the amount of extracted polymer (physically and non-bonded) as a function of a specific chemically bound rubber. The amount of extracted polymer decreases with increasing specific bound rubber.

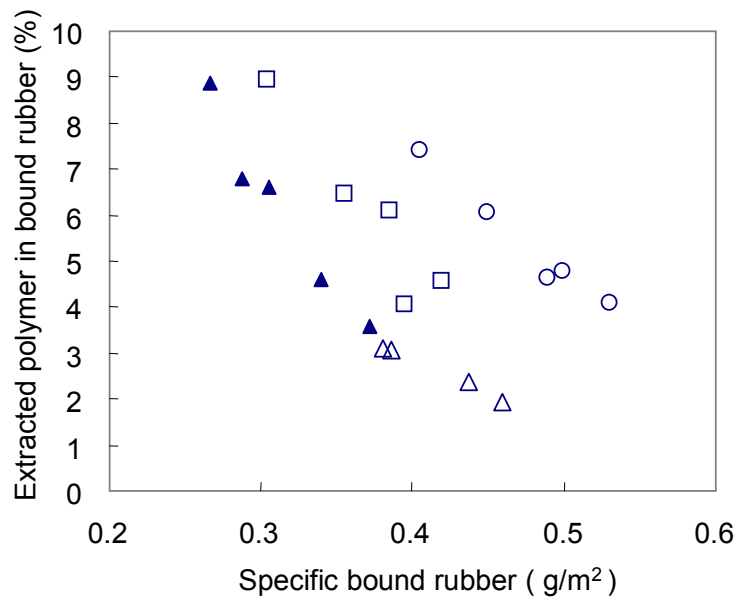

Figure 3.7: Extracted polymer with ammonia treatment in bound rubber as a function of specific bound rubber $(\circ)$ : 1115MP ; $(\Delta)$ : 1165MP ; ( $)$ ): 7005 ; ( $\triangle$ ): VN3 


\subsubsection{Qualitative analysis of the bound rubber after ammonia treatment}

The polarity differences between silica and polymer are also important factors for the formation of the interfacial layer on the silica surface. In the present study, pyrolysis gas chromatography was carried out on the bound rubber after ammonia treatment to estimate the content ratio between butadiene rubber (BR) and styrene-butadiene (SBR) rubber in the bound rubber layer. This content ratio could be an indication for the interaction strength between polymer and silica. Figure 3.8 shows the butadiene content in the bound rubber after ammonia treatment as a function of the mixing dump temperature.

The butadiene rubber content in the bound rubber increases with increasing mixing temperature. The butadiene rubber content in the bound rubber should be $25 \%$ according to the recipe. However, the butadiene rubber content in bound rubber is less than $25 \%$ as shown in Figure 3.8.

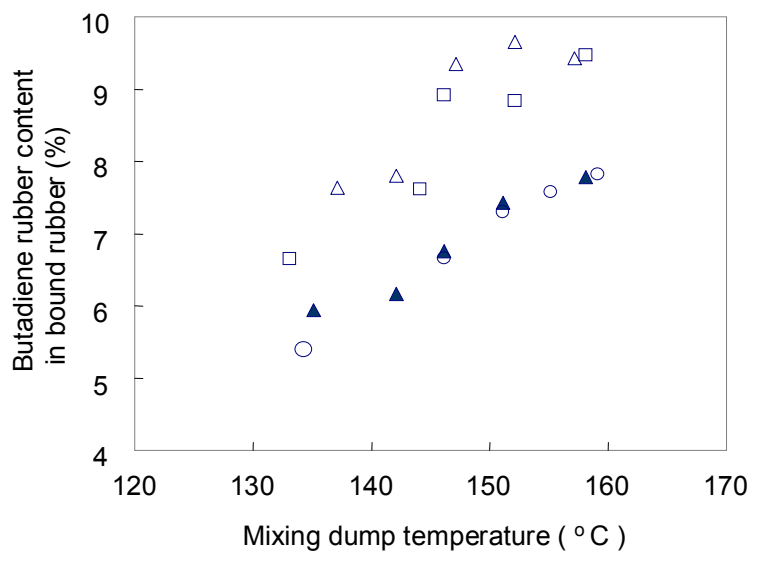

Figure 3.8 : Butadiene rubber content in bound rubber $(\bigcirc)$ : 1115MP ; $(\Delta)$ : 1165MP ; ( $)$ ): 7005 ; ( $\Delta$ ): VN3 
It indicates that the silica-butadiene rubber interaction is lower than the silicastyrene butadiene rubber interaction or styrene-groups are preferably absorbed on silica. This behavior was observed in model compound studies using inverse gas chromatography as well. ${ }^{[26,27]}$

Figures 3.9(a) and (b) show the weight ratio of each bonded polymer in the bound rubber to the initial weight according to the recipe. 

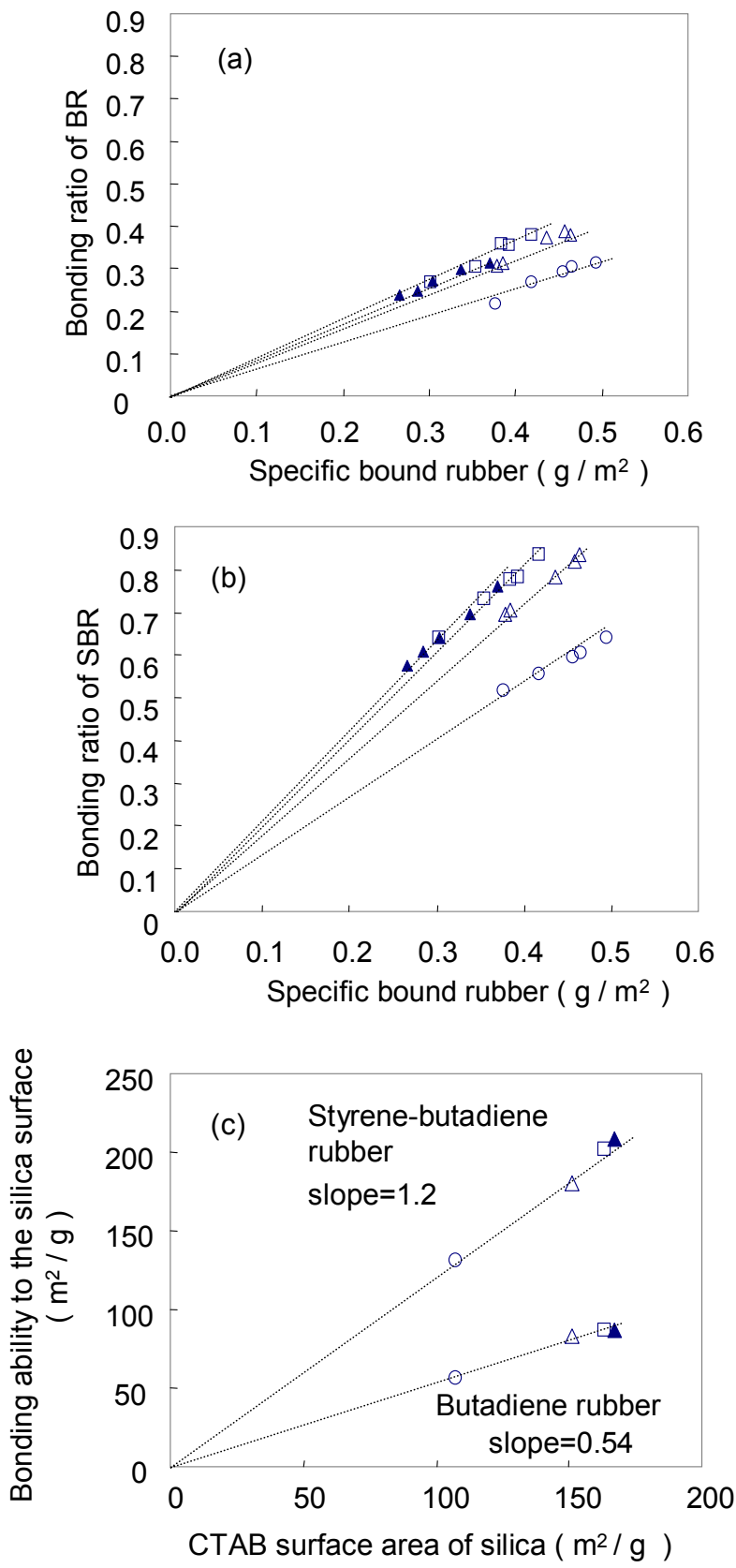

Figure 3.9 : Bonding ability of butadiene rubber and styrene butadiene rubber in bound rubber

(a) Bonding ability of BR in bound rubber

(b) Bonding ability of SBR in bound rubber

(c) Bonding ability of each rubber as a function of CTAB surface of silica

$(\circ)$ : 1115MP ; $(\Delta)$ : 1165MP ; ( $\triangle$ ): 7005 ; ( $\triangle$ ): VN3 
The slopes in these figures could be an indication of the bonding ability of each polymer to the silica surface. As can be seen in Figures 3.9(a) and (b), the slopes for butadiene rubber are much lower than those for styrene butadiene rubber. In addition, it is observed that the slopes depend on the CTAB surface area of silica. The slopes in Figures 9(a) and (b) were plotted as a function of the CTAB surface area of the silica. For each polymer, a linear relationship between the bonding ability of the polymer and the CTAB surface area of silica can be seen in Figure 9(c). In addition, the slope for butadiene rubber (0.54) is approximately half of that for SBR (1.20). This indicates that the bonding ability of butadiene-rubber to the silica surface is approximately half compared to that of styrene- butadiene rubber to the silica surface.

\subsubsection{Mechanical properties}

The mechanical properties after vulcanization at $160^{\circ} \mathrm{C}$ for the optimal cure time described in Figure 3.2 are shown in Figures 3.10(a)-(f).

In Figure 3.10(a), the elastic modulus decreases with increasing mixing dump temperature. According to Reuvekamp, the elastic modulus depends on the degree of filler-filler interaction. ${ }^{[17]}$ The VN3 silica shows a relatively higher elastic modulus compared to the HD silicas. For M100 no significant effect of the mixing dump temperature can be seen, even though 1115MP shows a relatively higher M100 than the other silicas. M300 increases with increasing mixing dump temperature as given in Figure 3.10(c). For elongation and tensile strength at break no clear tendency can be seen. M300/M100 often used as reinforcing index, increases with increasing mixing dump temperature. M300/M100 of the VN3 silica is relatively low compared to that of the HD silicas. The 1115MP silica shows the best reinforcing property, corresponding to rolling resistance as will be described later. 

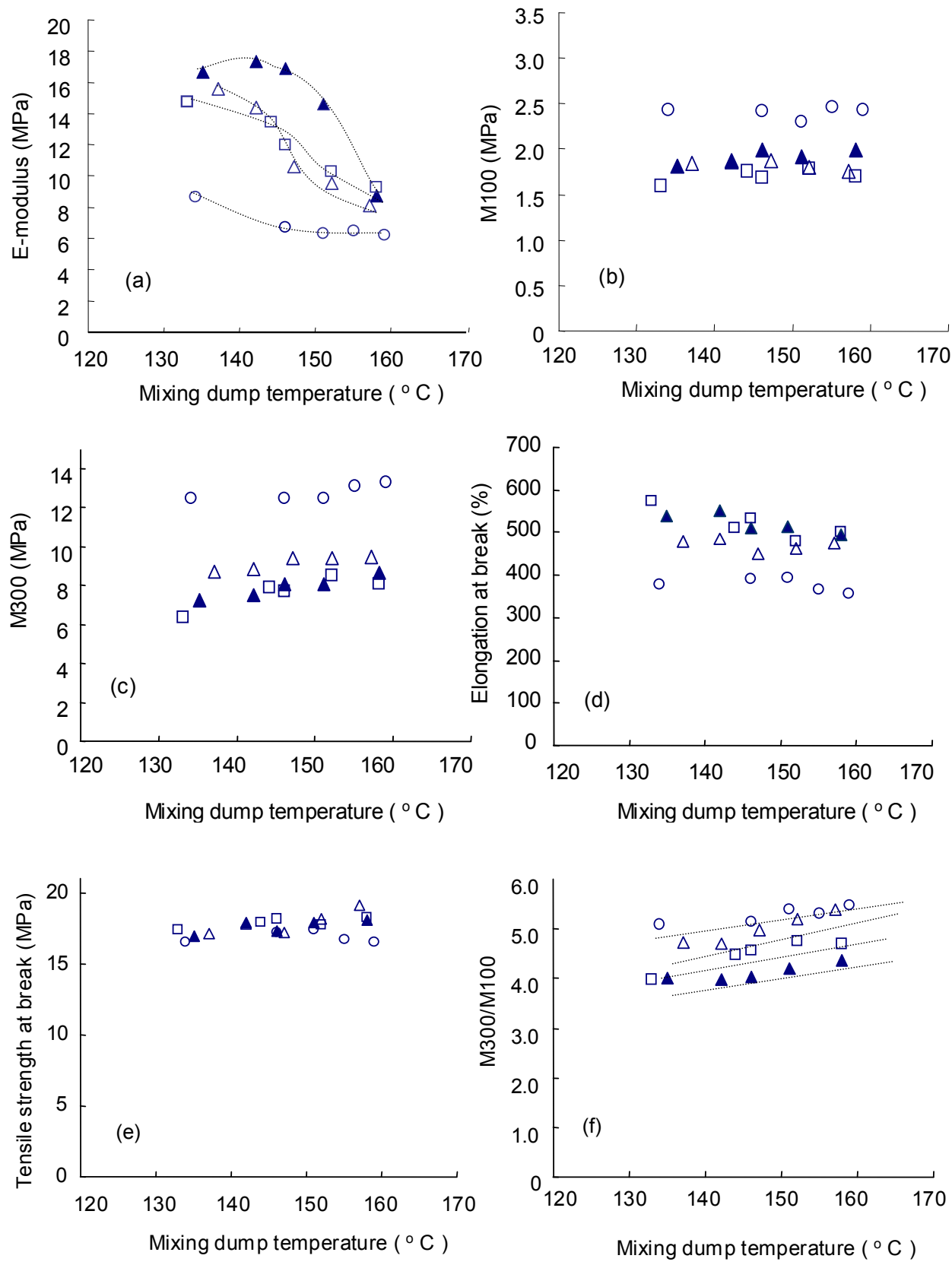

Figure 3.10: Comparison of mechanical properties

(a) E-modulus (b) M100 (c) M300 (d) Elongation at break

(e) Tensile strength at break (f) M300/M100

(O ): 1115MP ; ( $\Delta$ ): 1165MP ; ( $)$ ): 7005 ; ( $\Delta$ ): VN3 


\subsubsection{Visco-elastic properties: $\tan \delta$}

According to Wang et al., $\tan \delta$ is correlated to the inter-aggregate distance. ${ }^{[25]}$ Therefore, $\tan \delta$ can be taken as a measure of filler networking. Figure 3.11 shows $\tan \delta$ at $60^{\circ} \mathrm{C}$ for the different types of silica as a function of the mixing dump temperature.

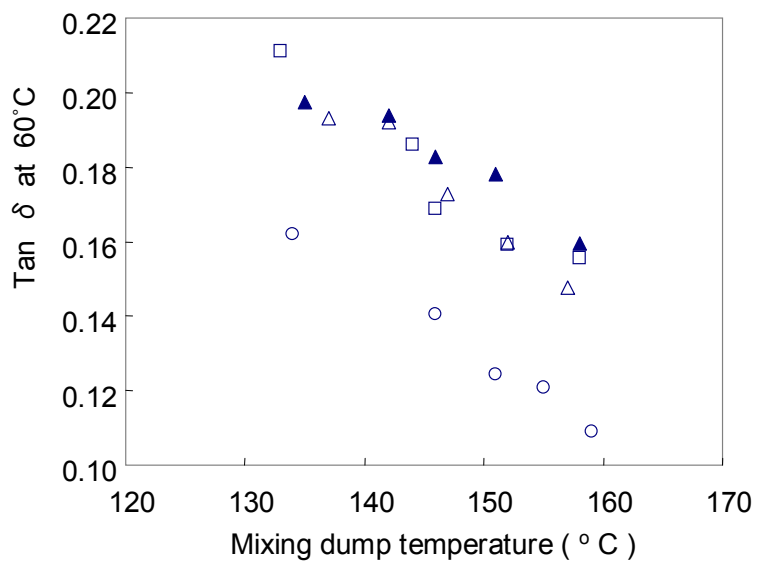

Figure 3.11: Tan $\delta$ at $60^{\circ} \mathrm{C}$ as a function of the mixing dump temperature $(\circ)$ : 1115MP ; $(\Delta)$ : 1165MP ; ( $\square$ ): 7005 ; ( $\Delta$ ): VN3

Tan $\delta$ at $60^{\circ} \mathrm{C}$ decreases with increasing mixing dump temperature. It is interesting to see that the $1115 \mathrm{MP}$ silica stands out with the lowest $\tan \delta$ at $60^{\circ} \mathrm{C}$. This can be due to the lower CTAB surface area, which may result in the less filler-filler networking in a rubber matrix.

It is generally known that $\tan \delta$ at $60^{\circ} \mathrm{C}$ shows a good correlation with the rolling resistance of a tire. A lower tan $\delta$ at $60^{\circ} \mathrm{C}$ means a lower rolling resistance as explained in Chapter 2. Another common indication for rolling resistance of a tire is the reinforcing index M300/M100 ratio, relating to the shape of the tensile curve. ${ }^{[33]}$ Therefore, $\tan \delta$ at $60^{\circ} \mathrm{C}$ should show a correlation with the M300/M100 ratio. ${ }^{[17]}$ Figure 3.12 shows the relationship between $\tan \delta$ at $60^{\circ} \mathrm{C}$ and M300/M100 ratio. 


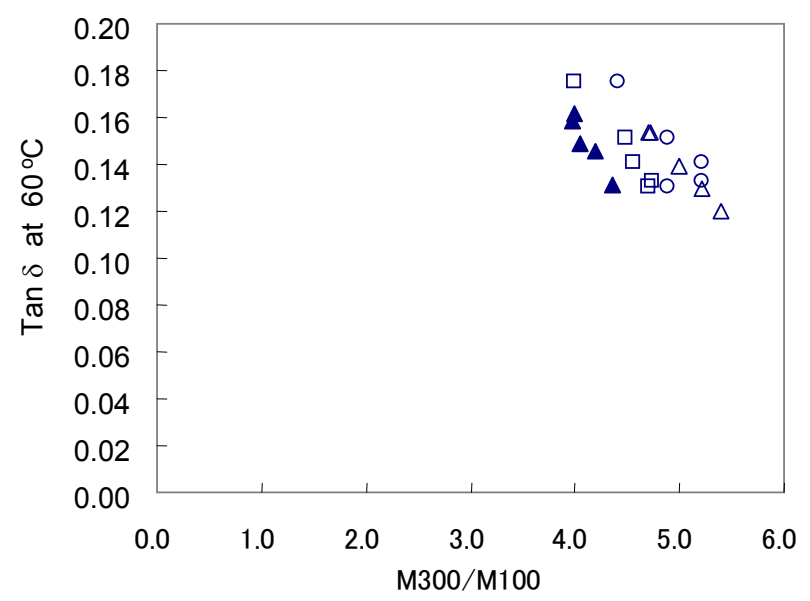

Figure 3.12: Tan $\delta$ at $60^{\circ} \mathrm{C}$ as a function of M300/M10C for the different types of silica $(\circ)$ : 1115MP ; $(\Delta):$ 1165MP ; ( $\triangle$ ): 7005 ; ( $\Delta$ ): VN3

Indeed, $\tan \delta$ at $60^{\circ} \mathrm{C}$ tends to decrease with increasing M300/M100 ratio, although there is quite some scatter in the data.

\subsection{Discussion}

\subsubsection{Effect of bound rubber on the visco-elastic properties : $\tan \delta$}

The interfacial layer between polymer and silica strongly depends on the type of the polymer, the CTAB surface area of the silica and the mixing conditions. Therefore, it is relevant to consider the effect of the interfacial layer on the silica surface as it influences the physical/mechanical properties. Also the loss tangent $(\tan \delta)$ strongly depends on the interfacial layer. ${ }^{[25]}$

For silica filled compounds, it is commonly understood that filler-filler networking takes place easily because of the polarity differences between polymer and silica. The filler-filler networking is then characterized by a stress softening with increasing strain, the so-called Payne effect, which is generally defined as the storage modulus ( $G^{\prime}$ ) at the low strain. ${ }^{[6,7]}$ Figure 3.13 shows the $G^{\prime}$ at $0.56 \%$ strain in the unvulcanized state as a function of specific chemically bound rubber. G' at $0.56 \%$ strain shows a good correlation with the specific chemically bound rubber. 


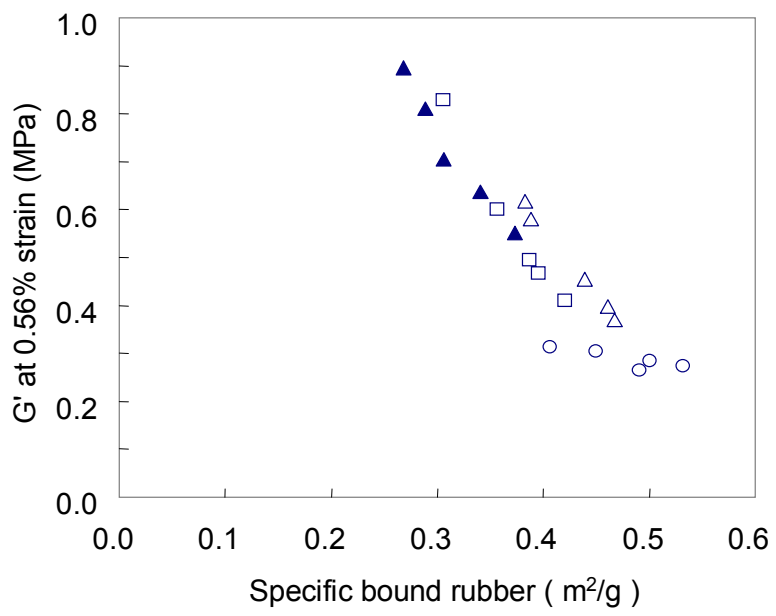

Figure 3.13: G' at $0.56 \%$ strain as a function of the specific bound rubber

$(\circ)$ : 1115MP ; $(\Delta)$ : 1165MP ; ( $)$ ): 7005 ; ( $\triangle$ ): VN3

Indeed, G' at $0.56 \%$ strain decreases with increasing specific chemically bound rubber and, apart from $1115 \mathrm{MP}$, all other silicas coincide more or less on one master-curve. A logical interpretation of the decrease of the Payne effect with increasing specific bound rubber is the increased chemical bonding of coupling agent and polymer on the silica surface. This interfacial layer bridges the polarity difference between the polymer and the silica.

Figure 3.14 shows the $\tan \delta$ at $60^{\circ} \mathrm{C}$ in the vulcanized state as a function of the specific chemically bound rubber.

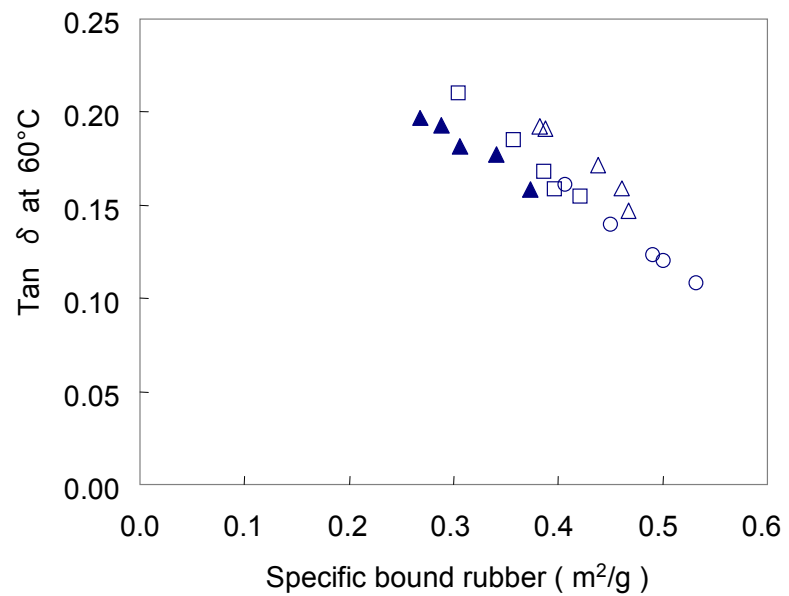

Figure 3.14 : $\operatorname{Tan} \delta$ at $60^{\circ} \mathrm{C}$ as a function of the specific bound rubber

$(\circ)$ : 1115MP ; $(\Delta)$ : 1165MP ; $(\square)$ : 7005 ; ( $\Delta$ ): VN3 
$\operatorname{Tan} \delta$ at $60^{\circ} \mathrm{C}$ also shows a correlation with the specific bound rubber. As mentioned above, $\tan \delta$ correlates with the inter-aggregate distance. ${ }^{[25]}$ The chemical bonding of polymer on the silica surface increases the inter-agregate distance, consequently resulting in the decrease of $\tan \delta$ at $60^{\circ} \mathrm{C}$.

Taking these results into account, it is postulated that the interfacial area of the silica surface is the dominant factor in determining the visco-elastic properties.

\subsubsection{Estimation of the interfacial layer on the silica surface}

To estimate the bound rubber thickness on the silica, the Pliskin-Tokita equation (equation 3.4) is applied, which is based on a layer of bound rubber formed on the filler particle. ${ }^{[34]}$

$$
V_{b}=b f\left(\frac{\phi \rho S}{1-\phi}\right)+\Gamma
$$

where $V_{b}$ is the volume fraction of bound rubber in the polymer, $b$ the thickness of the bound rubber layer, $f$ the fraction of filler surface exposed to the polymer sol, $\phi$ is the volume fraction of silica, $\rho$ is the density of the silica, $\Gamma$ is the fraction of gel in the gum. For gel free polymers such as $\mathrm{S}-\mathrm{SBR}$, where $\Gamma=0$ and $\mathrm{f}=1$, a plot of bound rubber as a function of $\phi \rho S /(1-\phi)$ should result in a straight line, where the slope represents the thickness of the bound rubber layer on the filler particle.

The effective volume fraction of bound rubber, which is chemically attached in the interfacial area on the silica surface, should be considered. By eliminating the effect of physically bonded polymer on the silica surface, the effective volume fraction of the silica which can form chemical bonds to the polymer is defined as $\phi$ eff.

$$
\begin{gathered}
\phi_{\text {eff }}=F \phi \\
F=\frac{\phi_{\text {eff }}}{\phi}=\frac{\mathrm{v}_{p}+\mathrm{v}_{f}-\mathrm{v}_{p p}}{\mathrm{v}_{p}+\mathrm{v}_{f}} \\
V_{b \text { eff }}=b_{\text {eff }} \times f \times\left(\frac{\phi_{\text {eff }} \rho S}{1-\phi_{\text {eff }}}\right)
\end{gathered}
$$

where $F$ is the fraction of the filler which is chemically active, $v_{p}$ is the volume fraction of the polymer in the bound rubber before ammonia treatment, $v_{f}$ is the volume fraction of the filler, $v_{p p}$ is the volume fraction of the polymer which is detached by ammonia treatment, $V_{\text {beff }}$ is the volume fraction of the remaining bound rubber after ammonia treatment in the polymer, $b_{\text {eff }}$ is the effective bound rubber thickness. 
Figure 3.15 shows Pliskin-Tokita plot for the different types of silica. Although a deviation from a straight line passing through zero can be seen at higher $\mathrm{f} \phi_{\text {eff }} \mathrm{pS} /(1$ $\left.\phi_{\text {eff }}\right), V_{\text {beff }}$ increases linearly for each silica with increasing $f \phi_{\text {eff }} \mathrm{PS} /\left(1-\phi_{\text {eff }}\right)$.

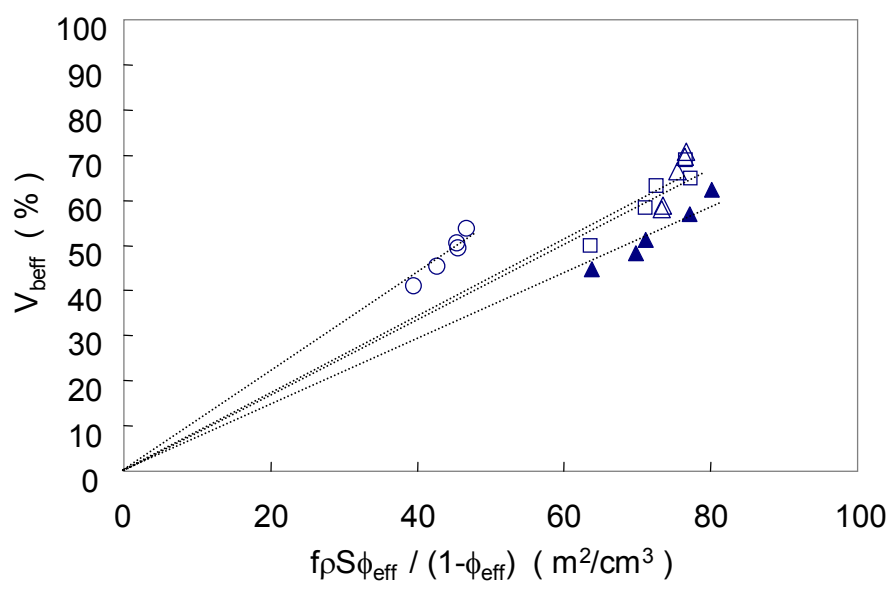

Figure 3.15: Pliskin-Tokita plot for the different types of silica $(O)$ : 1115MP ; $(\Delta)$ : 1165MP ; $(\square)$ : 7005 ; ( $\Delta$ ): VN3

The deviation from the line passing through zero could be due to some preliminary cross-linking resulting from the donation of sulfur atoms from TESPT and recombination between the polymers during mixing.

Figure 3.16 shows the estimated effective bound rubber thickness as a function of the dump temperature.

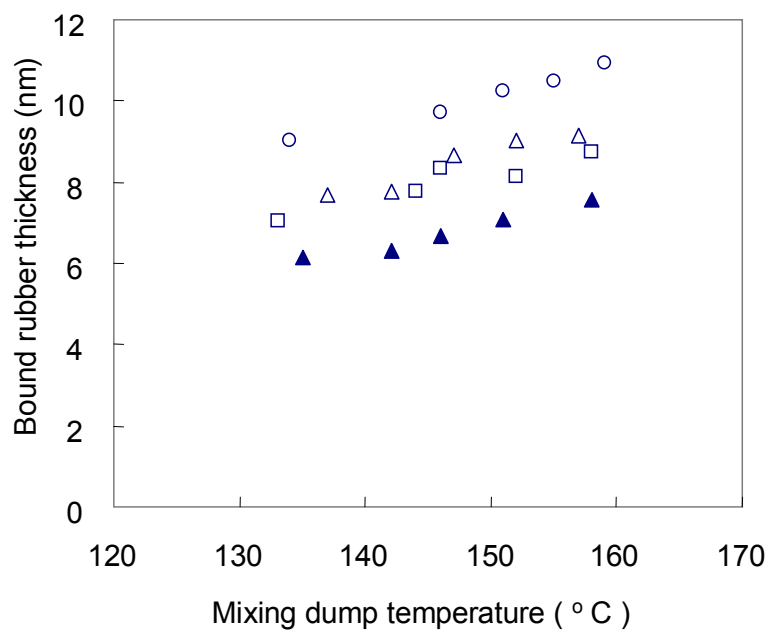

Figure 3.16: Estimated bound rubber thickness as a function of mixing dump temperature

$(\circ)$ : 1115MP ; $(\Delta)$ : 1165MP ; ( $)$ : 7005 ; ( $\Delta$ ): VN3 
The bound rubber thickness increases with increasing mixing dump temperature due to the higher degree of silanization. Average thicknesses of the bound rubber layer were calculated as shown in Table 3.5.

As given in Table 3.5, the average thickness of the bond rubber decreases with increasing CTAB surface area of the silica. In the case of carbon black, a similar phenomenon was observed by Wolff et al., O'Brien et al. and Nishi. ${ }^{[32,35,36]}$

Table 3.5: Average effective bound rubber thickness

\begin{tabular}{|l|c|c|c|}
\hline \multicolumn{1}{|c|}{ Silica } & Type & CTAB & $\begin{array}{c}\text { Thickness range }(\mathrm{nm}) \\
\text { (average) }\end{array}$ \\
\hline 1115MP & HDS & 108 & $9.1-11.0(10.1)$ \\
\hline 1165MP & HDS & 152 & $7.7-9.0(8.5)$ \\
\hline Ultrasil7005 & HDS & 164 & $7.1-8.8(8.1)$ \\
\hline VN3 & VN3 & 168 & $6.2-7.5(6.8)$ \\
\hline
\end{tabular}

According to their study, this phenomenon can be caused by agglomeration of silica aggregates, which reduces the interfacial area between the silica and the polymer. Figure 3.17 shows the thickness ratio of the bound rubber $\left(b_{\text {eff }}\right)$ to the average primary particle radius of the silica $(r)$ as a function of the mixing dump temperature.

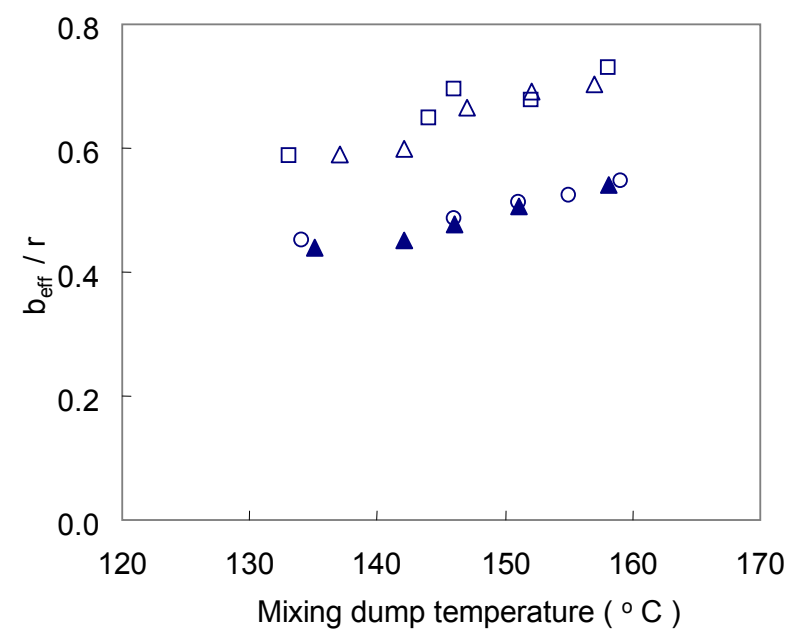

Figure 3.17: Thickness ratio of bound rubber to the primary particle size of silica as a function of the mixing dump temperature $(O)$ : 1115MP ; $(\Delta)$ : 1165MP ; $(\square)$ : 7005 ; ( $\triangle$ ): VN3

The thickness ratio $\left(b_{\text {eff }} / r\right)$ increases with increasing mixing dump temperature. The thickness ratio has the following order: 
For VN3 silica the thickness ratio $\left(b_{\text {eff }} / r\right)$ is almost the same as for $1115 \mathrm{MP}$ in spite of the higher CTAB surface area of VN3 silica. In the case of VN3, the Payne effect is high compared to the HD silica such as 1115MP due to flocculation of aggregates; hence the effective interfacial area on the silica surface of VN3 decreases. As a result, the bound rubber thickness can also be decreased.

\subsubsection{Determining factor for reinforcing index (M300/M100)}

According to Payne's interpretation of the reinforcing effect of fillers in rubber compounds, filler-filler networking causes the increase in modulus ${ }^{[6,7]}$ However, the filler-filler networking is broken at a deformation of approximately $10 \%$ or more. Therefore, it is considered that the reinforcing index (M300/M100), which is generally used for silica filled compounds, must be the result of the reinforcing effect of discontinuous filler particles, since the Payne effect does not apply for large deformations. The bound rubber is a dominant factor for the reinforcing property, in particular the thickness of the bound rubber layer. ${ }^{[21,32]}$ For Z1115MP silica, the highest reinforcing index M300/M100 has been found (see Figure $3.10(f))$, although its particle size is large compared to the other silicas. Taking this into account, the ratio of the bound rubber thickness to the particle size of the silica might be considered. Furthermore, the effective interfacial area on the silica particles is also an important factor for the formation of bound rubber on the silica surfaces. Therefore, the specific chemically bound rubber related to the interfacial area between the polymer and the silica surface both should be taken into account for the reinforcing index (M300/M100).

Figure 3.18 shows M300/M100 as a function of the specific bound rubber.

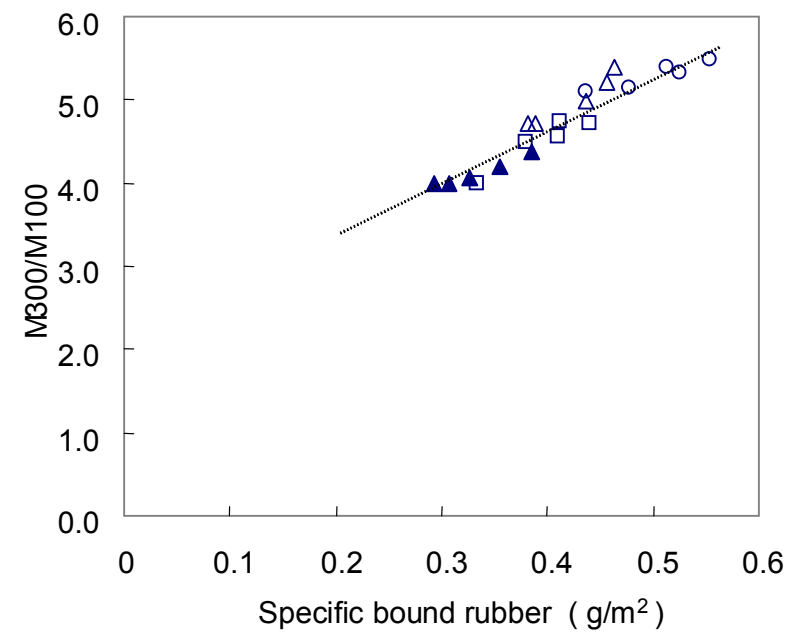

Figure 3.18: Reinforcing index (M300/M100) as a function of the specific bound rubber

$(\circ)$ : 1115MP ; $(\Delta)$ : 1165MP ; ( $\triangle$ ): 7005 ; ( $\triangle$ ): VN3

In this figure, the specific chemically bound rubber $\left(\mathrm{V}_{\text {beff }} / \mathrm{CTAB}\right)$ is used as the interfacial parameter. M300/M100 shows a correlation with the specific chemically bound rubber: all silicas merge into one master-curve. Therefore, the chemically bound rubber per unit interfacial area between the silica and the polymer seems to play the dominant role in determining the reinforcing index in the silica filled 
compounds.

\subsection{Conclusions}

The interfacial area on the silica surface involved in the filler-polymer interaction can be estimated using the bound rubber measurement with an ammonia treatment. The interfacial area on the silica surface as quantified by the specific chemically bound rubber increases with increasing mixing dump temperature because of a high degree of silanization.

The specific chemically bound rubber strongly affects the physical/mechanical properties, including the visco-elastic properties $(\tan \delta)$. Due to the increase of the chemically bonded polymer on the silica surface, the polarity difference between the polymer and the silica decreases. As a result, G' at $0.56 \%$ strain (Payne effect) and $\tan \delta$ at $60^{\circ} \mathrm{C}$ as related to the inter-aggregate distance also decrease. The reinforcing index also strongly depends on the interfacial layer between the polymer and the silica. M300/M100 shows a correlation with the specific chemically bound rubber with all silicas on one master curve.

The bonding ability of butadiene to silica is lower than that of styrene. Considering the results in the present study, the chemical bonding of polymer on the silica surface turns out to be the dominant factor in determining the physical properties of the silica filled tire rubbers. 


\subsection{References}

1. T.A. Okel, W.H. Waddell, Rubber Chem. Technol., 67, 217 (1994)

2. J.-B. Donnet, Kautsch. Gummi Kunstst., 47, 628 (1994)

3. M.P. Wagner, Rubber Chem. Technol., 49, 703 (1976)

4. S. Wolff, M.-J. Wang, Rubber Chem. Technol., 65, 329 (1992)

5. R.W. Cruse, M.H.Hofstertter, L.M. Panzer, R.J. Pickwell, Rubber \& Plastics News, 14 (1997)

6. A.R. Payne, R.E. Whittaker., Rubber Chem. Technol., 44, 440 (1972)

7. A.Y. Coran, J.-B. Donnet, Rubber Chem. Technol., 65, 1016 (1992)

8. B.T. Poh, Eur. Polym. J., 34, 975 (1998)

9. S. Wolff, Kautsch. Gummi Kunstst., 34, 280 (1981)

10. H.-D. Luginsland, Kautsch. Gummi Kunstst., 53, 39 (2000)

11. F. Thurn, S. Wolff, Kautsch. Gummi Kunstst., 28, 733 (1975)

12. S. Wolff, Rubber Chem. Technol., 55, 967 (1982)

13. S. Wolff, Kautsch. Gummi Kunstst., 36, 969 (1983)

14. S. Wolff, E.-H. Tan, J.-B. Donnet, Kautsch. Gummi Kunstst., 47, 485 (1994)

15. S. Wolff, M.J. Wang, Kautsch. Gummi Kunstst., 47, 17 (1994)

16. S. Wolff, Rubber Chem. Technol., 69, 325 (1996)

17. L.A.E.M Reuvekamp, in Thesis : "Reactive mixing of silica and rubber for tires and engine mounts", 2003, Dept. Rubber Technol., Univ. of Twente: Enschede, the Netherlands

18. H.-D. Luginsland, Am. Chem. Soc., Rubber Div. Meeting, Savannah, Georgia, April 29 - May 1, 2002

19. J. Janzen, Rubber Chem. Technol., 44, 1287 (1971)

20. A. Voet, J.C. Morawski, J.B. Donnet, Rubber Chem. Technol., 50, 342 (1977)

21. S. Wolff, Rubber Chem. Technol., 69, 325 (1996)

22. A.I. Medalia, J. Interface. Sci., 32, 115 (1970)

23. G. Kraus, Rubber Chem. Technol., 44, 199 (1971)

24. G. Kraus, Rubber Chem. Technol., 51, 297 (1978)

25. M.-J. Wang, S. Wolff, E.-H. Tan, Rubber Chem. Technol., 66, 178 (1993)

26. M.-J. Wang, S. Wolff, Rubber Chem. Technol., 64, 559 (1991)

27. M.-J. Wang, S. Wolff, Rubber Chem. Technol., 64, 714 (1991)

28. K.E. Polmanteer, C.W. Lentz, Rubber Chem. Technol., 48, 795 (1975)

29. S. Hirayabnagi, Nippon Gomu Kyukaishi., 55, 302 (1982)

30. H.D. Luginsland, Kautsch. Gummi Kunstst., 53, 10 (2000)

31. A. Hasse, O. Klockmann, Kautsch. Gummi Kunstst., 44, 236 (2002)

32. S. Wolff, M.-J. Wang, E.-H. Tan, Rubber Chem. Technol., 66, 163 (1993)

33. R. Rauline, EP 0 501227A1, Michelin \& Cie, (February 12, 1992)

34. I. Pliskin, N. Tokita, J. Appl. Polym. Sci., 16, 473 (1972)

35. J. O'Brien, E. Cashell,G.E. Wardell, V.J. McBrierty, Macromolecules, 9, 653 (1976)

36. T. Nishi., J. Polym. Sci., Phys. Ed., 12, 685 (1971) 
Chapter 3 


\section{Chapter 4}

\section{INSIGHT INTO THE KINETICS OF FLOCCULATION IN}

\section{SILICA REINFORCED RUBBER COMPOUNDS}

Filler flocculation plays an important role in reinforcement of silica filled rubber compounds, even if coupling agents are applied. It is known that silica tends to flocculate during the early stages of vulcanization, when no dense rubber network has been formed yet. In the present study, flocculation was monitored by following the change in storage modulus at low strain, the so-called Payne effect, using a RPA2000 dynamic mechanical tester. The kinetic parameters: the rate constant and the activation energy of the silica flocculation were calculated according to the well-known Arrhenius equation. On basis of the value of the activation energy obtained for flocculation, it can be concluded that silica flocculation is a purely physical phenomenon.

Bound rubber measurements were also done in order to estimate the interfacial interaction layer between silica and polymer resulting from the coupling agent. The silica flocculation rate constant decreases with increasing interfacial interaction layer on the silica surface. This indicates that the decrease of the flocculation rate is due to a shielding effect of coupling agent. In addition, it is suggested that the attractive forces related to polarity differences between the silica and the rubber are the determining factor for silica flocculation. 


\subsection{Introduction}

The dispersion of a filler in a rubber matrix depends on the polarity difference between the polymer and the filler. This polarity difference is significantly larger in a silica-filled system compared to a carbon black filled rubber, due to the high concentration of silanol groups on the silica surface. Furthermore, the silica particles interact with each other and a strong filler-filler-network is formed. Even though this network is broken during mixing, the filler tends to re-agglomerate afterwards.
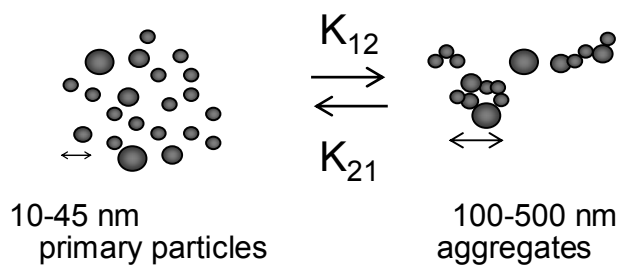
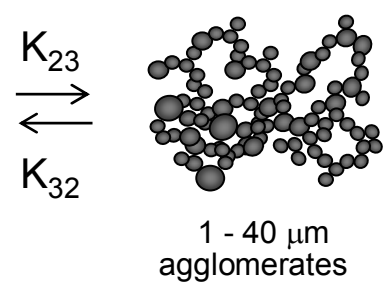

Figure 4.1 : Schematic model of filler aggregation and agglomeration

Active fillers such as precipitated silicas are commonly specified by three characteristic sizes: those of the primary particles, of the aggregates and of the agglomerates, as shown in Figure $4.1 .^{[1]}$ In the case of silica, the primary particle size is typically $10-45 \mathrm{~nm}$. For the aggregates formed by multiple primary particles due to physical interaction, the typical dimensions are $100-500 \mathrm{~nm}$. These aggregates flocculate or re-agglomerate into agglomerates of which the typical dimensions are $1-40 \mu \mathrm{m}$.

Luginsland et al. monitored the flocculation of silica dispersed in rubber by using the Rubber Process Analyzer RPA2000 ${ }^{[2]}$ According to this study, it was suggested that the flocculation process is determined by the following parameters:

- the silica-silica interaction, which depends on the silica loading, the relative surface area and the degree of silanization;

- the silica-polymer interaction;

- the filler mobility in the rubber, which depends on the viscosity and temperature of the rubber matrix;

It is commonly accepted that breakdown of the silica network under strain and the flocculation of silica are reversible processes ${ }^{[1-3]}$ Böhm et al. experimentally demonstrated that flocculation of the silica takes place at the beginning of the vulcanization process. ${ }^{[4,5]}$ Figure 4.2 shows a typical cure curve with a flocculation hump measured by the RPA 2000. For the filler-filled compound, an increase in torque can be seen at the very beginning of the vulcanization.

The silica properties, for instance the structure which is measured by adsorption of dibutylphthalate (DBP), have a strong influence on the dispersion of the silica in the rubber matrix. ${ }^{[6]}$ In the case of a relatively low-structured silica, a poor 
dispersion is found: A significant amount of the silica remains undispersed on micrometer-scale: the macro-dispersion. Highly-structured silica types result in a high percentage of primary particles, whereas the highly-dispersible silica types are well dispersed on nanometer scale: micro-dispersion. In the latter case, the aggregate-structure is preserved resulting in a strong reinforcing effect. As a result, the dynamic and mechanical properties of such silica filled compounds strongly depend on the micro-dispersion of the silica.

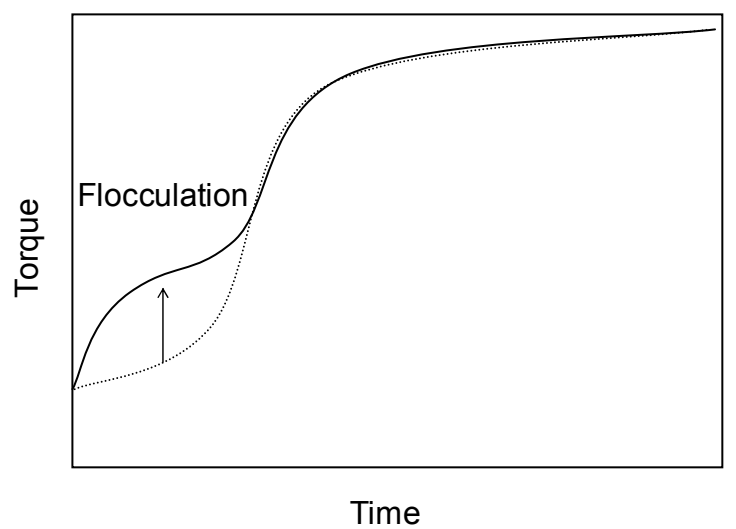

Figure 4.2 : Illustration of the cure curves with flocculation

Silica flocculation, the re-agglomeration of the silica particles after mixing and before curing, plays an important role in reinforcement, even if a coupling agent is applied. In the present chapter the kinetic parameters of silica flocculation are measured by using a RPA2000, in order to estimate the influence of reagglomeration on the material properties. The kinetics of this process are compared for different types of silica. In addition, the effect of the bound rubber interfacial interaction on silica flocculation will be investigated.

\subsection{Experimental}

\subsubsection{Preparation of the compounds}

All experiments were performed by using a typical tire tread compound according to the fuel-saving green tire technology as shown in Table 3.2 (see Chapter 3). ${ }^{[/]}$ The different silica types used in this investigation are listed in Table 3.1 (see Chapter 3). The silicas are ordered by increasing CTAB value. Also the classification of the different types of silica, as conventional silica (CV) and highly dispersible silica (HD), is listed in Table 3.1. The amount of silane applied in the recipes was adjusted according to equation 3.1(see Chapter 3), in which the amount of silane was adjusted for all silicas to be the same in relation to their CTAB surface areas. The total amount of active sulfur was adjusted to $2.1 \mathrm{phr}$, being the sum of the sulfur contained in the silane and in the curatives. 
Mixing was done in 3 steps. The dump temperature was always kept below $160^{\circ} \mathrm{C}$. All compounds were mixed using the conditions described in Table 3.3 (see Chapter 3).

\subsubsection{Measurement of the cure characterisitics}

The cure curve was measured by using the RPA 2000 under the following conditions: temperature $160^{\circ} \mathrm{C}$, frequency $0.833 \mathrm{~Hz}$, strain $2.79 \%$, till a maximum of 30 minutes. According to Böhm et al. silica flocculation takes place at the very beginning of vulcanization. ${ }^{[3,4]}$ Therefore, emphasis was put on the increase of the torque in the initial phase of vulcanization.

\subsubsection{Measurement of the kinetic parameters of silica flocculation}

The modulus decrease with amplitude in a dynamic mechanical test is commonly used to understand the reinforcing mechanism of fillers in rubber compounds. Several contributions to the modulus are commonly defined for the reinforcement of filled rubber compounds: the hydrodynamic effect due to the presence of the filler, a contribution from the crosslinked polymer network, a contribution from fillerpolymer interactions and one from filler-filler interactions. Particularly at small deformations of the reinforced rubber, the filler-filler interactions prominently contribute to the physical properties of the filled compounds, in particular the modulus: called the Payne effect. ${ }^{[8]}$ Consequently, it is common practice these days to use the storage modulus G' at low strain amplitude as a measure for fillerfiller interactions or filler dispersion.

For the uncured compounds mixed at $150^{\circ} \mathrm{C}$, the mobility of the silica particles at elevated temperatures was monitored by using the RPA2000. The storage modulus at $0.56 \%$ strain amplitude was monitored at different temperatures between $90^{\circ} \mathrm{C}$ and $140^{\circ} \mathrm{C}$, and the increase taken as evidence for silica flocculation. The following procedure was applied to monitor the Payne effect development in time:

> 6 Grams of the uncured compound was put into the RPA chamber;

$>$ The sample was preheated at $90^{\circ} \mathrm{C}, 100^{\circ} \mathrm{C}, 110^{\circ} \mathrm{C}, 120^{\circ} \mathrm{C}, 130^{\circ} \mathrm{C}, 140^{\circ} \mathrm{C}$ for 1 minute;

$>$ The storage modulus at $0.56 \%$ strain amplitude was measured every 2 minutes within a period of 12 minutes at constant temperature.

The degree of distribution or dispersion $x$ can be expressed by the ratio of the Payne effect at time $t$ and at infinite time:

$$
x=\frac{G^{\prime}(t)-G^{\prime}(i)}{G^{\prime}(f)-G^{\prime}(i)}
$$

where $G^{\prime}(t)$ is the storage modulus at $0.56 \%$ strain amplitude after heating time $t$, $\mathrm{G}^{\prime}(\mathrm{i})$ is the storage modulus after preheating for 1 minute and $G^{\prime}(f)$ is the final storage modulus after heating for 12 minutes .

In the present study, it was supposed that silica flocculation can be described as a 
first order reaction. The kinetics of the flocculation process can then be described by simple model equations for the kinetic parameters: the rate constant $k_{a}$ and the activation energy $\mathrm{E}_{\mathrm{a}}$ of the silica flocculation:

$$
\begin{aligned}
& k_{a}=\frac{\ln \left(1-x_{1}\right)-\ln \left(1-x_{2}\right)}{t_{2}-t_{1}} \quad\left[\min ^{-1}\right] \\
& \ln k_{a}=\ln \left(k_{0}\right)-\frac{E_{a}}{R T} \quad[k J / \mathrm{mol}]
\end{aligned}
$$

where $\mathrm{t}$ is the heating time and $\mathrm{T}$ is the absolute temperature. In a so-called Arrhenius plot the flocculation rate constant can be plotted on a logarithmic scale versus the inverse temperature; the slope of the straight line gives the activation energy, divided by the Gas constant R.

\subsubsection{Bound rubber measurements}

Bound rubber measurements were done for rubber compounds prepared with different dump temperatures. These values were used to estimate the average thickness of the bound rubber layer on the filler surface. For the present purpose only chemically bound rubber is taken into account. Therefore, an ammonia treatment was done prior to the bound rubber measurements. According to Wolff and Polmanteer et al., ammonia treatment cleaves physically bound rubber. ${ }^{[9,10]}$ The chemically bound rubber measurement was done in the following way:

$>$ 0,2 Grams of uncured rubber without curatives was put into a metal cage;

$>$ The sample in the cage was immersed in $100 \mathrm{ml}$ toluene for 72 hours at room temperature;

$>$ Toluene was renewed every 24 hours;

$>$ The sample was removed out of the toluene and dried for 24 hours;

$>$ The sample was put into an ammonia atmosphere with toluene for 72 hours in order to cleave physical linkages;

$>$ The sample was immersed in $100 \mathrm{ml}$ toluene for 72 hours at room temperature. Toluene was renewed every 24 hours;

$>$ The sample was dried for 24 hours and weighed.

The effective volume fraction of chemically bound polymer to the silica $V_{b}$ eff was calculated according to equation 3.2(see Chapter 3).

\subsubsection{Mooney viscosity $M L(1+4)$}

For the uncured compounds, the Mooney viscosity $\mathrm{ML}(1+4)$ was measured at different temperatures within the temperature window chosen for this investigation $\left(90^{\circ} \mathrm{C}-140^{\circ} \mathrm{C}\right)$ using a Mooney viscometer $2000 \mathrm{E}$ from Alpha Technologies. 


\subsection{Results}

\subsubsection{Kinetic parameters of silica flocculation}

Figure $4.3(\mathrm{a})$ shows the cure curves at $160^{\circ} \mathrm{C}$ for the compounds containing the various types of silica as given in Table 3.1 (see Chapter 3 ).
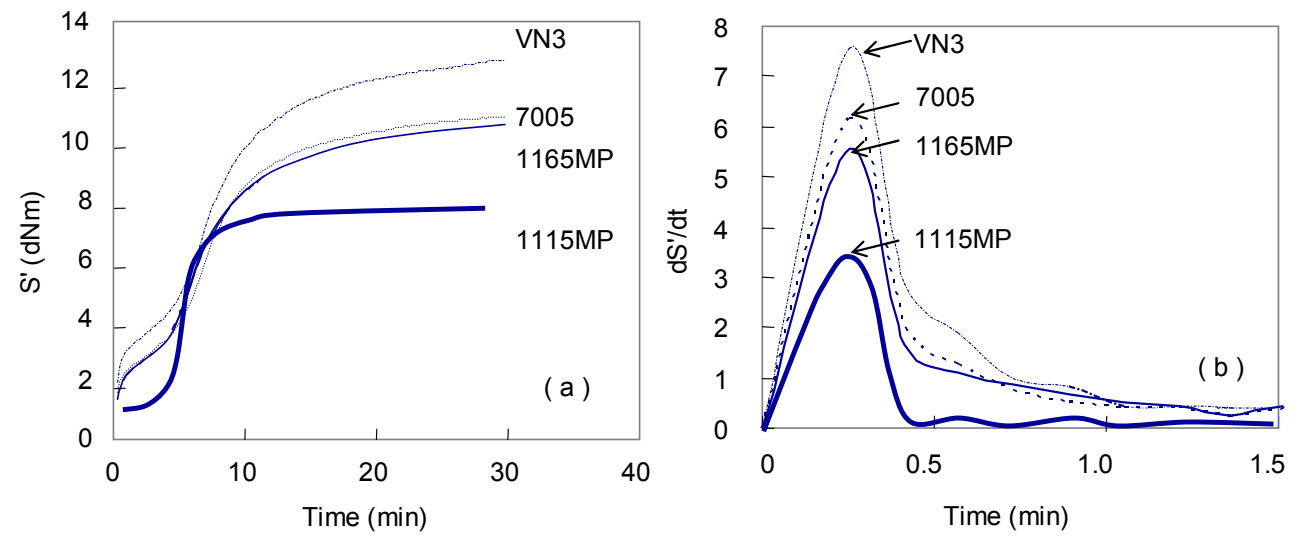

Figure 4.3: Comparison of the rheometer curves of $160{ }^{\circ} \mathrm{C}$ for the different types of silica (a) Rheogram (b) Derivative curves

( - ) :1115MP ; ( - ):1165MP ; (-..): 7005 ; (-- ) : VN3

For all samples an increase of the torque value at the very beginning of the vulcanization can be seen, although no significant increase of the torque for 1115MP silica. Figure 4.3(b) shows the corresponding derivatives of the cure curves. High derivative values corresponding to silica flocculation can be seen at the very beginning of vulcanization, except for 1115MP silica.

For silica filled compounds, it is known that silica flocculation is faster at higher temperatures. ${ }^{[5]}$ A direct observation of silica flocculation is possible by following the change of the storage modulus at low strain amplitude during the temperature treatment. In order to calculate the flocculation kinetics of the silica, the storage modulus at $0.56 \%$ strain amplitude was monitored during heating at different temperatures. Figure 4.4 shows an increasing storage modulus with time during a typical temperature treatment of $100{ }^{\circ} \mathrm{C}$. 


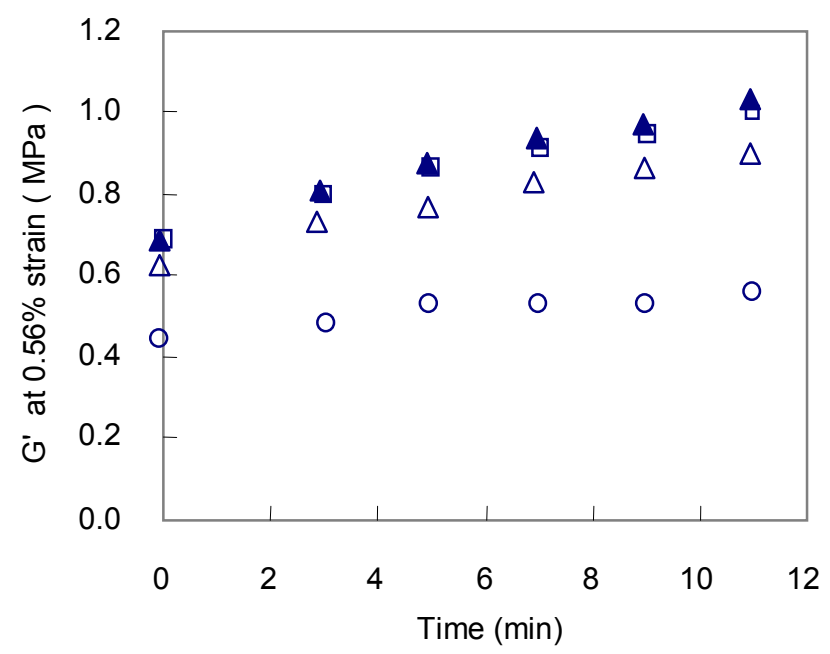

Figure 4.4 : Storage modulus $\mathrm{G}^{\prime}$ at $0.56 \%$ strain as a function of heating time at $100{ }^{\circ} \mathrm{C}$

$(\circ)$ : 1115MP ; $(\Delta): 1165 \mathrm{MP} ;(\square): 7005$; ( $\Delta)$ : VN3

Based on equation 4.3, the flocculation rate constants can be calculated for the various types of silica at the different temperatures. These rate constants of silica flocculation $\mathrm{k}_{\mathrm{a}}$ are summarized in Table 4.1.

Table 4.1 : Comparison of flocculation rates and activation energy

\begin{tabular}{|c|c|c|c|c|c|}
\hline & $\begin{array}{c}\text { Temperature } \\
\left({ }^{\circ} \mathrm{C}\right)\end{array}$ & $1115 \mathrm{MP}$ & $1165 \mathrm{MP}$ & 7005 & VN3 \\
\hline \multirow{3}{*}{$\mathrm{ka}^{-1}$} & 90 & 0.19 & 0.22 & 0.23 & 0.23 \\
\cline { 2 - 6 }$\left(\mathrm{min}^{-1}\right)$ & 100 & 0.22 & 0.24 & 0.25 & 0.25 \\
\cline { 2 - 6 } & 110 & 0.23 & 0.25 & 0.30 & 0.29 \\
\cline { 2 - 6 } & 120 & 0.25 & 0.27 & 0.31 & 0.30 \\
\hline & 130 & 0.26 & 0.29 & 0.34 & 0.32 \\
\hline \multicolumn{2}{|c}{$\mathrm{E}_{\mathrm{a}}(\mathrm{kJ} / \mathrm{mol})$} & 0.28 & 0.30 & 0.35 & 0.34 \\
\hline
\end{tabular}

The flocculation rate constants increase with temperature, as expected. It is also clear that the flocculation rate of the silica types depends on the surface area of the fillers. In fact, the flocculation rate constant of the silicas increases with increasing CTAB surface of the silica. The activation energy of the flocculation process was calculated on basis of the $\mathrm{k}_{\mathrm{a}}$-values at the various temperatures applied, as given in Table 4.1. For all silica types, the activation energy was in the range of $10[\mathrm{~kJ} / \mathrm{mol}]$, indicating a physical process indeed.

From the increase of the torque at the very beginning of vulcanization at $160{ }^{\circ} \mathrm{C}$ 
due to the silica flocculation, Figure 4.5 shows the maximum derivative value as taken from Figure 4.3(b), as a function of the CTAB surface area of the silicas.

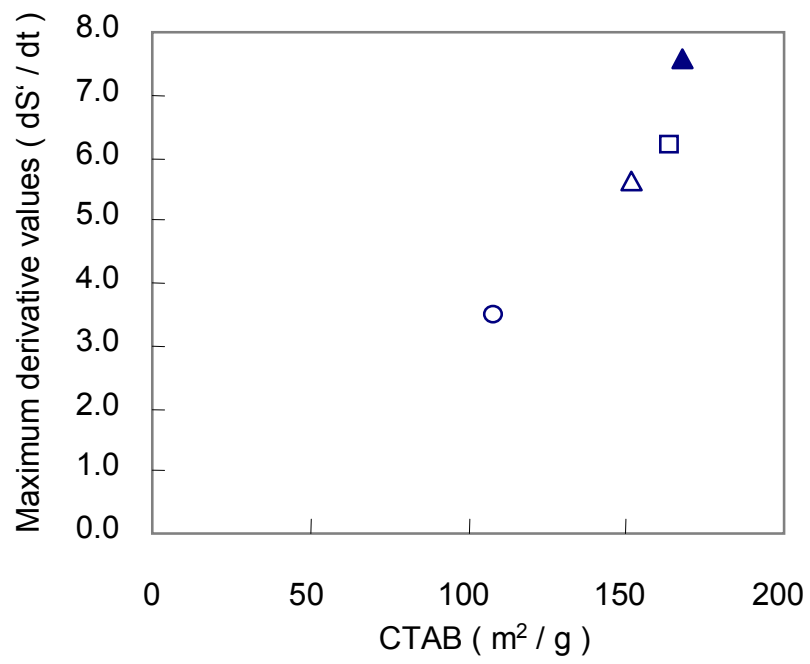

Figure 4.5 : Maximum derivative value at $160^{\circ} \mathrm{C}$ as a function of CTAB surface area

$(\circ): 1115 \mathrm{MP} ;(\Delta): 1165 \mathrm{MP} ;(\square)$ : $7005 ;(\Delta):$ VN3

The graph shows an almost linear relationship. In addition, the flocculation rate constants of the various types of silica are plotted in Figure 4.6 as a function of the maximum derivative value from Figure 4.3(b) for the various temperatures applied.

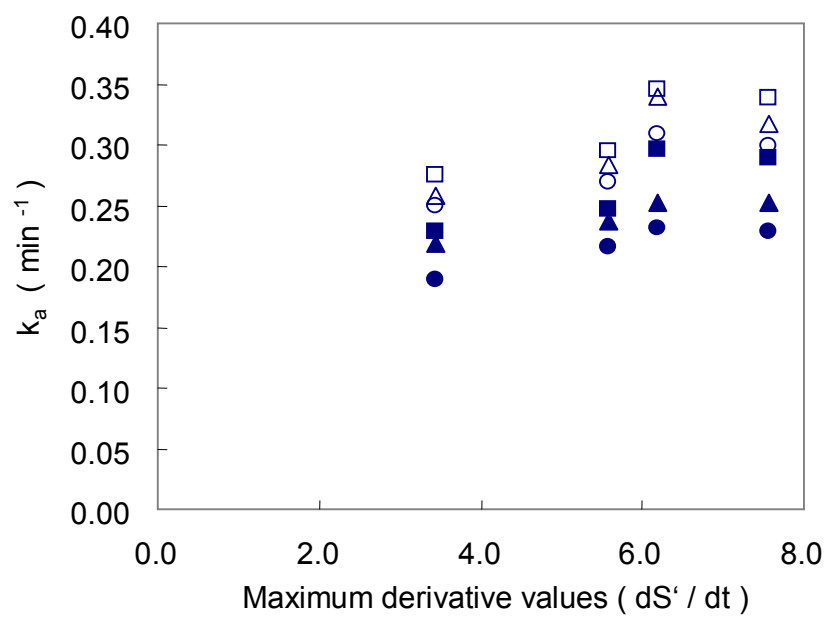

Figure 4.6 : Flocculation rate constant $k_{a}$ as a function of maximum derivative values of cure curves at $160^{\circ} \mathrm{C}$

$(\bullet): 90^{\circ} \mathrm{C} ;(\triangle): 100{ }^{\circ} \mathrm{C} ;(\cdot): 110^{\circ} \mathrm{C}$;

$(\circ): 120^{\circ} \mathrm{C} ;(\Delta): 130^{\circ} \mathrm{C} ;(\square): 140^{\circ} \mathrm{C}$ 
Like in Figure 4.5, the flocculation rate constants of the silicas also become larger with increasing maximum derivative value from the curemeter curve.

\subsubsection{Bound rubber contents}

Silica flocculation is caused by polarity differences between the filler and the polymer, even when a silane coupling agent is applied. However, when the interfacial interaction layer between silica and polymer becomes larger, the effects of the polarity differences must decrease. Therefore, the measurement of bound rubber may allow a qualitative estimation of the interfacial interaction layer between silica and polymer.

It is well known that the bound rubber content decreases with increasing temperature and by ammonia treatment. ${ }^{[9,10]}$ This is due to the fact that bound rubber is at least partially physically bound to the filler surface. However, in the case of silica in the presence of a silane coupling agent, a chemical reaction takes place during mixing, in which the coupling agent chemically reacts with the silanol groups on the silica surface. In Figure 4.7, the extracted polymer by ammonia treatment corresponds to the polymer physically bound to the silica surface: The amount of physically bound polymer decreases with increasing mixing dump temperature, which means that the chemically bound polymer increases due to a higher degree of silanization.

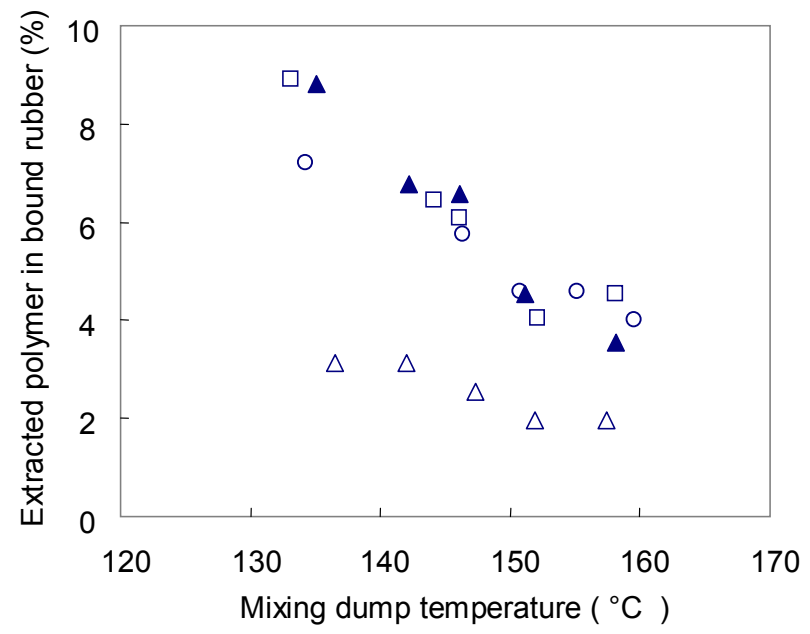

Figure 4.7 : Amount of extracted polymer by ammonia treatment as a function of the mixing dump temperature

$(\circ)$ : 1115MP ; $(\Delta): 1165 \mathrm{MP} ;(\square): 7005 ;(\Delta):$ VN3

We propose to use the specific bound rubber, the chemically bound rubber relative to the accessible silica surface area, by using Equation 3.3 (see Chapter 3). The specific bound rubber is an indication of the amount of chemically bound polymer on the filler surface. 
Figure 4.8 shows the specific bound rubber values as a function of the dump temperature after mixing.

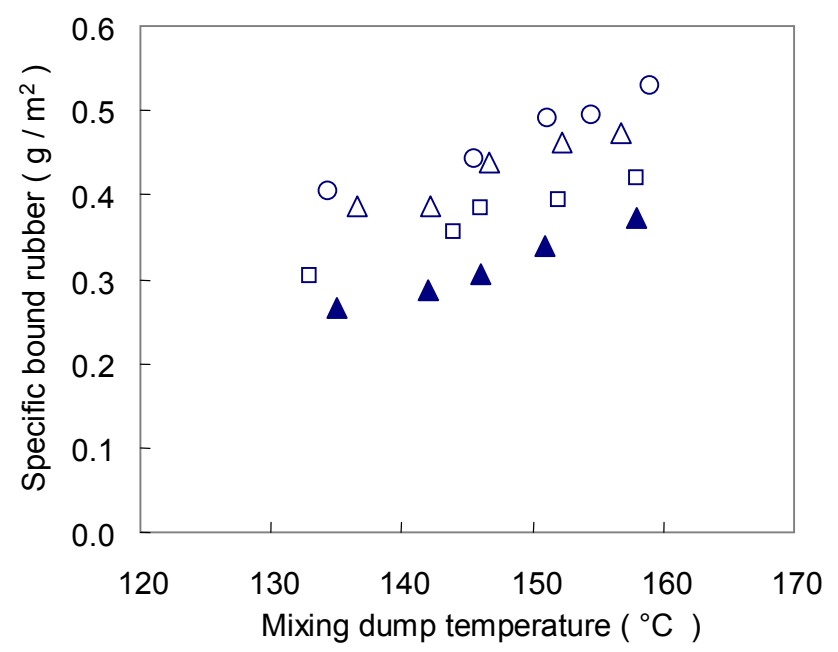

Figure 4.8 : Specific bound rubber as a function of the mixing dump temperature

$(\circ): 1115 \mathrm{MP} ;(\Delta): 1165 \mathrm{MP} ;(\square): 7005 ;(\triangle):$ VN3

The specific bound rubber content increases with increasing dump temperature due to a higher degree of silanization. In addition, the specific bound rubber strongly depends on the CTAB surface area of silica, as can be seen in Figure 4.9:

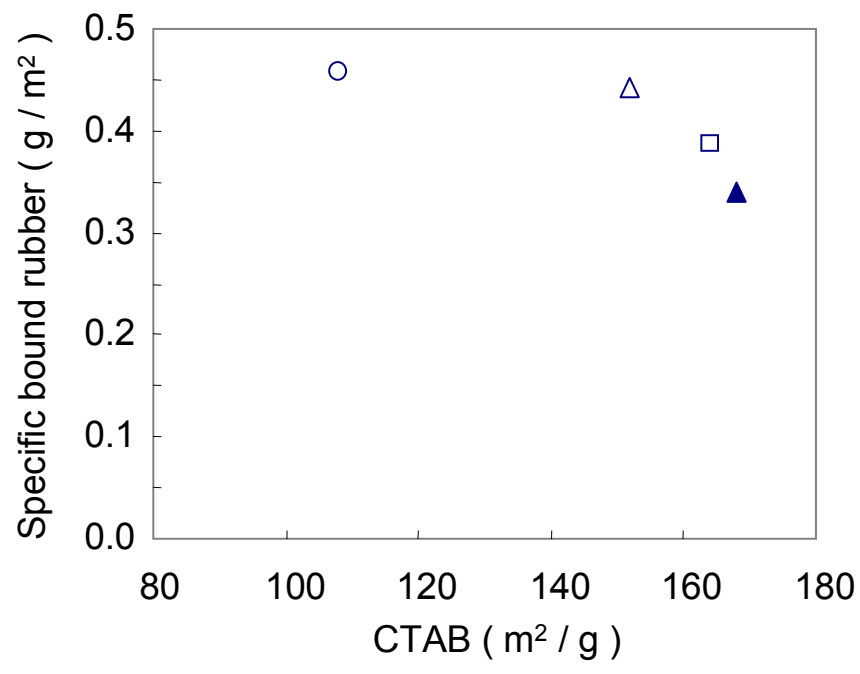

Figure 4.9 : Specific bound rubber at the mixing dump temperature of $150^{\circ} \mathrm{C}$ as a function of the CTAB surface area

$(\circ): 1115 \mathrm{MP} ;(\triangle): 1165 \mathrm{MP} ;(\square): 7005 ;(\Delta):$ VN3

It decreases with increasing CTAB surface area. These results indicate that the 
effectiveness of the interaction between polymer and filler surface via the coupling agent is reduced with increasing CTAB surface area.

\subsection{Discussion}

The initial torque increase as shown in Figure 4.3(a) is attributed to filler flocculation. ${ }^{[5,11]}$ Within the series of highly dispersible silicas, 7005 silica shows the highest derivative peak value. For the highly dispersible silica $1115 \mathrm{MP}$ with the lowest CTAB surface area, the derivative value at the first peak is lowest compared to the others. The conventional silica VN3 has the highest derivative value peak of all. The results tend to indicate that the flocculation rate decreases with decreasing CTAB-surface: from VN3 over Ultrasil 7005 and 1165MP to $1115 \mathrm{MP}$.

However, the flocculation rate does not only depend on the surface area of the silica. With increasing temperature, the mobility of the silica particles in the rubber compound greatly increases. As a result, the probability of contact between silica particles also increases. In addition, the low activation energy values show that the process is a physical phenomenon. By taking these facts into account, we propose to describe the kinetics of the flocculation process by a simplified model. With the simplified assumption that all filler particles have spherical dimensions, irrespective of whether they are primary particles or aggregates, the mobility of these particles in terms of their diffusion constant $D$ can be described by equation 4.4 , the StokesEinstein equation:

$$
D=\frac{k T}{6 \pi \eta r}
$$

where $\mathrm{k}$ is Boltzmann's constant, $\mathrm{T}$ is the absolute temperature, $\eta$ is the viscosity of the matrix and $r$ is the hydrodynamic radius of the filler particles.

\subsubsection{Calculation of diffusion coefficient}

In order to calculate the diffusion constants for the various silicas, the hydrodynamic radius $r$ and the apparent matrix viscosity $\eta$ need to be estimated. For the hydrodynamic radius, the thickness of the chemically bound interfacial interaction layer is an important factor to be taken into account as part of the filler particle. Suppose that the thickness of the interfacial layer is $b$, then the hydrodynamic radius of the filler particles $r$ is expressed as the apparent radius involving the interfacial layer $r_{a p p}$ :

$$
r=r_{\text {app }}=r_{f}+b
$$

With $r_{\mathrm{app}}$ the apparent radius of the equivalent particle to be inserted in equation.4.5 and $r_{f}$ is the radius of the filler particle.

In order to estimate the thickness of the interfacial interaction layer between silica and polymer, the Pliskin-Tokita equation (equation 4.6) may be applied. This equation is based on the assumption that a layer of bound rubber is formed on the filler particles ${ }^{[12]}$. 


$$
v_{b}=b f\left(\frac{\phi \rho S}{1-\phi}\right)+\Gamma
$$

where $V_{b}$ is the volume fraction of bound rubber in the polymer, $b$ is the bound rubber thickness, $f$ is the fraction of filler surface exposed to the insoluble polymer in the bound rubber measurement, $\Gamma$ is the fraction of gel which is insolubles naturally occurring in a rubber polymer due to excessive branching or coming from production, $\phi$ is the volume fraction of the filler, $\rho$ is the density of the filler and $S$ is the specific surface area of the silica obtained from the CTAB measurement. SSBR is practically gel-free, therefore $\Gamma$ in equation 6 can be put equal to zero. Consequently, a plot of bound rubber as a function of $\phi \rho S /(1-\phi)$ should result in a straight line, with the slope representing the thickness of the bound rubber layer.

As indicated above, bound rubber is at least partially physically bound to the filler surface. However, in the case of silica with a silane coupling agent present, the silane chemically reacts with the silanol groups on the filler surface. Therefore, only the chemically active interfacial area of the silica should be considered. Figure 4.7 depicts the extracted polymer physically bound to the silica surface: The amount of physically bound polymer decreases with increasing mixing dump temperature, which means that the chemically bound polymer increases due to a higher degree of silanization. The effective volume fraction of the silica which can form chemical bonds to the polymer is defined as $\phi_{\text {eff. }}$

$$
\begin{aligned}
& \phi_{\text {eff }}=F \phi \\
& F=\frac{\phi_{\text {eff }}}{\phi}=\frac{\mathrm{v}_{p}+\mathrm{v}_{f}-\mathrm{v}_{p p}}{\mathrm{v}_{p}+\mathrm{v}_{f}} \\
& V_{b \text { eff }}=b_{\text {eff }} \times f \times\left(\frac{\phi_{\text {eff }} \rho S}{1-\phi_{\text {eff }}}\right)
\end{aligned}
$$

where $V_{\text {beff }}$ is the volume fraction of the remaining bound rubber after ammonia treatment in the polymer, $F$ is the fraction of the filler which is chemically active, $v_{p}$ is the volume fraction of the polymer in all bound rubber, $v_{f}$ is the volume fraction of the filler, $v_{p p}$ is the volume fraction of the polymer which is detached by ammonia treatment, $b_{\text {eff }}$ is the effective bound rubber thickness.

According to equation.4.9, the thickness of the interfacial interaction layer resulting from the chemically bonded polymer can be estimated. Figure 4.10 shows the Pliskin-Tokita plot. 


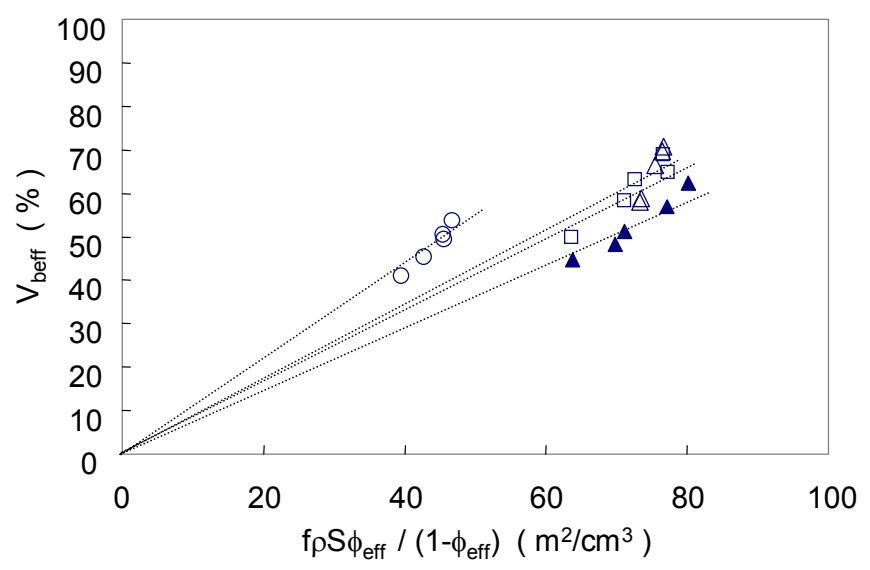

Figure 4.10: Pliskin-Tokita plot for the different types of the silicas $(\circ)$ : 1115MP ; $(\Delta): 1165 \mathrm{MP} ;(\square)$ : 7005 ; ( $\Delta)$ : VN3

The slope, corresponding to the bound rubber thickness, decreases with increasing CTAB surface area of the silicas. In comparison with the decrease in specific bound rubber with increasing CTAB surface area of the silica as given in Figure 4.9, this can be due to a lower surface activity of the silica resulting from the silica flocculation. There is a deviation from lines through zero, especially at higher effective volume fraction of the silica $\phi_{\text {eff }}$. This is due to an increased silanization at higher dump temperature. Therefore, the average thickness of the chemically bound interfacial layer was calculated by using the separate data points. The results of the calculation in terms of apparent hydrodynamic radius of the filler particles are summarized in Table 4.2.

Table 4.2 : Estimated apparent particle size

\begin{tabular}{|l|c|c|c|c|c|}
\hline Silica & Type & $\begin{array}{c}\text { Primary particle } \\
\text { size }(\mathrm{nm})\end{array}$ & $\begin{array}{c}\text { CTAB } \\
\left(\mathrm{m}^{2} / \mathrm{g}\right)\end{array}$ & $\begin{array}{c}\text { Thickness range } \\
\text { (average } \mathrm{nm})\end{array}$ & $\begin{array}{c}\text { Apparent } \\
\text { hydrodynamic } \\
\text { radius } \\
(\mathrm{nm})\end{array}$ \\
\hline $1115 \mathrm{MP}$ & HDS & 20 & 108 & $9.1-11(10)$ & 30.1 \\
\hline $1165 \mathrm{MP}$ & HDS & 13 & 152 & $7.7-9.0(8.5)$ & 21.5 \\
\hline 7005 & HDS & 12 & 164 & $7.1-8.8(8.1)$ & 20.1 \\
\hline VN3 & VN3 & 14 & 168 & $6.2-7.5(6.8)$ & 21.8 \\
\hline
\end{tabular}

The apparent radius of the filler particles seems to depend on the CTAB surface area of silica.

The viscosity $\eta$ may be approximated by relating it to the Mooney viscosity. Nakajima and Harrel derived an expression for the total shear stress in the Mooney rheometer, to be proportional to the total Mooney torque divided by the cube of the rotor radius. ${ }^{[13]}$ One Mooney unit equals $0.083 \mathrm{Nm}$, as given in the appropriate Mooney standard. ${ }^{[14]}$ Making the further simplification, that the cube of 
the rotor radius may be replaced by the sample volume $\varsigma$ and dividing the stress by the apparent shear rate of the measurement, $\dot{\gamma}$, approximately $2\left[\mathrm{~s}^{-1}\right.$ ], the viscosity $\eta$ can be approximated by equation.4.10:

$$
\eta \propto \frac{0.083 \times M L(1+4)}{\varsigma} \times\left(\frac{1}{\dot{\gamma}}\right)[\mathrm{Pa} / \mathrm{s}]
$$

By substituting equations 4.5 and 4.10 into equation 4.4 , the diffusion coefficient can be estimated as follows:

$$
D=\frac{K T}{6 \pi r_{\text {app }}} \times \frac{1}{\left(\frac{0.083 \times M L(1+4)}{\varsigma}\right) \times\left(\frac{1}{\dot{\gamma}}\right)} \quad\left[\mathrm{m}^{2} / \mathrm{t}\right]
$$

Figure 4.11 shows the calculated diffusion coefficient of the filler particles as a function of temperature.

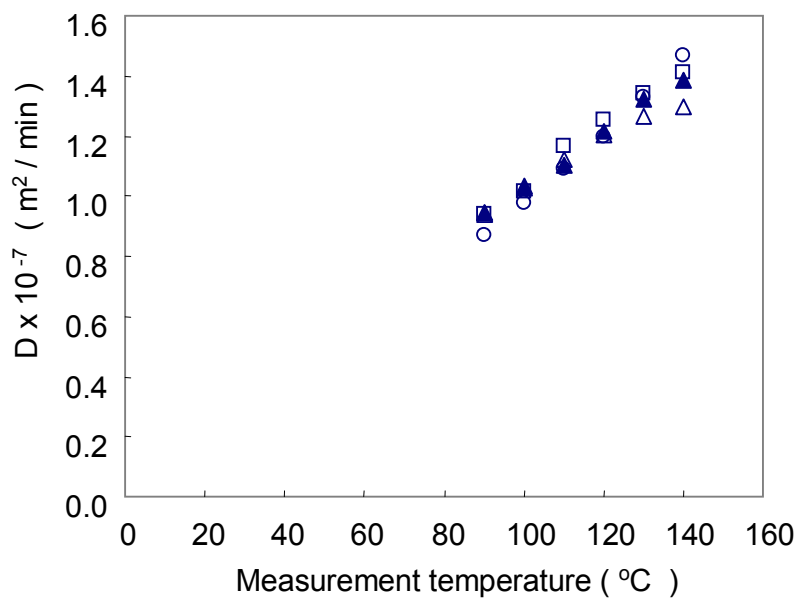

Figure 4.11 : Calculated diffusion constant of the silica particles as a function of the measurement temperature $(\circ)$ : 1115MP ; $(\Delta): 1165 \mathrm{MP} ;(\square): 7005$; ( $\Delta)$ : VN3 
As expected, the diffusion coefficient increases with increasing temperature according to equation 4.11. In Figure 4.12, the flocculation rate constant of the silica particles is plotted as a function of the calculated diffusion coefficients:

The diffusion coefficient shows a good correlation with the flocculation rate

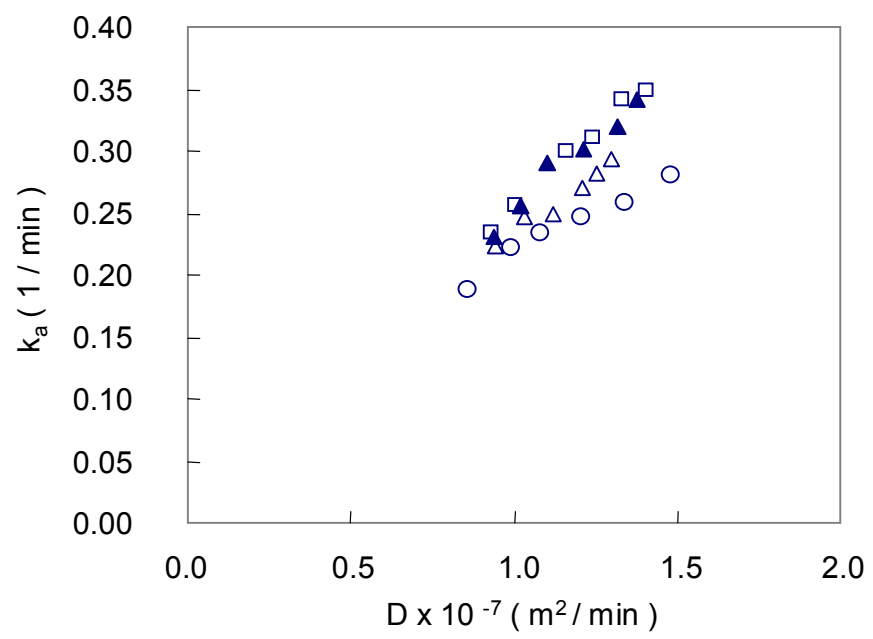

Figure 4.12 : Relationship between the flocculation rate constant and the calculated diffusion constant of the filler particles

$(\circ):$ 1115MP ; $(\Delta): 1165 \mathrm{MP} ;(\square): 7005 ;(\Delta):$ VN3

constant of the silica particles. This is another indication that flocculation is a pure physical process.

\subsubsection{Effect of bound rubber on silica flocculation}

The effectiveness of the interaction between the silica surface and the silane plays an important role in the flocculation. As already indicated above, a large polarity difference exists between silica and rubber polymer, and additionally the silica strongly tends to form self associated structures through hydrogen bonding. ${ }^{[16,17]}$ In order to reduce the polarity differences and the self associated structure, silane coupling agents are generally applied. Figure 4.13 shows the flocculation rate constant of the silicas as a function of specific chemically bound rubber.

It shows, that the flocculation rate constant remains constant and high up to a specific bound rubber content of approximately $0.40\left[\mathrm{~g} / \mathrm{m}^{2}\right]$ for all silicas and then decreases with increasing specific bound rubber. This indicates, that the silane coupling agent is not only hydrophobating the silica surface, but also forms the basis for the interfacial interaction between silica and polymer. The filler surface needs a certain minimum threshold coverage with chemically bound rubber through the silane, above which flocculation becomes restricted. This also proves that the decrease of the flocculation rate of silica is due to the shielding effect of the coupling agent. 


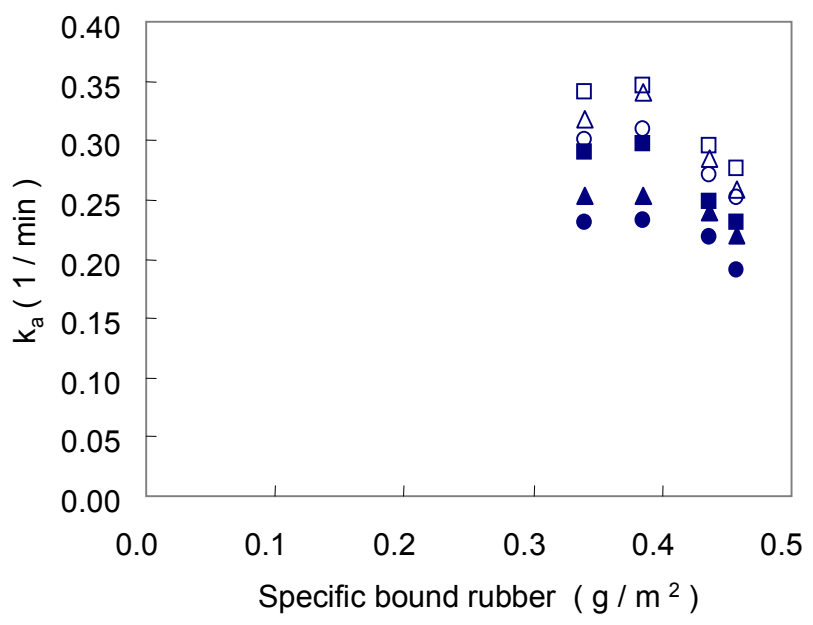

Figure 4.13 : Flocculation rate constant $\mathrm{k}_{\mathrm{a}}$ as a function of specific bound rubber

(• ) : $90^{\circ} \mathrm{C} ;(\triangle): 100{ }^{\circ} \mathrm{C} ;(\bullet): 110^{\circ} \mathrm{C}$;

(०): $120^{\circ} \mathrm{C} ;(\Delta): 130^{\circ} \mathrm{C} ;(\square): 140^{\circ} \mathrm{C}$

\subsection{Conclusion}

Flocculation of silica fillers takes place in rubber compounds due to polarity differences between silica and polymer, even if a silane coupling agent is applied. When the compound is vulcanized, flocculation takes place at the very beginning of the process, indicated by an initial increase in torque. This flocculation process during vulcanization plays an important role in the final dispersion of the silica in the vulcanized rubber. The kinetics of this silica flocculation can be estimated from the dynamic properties as measured in a Rubber Process Analyzer: in particular from the development of the modulus at small strain: the Payne effect. The flocculation rate is strongly dependent on temperature. The activation energy is less than $10[\mathrm{~kJ} / \mathrm{mol}]$, therefore the flocculation process can be considered as a mainly physical phenomenon.

The interfacial interaction layer between silica and polymer, consisting of chemically bound rubber, plays an important role in the flocculation process of the silica. With increasing CTAB surface area of the filler, the filler-filler networking becomes stronger, resulting in a faster flocculation rate.

The mobility of the silica particles in the rubber compound can be described by a diffusion process. For the calculation of the pertinent diffusion coefficient, the interfacial chemical interaction layer between silica and polymer needs to be taken into account. The thickness of the interfacial layer can be estimated by using a Pliskin-Tokita plot, which allows the estimation of the apparent particle diameter, including the interfacial chemical interaction layer between silica and polymer. The 
viscosity of the filled compound can be roughly estimated using the Mooney viscosity values. Both entities together allow to estimate the diffusion coefficient. The resulting diffusion coefficients increase with temperature and CTAB surface area of the silicas. The estimated diffusion coefficients show a good correlation with the flocculation rate constants. In addition, the flocculation rate constants of the silica particles show a good correlation with the specific bound rubber which chemically interacts with silane coupling agent on the filler surface: the flocculation rate decreases with increasing specific bound rubber content.

\subsection{References}

1. Y. Li, M.J. Wang, T. Zhang, X. Fu, Rubber Chem. Technol., 67, 693 (1994)

2. H. D. Luginsland, J. Fröhlich, A. Wehmeier, Rubber Chem. Technol., 75, 563 (2002)

3. A. Y. Coran, J.-B. Donnet, Rubber Chem. Technol., 65, 1016 (1992)

4. G. G. Böhm, M. N. Nguyen, J. Appl. Polym. Sci. 55, 1041 (1995)

5. C.-C Lin, W. L. Hergenrother, E. Alexanian, G. G. A. Böhm, Paper presented at the International Rubber Conference, Cleveland, Ohio, October 16-19, 2001

6. J.W.M. Noordermeer, L.A.E.M. Reuvekamp, M. Debowski, P.J. van Swaaij, G.J. Vancso, 167th Technical Meeting ACS Rubber Division, San Antonio (U.S.A), Paper 44, (16-18 May 2005)

7. R. Rauline, EP 0501227, US 5.227.425, Campagnie Generale des Establissements Michelin

8. A.R. Payne, in "Reinforcement of elastomers", G. Kraus Ed., Interscience Publ. New Yok, 1965

9. S. Wolff, M.-J. Wang, E.-H. Tan, Rubber Chem. Technol., 66, 163 (1993)

10. K. E. Polmanteer, C. W. Lentz, Rubber Chem. Technol., 48, 795 (1975)

11. L. A. E. M. Reuvekamp, S. C. Debnath, J. W. Ten. Brinke, P. J. Van. Swaaij, J. W. M. Noordermeer, Rubber Chem. Technol. 76, 43 (2004)

12. I. Pliskin, N. Tokita, J. Appl. Polym. Sci. 16, 473 (1972)

13. N. Nakajima, E.R. Harrell, Rubber Chem. Technol. 52, 9 (1979)

14. ISO 289, Rubber, unvulcanized - Determinations using a shearing-disk viscometer - Part 1: Determination of the Mooney viscosity

15. F. M. H. Villars, G. B. Benedek, "PHYSICS with illustrative examples from medicine and biology", Vol.2 (1974)

16. M.-J. Wang, S. Wolff, J.-B. Donnet, Rubber Chem. Technol., 64, 714 (1991)

17. M.-J. Wang, S. Wolff, J.-B. Donnet, Rubber Chem. Technol., 64, 559 (1991) 
Chapter 4 


\section{Chapter 5}

\section{ULTRA SMALL-ANGLE X-RAY SCATTERING STUDY}

\section{OF SILICA FLOCCULATION IN FILLED RUBBER}

In the present study USAXS measurements are applied for a qualitative analysis of the flocculation process of silica fillers in rubber during vulcanization by using SPring-8 (Super Photon ring-8, Japan Atomic Energy Research Institute); Beam line BL19B2, world's largest third-generation synchrotron radiation facility.

The size of silica aggregates and agglomerates impacts on the physical properties of filled rubber. In this study the silica flocculation during vulcanization is monitored using the USAXS technique for two different types of silica: the highly dispersible silica $1165 \mathrm{MP}$ and the conventional silica VN3. The cutoff length of the silica aggregate $R_{\mathrm{ss}}$ and the mass fractal dimension $D_{m}$, which indicate the degree of flocculation of aggregates, are estimated according to the modified Unified equation. The aggregate radius $R_{a}$ is estimated to be related to the lower cut-off length $R_{s s}$, indicating the radius of gyration of the mass-fractal structure. For both silicas $R_{a}$ increases during vulcanization. For the conventional silica VN3 an increase of $D_{m}$ is observed, whereas no significant increase of $D_{m}$ can be seen for the HD silica 1165MP. $R_{a}$ of VN3 is a relatively high compared to that of $1165 \mathrm{MP}$. On the other hand, the VN3 silica shows a relatively lower $D_{m}$ compared to that of $1165 \mathrm{MP}$. These results indicate that VN3 has a larger size of aggregates and lower degree of agglomeration of its aggregates.

The presence of TESPT decreases the aggregate radius of silica. However, in the absence of TESPT a low mass-fractal dimension, which means a low degree of agglomeration of aggregates, is observed. This results from a lower mobility of silica aggregates, depending on the size of the aggregates. The silica loading also has an influence on the flocculation process. The aggregate radius increases as the silica loading is increased. At the same time, a higher mass-fractal dimension, therefore also higher degree of agglomeration can be seen at higher silica loading. 


\subsection{Introduction}

Filler dispersion in rubber compounds plays an important role in physical properties of filler reinforced rubber. The dispersion of filler in a rubber matrix strongly depends on the polarity difference between polymer and filler, such as carbon black or silica.

It is generally known that the hierarchical structure of fillers such as the primary particle, aggregates and agglomerates can still be recognized in a filled rubber. The presence of remaining agglomerates strongly negatively affects the reinforcing properties of the fillers in rubber, while the aggregates are the real reinforcing species. According to Chapter 3, the reinforcing properties strongly depend on the following factors: (1) the degree of physically linked aggregates in the filler network, as often quantified by the Payne effect, and (2) polymer-filler interaction, described as the specific bound rubber $\left(\mathrm{m}^{2} / \mathrm{g}\right)$.

However, the relationship between the morphological properties of silica and the reinforced properties of rubber is not fully understood. Many morphological studies such as TEM microscopy and measurement of the electrical percolation threshold have been done extensively to investigate the filler structure. ${ }^{[1-8]}$ For 3-dimensional observations using TEM, the high volume fraction of fillers such as commonly used in typical tire tread compounds, leads to difficulties to investigate the filler structure, because of an overlapping of the structure along the electron beam direction. In addition, the special thin sample of 50-100nm thickness required for TEM observation, smaller than the average aggregate size, also lead to difficulties regarding 3-dimensional observation. On the other hand, the measurement of the electrical percolation threshold is a useful technique for a carbon black filled compound because of its high conductivity. However, this measurement can not be applied to silica filled compounds as used in the previous chapters due to lack of conductivity of silica.

For 3-dimensional characterization of filler-filled compounds, small angle scattering is a useful technique to understand the morphological properties of fillers in a rubber matrix. Ultra small angle scattering (USAS) and small angle scattering (SAS) using X-rays, neutrons and light have been widely used to investigate the morphological structure of fillers in rubber matrixes. ${ }^{[9-13]}$

In the present chapter, ultra small angle X-ray scattering (USAXS) which can cover the scattering angle $q$ range of 0.01 to $0.4 \mathrm{~nm}^{-1}$ is applied to characterize the filler morphology in a rubber compound. The focus is on silica flocculation in a rubber compound during vulcanization. It is worth to remind that the activation energy of the silica flocculation is approximately $10 \mathrm{~kJ} / \mathrm{mol}$ as described in Chapter 4 . It was indicated that silica flocculation is purely physical phenomenon. ${ }^{[14]}$ In addition, Reuvekamp et al. proposed that the flocculation of the silica takes place at the very beginning of the vulcanization.

In the present chapter we focus on the morphological properties of the silica during vulcanization. The structural-hierarchical parameters such as the mass-fractal dimension and the size of the aggregates are estimated using the Beaucage unified equation, which is composed of a Guinier scattering function combined with 
a power-law scattering. Based on the differences of the structural parameters between highly dispersible silica and conventional silica, the morphological properties in the rubber compound will be investigated.

\subsection{Experimental}

\subsubsection{Sample preparation}

The compound formulations are based on a typical tire tread compound according to the fuel-saving green tire technology as shown in Table 5.1.

Table 5.1 : Compound formulation

\begin{tabular}{|c|c|c|c|}
\hline Component & Product name & Supplier & phr \\
\hline S-SBR* & Buna VSL5025 HM-1 & Lanxess & 103 \\
\hline $\mathrm{BR}$ & Nipol 1220 & Nippon Zeon & 25.0 \\
\hline Silica & listed in Table 5.2 & listed in Table 5.2 & 80.0 \\
\hline Silane (TESPT) & Si69 & Degussa & $\begin{array}{l}0 \text { or as listed } \\
\text { in Table } 5.2\end{array}$ \\
\hline Aromatic oil & Tudalen 3570A & Hansen \& Rosenthal & 4.40 \\
\hline Zinc oxide & $\mathrm{ZnO}$ & Merck & 2.50 \\
\hline Stearic acid & Steraric acid & Merck & 2.50 \\
\hline \multicolumn{4}{|l|}{ Curatives: } \\
\hline Sulfur & & J.T. Baker & Variable \\
\hline CBS & Santocure CBS & Flexsys & 1.70 \\
\hline DPG & Perkacit DPG & Flexsys & 2.00 \\
\hline
\end{tabular}

※37.5 phr oil extended

Table 5.2 : Structural analytical data of the silica types

\begin{tabular}{|c|c|c|c|c|c|c|}
\hline Type & $\begin{array}{l}\text { Product } \\
\text { name }\end{array}$ & Source & $\begin{array}{l}\text { BET } \\
\left(\mathrm{m}^{2} / \mathrm{g}\right)\end{array}$ & $\begin{array}{l}\text { CTAB } \\
\left(\mathrm{m}^{2} / \mathrm{g}\right)\end{array}$ & $\begin{array}{l}\text { DBP } \\
(\mathrm{g} / 100 \mathrm{~g})\end{array}$ & $\begin{array}{l}\text { Silane loading } \\
\quad(\mathrm{phr})\end{array}$ \\
\hline HD & Zeosil 1165MP & Rhodia Silices & 155 & 152 & 196 & 6.4 \\
\hline $\mathrm{CV}$ & Ultrasil VN3 & Degussa & 177 & 168 & 183 & 7.1 \\
\hline
\end{tabular}

In the present chapter two types of silica, a highly dispersible silica and a conventional silica are used. The amount of silane applied in the recipes was adjusted according to equation 3.1 as shown in Chapter 3 , which is related to CTAB surface area of the silica. The total amount of active sulfur was adjusted to $2.1 \mathrm{phr}$, being the sum of the sulfur contained in the silane and in the curatives. Structural analytical data of the silicas are shown in Table 5.2.

For mixing the compounds, a tangential type internal mixer with 1.7 I volume was used. The mixing procedure was the same as in Chapter 3. 


\subsubsection{Ultra small-angle $X$-ray scattering (USAXS) measurement}

The USAXS measurement was done at ambient pressure by using SPring-8 (Super Photon ring-8, Japan Atomic Energy Research Institute); Beam line BL19B2, world's largest third-generation synchrotron radiation facility. The time division method was applied in the present investigation. A layout of the measurement system is described in Figure 5.1.

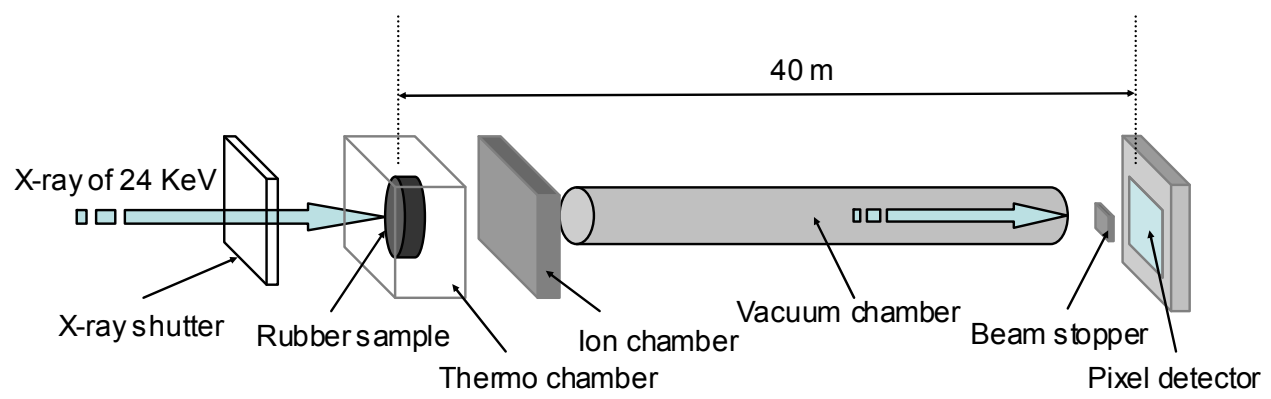

Figure 5.1 : Schematic layout of USAXS equipment

The X-ray scattering was detected using the pixel detector (PILTUS) covering the q-range of $0.01 \sim 0.4 \mathrm{~nm}^{-1}(\mathrm{q}=(4 \pi / \lambda) \sin \theta: \theta=$ scattering angle $; \lambda=$ wave length of the $\mathrm{X}$-ray=0.5 $\AA$ [24 keV]). The distance between the sample and the pixel detector (PILTUS) is approximately $40 \mathrm{~m}$, therefore the ultra small-angle scattering X-rays can be detected.

The silica filled rubbers of about $1 \mathrm{~mm}$ thickness were held in the thermostatic chamber at the specified temperature for $1500 \mathrm{sec}$. Data correction was done for sample transmission and for background scattering arising from air and fused quartz on the thermostatic chamber.

\subsubsection{Data analysis}

A schematic scattering profile combining ultra small-angle neutron scattering (USANS), ultra small-angle X-ray scattering (USAXS) and small angle X-ray scattering (SAXS) for a precipitated silica are shown in Figure 5.2. ${ }^{[11,12]}$

At least three distinguished levels of the structure of silica can be detected, corresponding to morphological properties such as the size of the primary particles, the degree of aggregation or agglomeration and the surface profile of the particles. 


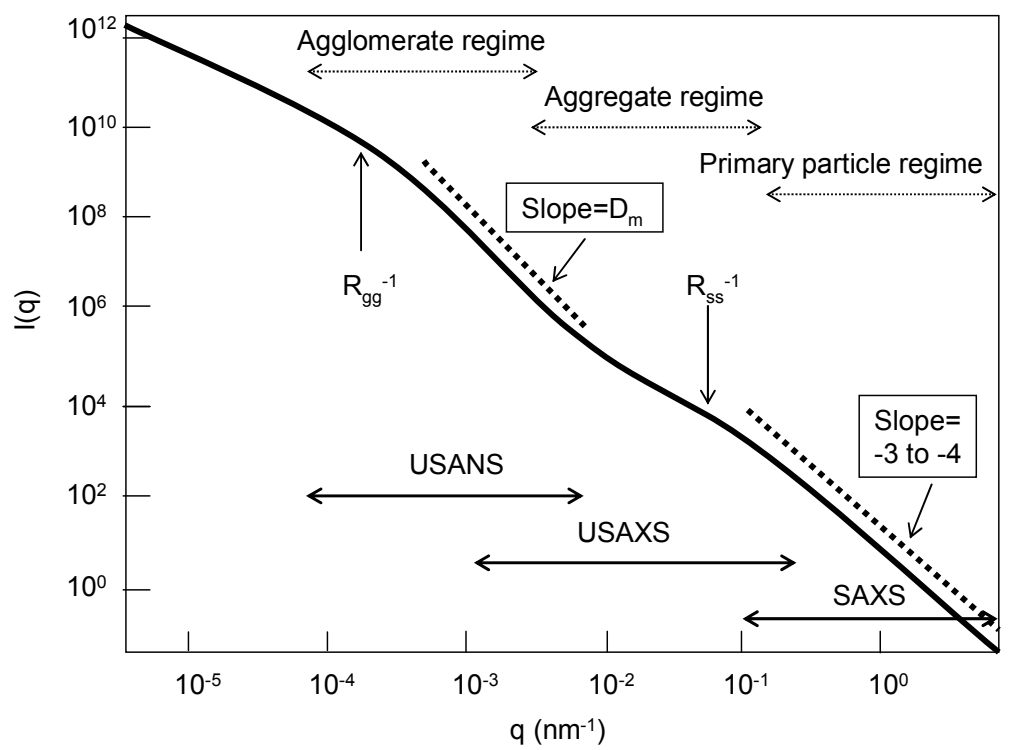

Figure 5.2 : Schematic combined USANS, USAXS and SAXS profiles for silica powder

In general, for the scattering data as shown in Figure 5.2, a curve fitting using a unified approach developed by Beacaug ${ }^{[15]}$ is applied for estimation of the structural parameters such as $R_{\mathrm{ss}}$ and $\mathrm{R}_{\mathrm{gg}}$ corresponding to the size of aggregates and agglomerates, respectively. The power-law scattering profile is described as in equation 5.1 .

$$
I(q) \cong q^{-p}
$$

where $I(q)$ is the scattering intensity at the scattering angle $q$ and $p$ is the power law exponent.

In the high q region the scattering intensity decays following Porod's law. The power law value $p=4$ indicates the scattering from the smooth surface of the particles. However, it is well known that the filler surface such as of carbon black and silica is not smooth but rough ${ }^{[16,17]}$ In this case, the surface fractal dimension $\left(D_{s}\right)$ is related to the power-law exponent $p$ as follows:

$$
p=2 d-D_{s}
$$

where $d$ is the Euclidean dimension of the space $(d=3)$ and $D_{s}$ is the surface fractal dimension. If $\mathrm{I}(\mathrm{q})$ is plotted as a function of $\mathrm{q}$ logarithmically, the slope of $\ln (\mathrm{I}(\mathrm{q})$ ) vs. $\ln (\mathrm{q})$ plot can vary between -3 and -4 .

On the other side, at low q, the so-called Guinier region, the scattering intensity decays following Guinier's law. The decay of the scattering intensity in this region can be described as shown in equation 5.3: 


$$
I(q) \cong I(0) \exp \left(-\frac{q^{2} R_{i}^{2}}{3}\right)
$$

where $R_{i}$ is the structural size of aggregates or agglomerates.

At low scattering angles q two Guinier regions, which mean the two levels of aggregate and agglomerate sizes, can be seen. As shown in Figure 5.2, two discrete shape-factor profiles such as $\mathrm{R}_{\mathrm{gg}}{ }^{-1}$ and $\mathrm{R}_{\mathrm{ss}}{ }^{-1}$ can be seen, which can be derived from the Guinier scattering function Equation 5.3. $R_{g g}{ }^{-1}$ and $R_{s s}{ }^{-1}$ indicate the upper and lower cut-off length of the mass-fractal structure, respectively. The power-law scattering between these two Guinier regions indicates the mass-fractal structure $D_{m}$. In fact, the power-law slope in this region means the mass-fractal dimension, therefore the power law index $p$ in equation 5.1 , is characterized as follows: ${ }^{[13]}$

$$
p=D_{m}
$$

For the qualitative analysis of the structural parameters based on the unified equation, the following equation is applied to the scattering profiles in the present study. ${ }^{[13]}$

$$
\begin{gathered}
I(q)=A \\
\exp \left(-\frac{q^{2} R_{g g}^{2}}{3}\right) q^{-p}+B \exp \left(-\frac{q^{2} R_{g g}^{2}}{3}\right)+C \exp \left(-\frac{q^{2} R_{s s}^{2}}{3}\right) \times\left[\operatorname{erf}\left(\frac{q R_{g g}}{\sqrt{6}}\right)\right]^{3 D_{m}} q^{-D_{m}} \\
+D \exp \left(-\frac{q^{2} R_{s s}^{2}}{3}\right)+E\left[\operatorname{erf}\left(\frac{q R_{s s}}{\sqrt{6}}\right)\right]^{3\left(2 d-D_{s}\right)} q^{-\left(2 d-D_{s}\right)}
\end{gathered}
$$

where $R_{\mathrm{gg}}$ and $\mathrm{R}_{\mathrm{ss}}$ are the upper (agglomerates) and lower (aggregate) cut-off length of the mass-fractal structure, respectively, and $A, B, C, D$ and $E$ are constants.

In the present study, no upper cut-off length $\left(R_{\mathrm{gg}}\right)$ for the mass-fractal structure can be seen in the covered $\mathrm{q}$, as will be described later. Therefore, the first two terms in equation 5.5 can be neglected and the third term, which is an error function, can be taken constant. Taking these assumptions into account, equation 5.5 can be simplified as follows: ${ }^{[13]}$

$$
\begin{aligned}
I(q)=C \exp \left(-\frac{q^{2} R_{s s}^{2}}{3}\right) \times q^{-D_{m}} \\
+D \exp \left(-\frac{q^{2} R_{s s}^{2}}{3}\right)+E\left[\operatorname{erf}\left(\frac{q R_{s s}}{\sqrt{6}}\right)\right]^{3\left(2 d-D_{s}\right)} q^{-\left(2 d-D_{s}\right)}
\end{aligned}
$$

By using eq.5.6, the structural parameters such as $R_{s s}$ and $D_{m}$ are estimated in the present study. The lower cut-off length $R_{s s}$ indicates the radius of gyration of the mass-fractal structure. 


\subsection{Results}

\subsubsection{Comparison of the structural parameter between highly dispersible(HD) silica and conventional(CV) silica}

Figures 5.3 (a) and (b) show examples of USAXS scattering profiles for the highly dispersible silica and the conventional silica at different times. For both silicas, one form-factor profile $\left(\mathrm{R}_{\mathrm{ss}}{ }^{-1}\right)$, as assumed by a Guinier scattering profile, is observed. In addition, two different slopes at high and low q are visible, which indicate massfractal structures with mass-fractal dimension $\left(D_{m}\right)$ and the primary particles with their surface fractal dimension. The power-law values $p$ at the high $q$ do not show a value of $p=4$, but 3.3 and 3.1 respectively. This means that the surface of the primary particles is not smooth.
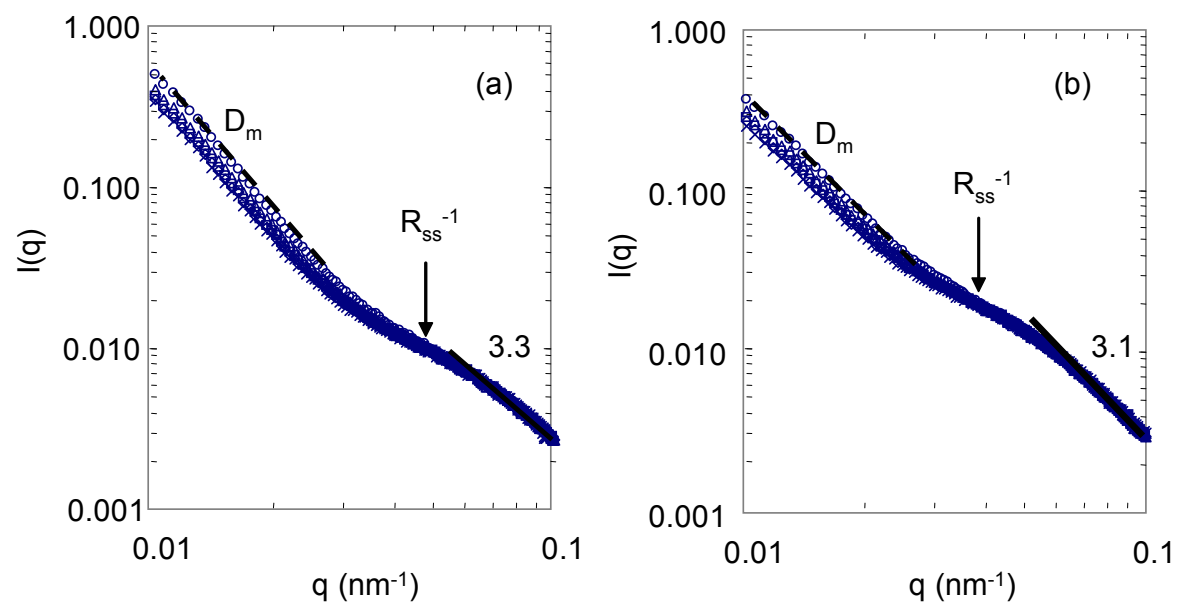

Figure 5.3 : USAXS scattering profiles at $120^{\circ} \mathrm{C}$

(a) : Highly dispersible silica (1165MP) ; (b) : Conventional silica (VN3)

$(\circ): 0 \mathrm{~min} ;(\Delta): 5 \mathrm{~min} ;(\square): 10 \mathrm{~min} ;(\diamond): 15 \mathrm{~min} ;(\mathrm{x}): 20 \mathrm{~min}$

In order to investigate the silica flocculation phenomenon, the radius of gyration cut-off length $R_{\mathrm{ss}}$ and the mass-fractal dimension $D_{m}$ for each silica were estimated according to equation 5.6. Based on the assumption that the shape of aggregates is spherical with radius $R_{a}$, the radius of gyration $R_{s s}$ can be described in relation to $\mathrm{R}_{\mathrm{a}}$ as follows: ${ }^{[11,13,15] \text { : }}$

$$
R_{s s}=\sqrt{\frac{3}{5}} \times R_{a}
$$

In the present study we therefore can assume that $R_{s s}$ and $D_{m}$ indicate the size of aggregates and the degree of the agglomeration of the aggregates, respectively.

Figures 5.4 (a) and (b) show the estimated radius of the silica aggregates as a function of vulcanization time at the different temperatures. 

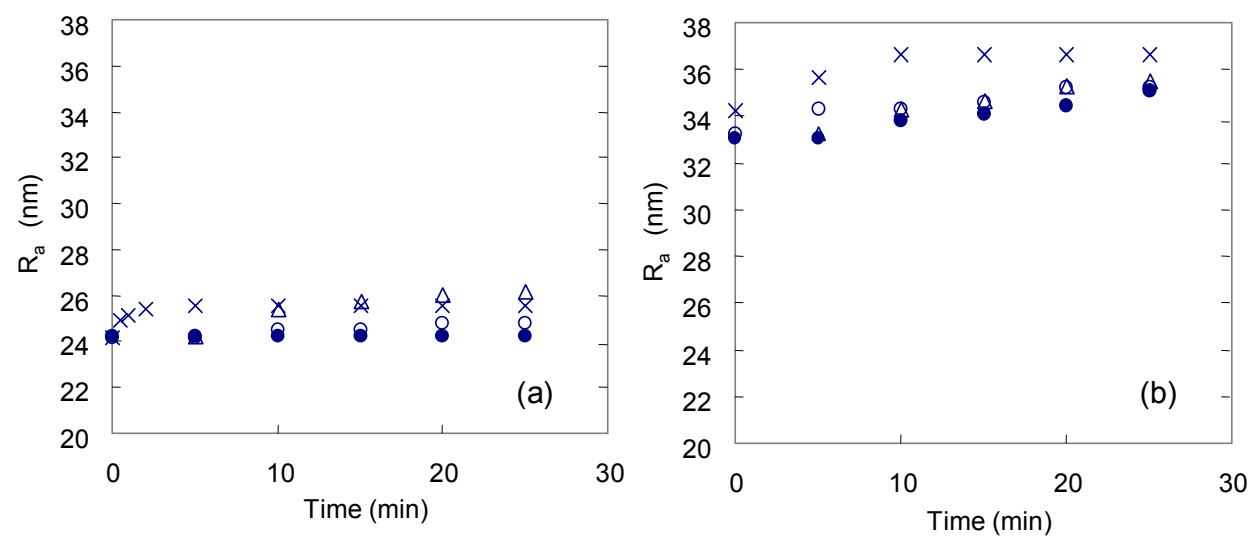

Figure 5.4 : Radius of aggregates $R_{a}$ as a function of vulcanization time at specified temperatures

(a) : Highly dispersible silica (1165MP) ; (b) : Conventional silica (VN3)

$(\bullet): 90^{\circ} \mathrm{C} ;(\circ): 100^{\circ} \mathrm{C} ;(\triangle): 120^{\circ} \mathrm{C} ;(\mathrm{x}): 160^{\circ} \mathrm{C}$

The aggregate radius of the CV silica is relatively high compared to that of the HD silica. In addition, the aggregate radius of the $\mathrm{CV}$ silica increases slightly faster than that of HD silica as temperature and time are raised. This translates into the fact that the flocculation rate of the $\mathrm{CV}$ silica is relatively fast compared to that of the HD silica. This tendency of increasing aggregate size corresponds to the flocculation rate estimated by the RPA2000 measurements as described in Chapter $4{ }^{[14]}$ Indeed, the aggregate radius of the HD silica and the CV silica can be estimated as 24 to $26 \mathrm{~nm}$ and 33 to $37 \mathrm{~nm}$, respectively.

At the highest vulcanization temperature of $160^{\circ} \mathrm{C}$, the aggregate radius increases quickly till a vulcanization time of 10 minutes and then remains unchanged. This means that once the crosslinking reaction proceeds, silica flocculation does not take place any more.

Figures $5.5(a)$ and (b) show the mass-fractal dimension $D_{m}$ as a function of the vulcanization time at the different temperatures. For both silicas $D_{m}$ increases with an increase of vulcanization temperature. However, in the case of the HD silica, no significant change of $D_{m}$ during vulcanization can be seen except for the vulcanization temperature of $160^{\circ} \mathrm{C}$. For the VN3 silica it is clearly seen that $D_{m}$ increases with increasing vulcanization time. 

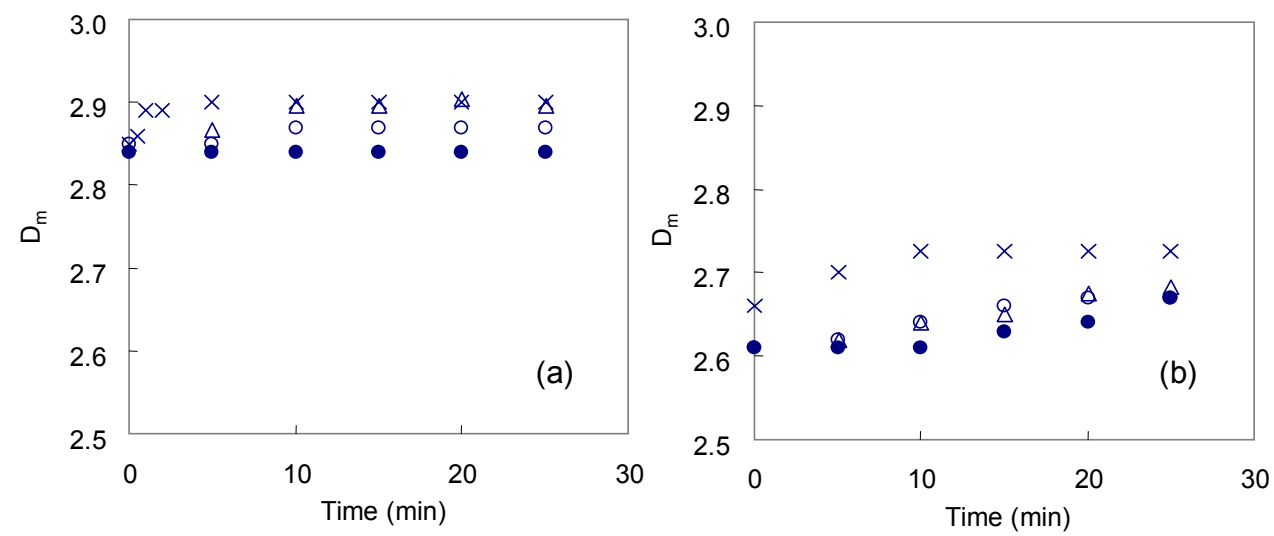

Figure 5.5 : Mass-fractal dimension $D_{m}$ as a function of vulcanization time at specified temperatures

(a) : Highly dispersible silica (1165MP) ; (b) : Conventional silica (VN3)

(•) : $90^{\circ} \mathrm{C} ;(\circ): 100^{\circ} \mathrm{C} ;(\triangle): 120^{\circ} \mathrm{C} ;(\mathrm{x}): 160^{\circ} \mathrm{C}$

It is interesting to find that the mass-fractal dimension of the CV silica is relatively low compared to that of the HD silica, while the $R_{s s}$ of the $C V$ silica is higher than that of the HD silica.

\subsubsection{Effect of the filler loading on the structural parameters}

Figures 5.6(a) and (b) show the radius of aggregates with different silica loading as a function of vulcanization time. As is evident from Figures 5.6(a) and (b) for both silicas, a higher $R_{a}$ is found especially for higher silica loading.
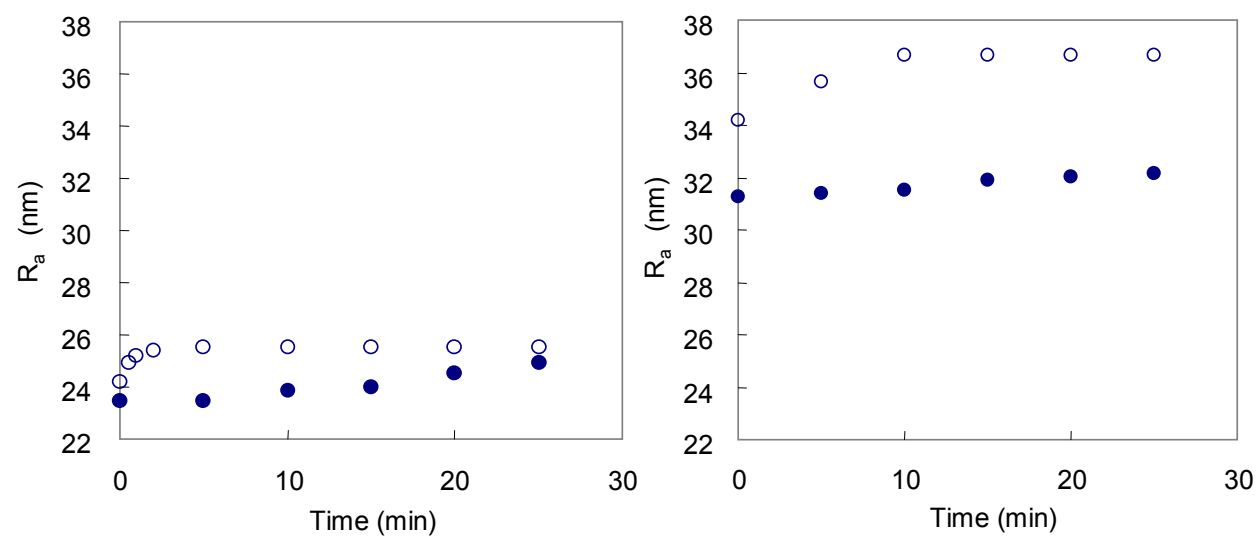

Figure 5.6 : Radius of aggregates $R_{a}$ as a function of vulcanization time at different loadings of silica

(a) : Highly dispersible silica (1165MP) ; (b) : Conventional silica (VN3)

(•) : $60 \mathrm{phr}:(\circ): 80 \mathrm{phr}$ 
Figures 5.7 (a) and (b) show the mass-fractal dimension with different silica loading as a function of vulcanization time. For both silicas, $D_{m}$ increases as the vulcanization proceeds. In addition, with increasing silica loading, $D_{m}$ increases. Again, $D_{m}$ of the CV silica is relatively low compared to that of the HD silica.
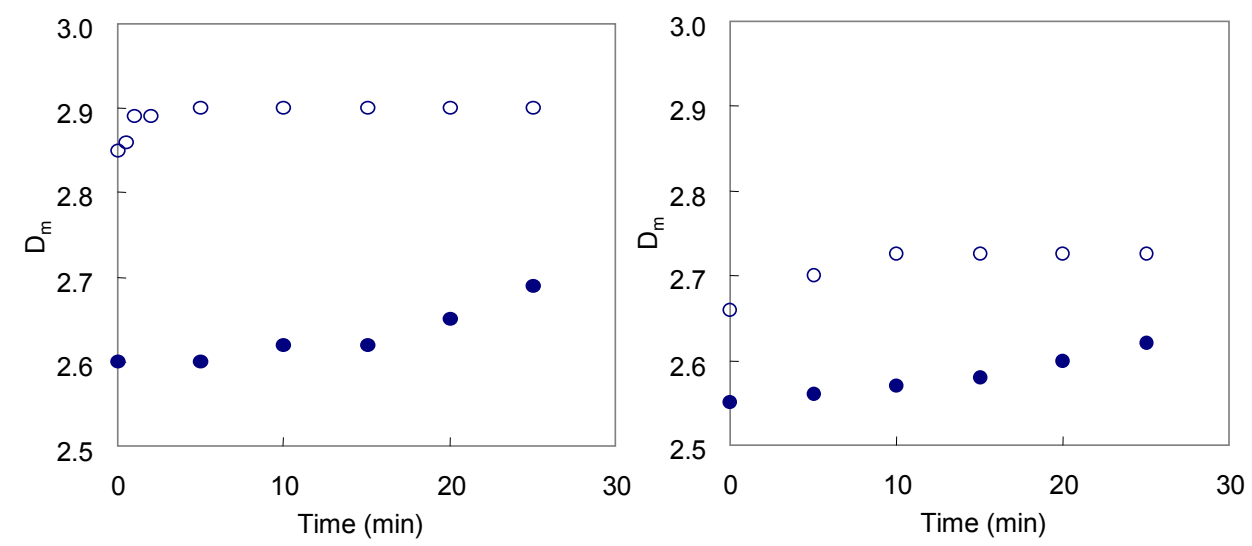

Figure 5.7 : Mass-fractal dimension $D_{m}$ as a function of vulcanization time at different loadings of silica

(a) : Highly dispersible silica (1165MP) ; (b) : Conventional silica (VN3)

(•) : $60 \mathrm{phr}$; ( $)$ ): $80 \mathrm{phr}$

\subsubsection{Effect of the presence of silane on the structural parameters}

The effect of the presence of TESPT on the structural parameters was investigated and the results are shown in Figures 5.8 (a) and (b).
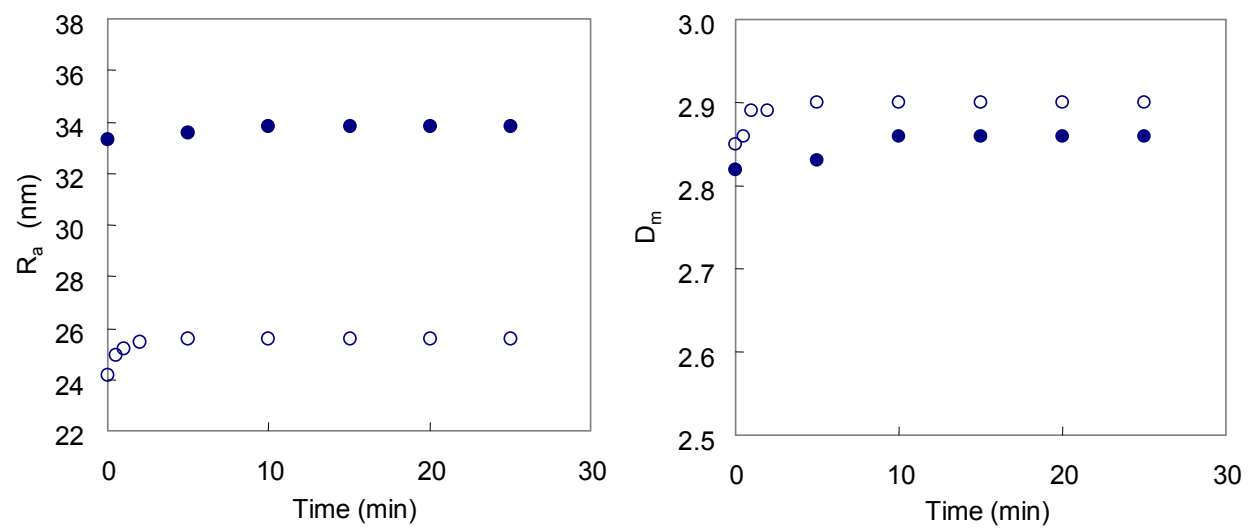

Figure 5.8 : Effect of TESPT on the structural parameters of 1165MP silica (a) : Radius of aggregates $\left(R_{\mathrm{a}}\right)$; (b) : Mass-fractal dimension $\left(D_{m}\right)$

(• ) : without TESPT ; $(\circ)$ : with TESPT 
In the absence of TESPT, the aggregate radius $R_{a}$ of the HD silica increases. The higher $R_{a}$ can be related to a lower mobility of the aggregates as will be discussed later. In addition, the mass-fractal dimension $D_{m}$ is relatively low in the absence of TESPT, which means a lower degree of the agglomeration of the aggregates.

\subsection{Discussion}

The morphology of HD silica and of CV silica has been studied during vulcanization by using the USAXS technique. It was observed that the lower cut-off length $R_{\mathrm{ss}}$, which indicates the radius of gyration of the silica aggregate, increases during vulcanization. In addition, an increase of $D_{m}$ the mass-fractal dimension, was seen. It is known that the spherical aggregate of radius $R_{a}$ is linked to $R_{s s}$, hence the aggregates size increases during the vulcanization. From a morphological point of view, it can be mentioned that the HD silica and the CV silica both have a primary particle diameter of approximately $14 \mathrm{~nm}$. Therefore, the following mechanism regarding the hierarchical structure can be proposed as shown in Figure 5.9.

(a)

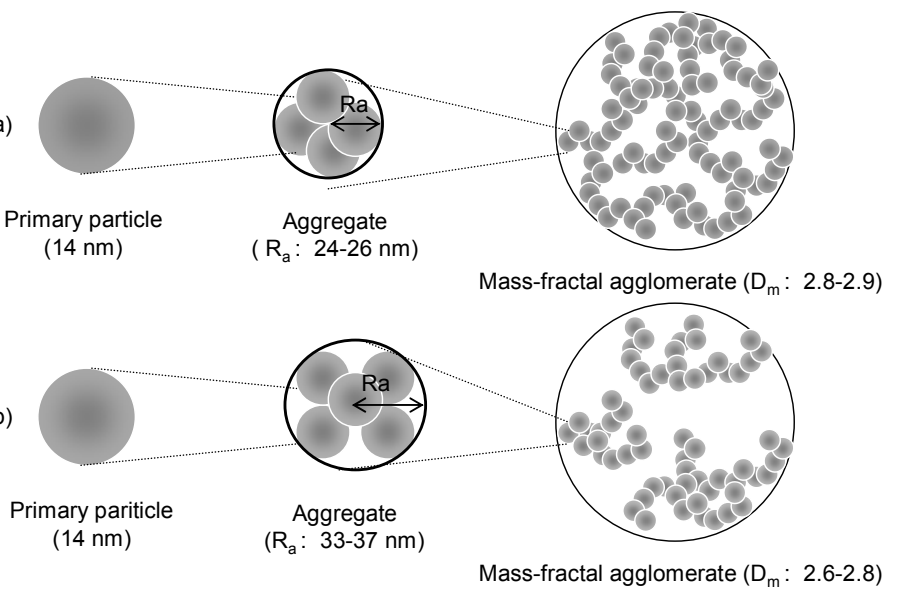

Figure 5.9 : Schematic model of morphological structure during vulcanization (a) : Highly dispersible silica (1165MP) ; (b) : Conventional silica (VN3)

It was found that the aggregate radius $R_{a}$ of the HD silica and the CV silica were approximately $24-26 \mathrm{~nm}$ and $33-37 \mathrm{~nm}$, respectively.

For the CV silica, the increase of aggregate radius $R_{a}$ during vulcanization is relatively fast compared to the HD silica: Figure 5.4. This corresponds to the flocculation rate of the silicas estimated by the RPA2000 measurements as described in the previous Chapter 4. In this RPA measurement, an increase of storage modulus G' during a heating process was observed due to silica flocculation. This increase of ' $G^{\prime}$ could be related to an increase of the aggregate size as shown in that chapter. In fact, the present results conclusively indicate that the increase of the aggregate size results in the increase of the storage modulus in silica-filled rubber. 
A next point to focus on is the degree of agglomeration of the aggregates. In the previous chapter, due to the fact that the activation energy of the silica flocculation is approximately $10 \mathrm{~kJ} / \mathrm{mol}$, it was indicated that the silica flocculation is a purely physical phenomenon. ${ }^{[14]}$ As stated before, for the estimation of the structural parameters such as the aggregate radius $R_{a}$ and the mass-fractal dimension $D_{m}$, it was assumed that the shape of the aggregates or the agglomerates is spherical. Therefore, the mobility of the particles in terms of their diffusion constant $D$ can be described by eq. 5.8. ${ }^{[18,19]}$, the Stokes-Einstein equation:

$$
D=\frac{K T}{6 \pi \eta r}
$$

where: $\mathrm{D}$ is the diffusion coefficient, $\mathrm{K}$ is Boltzmann's constant, $\mathrm{T}$ is the absolute temperature, $\eta$ is the viscosity of the matrix and $r$ is the hydrodynamic radius of the particle.

The aggregate radius of the CV silica VN3 is relatively high compared to that of the $\mathrm{HD}$ silica $1165 \mathrm{MP}$. This indicates that the hydrodynamic radius $r$ of the $\mathrm{CV}$ silica is relatively high in comparison with the HD silica. As a result, the mobility of aggregates of the CV silica can be low according to Equation 5.8. This low mobility of the aggregates then leads to a lower degree of agglomeration of aggregates $D_{m}$.

The silica loading also influences the morphological properties of filled rubber. In Figure 5.6, the radius of aggregates is higher as the silica loading is increased. The degree of agglomeration of the aggregates $D_{m}$ also increases with higher silica loading. The attractive force between the particles depends on their distance between. In other words, the correlation length between the particles, which means that the particles can attract each other, increases with higher silica loading. As a result, the degree of flocculation of aggregates increases, which is observed as an increase of the mass-fractal dimension $D_{m}$. Therefore, the degree of silica loading is one of the dominant factors for the flocculation process in silica-filled rubber.

In view of the previous results, the effect of the coupling agent TESPT can now also easily be understood. The polarity difference between silica and the polymers play an important role in the morphology of the rubber matrix. TESPT reduces the polarity difference between silica and polymer. In the absence of TESPT, the aggregate radius $R_{a}$ is obviously larger as shown in Figure 5.8, due to a higher driving force for demixing. On the other hand, the degree of the agglomeration of aggregates $D_{m}$ then decreases, due to a decrease of mobility of the aggregates. 


\subsection{Conclusions}

The flocculation phenomenon of the silica in rubber has been monitored during vulcanization by using USAXS technique. This technique is useful for real time analysis of silica flocculation.

The aggregate size of the CV silica is relatively high compared to that of the HD silica. The aggregate radii $R_{a}$ for the HD silica and the CV silica can be estimated as $24-26 \mathrm{~nm}$ and $33-37 \mathrm{~nm}$, respectively.

The aggregate radius of the $\mathrm{CV}$ silica increases fast during vulcanization compared to the HD silica. This result corresponds with the flocculation rate of silica, as estimated by using RPA2000 measurements in Chapter 4. On the other hand, for the CV silica, the degree of agglomeration of the aggregates $D_{m}$ is relatively lower than for the HD silica. This results from the lower mobility of the aggregates because of large aggregate size.

An increase of silica loading causes the aggregate radius $R_{a}$ and the mass-fractal dimension of the agglomerates $D_{m}$ to increase as well. TESPT plays an important role in the reducing the aggregate radius $R_{a}$ of silica. In the absence of TESPT an increase in aggregates radius was found. Since the mass-fractal dimension $D_{m}$ strongly depends on the aggregate size of silica, corresponding to physical diffusion of fillers aggregates, in the absence of TESPT a lower mass fractal dimension, which means a decrease of the mobility of the aggregates, was observed.

The present results again confirm that silica flocculation is a physical phenomenon, as already demonstrated in Chapter 4. 


\subsection{References}

1. A.J. Medalia, J. Colloid Interface Sci., 24, 393 (1967)

2. W.M. Hess, L.L Ban, G.C. McDonald, Rubber Chem. Technol., 42, 1209 (1969)

3. W.M. Hess, G.C. McDonald, E.M. Urban, Rubber Chem. Technol., 44, 204 (1972)

4. C.R. Herd, G.C. McDonald, W.M. Hess, Rubber Chem. Technol., 65, 107 (1992)

5. A.J. Medalia, Rubber Chem. Technol., 59, 432 (1986)

6. G.B. Ouyang, Kautsch. Gummi Kunstst, 55, 104 (2002)

7. Y. Gefen, A. Aharony, S. Alexander, Phy. Rev. Lett., 50, 77 (1983)

8. D. Stroud, D.J. Bergman, Phy. Rev. B, 25, 2061 (1982)

9. M. Klüppel, G. Heinrich, Rubber Chem. Technol., 68, 623 (1995)

10. D. Göritz, G.J. Schneider, Kautschuk HerbstKolloquium DIK, Hannover Germany 10-13 Nov. 2004

11. D.J. Kohls, D.W. Schaefer, Paper No. 68 presented at the Fall 170th Technical Meeting of the Rubber Division, American Chemical Society, Cincinnati, OH, 10-12 Oct. 2006

12. D.W. Schaefer, D.J. Kohls, Paper No. 69 presented at the Fall 170th Technical Meeting of the Rubber Division, American Chemical Society, Cincinnati, OH, 10-12 Oct. 2006

13. T. Koga, T. Hashimoto, M. Takenaka, K. Aizawa, N. Amino, M. Nakamura, D. Yamaguchi, S. Koizumi, Macromolecules, 41, 453 (2008)

14. S. Mihara, R.N. Datta, W.K. Dierkes, J.W.M. Noordermeer, Paper No. 63 presented at the Fall 172th Technical Meeting of the Rubber Division, American Chemical Society, Cleveland, OH, 16-18 Oct. 2007

15. G.J. Beaucage, J. Appl. Crystallogr., 28, 717 (1995)

16. T.P. Rieker, M. Hindermann-Bischoff, Langmuir, 16, 5588 (2000)

17. P.W. Schmidt, J. Appl. Crystallogr., 24, 414 (1991)

18. G.G. Böhm, M. Nguyen, J. Appl. Polym. Sci. 55, 1041 (1995)

19. F.M.H. Villas, G.B. Benedek, "PHYSICS with illustrative examples from medicine and biology", Vol.2 (1974) 


\title{
Chapter 6
}

\section{REINFORCEMENT MECHANISM OF SILICA WITH ALTERNATIVES FOR DPG: PART 1}

\author{
EFFECT OF PKa VALUE OF AMINES ON THE \\ SILANIZATION KINETICS IN MODEL OLEFIN \\ EXPERIMENTS
}

The interfacial interaction between silica and polymer plays an important role in the physical properties of silica-reinforced rubber. Therefore, it is important how to control the interfacial interaction between silica and polymer. One possibility is acceleration of the silanization reaction by using amines like 1,3-diphenylguanidine (DPG). Although DPG is widely used in tire tread compounds, its use is suspect for reasons of toxicity. Therefore, alternatives for DPG are required for the near future.

In this study we choose several amines with different pKa values as DPG alternatives. The kinetic parameters such as the reaction rate and the activation energy in a model olefin system are estimated according to the Arrhenius equation. The rate constant of the silanization reaction remains unchanged till a $p K a=6.5$ for the amines and then increases quickly with increasing $p K a$ value. DPG and DPG-alternatives such as Quinuclidine and 3-Quinuclidinol show a high silanization rate. By using amines with high pKa values the activation energy (Ea) decreases till one third. For the accelerating mechanism of the amines a nucleophilic catalytic reaction can be proposed. This implies that the hydration of TESPT is the rate-determining factor.

The three amines DPG, Quinuclidine and 3-Quinuclidinol are applied in a typical tire tread compound. These amines show lower Payne effect values in the silicafilled rubber, in correspondence with their comparable positive effect on the silanization reaction. 


\subsection{Introduction}

As mentioned in the previous Chapter 3, the interfacial interaction between silica and polymer plays an important role in the physical properties of silica-reinforced rubber. Therefore, controlling the interfacial interaction between silica and polymer with silane coupling agents is important. One of the possibilities is to enhance the silanization reaction by using amines. Amines such as 1,3-diphenylguanidine (DPG), enamines $\left(\mathrm{R}_{2} \mathrm{C}=\mathrm{CR}-\mathrm{NR}_{2}\right)$ and aldimines ( $\mathrm{R}-\mathrm{CH}=\mathrm{N}-\mathrm{R}^{\prime}$ ) (where $\mathrm{R}, \mathrm{R}^{\prime}=$ hydrocarbon groups) are capable of accelerating the silanization reaction when these amines are mixed with silica and silane. ${ }^{[1,2]}$

The silane chemistry is so complicated that an understanding of the mechanism of each reaction such as silanization, silane-rubber coupling and the crosslinking reaction during rubber processing is required. For the silanization reaction with bis(triethoxysilylpropyl) tetrasulphide (TESPT), the first reaction step is hydrolysis on one alkoxy group to form reactive silanol group with release of a molecule of ethanol. $^{[3]}$ It is well known that this reaction is rather slow. The reaction rate constant of hydrolysis increases with increasing reaction temperature and the presence of acid or alkaline compounds. ${ }^{[4]}$ The next step is the reaction between the hydrolyzed silane and a silanol group on the silica surface. This coupling reaction is called the primary reaction. For the primary reaction, it is well known that hydrolysis of TESPT is the rate-determining step. On the other hand, the condensation of adjacent ethoxy groups of TESPT, the so-called the secondary reaction, takes place as well.

A kinetic study regarding the silanization reactions was done by Gorl et al. ${ }^{[4]}$ In this study, it was demonstrated that the reaction rate constant of the primary reaction is about 10 to 20 faster than that of the secondary reaction. The activation energy of the primary reaction was estimated as $47 \mathrm{~kJ} / \mathrm{mol}$ in a model olefin system. As mentioned above, the amine DPG promotes the silanization reaction. Although DPG is still widely used in silica-filled tire compounding, its use is subject to debate for toxicity concerns. DPG used in rubber manufacturing causes a form of contact dermatitis referred to as "rubber itch", which is observed most often for workers involved in pigment blending, mixing, and extrusion. ${ }^{[5]}$

In the present study we focus on the effect of DPG and DPG alternatives on the silanization reaction in a model olefin system. The effect of $\mathrm{pKa}$ values of these amines is especially investigated. The kinetic parameters such as the rate constant and the activation energy are estimated according to the Arrhenius equation. Further, Payne effect measurements are done in silica-filled rubber. Then the function of amines in silica-filled rubber will be discussed. 


\subsection{Experimental}

\subsubsection{Sample preparation for the model compound study}

In the present study $\mathrm{n}$-decane was selected as a model alkane compound. Several different types of the amines having different pKa values were mixed in the reaction mixture. The amines are listed in Table 6.1. $0.2 \mathrm{~g}$ of silica, $2 \mathrm{ml}$ of $\mathrm{n}$-decane, $0.02 \mathrm{~g}$ of TESPT (Si69) and $9.47 \mathrm{mmol}$ of the amine were weighed in the reaction ampoule, as given in Figure 6.1. To react the mixtures, the following procedures were applied:

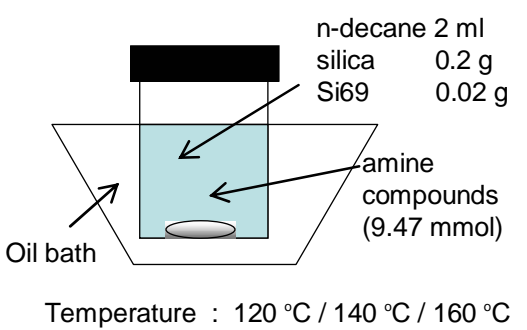

Figure 6.1 : Reaction set up of the model study

1. The ampoule including the reaction mixture was flushed with $\mathrm{N}_{2}$ before closure.

2. The ampoules were dipped into an oil bath at specified temperature for different reaction times.

3. After the reaction, the ampoules were cooled in an ice/water bath.

4. The ampoules were opened and the reaction mixture was taken from the ampoule.

5. $2 \mathrm{ml}$ of diethyleneglycol-monobutylether was added and stirred for 5 minutes to remove all physical-bonded silane on the silica surface.

6 . The reaction mixture was filtered by using a $45 \mu \mathrm{m}$ porous filter.

7. The filtered reaction mixture was diluted by a factor of ten with acetonitrile.

8. Quantitative determination of the free TESPT in the sample solution was done using HPLC.

Table 6.1 : Amines used in the present study

\begin{tabular}{lcc}
\hline Amine & pKa & symbol \\
\hline Quinuclidine & 11.5 & $\Delta$ \\
Ethylenediamine & 10.7 & $\boldsymbol{\bullet}$ \\
Quinuclidinol & 10.1 & $\square$ \\
1,3-Diphenylguanidine (DPG) & 10.1 & $\diamond$ \\
1,4-Diazabicyclo[2,2,2]octane (DABCO) & 8.80 & + \\
Picolinic amine & 7.70 & $\mathbf{\Delta}$ \\
2-Picoline & 5.90 & $\circ$ \\
Picolinic acid & 4.40 & $*$ \\
Picoline-N-oxide & 1.30 & $\bullet$ \\
\hline
\end{tabular}

All amines were obtained from Aldrich. 


\subsubsection{HPLC measurement}

A quantitative analysis of the remaining TESPT in the reaction mixtures was done according to the chromatographic conditions as given in Table 6.2.

Table 6.2 : Chromatographic conditions

\begin{tabular}{ll}
\hline Column & Nucleosil 100-5 C18 HD (reverse phase) \\
Length of column & $250 \mathrm{~mm}$ \\
Internal diameter of column & $4.6 \mathrm{~mm}$ \\
Mobile phase & Acetonitrile : water = $97: 3$ \\
Flow rate & $0.3 \mathrm{ml} / \mathrm{min}$ \\
Temperature & $23^{\circ} \mathrm{C}$ \\
Detector & UV (DAD) \\
Wavelength & $254 \mathrm{~nm}(200$ to $700 \mathrm{~nm})$ \\
Injection volume & $0.5 \mu \mathrm{l}$ \\
\hline
\end{tabular}

\subsubsection{Kinetic analysis}

For the kinetic parameters of the silanization reaction, the conversion of TESPT was estimated using LC measurements according to the chromatographic conditions as given in Table 6.2. A typical chromatogram of TESPT is shown in Figure 6.2.

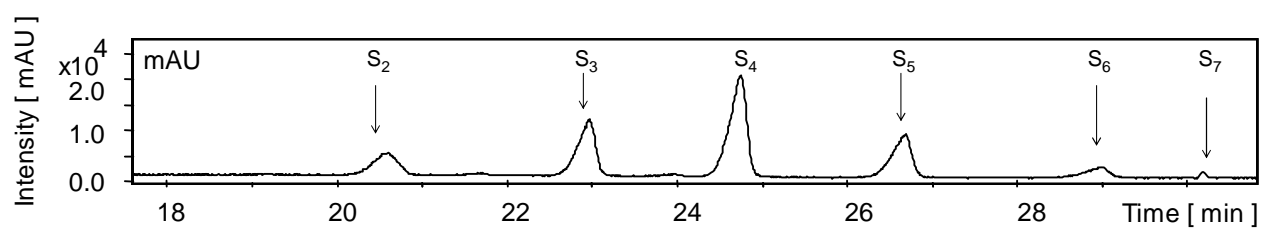

Figure 6.2 : Typical chromatogram of TESPT

In this figure the different types of polysulfide isomers of TESPT from $S_{2}$ to $S_{7}$ can be seen. The conversion of TESPT: $x_{c}$ can be calculated as follows:

$$
x_{c}=\frac{c(0)-c(t)}{c(0)}
$$

where $C(0)$ and $C(t)$ are the summed amounts of unreacted TESPT isomers at time 0 and time t, respectively.

In the present study, it was supposed that the silanization reaction can be described as a first order reaction. ${ }^{[3]}$ The kinetics of the silanization reaction can then be described by a simple model equation for the kinetic parameters. The rate constants $\mathrm{k}_{1}$ (primary reaction) and $\mathrm{k}_{2}$ (secondary reaction), and the activation energy $E_{a}$ of the silanization reaction: 


$$
\begin{gathered}
k=\frac{\ln \left(1-x_{c}\right)}{t}\left[\mathrm{~min}^{-1}\right] \\
\ln k=-\frac{E_{a}}{R T}+A \quad[\mathrm{~kJ} / \mathrm{mol}]
\end{gathered}
$$

where $\mathrm{k}$ is the rate constant of reaction, $\mathrm{t}$ is the reaction time, $\mathrm{T}$ is the absolute temperature. In a so-called Arrhenius plot the rate constant of the silanization reaction can be plotted on a logarithmic scale versus the inverse temperature; the slope of the straight line through the points gives the activation energy, divided by the Gas constant R.

\subsubsection{Rubber compound for Payne effect measurements}

The compound recipe for Payne effect measurements is based on the typical tire tread compound. The compound formulation is shown in Table 6.3. In the present study curatives are not applied. The amount of silane is employed according to equation 3.1 (Chapter 3). The amount of all amines is the same on molar basis: $9.47 \mathrm{mmol}$. Mixing was done in two steps without curatives. The different types of amines were mixed in the $1^{\text {st }}$ mixing step. The dump temperature at the $1^{\text {st }}$ mixing step was controlled at $150^{\circ} \mathrm{C}$ by adjusting the rotor speed. In addition, Zinc oxide was mixed in the $2^{\text {nd }}$ mixing step because the presence of zinc oxide results in premature scorch during the silanization reaction. ${ }^{[6]}$

Table 6.3 : Compound formulations

\begin{tabular}{llll}
\hline Component & Product name & Source & phr \\
\hline S-SBR* & Buna VSL5025 HM-1 & Lanxess & 103 \\
BR & Nipol 1220 & Nippon Zeon & 25.0 \\
Silica & Ultrasil VN3 & Degussa & 80.0 \\
Silane (TESPT) & Si69 & Degussa & 7.10 \\
Amine compounds & Listed in Table 6.1 & Listed in Table 6.1 & Variable (9.47 mmol) \\
Aromatic oil & Tudalen 3570A & Hansen \& Rosenthal & 4.40 \\
Zinc oxide & - & Merck & 2.50 \\
Stearic acid & - & Merck & 2.50 \\
\hline & & & $* 37.5$ phr oil extended
\end{tabular}

\subsubsection{Payne effect measurement (Storage modulus G' at 0.56\% strain)}

Payne effect measurements were done using a Rubber Process Analyzer RPA2000 from Alpha Technologies. The storage modulus at $0.56 \%$ strain for unvulcanized rubber was measured under the following conditions; temperature: $100^{\circ} \mathrm{C}$ and frequency: $0.5 \mathrm{~Hz}$. This measurement may be used as a measure of the Payne effect. ${ }^{[8,9]}$ 


\subsection{Results}

6.3.1 Effect of the various amines on the primary reaction of silanization in model experiments

The reaction conversions of TESPT at 120,140 and $160^{\circ} \mathrm{C}$ are shown in Figures 6.3 (a)-(c). In these figures the broken line shows an amine-free system.

In the presence of amines such as DPG, Quinuclidine and 3-Quinuclidinol the reaction conversion of TESPT drastically increases at the beginning of the silanization reaction and then increases at a slower pace. In addition, with increasing temperature a higher conversion of TESPT can be seen, particularly at the beginning of the reaction. As demonstrated by Görl et al., the increase of temperature accelerates the hydrolysis reaction of TESPT. ${ }^{[4]}$ 

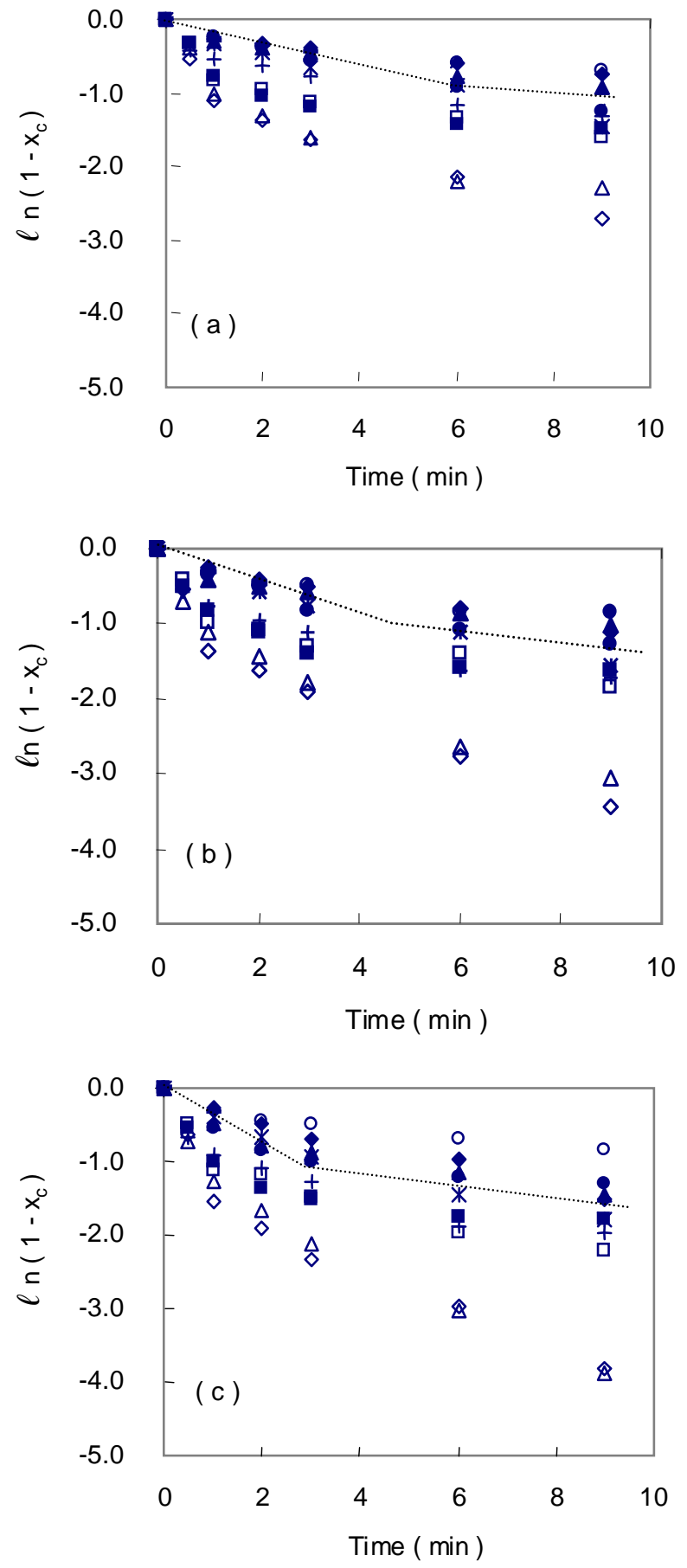

Figure 6.3 : Reaction conversion of TESPT during the reaction (a) : $120^{\circ} \mathrm{C}$; (b) : $140^{\circ} \mathrm{C}$; (c) : $160^{\circ} \mathrm{C}$

Symbols as in Table 6.1 ; Broken line (--- ) : Amine free 


\section{Chapter 6}

According to these authors, the fast increase of reaction conversion for TESPT at the beginning of the silanization is due to the primary reaction of TESPT, and the relatively slow conversion of TESPT later on is the result of the secondary reaction of TESPT in model olefin system. ${ }^{[3,4]}$ In addition, Kim et al. demonstrated that the hydrolysis reaction of TESPT is accelerated in the presence of water due to a bimolecular $\mathrm{S}_{\mathrm{N}} 2$ reaction. ${ }^{[10]}$ Amines generally are nucleophilic of nature and show dissociation behavior. These natures depend on the acid dissociation constant $\mathrm{pKa}$ of the amines.

The kinetic parameters of the primary reaction as a function of $\mathrm{pKa}$ values of the amines are shown in Figure 6.4.

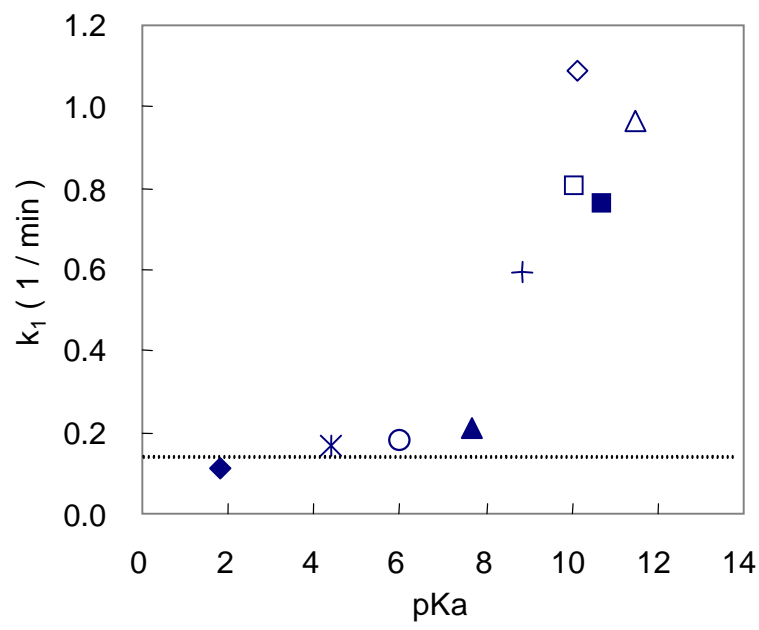

Figure 6.4 : Rate constant of the primary reaction as a function of the pKa values of the amines

Symbols as in Table 6.1; Broken line (---) : Amine free

The rate constant of the primary reaction of TESPT increases slowly till around $\mathrm{pKa}=6.5$ and then increases quickly with increasing $\mathrm{pKa}$ values of the amines. Especially for DPG, Quinuclidine and 3-Quinuclidinol, a high rate constant of the primary reaction can be seen. 
Figure 6.5 shows the activation energy of the primary reaction $E_{a}$ as a function of pKa value for the different amines. The activation energy $E_{a}$ decreases a little till around $\mathrm{pKa}=6.5$ and then suddenly decreases with increasing $\mathrm{pKa}$ value of the amines. For amines with high pKa value such as DPG, Quinuclidine and 3Quinuclidinol the activation energy decrease till approximately one third of the value for low pKa.

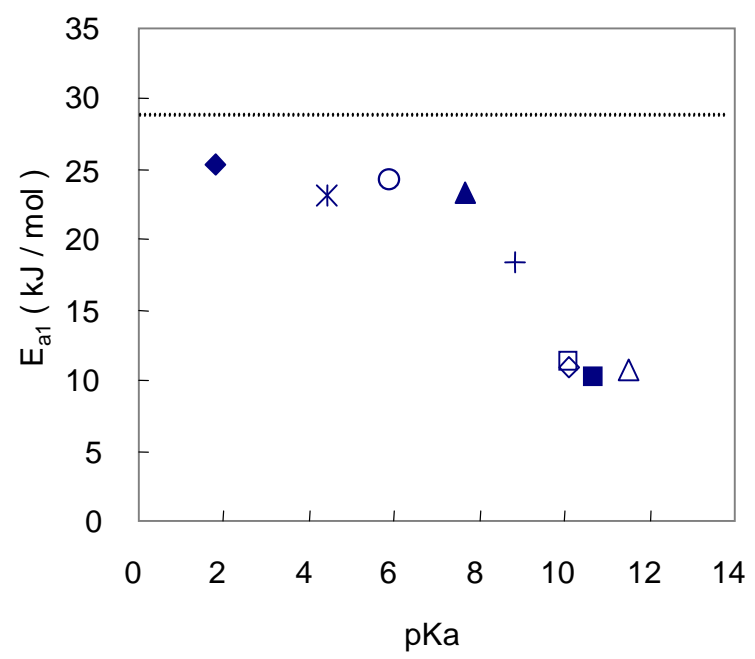

Figure 6.5 : Activation energy of the primary reaction as a function of the pKa values of the amines Symbols as in Table 6.1 ; Break line (---) : Amine free

Considering these results, it is clear that amines with high pKa act as promoters of the silanization reaction.

\subsubsection{Effect of the amine on the secondary reaction of silanization}

The secondary reaction is the condensation between adjacent ethoxy groups of TESPT which are already bound to the silica surface. In the present study the rate constant of the secondary reaction was estimated. Figure 6.6 shows the rate constant of the secondary reaction as a function of the pKa values of the amines. 


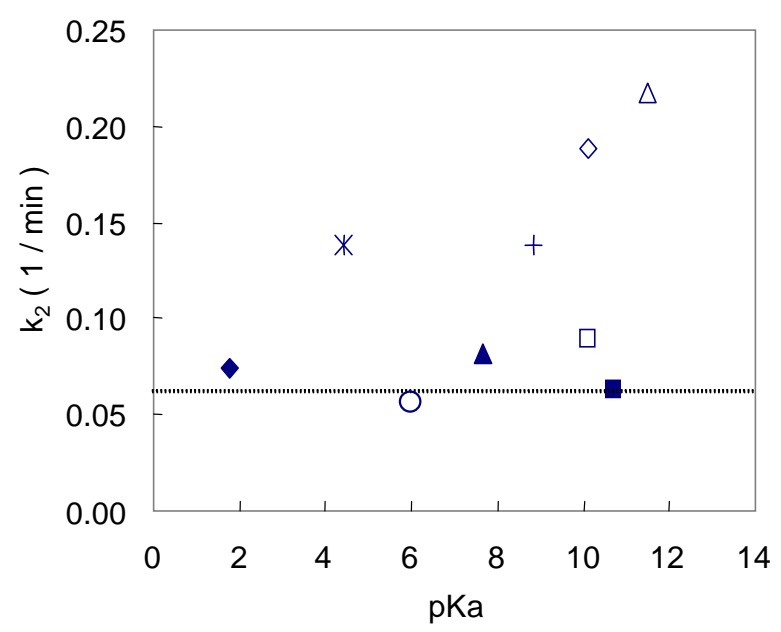

Figure 6.6 : Rate constant of the secondary reaction as a function of the pKa values of the amines Symbols as in Table 6.1 ; Break line (---) : Amine free

Although the data are scattered, the rate constants of the secondary reaction $\mathrm{k}_{2}$ tend to increase with increasing pKa value of the amines. The scattering in the results is due to the fact that the resolution in the chromatograms is insufficient to measure accurately because of the low concentration of TESPT at the end of the reaction. The rate constant of the secondary reaction $\mathrm{k}_{2}$ is relatively low compared to that of the primary reaction. This means that amines are mainly capable of promoting the primary reaction of TESPT with silica. 


\subsubsection{Effect of the pKa value for the amines on Payne effect in a silica reinforced rubber}

The storage modulus G' at the low strains (0.56\%), the so-called Payne effect, was also measured by using the Rubber Processing Analyzer (RPA2000). Figure 6.7 shows the Payne effect values, G' at $0.56 \%$ strain, as a function of pKa value of

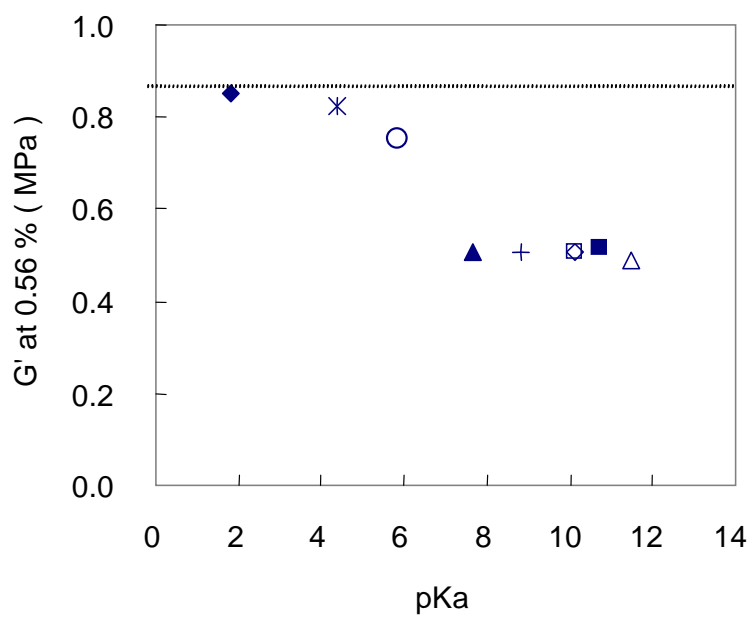

Figure $6.7:$ G' at $0.56 \%$ strain as a function of the pKa value of the amines Symbols as in Table 6.1 ; Broken line (---) : Amine free

the amines. G' at $0.56 \%$ strain decreases slowly till around $\mathrm{pKa}=6.5$ and then decreases quickly with increasing pKa of the amines. It is clear that a decrease of the $G^{\prime}$ at $0.56 \%$ is corresponding to an increasing rate constant and a decreasing activation energy of the primary reaction. Therefore, it was inferred that the amines with a pKa value of more than 6.5 can promote the silanization reaction in silicafilled rubber.

\subsection{Discussion}

\subsubsection{Promotion of the silanization reaction by amine compounds}

The first step of the silanization reaction is hydrolysis of one ethoxy group of TESPT at least to form an active silanol group. ${ }^{[4]}$ This hydrolysis step is rather slow, because the hydrolysis is the rate-determining factor for the silanization. ${ }^{[4,7,10,11]}$ Kim et al. proposed a mechanism for acid-catalyzed and base-catalyzed hydrolysis. ${ }^{[10]}$ This mechanism is described as a bimolecular $\mathrm{S}_{\mathrm{N}} 2$ type reaction of displacement of the leaving group. The rate of the hydrolysis reaction then depends on the presence of an acidic or alkaline medium. Therefore, the acidity of the silica surface could influence the silanization reaction.

In general, the acidity of the silica surface is a pH of around 6 to 7 . The dissociation of the amines could depend on the acidity of silica surface. The properties of amines such as nucleophilicity, dissociation behavior and steric hinderance depend on the pKa value of the amines. Actually, in the present study 


\section{Chapter 6}

the rate constant of the silanization reaction increases fast at pKa>6.5. Therefore, considering the influence of the $\mathrm{pKa}$ of the amines on the silanization, the following mechanisms can be proposed:

\section{Nucleophilic-activated hydrolysis; pKa of the amines $>6.5$}

For amines with high $\mathrm{pKa}$ value (pKa>6.5), it is proposed that the amines act as nucleophilic catalysts which enhance the release of an ethoxy group from TESPT. Taking this into account, the following pathways can be proposed. $A S_{N} 2$ reaction takes place in the presence of the amine and the amine acts as a proton transfer agent. As a result, the hydrolysis of TESPT proceeds via a pentacoordinateintermediate as shown in Figure 6.8.

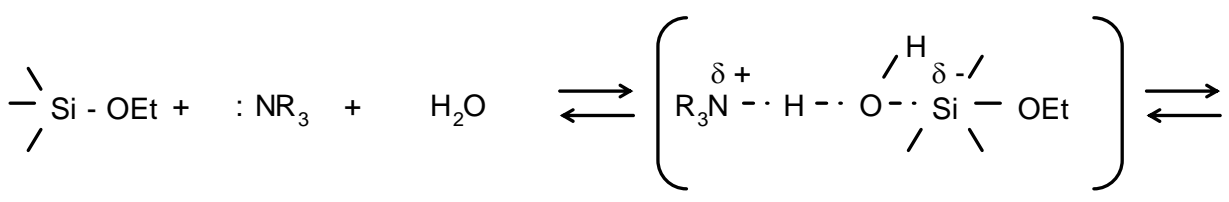

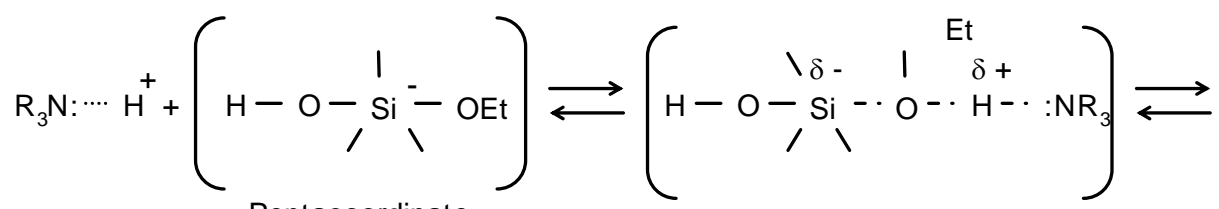

$$
\begin{aligned}
& \text { Pentacoordinate } \\
& \text { intermediate } \\
& \frac{1}{\mathrm{Si}-\mathrm{OH}}+: \mathrm{NR}_{3}+\mathrm{EtOH}
\end{aligned}
$$

Figure 6.8 : Reaction mechanism of nucleophilic-ac tiv ated hydrolysis[10]

In this reaction mechanism, the rate constant of hydrolysis on TESPT can increase in the amine present. 


\section{TESPT condensation; pKa of amine < pH of the silica surface}

Figure 6.9 represents the acid-catalyzed hydrolysis mechanism of TESPT. In this reaction mechanism, a pentacoordinate-intermediate with the incoming nucleophile and leaving group can be seen as well.

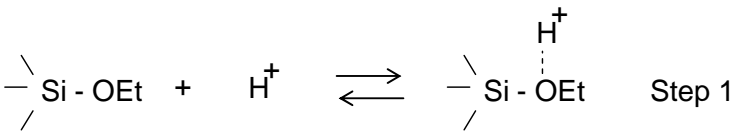

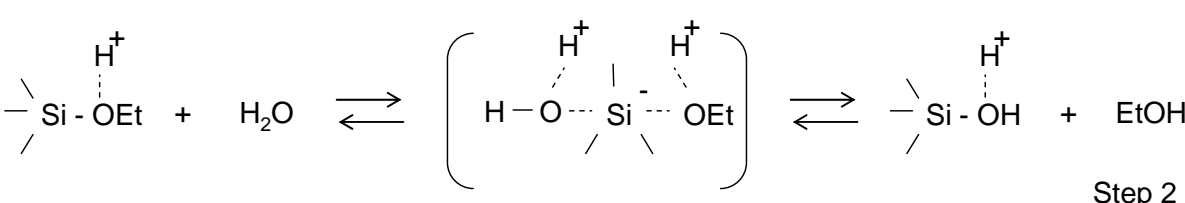

$$
\begin{aligned}
& \underset{/}{-} \stackrel{\mathrm{Hi}^{+}}{\mathrm{OH}^{+}} \stackrel{-}{\longleftarrow} \mathrm{Si}-\mathrm{OH}+\mathrm{H}^{+}
\end{aligned}
$$

Figure 6.9 : Reaction mechanism of acid catalyzed hydrolysis ${ }^{[10]}$

In case the pKa value of the amines is lower than 6.5 , which is lower than the $\mathrm{pH}$ value of the silica surface, the primary reaction is not accelerated, even in the presence of the amines. As a matter of fact, in the presence of amines with lower pKa vales, the condensation between adjacent ethoxy groups of TESPT could mainly be accelerated. This condensation is an undesirable reaction during rubber processing.

\subsection{Conclusions}

The influence of amines on the silanization kinetics was investigated in a model olefin system. The rate constant of the silanization reaction increases quickly in the presence of amines such as DPG, Quinuclidine and 3-Quinuclidinol, which have high acid dissociation constant $\mathrm{pKa}(>6.5)$. On the other hand, in the presence of amines with low pKa $(<6.5)$, no significant increase of the rate constant of the silanization reaction can be seen. For DPG, Quinuclidine and 3-Quinuclidnol, the rate constants of the silanization reaction approximately increase by a factor of six in comparison with the amine-free system.

The activation energy of silanization strongly depends on the pKa value of amines. The activation energy of the silanization reaction remains more or less unchanged till around $\mathrm{pKa}=6.5$ and then decreases fast with increasing pKa value of amines. For DPG, Quinuclidine and 3-Quinuclidinol, the activation energies approximately decrease till one third compared to the amine-free system. Considering these results, the amines with higher pKa value $(>6.5)$ act as catalysts for the silanization reaction. 
The secondary reaction resulting from condensation of TESPT is slightly accelerated in the presence of amines. However, the rate constant of the secondary reaction is rather slow compared to that of the primary reaction.

For the promotion of hydrolysis which is the rate determining step of the silanization reaction, a nucleophile-activated reaction and direct bonding of the amine- $\mathrm{H}_{2} \mathrm{O}$ complex to TESPT was proposed.

\subsection{References}

1. W. David, U.S. Pat. 6.951.897 to Michelin Recherche et Technique S.A., (2307-2002)

2. W. Katarzyna, U.S. Pat. $6,984,689$ to Michelin Recherche et Technique S.A.,(23-07-2002)

3. A. Hunsche, U. Görl, A. Müller, M. Knaak, T. Göbel, Kautsch. Gummi Kunstst., 50, 881 (1997)

4. U. Görl , A. Hunsche, A. Müller, H.G. Koban, Rubber Chem. Technol., 70, 608 (1997)

5. R. D. Irwin, National toxicology program report, North Carolina, USA, NTP technical report \#42 (1995)

6. Reuvekamp. L.A.E.M., "Reactive mixing of silica and rubber for tires and engine mounts", Thesis: 2003, Dept. Elastomer Technology and Engineering., Univ Twente: Enschede

7. A. Hunsche, U. Görl, H.G. Koban, T. Lehmann, Kautsch. Gummi Kunstst., 51, 525 (1998)

8. A.R. Payne, Rubber Chem. Technol., 39, 365 (1966)

9. A. Coran, J. Donnet, Rubber Chem. Technol., 65, 1016 (1992)

10. K. J. Kim, J. Vanderkooi, Rubber. Chem Technol. 78, 84 (2005)

11. F. Beari, J. Organometallic Chem., 625, 208 (2001) 


\section{Chapter 7}

\section{REINFORCEMENT MECHANISM OF SILICA WITH ALTERNATIVES FOR DPG: PART 2}

\section{EFFECT OF AMINES ON SILANE CHEMISTRY IN RUBBER PROCESSING}

Silane chemistry plays an important role in reinforcement of silica filled rubbers. It is well known that the silanization reaction is accelerated by an amine compound, in particular 1,3-diphenyl-guanidine (DPG).

In the present study the influence of amines: DPG, quinuclidine and 3-quinuclidinol on the reactions between TESPT and two unsaturated model-olefins: 2,3-dimethyl-2butene(TME) and 3-methyl-1-pentene(3-m-1-p), and between TESPT and DPG in absence of silica is investigated using model experiments and subsequent analysis with LC-MS.

Even without free elemental sulfur present, the amount of cross-linked products between the model olefins significantly increases in the presence of amines and particularly DPG. The tri-sulfide isomer of TESPT significantly increases in the presence of the amines, which contributes to a sulfur-donor effect of TESPT. Additionally, the LC-MS experiments demonstrate that the presence of the amines: $D P G$, quinuclidine and 3-quinuclidinol accelerates the silane/model olefins coupling, and that DPG itself also reacts with TESPT during processing. Therefore, a significant amount of DPG could be consumed during regular rubber processing due to this mutual TESPT-DPG reaction. 


\subsection{Introduction}

The chemistry of silane coupling agents during rubber processing is an important factor for silica reinforced rubbers. Bis-(triethoxysilylpropyl)tetrasulfide (TESPT) is widely used as coupling agent for silica-reinforced tire applications. For TESPT several chemical reactions can take place during rubber processing. Hunsche et al. proposed a mechanism for silica-silane coupling (primary reaction), as well as for the condensation of TESPT with itself (secondary reaction) during processing ${ }^{[1]} \mathrm{A}$ kinetic study regarding these two reactions was done by Görl et al ${ }^{[2]}$ According to this study, the rate constant of the primary reaction is about 10 to 20 times higher compared to that of the secondary reaction. Additionally, the activation energy of the primary reaction was calculated to amount to $47 \mathrm{~kJ} / \mathrm{mol}$. Debnath and Reuvekamp et al. demonstrated that a cross-linking reaction between the silane and the rubber polymers takes place as measured in a model olefin system, even in absence of elemental sulfur. ${ }^{[3,4]}$ In addition, a TESPT-model olefin complex was observed.

It was reported that TESPT can possibly react with the rubber matrix during vulcanization in different ways. By Görl and Luginsland et al. the following reaction mechanism during vulcanization was proposed. ${ }^{[5,6]}$ First, the sulfur rank distribution in TESPT thermo-sensitively changes during the heating process and consequently an increase of the tri-sulfide moiety of TESPT at the expense of the poly-sulfide can be seen. Second, after the change of the sulfur rank distribution in the TESPT molecule a cure accelerator such as CBS may react with the polysulfide chain in TESPT. Third, the TESPT may incorporate part of free elemental sulfur present in the rubber compound. All these reactions contribute to the TESPT-polymer coupling during vulcanization.

It is well known that the silanization reaction of silica by silane requires the presence of an amine compound, commonly DPG. The present chapter focuses on the role of amines during silica/silane processing. Amines with high pKa may promote the silanization reaction of the silica, but also the cross-linking reaction afterwards. Furthermore, it has been suggested that a mutual reaction between DPG and TESPT takes place during processing. A model olefin compound study is applied in an attempt to independently monitor all these reactions. The reactions between TESPT and DPG and between TESPT and two unsaturated model-olefins in absence of silica will be monitored, making use of Liquid Chromatography Mass Spectroscopy (LC-MS) to analyze the pertinent reaction products. 


\subsection{Experimental}

\subsubsection{Sample preparation}

\subsubsection{Model compounds:}

The Unsaturated compounds 2,3-dimethyl-2-butene called tetra-methyl ethylene (TME), and 3-methyl-1-pentene (3-m-1-p) were used for the study of the reactions with TESPT and between TESPT and DPG. The chemical structures are shown in Figure 7.1 .

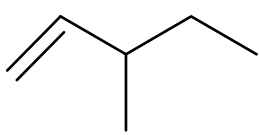

3-methyl-1-pentene

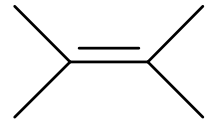

2,3-dimethyl-2-butene

Figure 7.1 : Molecular structure of model olefins

TME and 3-m-1-p have resemblances with the ethylene- and vinyl-structures of the butadiene units in SBR. The materials, which were used during the experiments, are listed in Table 7.1. Amines, which are capable of accelerating the silanization reaction as described in Chapter 5, were applied in the present study.

Table 7.1: Composition of reaction mixtures (g)

\begin{tabular}{lcccccccc}
\hline & \multicolumn{1}{c}{ Mixture 1} & Mixture 2 & Mixture 3 & Mixture 4 & Mixture 5 & Mixture 6 & Mixture 7 \\
\hline 2,3-dimethy-2-butene(TME) & 0.4000 & 0.4000 & 0.4000 & 0.4000 & - & - & - \\
3-methy-1-pentene(3-m-1p) & - & - & - & - & 0.4000 & 0.4000 & 0.4000 \\
TESPT & 0.0320 & 0.0320 & 0.0320 & 0.0320 & 0.0320 & 0.0320 & 0.0320 \\
Quinuclidine & - & 0.0037 & - & - & 0.0037 & - & - \\
3-Quinuclidinol & - & - & 0.0042 & - & - & 0.0042 & - \\
Diphenylguanidine(DPG) & - & - & - & 0.0071 & - & - & 0.0071 \\
\hline
\end{tabular}

\subsubsection{Reaction procedure:}

Reaction mixtures as listed in Table 7.1 were used, where the different amounts of the various amines represent equimolar quantities. The amount of the amines in the reaction mixture is according to the fuel-saving green tire technology. The mixtures were weighed into special glass reaction ampoules as shown in Figure 7.2. Also a magnetic stirrer was included in the ampoules. The ampoules were flushed with nitrogen and sealed by melting the neck. To react the mixtures, the following procedure was applied: 
The ampoules were dipped into an oil bath at specified temperature for different reaction times.

1. After the reaction, the ampoules were cooled down in an ice/water bath.

2. The ampoules were opened and the reaction mixture was taken from the ampoule.

3. The reaction mixture was filtered by using a $45 \mu \mathrm{m}$ porous filter.

4. The filtered reaction mixture was diluted by a factor of ten with acetonitrile.

5. A quantitative determination of the free TESPT in the sample solution was done using HPLC.

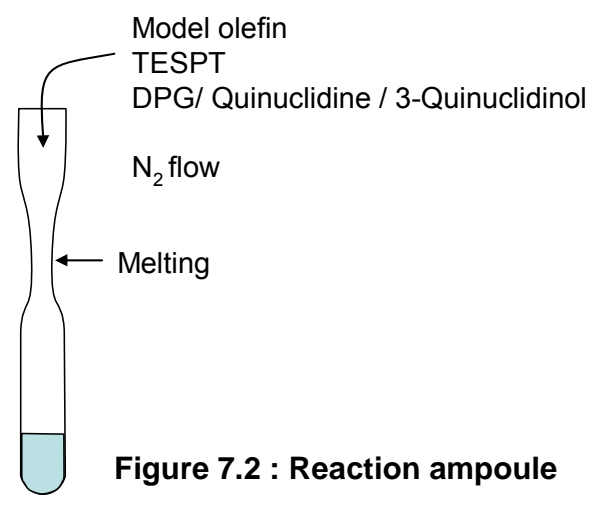

\subsubsection{LC-MS analysis}

High Pressure Liquid Chromatography measurements were done according to the chromatographic conditions as given in Table 7.2. An Atmospheric Pressure

Table 7.2 : HPLC and MS conditions

\begin{tabular}{ll}
\hline HPLC conditions & \\
Column & Nucleosil 100-5 C18 HD (reverse phase) \\
Length of column & $250 \mathrm{~mm}$ \\
Internal diameter & $4.6 \mathrm{~mm}$ \\
Mobile phase & Acetonitrile : water = $97: 3$ \\
Flow rate & $0.3 \mathrm{ml} / \mathrm{min}$ \\
Temperature & $23^{\circ} \mathrm{C}$ \\
Detector & $\mathrm{UV}(\mathrm{DAD})$ \\
Wavelength & $254 \mathrm{~nm}(200$ to $700 \mathrm{~nm})$ \\
Injection volume & $0.5 \mathrm{ml}$ \\
& \\
MS ionization conditions in APCl \\
Flow rate & $20 \mathrm{ml} / \mathrm{min}$ \\
Nebuliser gas pressure $25 \mathrm{psi}$ \\
Dry gas flow & $3 \ell / \mathrm{min}$ \\
Dry gas Temp. & $320{ }^{\circ} \mathrm{C}$ \\
Vaporise Temp. & $425{ }^{\circ} \mathrm{C}$ \\
\hline
\end{tabular}

Chemical Ionization (APCl) interface was applied for ionization of the reaction products and mass spectroscopic analysis of the ions. APCI uses a reagent ion to 
react with the target molecules and form ions by protonation. Therefore, the peak from the target molecule $M$ in the mass spectra can be found with the molar mass $\mathrm{M}+1$ because the $[\mathrm{M}+\mathrm{H}]^{+}$-ion is formed.The ionization conditions are shown in Table 7.2.

\subsection{Results and Discussion}

\subsubsection{Influence of amines on crosslinking reaction between the model olefins}

Debnath et al. proposed that a crosslinked product is formed as shown in Figure 7.3 , due to the insertion of sulfur released from TESPT during the reaction of the model olefin system. ${ }^{[4]}$

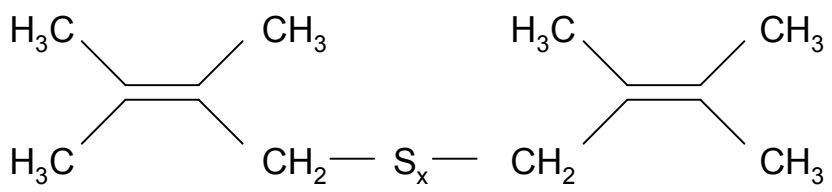

Figure 7.3 : Crosslinked product between TME

In the formation of this cross-linked product, an accelerator such as CBS is capable of accelerating the cross-linking reaction. A typical chromatogram of a cross-linked reaction mixture of TME is shown in Figure 7.4.

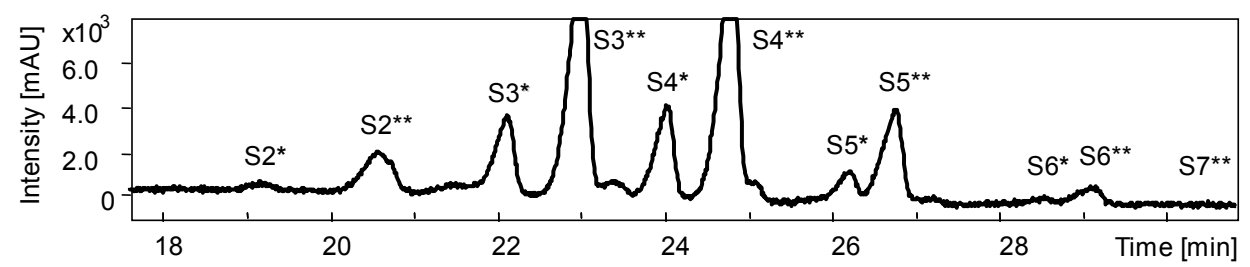

Figure 7.4 : Typical chromatogram of reaction mixture

* : Cross-linked products of TME

**: TESPT

The peaks of the crosslinked products, as characterized by Debnath et al., are indicated in Figure 7.3 with an asterisk. A variety of sulfur ranks are present, even though elemental sulfur was not applied in the mixtures.

Debnath et al. demonstrated that TESPT acts as a sulfur donor, even in the absence of cure accelerators. The formation of the cross-linked products in the present study results from this sulfur donor effect of TESPT. In addition, it was reported that the donated sulfur coming from TESPT is more active compared to normal elemental sulfur used in compounding. ${ }^{[4]}$ 
Figures 7.5(a) and (b) show the total summed peak areas of the sulfur cross-linked products for the mixtures in Table 7.1 as a function of reaction time. For both olefins, the total summed peak areas of the cross-linked products increase with longer reaction times. In the presence of amines the increase of the cross-linked products is much faster compared to the amine-free system. It confirms that TESPT is capable of thermally reacting with rubber during processing at excess temperature, even in the absence of cross-linking agent. ${ }^{[3,4]}$ This reaction between the sulfur released from TESPT and the rubber leads to the well known processing difficulties due to premature crosslinking or scorch during silica rubber processing. ${ }^{[3]}$
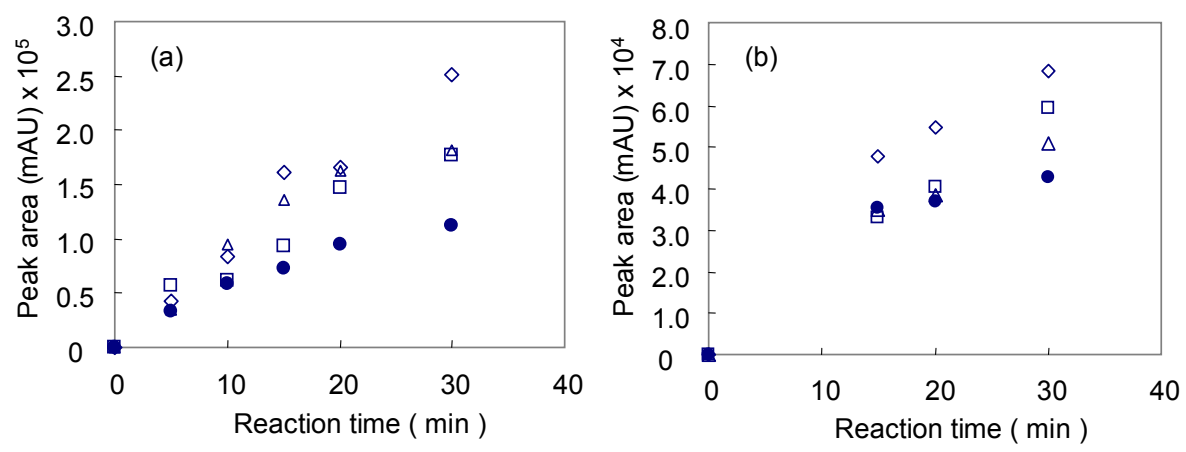

Figure 7.5 : Total peak areas of cross-linked products at $140 \circ \mathrm{C}$ as a function of the reaction time (a) : TME with TESPT ; ( b ) : 3-methyl-1-pentene with TESPT

$(\bullet)$ : Amine free $;(\Delta):$ Quinuclidine $;(\square): 3$-Quinuclidinol ; $(\diamond)$ : DPG

\subsubsection{Influence of amines on thermal stability of the polysulfide in TESPT}

The spontaneous cross-linking reaction by TESPT as shown in the previous paragraph strongly depends on the reaction temperature and the presence of DPG. At the temperatures applied in the present study and without elemental sulfur used, it was demonstrated that TESPT acts as a sulfur donor. Considering this, the sulfur rank distribution in TESPT could also change during the reaction. Figures 7.6(a)(d) show the sulfur rank distributions of TESPT in the presence of TME with the amines, as a function of reaction time at $140^{\circ} \mathrm{C}$. 

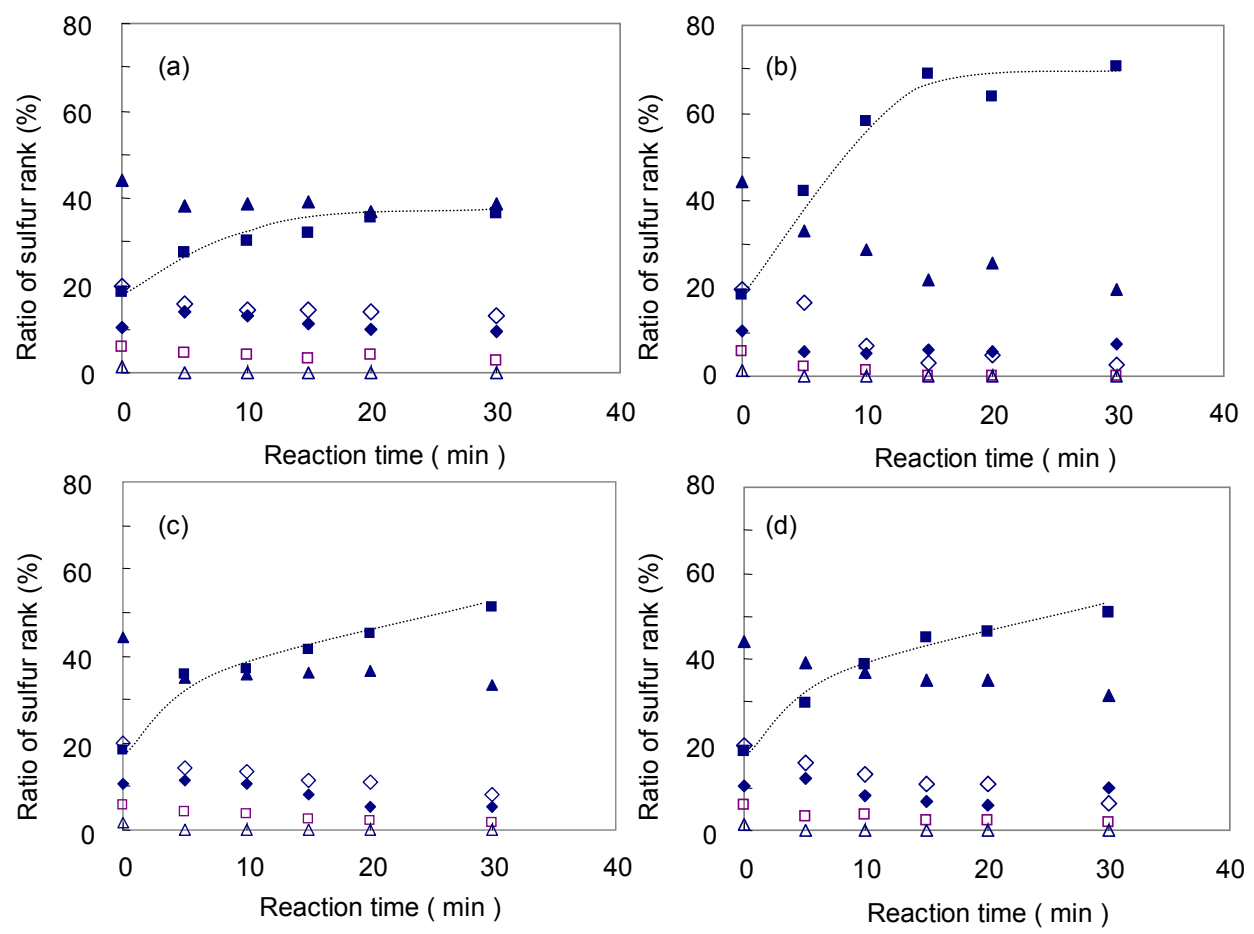

Figure 7.6 : Sulfur rank ratio (2-7) of TESPT in the presence of TME at $140{ }^{\circ} \mathrm{C}$ as a function of the reaction time

(a) : Amine free ; ( b ) : Quinuclidine ; (c) : 3-Quinuclidinol

(d) : DPG

$(\diamond): \mathrm{S} 2 ;(\bullet): \mathrm{S} 3 ;(\triangleleft): \mathrm{S} 4 ;(\diamond): \mathrm{S} 5 ;(\square): \mathrm{S} 6 ;(\Delta): \mathrm{S} 7$

For all mixtures an increase of the tri-sulfide variant of TESPT at the expense of the tetra-sulfide and di-sulfide can be seen. Due to the presence of amines the increase of the tri-sulfide is relatively faster compared to the amine-free system. Especially quinuclidine shows a significant increase of the tri-sulfide in TESPT. For the poly-sulfides with $\geq S_{5}$, no significant differences can be seen. 
Figure 7.7 shows the average sulfur rank as a function of reaction time.

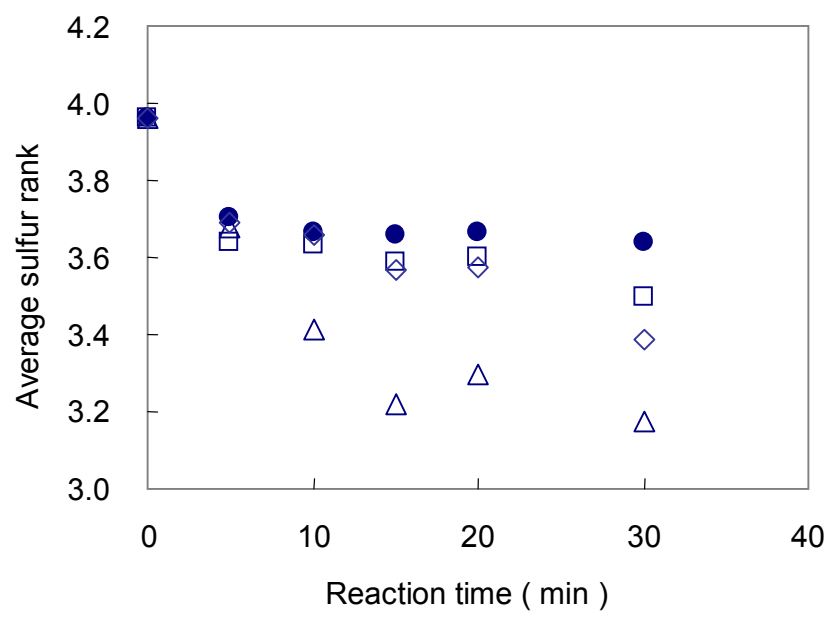

Figure 7.7 : Average sulfur rank of TESPT in the presence of TME at $140^{\circ} \mathrm{C}$ as a function of the reaction time

$(\bullet)$ : Amine free $;(\Delta)$ : Quinuclidine ;

() : 3-Quinuclidinol ; $(\diamond)$ : DPG

For all of the reaction mixtures, the average sulfur rank decreases with increasing reaction time due to the presence of amines. In the presence of amines, the decrease of the average sulfur rank is relatively faster compared to the amine-free system. It is interesting to see that quinuclidine shows the most drastic decrease of the average sulfur rank. This decrease of the average sulfur rank corresponds to the release of sulfur atoms, resulting in the generation of the active sulfur in the reaction system. This active sulfur is then capable of forming the cross-linked products between the model olefins. 


\subsubsection{Influence of amines on reaction of TESPT with model olefin compounds}

By using LC-MS, the formation of TESPT-model olefin complexes was studied. The results of LC-MS measurements done with several reaction mixtures at $140{ }^{\circ} \mathrm{C}$ for 30 minutes are shown in Figures 7.8(a)-(f) and Figure 7.9(a)-(f).

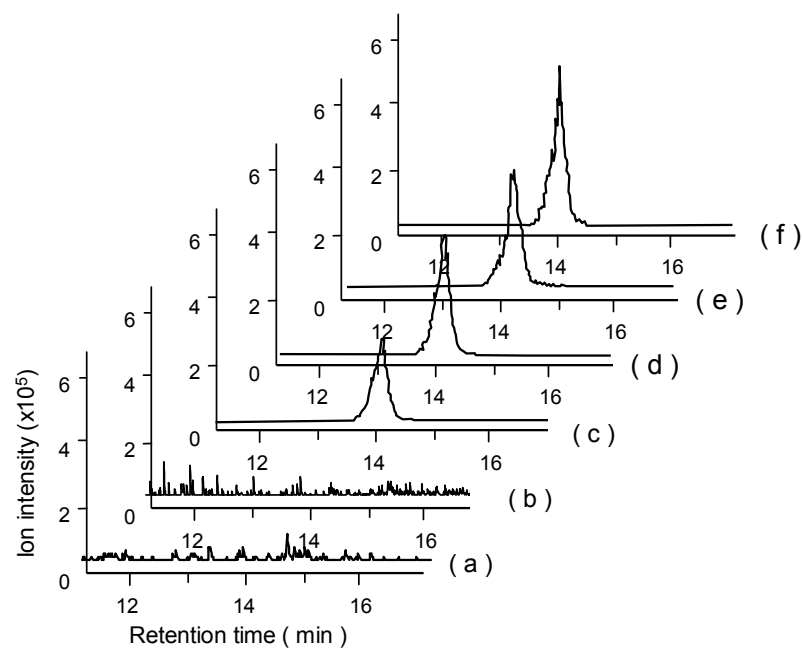

Figure 7.8 : Extracted ion chromatogram at $323 \mathrm{~m} / \mathrm{z}$ of the TME-TESPT complex after reaction at $140{ }^{\circ} \mathrm{C}$ for 30 minutes

( a ) : TME ; ( b ) : TESPT+DPG ; ( c ) : TME+TESPT ; ( d ) : TME+TESPT+Quinuclidine ;

(e) : TME+TESPT+3-Quinuclidinol ; ( f ) TME+TESPT+DPG

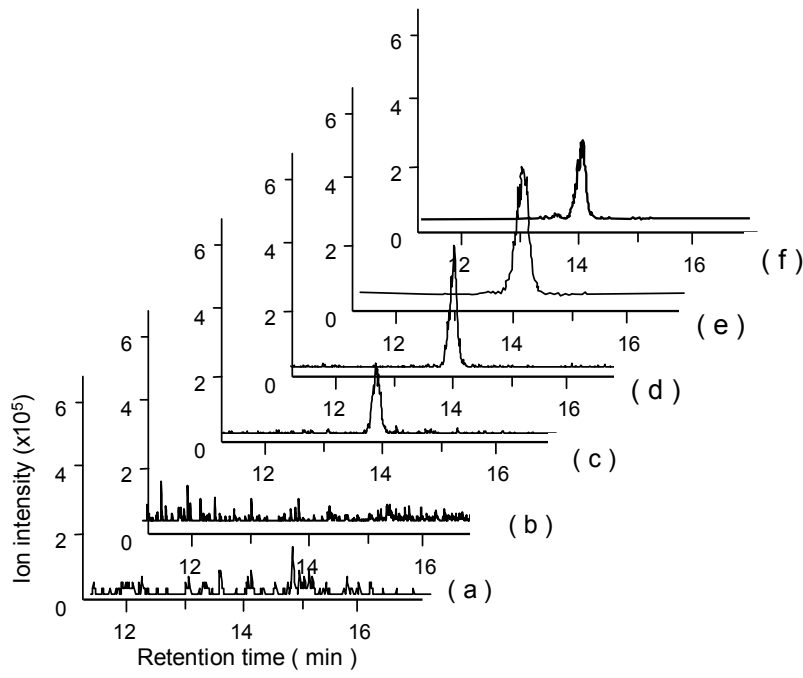

Figure 7.9 : Extracted ion chromatogram at $323 \mathrm{~m} / \mathrm{z}$ of the 3-methyl-1-pentene-TESPT complex after reaction at $1400^{\circ} \mathrm{C}$ for 30 minutes
( a ) : 3-m-1-p ; ( b ) :TESPT+DPG ; ( c ) : 3-m-1-p +TESPT ;
(d ) : 3-m-1-p+TESPT+Quinuclidine ; ( e ) : 3-m-1-p +TESPT+3-Quinuclidinol ;
(f ) 3-m-1-p +TESPT+DPG 
Only in those mixtures wherein the model olefins and TESPT are jointly present, the model olefin compound spectrum shows the presence of a reaction product with $323 \mathrm{~m} / \mathrm{z}$.

No other peaks can be seen if either one is absent.
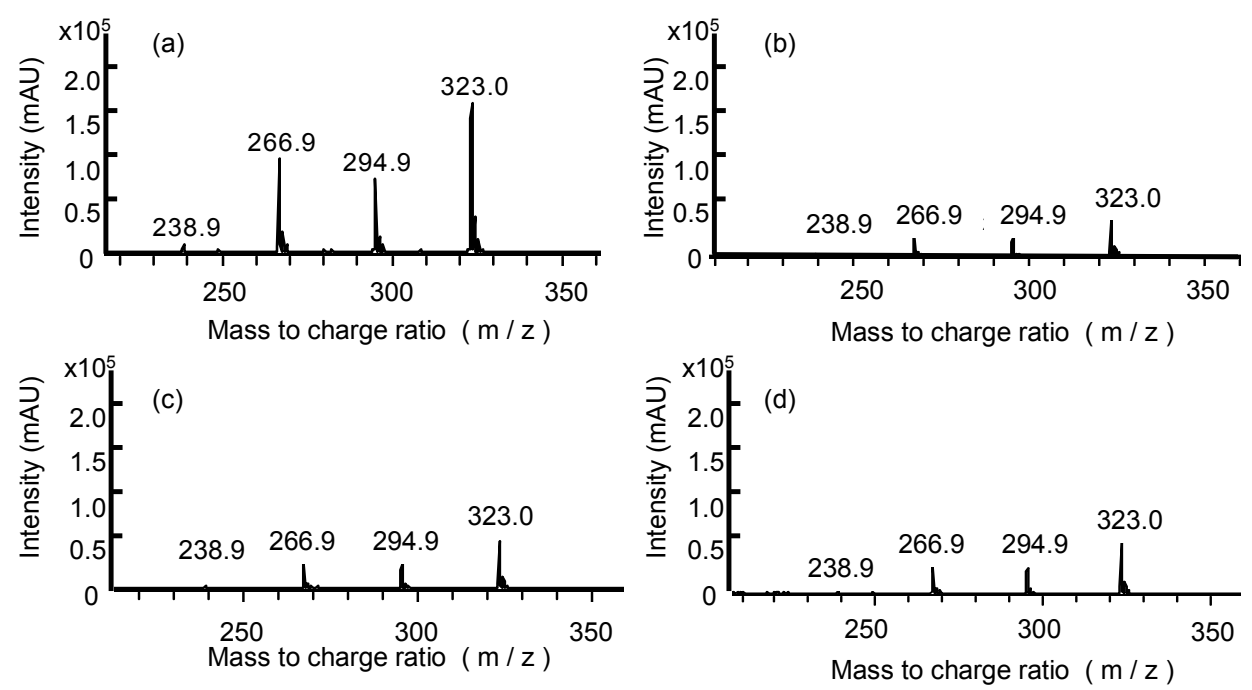

Figure 7.10 : Fragmentation pattern of fraction with $323 \mathrm{~m} / \mathrm{z}$ after reaction at $140{ }^{\circ} \mathrm{C}$ for 30 minutes

(a ) : TME+TESPT ; ( b ) : TME+TESPT+Quinuclidine ;

(c) : TME+TESPT+3-Quinuclidinol ; ( d ) : TME+TESPT+DPG
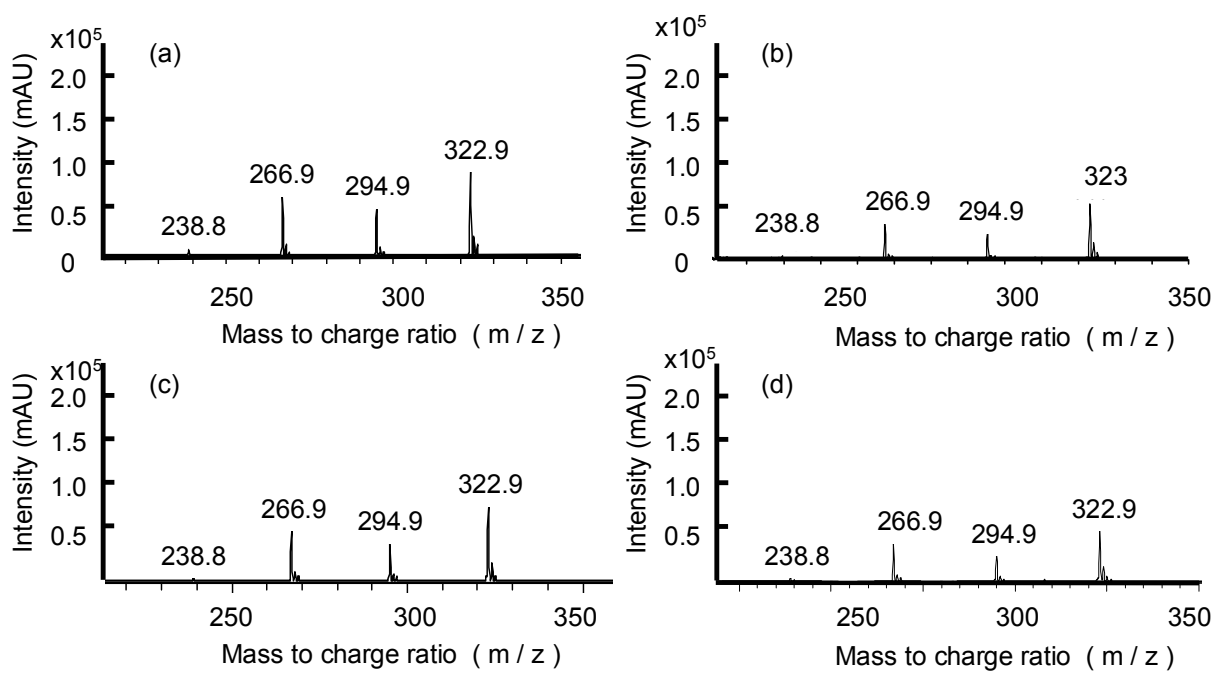

Figure 7.11 : Fragmentation pattern of fracion with $323 \mathrm{~m} / \mathrm{z}$ after reaction at $140{ }^{\circ} \mathrm{C}$ for 30 minutes

( a ) : 3-m-1-p + TESPT ; ( b ) : 3-m-1-p + TESPT+Quinuclidine ;

( c ) : 3-m-1-p + TESPT + 3-Quinuclidinol ; ( d ) : 3-m-1-p + TESPT + DPG

To make sure that the ion extracted peak of $323 \mathrm{~m} / \mathrm{z}$ corresponds to the TESPTmodel olefin complex, further fragmentation of this peak using the MS was done 
for the TME-TESPT complex. Masses of $295 \mathrm{~m} / \mathrm{z}, 267 \mathrm{~m} / \mathrm{z}$ and $239 \mathrm{~m} / \mathrm{z}$ coming from the TESPT-TME or TESPT-3-m-1-p complex are obtained, as shown in Figures 7.10(a)-(d) and Figures 7.11(a)-(d).

In the LC-MS measurement using $\mathrm{APCl}$ an acetonitrile/water mixture is used as mobile phase. Therefore, protonated model olefin/TESPT complexes $\left[\mathrm{M}+\mathrm{H}^{+}\right]$can be detected as shown in Figures 7.12 (a) and (b).

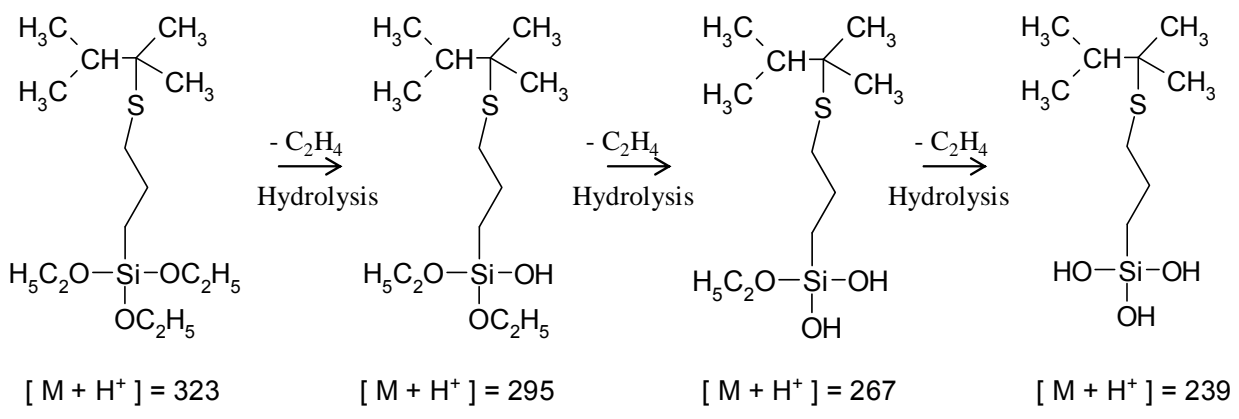

Figure 7.12 : Possible structure of TME-TESPT complex according to the fraqment with $323 \mathrm{~m} / \mathrm{z}$

This decrease with each time $28 \mathrm{~m} / \mathrm{z}$ can be related to progressive hydrolysis of the ethoxy groups of the TESPT moiety. TESPT can split in its polysulfide chain during the reaction, resulting in the generation of radical species. The radicals are capable of reacting with the double bond of the model olefins directly. From a radical-stability point of view, the allylic position on the model olefins can also possibly react with the splitted TESPT. However, the obtained masses in the fragmentation pattern do not correspond to the model olefin/TESPT complexes bonded on the allylic position in the model olefins.

Considering these results of the LC-MS analysis, the structures for the model olefin/TESPT complexes can be proposed as shown in Figures 7.13(a) and (b).
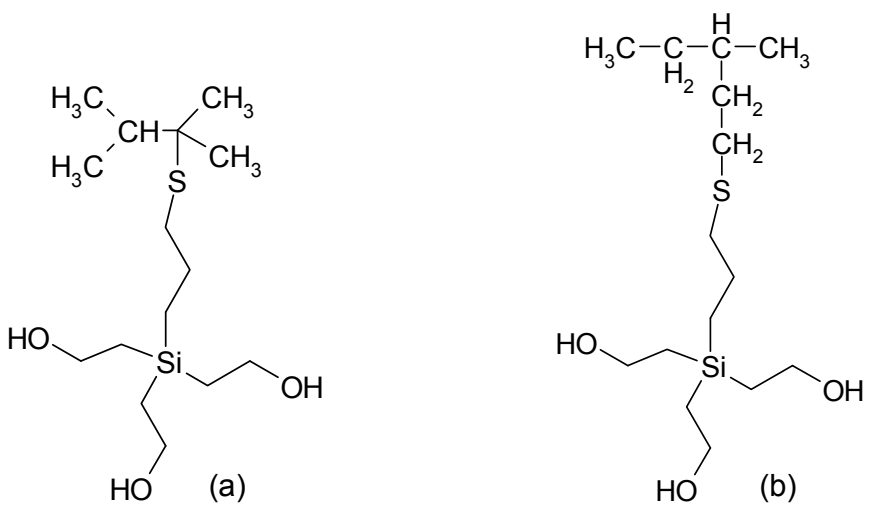

Figure 7.13 : Possible structure according to the extracted ion chromatogram at $323 \mathrm{~m} / \mathrm{z}$

( a ) : TME-TESPT complex ; ( b ) : 3-m-1-p-TESPT complex 
For these two structures it looks like the reactive site is not the allylic position in the model olefin compound. Thun and Wolff already demonstrated that triethoxysilylpropylthiol is capable of reacting with rubber. $^{[7]}$ The reaction mechanism of triethoxysilylpropylthiol with the polymer was proposed by Gorski and Klemm. ${ }^{[8]}$ According to their mechanism, an addition reaction of the thiol group to the double bond takes place regioselectively at the vinyl- and the cisconfigurations of the polymer.

The amount of the two TESPT-model olefin complexes increases with increasing reaction time as shown in Figures 7.14(a) and (b). Again, the formation of the TESPT-model olefin complexes is accelerated by the presence of DPG and to a lesser extent by quinuclidine and 3-quinuclidinol.
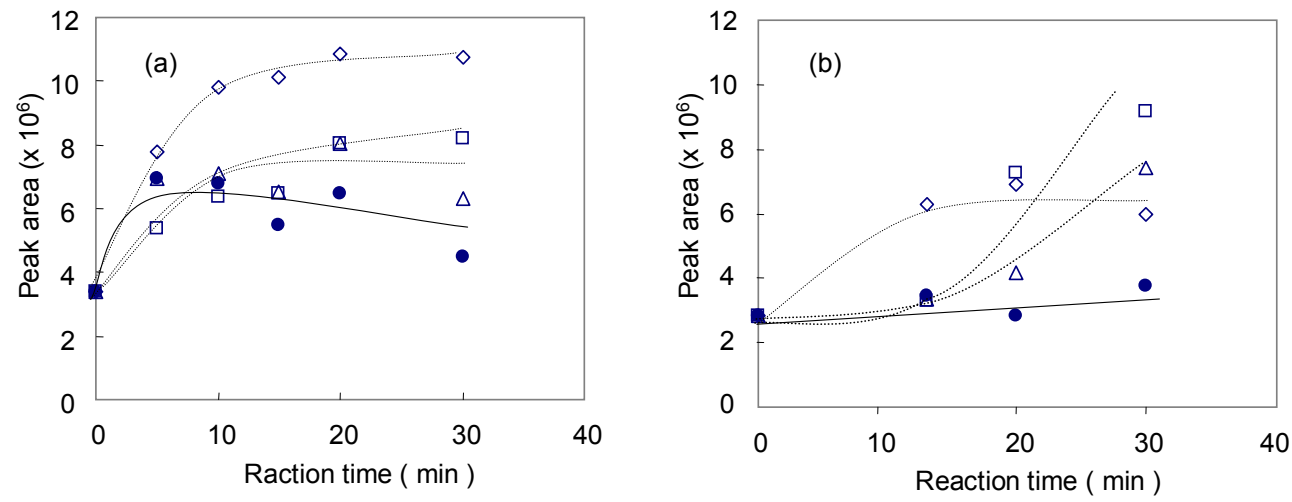

Figure 7.14 : Total peak area of TESPT-model olefin complex at $140^{\circ} \mathrm{C}$ as a function of the reaction time

(a) : in TME ; (b) : in 3-m-1-p

$(\bullet)$ : Amine free ; $(\Delta)$ : Quinuclidine ; $(\square)$ : 3-Quinuclidinol ; $\diamond)$; DPG 


\subsubsection{Reaction of DPG with TESPT}

DPG may be denoted as a secondary accelerator in silica reinforced rubber. According to Görl and Luginsland et al., an accelerator such as CBS is also capable of reacting with TESPT. ${ }^{[5,6]}$ Therefore, in the present study we studied the mutual reaction of the amines DPG, quinuclidine and 3-quinuclidinol with TESPT in the model olefin system as well. Figures 7.15(a) and (b) show the extracted ion chromatograms of $530 \mathrm{~m} / \mathrm{z}$ for several combinations of the reaction mixtures.
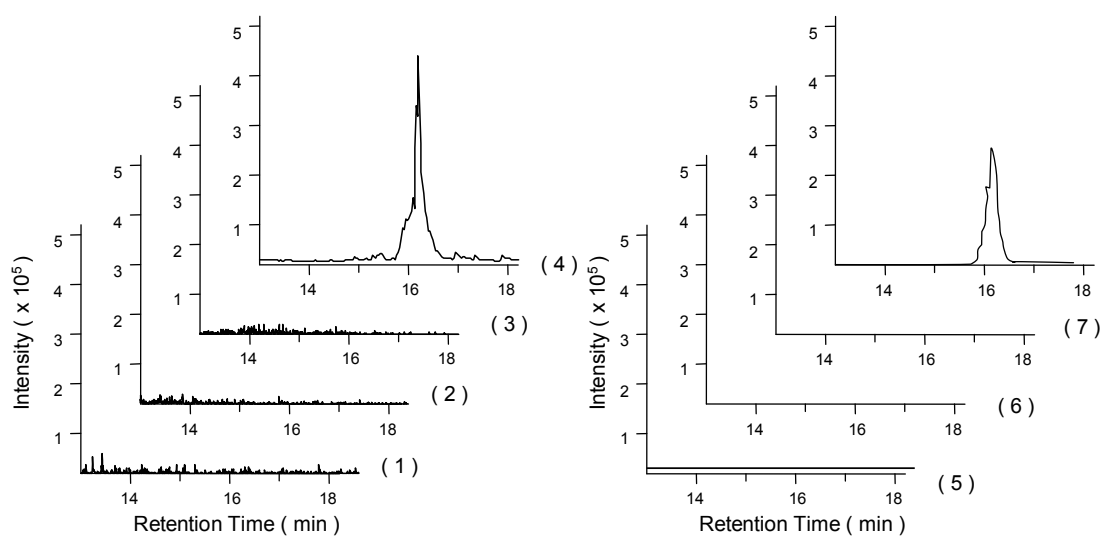

( 8 )

Figure 7.15 : Extracted ion chromatogram for $530 \mathrm{~m} / \mathrm{z}$ of TESPT-DPG complex after reaction at $140{ }^{\circ} \mathrm{C}$ for 30 minutes

(1) : TESPT + TME ; (2) : TESPT+TME + quinuclidine ;

(3) : TESPT+TME + 3-quinuclidinol ; (4) : TESPT + TME+DPG ;

(5) : TESPT + 3-m-1-p ; (6) : TESPT + 3-m-1-p + quinuclidine ;

(7) : TESPT + 3-m-1-p + 3-quinuclidinol ; (8) : TESPT + 3-m-1-p + DPG

In the presence of DPG an extracted ion peak of $530 \mathrm{~m} / \mathrm{z}$ can be seen. For this extracted ion peak, further fragmentation was done to make sure that this represents the DPG-TESPT complex. Figures 7.16(a)-(c) show the fragments of $530 \mathrm{~m} / \mathrm{z}$.

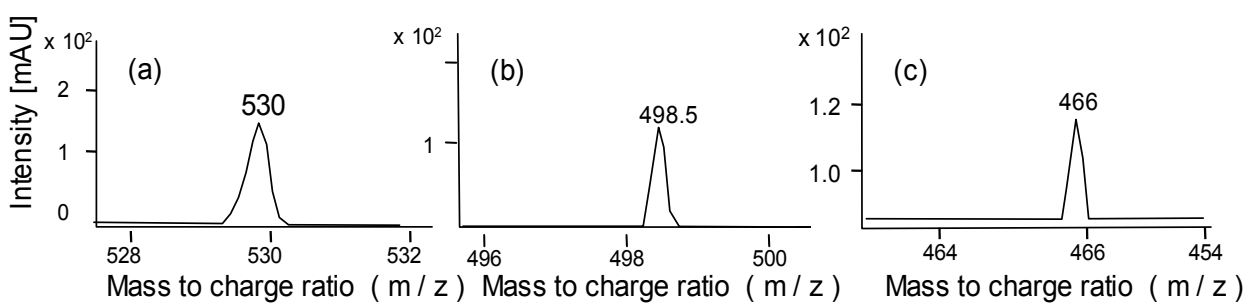

Figure 7.16 : Fragments of model TESPT-DPG complex due to elimination of sulfur ( a ) : $530 \mathrm{~m} / \mathrm{z}$; ( b ) : $498 \mathrm{~m} / \mathrm{z}$; ( c ) : $466 \mathrm{~m} / \mathrm{z}$

A decrease with $32 \mathrm{~m} / \mathrm{z}$ each is observed, which corresponds to elimination of sulfur atoms from the DPG-TESPT complex as shown in Figure 7.17. 


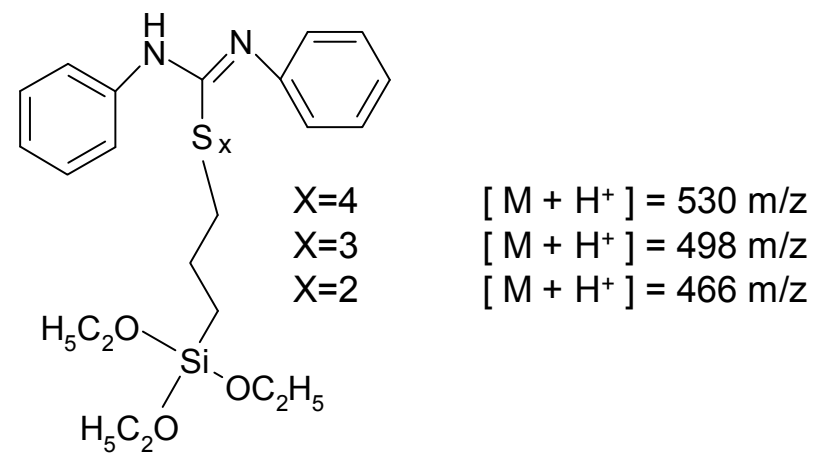

Figure 7.17 : Possible structure of the TESPT-DPG complex

Figures 7.18(a) and (b) show the peak areas of the extracted ion spectrum for 530 $\mathrm{m} / \mathrm{z}$ as a function of reaction time.
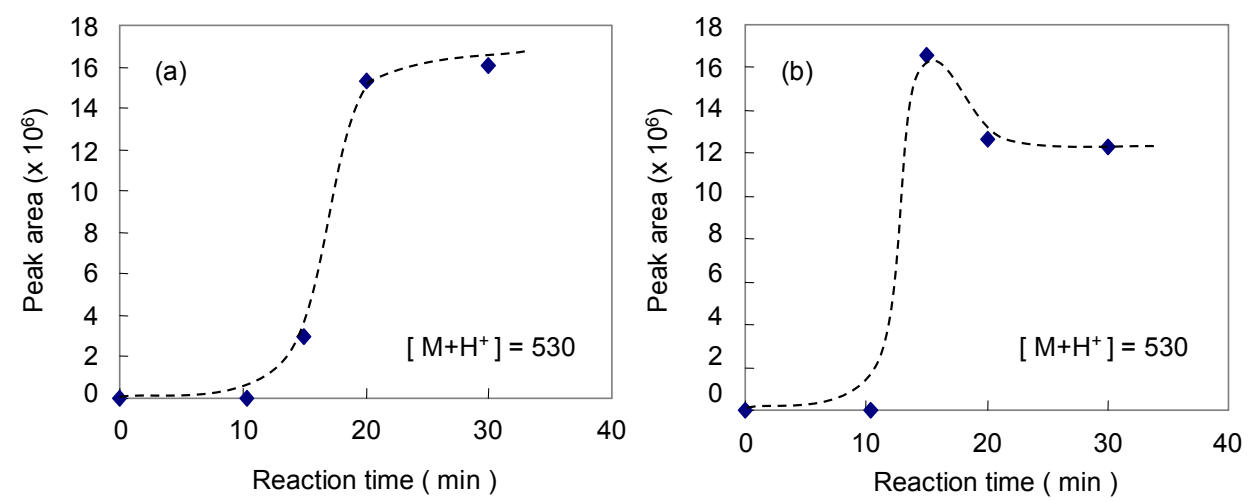

Figure 7.18 : Total peak area of DPG-TESPT complex at $140^{\circ} \mathrm{C}$ as a function of the reaction time

( a ) : TESPT-DPG with TME ; ( b ) : TESPT-DPG with 3-methyl-1-pentene

The amount of the DPG-TESPT complex slowly increases at the beginning of the reaction and then increases very fast. As described above, the primary reaction of TESPT takes place very fast at the very beginning of the silanization reaction. During the first phase, the rate constant of the formation of the DPG-TESPT complex may be retarded by the silanization reaction. In addition, the DPG-TESPT complex as given in Figure 7.17 might be capable of accelerating the sulfur donor effect of TESPT and therefore accelerate its own formation auto-catalytically. 


\subsection{Conclusions}

Model studied were done to understand the role of the amines DPG, quinuclidine and 3-quinuclidinol during processing of silica/silane reinforced rubber. The presence of amines affects the sulfur rank distribution of TESPT. Due to the presence of the amines DPG, quinuclidine and 3-quinuclidinol the tri-sulfide isomer in TESPT increases temporarily. This tri-sulfide in TESPT can possibly act as a sulfur donor during processing. As a result, the amount of cross-linked products drastically increases with amines, particularly DPG present, even in the absence of elemental sulfur.

The LC-MS experiments demonstrate that TESPT can itself react with the model olefin compounds in the presence of amines. The presence of the amines DPG, quinuclidine, 3-quinuclidinol can accelerate the reaction between TESPT and the model olefins. The mass spectrum of the TESPT/model olefin reaction products indicate that the active site of the model olefin, which reacts with the TESPT, is the unsaturated double bond and not the hydrogen of the allylic position of the model olefins.

DPG can also react with TESPT during processing. Therefore, significant amounts of DPG could be consumed during processing due to this mutual TESPT-DPG reaction. 


\subsection{References}

1. A. Hunsche, U. Görl, A. Muller, M. Knaak, Kautsch. Gummi Kunstst., 50, 881 (1997)

2. U. Görl, A. Hunsche, Paper presented at the technical meeting of the ACS Rubber Division, Louisville, Kentucky, October 8-11, 1996

3. L.A.E.M. Reuvekamp, J.W. ten Brinke, P.J. van Swaaij, J.W.M. Noordermeer, Rubber Chem. Technol., 75, 187 (2002)

4. S.C. Debnath, R. N. Datta, J. W. M. Noordermeer, Rubber Chem. Technol., 76, $1311(2003)$

5. U. Görl, J. Munzenburg, H.D Luginsland, A. Muller, Kautsch. Gummi Kunstst., 52, 588 (1999)

6. H.D Luginsland, Kautsch. Gummi Kunstst., 53, 10 (2000)

7. F. Thurn, S. Wolff, Kautsch. Gummi Kunstst., 28, 733 (1975)

8. U. Gorski, E. Klemm, Angew. Makromol. Chem. 254, 11 (1996) 


\title{
Chapter 8
}

\section{REINFORCEMENT MECHANISM OF SILICA WITH ALERNATIVES FOR DPG: PART 3}

\author{
EVALUATION OF QUINUCLIDINE AND \\ 3-QUINUCLIDINOL IN RUBBER COMPOUNDS
}

1,3-diphenylguanidine (DPG) is commonly used as secondary accelerator. As described in the previous Chapter 6, DPG promotes the silanization reaction between silica and coupling agent as well. However, DPG has a toxic concern; therefore, reduction or elimination of DPG will be required in the future. In the present chapter the DPG alternatives Quinuclidine (Q-ine) and 3-Quinuclidinol (Q-nol), which have similar $p K a$ values to DPG, are evaluated in rubber compounds. Due to the presence of $Q$-ine or Q-nol in the $1^{\text {st }}$ mixing step, the physical properties of silica filled rubber are greatly improved: 1) decrease of the Payne effect, 2) decrease of silica flocculation, 3) increase of reinforcing index (M300/M100), 4) decrease of tan $\delta$ at $60^{\circ} \mathrm{C}$. These improved physical properties result from an increase of bound rubber content due to the high efficiency of the silanization.

However, for cure rate and scorch time, a different tendency can be seen between Qine and Q-nol, and DPG itself. In the case of Q-ine or Qnol, the cure rate increases with increasing amounts of Q-ine or Qnol, and additionally the scorch time decreases. On the other hand, in case DPG is mixed in the silanization stage during the $1^{\text {st }}$ mixing step, a decrease in cure rate and an increase in scorch time can be seen with increasing amounts of DPG.

The potential of Q-ine and Q-nol to fully replace DPG was also investigated. Both DPG alternatives are capable of acting not only as a silanization accelerator but also as cure accelerator. Considering all the properties, it can be concluded that Q-ine and Q-nol are capable of replacing DPG, though a decrease of scorch time in the presence of Qine or Q-nol should be taken care of. 


\subsection{Introduction}

Amine accelerators are absorbed onto silica because of its acidic character, hence a marching modulus is observed in silica-filled rubber. 1,3-diphenylguanidine (DPG) is commonly used as secondary accelerator which not only acts as booster of cure but also reduces the marching modulus. In recent years, however, DPG has become suspect for reasons of toxicity. ${ }^{[1,2]}$ Therefore, reduction or elimination of DPG may become required in future. Accelerators and DPG alternatives, such as Quinuclidine and 3-Quinuclidinol, can improve the cure properties but also the silanziation kinetics as demonstrated in the previous chapter.

Amine compounds generally accelerate the silanization reaction during mixing. ${ }^{[3]}$ Recently, several patents regarding silanization accelerators such as primary, secondary and tertiary- amines, enamines $\left(-\mathrm{R}-\mathrm{C}=\mathrm{C}-\mathrm{NR}_{2}\right)$ and aldimines (R$\mathrm{CH}=\mathrm{CH}-\mathrm{NR}$ ) were filed by Michelin. ${ }^{[3]}$ According to these patents, the use of these amines in combination with DPG improves the silanization efficiency. In addition, it is reported that the primary vulcanization accelerator, for instance $\mathrm{N}$-cyclohexyl-2benzothiazole sulfenamide (CBS), is also capable of reacting with the polysulfide group in bis-(triethoxysilylpropyl)tetrasulfide(TESPT), and consequently the polysulfide group is activated. ${ }^{[4-6]}$

The silanization reaction in an internal mixer is accelerated when DPG is present. ${ }^{[3]}$ Considering the absorption of DPG by silica, it has been established that this is three times higher than that of conventional accelerators such as CBS. ${ }^{[7]}$

The work described in this chapter deals with alternative amines (DPG alternatives) that have similar pKa values to DPG. It is anticipated that these DPG alternatives are capable of doing similar functions as DPG, eliminating the toxic hazard of DPG in industrial practice. 


\subsection{Experiments}

\subsubsection{Sample preparation:}

All experiments were done using a typical tire tread composition as given in Table 8.1.

Table 8.1 : Compound formulations

\begin{tabular}{llll}
\hline Component & Product name & Supplier & phr \\
\hline S-SBR $※$ & Buna VSL5025 HM-1 & Lanxess & 103 \\
BR & Nipol 1220 & Nippon zeon & 25.0 \\
Silica & Ultrasil VN3 & Degussa & 80,0 \\
Silane (TESPT) & Si69 & Degussa & 7.10 \\
Aromatic oil & Tudalen 3570A & Hansen \& Rosenthal & 4.40 \\
Zinc oxide & ZnO & Merck & 2.50 \\
Stearic acid & & Merck & 2.50 \\
Amines & listed in Table 8.2 & Aldrich & Variable \\
& & & \\
Curatives: & & J.T. Baker & Variable \\
Sulfur & & Flexsys & 1.70 \\
CBS & Santocure CBS & Flexsys & 2.00 \\
DPG & Perkacit DPG & & \\
\hline
\end{tabular}

※37.5phr oil extended

The amount of silane applied in the recipes was adjusted according to equation 3.1(see Chapter 3), in which the amount of silane was adjusted for $80 \mathrm{phr}$ of the VN3 silica based on the CTAB surface areas. Quinuclidine (Q-ine) and 3Quinuclidinol (Q-nol) were chosen as DPG alternatives because of the following reasons ${ }^{[8,9]}$ :

$>$ Similar in the pKa value to DPG;

> Similar silanization kinetics as described in Chapter 6;

$>$ Less toxicity compared to DPG.

The chemical structures of these amines are shown in Table 8.2.

Table 8.2 : Chemical structure of amine

\begin{tabular}{l|c|c|c}
\hline \multicolumn{1}{c|}{ Amines } & Structure & $\mathrm{Mw}$ & remarks \\
\hline $\begin{array}{l}\text { Quinuclidine } \\
\begin{array}{l}\text { Q-ine) } \\
\text { pka=11.5 }\end{array}\end{array}$ & 111 & Toxic in contact with skin and if swallowed, irritating skin \\
\hline $\begin{array}{l}\text { 3-Quinuclidinol } \\
\begin{array}{l}\text { Q-nol) } \\
\text { pka=10.1 }\end{array}\end{array}$ & 127 & Exposure effect: Effect may be delayed. \\
\hline $\begin{array}{l}\text { Diphenylguanidine } \\
\text { (DPG) } \\
\text { pka=10.1 }\end{array}$ & 211 & $\begin{array}{l}\text { Toxic for reproduction, category 3, harmful, irritant } \\
\text { dangerous for environment }\end{array}$ \\
\hline
\end{tabular}

The amount of the DPG alternatives and DPG was varied in the 0 to $2 \mathrm{phr}$ range. Two different systems corresponding to different amounts of amines were applied 
in the present study. The mixing procedures are given in Table 8.3, the same as described in Chapter 3.

Table 8.3 : Mixing procedure

\begin{tabular}{|c|c|c|c|c|}
\hline Step 1 & & Step 2 & & Step 3 \\
\hline $\begin{array}{l}\text { Time } \\
\text { (min.sec) }\end{array}$ & Action & $\begin{array}{l}\text { Time } \\
(\text { min.sec) }\end{array}$ & Action & Action \\
\hline $\begin{array}{l}0.00 \\
1.00 \\
2.00 \\
\\
4.00 \\
4.20 \\
6.20\end{array}$ & $\begin{array}{l}\text { Add rubber } \\
\text { Add } 1 / 2 \text { silica, } 1 / 2 \text { silane, } 1 / 2 \text { amines } \\
\text { Add } 1 / 2 \text { silica, } 1 / 2 \text { silane, oil, } \\
\text { stearic acid, } 1 / 2 \text { amines } \\
\text { Ram up, sweep } \\
\text { Ram down } \\
\text { Dump }\end{array}$ & $\begin{array}{l}0.00 \\
1.00 \\
5.00\end{array}$ & $\begin{array}{l}\text { Add master batch } \\
\text { Add ZnO } \\
\text { Dump }\end{array}$ & $\begin{array}{l}\text { All curatives were mixed } \\
\text { on a two-roll mill. }\end{array}$ \\
\hline
\end{tabular}

System 1: In the $1^{\text {st }}$ mixing step, the Q-ine or Q-nol amine loading was varied in the range from 0 to $2.0 \mathrm{phr}$. Then the total amount of amines was adjusted to 2.0 phr by adding additional DPG at the $3^{\text {rd }}$ mixing step, which means that the total amine content was equal for all compounds.

System 2: The amines varied in the 0 to $2.0 \mathrm{phr}$ range were mixed in the $1^{\text {st }}$ mixing step like with system 1. However, the total amount of amines was not adjusted later on, which means that no additional DPG was applied to compensate for the level of total amine. Therefore, DPG is not fully replaced by Q-ine or Q-nol.

\subsubsection{Sample analysis}

\subsubsection{Vulcanization}

The optimal cure time was determined using a Rubber Process Analyzer RPA2000 dynamic rheological tester from Alpha technologies. The rheograms were measured under the following conditions: $160^{\circ} \mathrm{C}, 0.833 \mathrm{~Hz}$ and $2.79 \%$ strain for 30 minutes. The differential curves were calculated from the rheograms. For calculation of the optimal cure time, the same procedure was applied as given in Chapter 3.

Vulcanization was done in a Wickert laboratory press WLP1600 at $160^{\circ} \mathrm{C}$ and 100 bar for optimal cure time.

\subsubsection{Payne effect measurements}

Payne effect measurements were also done using the RPA2000. The storage modulus at $0.56 \%$ strain was measured under the following conditions: temperature: $100^{\circ} \mathrm{C}$ and frequency: $0.5 \mathrm{~Hz}$. This measurement may be used as a measure of the Payne effect.

For vulcanized compounds, the rubber samples were vulcanized in the chamber of the RPA2000 for the optimal cure time at $160^{\circ} \mathrm{C}$ and then cooled down till $100^{\circ} \mathrm{C}$. The same measurement conditions were applied for the Payne effect measurement of the vulcanized rubber as for the unvulcanized samples.

\subsubsection{Bound rubber measurements}

Bound rubber measurements were done for all rubber compounds. These values 
were used to estimate the specific bound rubber, which indicates the amount of chemically bound rubber on the silica surface. For the present purpose only the chemically bound rubber is taken into account. Therefore, an ammonia treatment was done prior to the bound rubber measurement. The chemically bound rubber measurement was done as given in the experimental section of Chapter 3.

\subsubsection{Mooney viscosity}

The Mooney viscosity measurement was done after the second mixing step by using a MV2000 viscosity analyzer from Alpha Technologies. The uncured sample was preheated for 1 minute at $100^{\circ} \mathrm{C}$ and then the Mooney viscosity was monitored with the rotor speed of $2 \mathrm{cpm}$ for 4 minutes.

\subsubsection{Mooney scorch (T5)}

Mooney scorch (T5) was measured using a MV2000E from Alpha technologies as well. The following conditions were applied: temperature: $125^{\circ} \mathrm{C}$, rotor speed: 2 cpm.

\subsubsection{Visco-elasticity property: $\tan \delta$ at $60^{\circ} \mathrm{C}$}

The tan $\delta$ at $60^{\circ} \mathrm{C}$ was measured after vulcanization using a Toyo Seiki viscoelastic spectrometer under the conditions of a frequency of $20 \mathrm{~Hz}$, an initial elongation strain of $10 \%$ and an amplitude of $\pm 2 \%$. It is generally known that the value of $\tan \delta$ at $60^{\circ} \mathrm{C}$ can be correlated with the rolling resistance of a tire.

\subsubsection{Flocculation kinetics}

The flocculation kinetics were also measured using the Rubber Process Analyzer RPA2000. The determination of the flocculation kinetics is described in Chapter 4.

\subsubsection{Mechanical properties}

The mechanical properties of the cured compounds were measured using a Zwick Z020 tensile tester according to ISO-37. 


\subsection{Results and Discussion}

\subsubsection{Effect of Q-ine or Q-nol keeping the total amine dosage equal (System 1)}

As described in Chapter 3, the degree of silanization affects the interfacial layer on the silica surface, resulting in a change of dynamic and reinforcing properties of silica-filled rubber. In this paragraph, the effect of the presence of amines such as Quinuclidine, 3-Quinuclidinol and DPG during the $1^{\text {st }}$ mixing step, and adjustment to a total amount of amines of 2phr by adding additional DPG during the $3^{\text {rd }}$ mixing step on the two-roll mill, on the physical properties is investigated.

\subsubsection{Cure properties}

Figures 8.1 (a) and (b) show rheograms and their differential curves for the DPG alternatives and DPG in System 1. For all amines the maximum torque decreases with increasing amount of the amines during the $1^{\text {st }}$ step mixing.

It is interesting to observe that the typical torque increase at the very beginning of the cure, which is an indication of the flocculation process of silica (see Chapter 4), decreases with $Q$-ine or Q-nol present in the $1^{\text {st }}$ mixing step. Hence, silica flocculation can be decreased with Q-ine or Q-nol in the $1^{\text {st }}$ mixing step.

For the differential curves of both DPG alternatives Q-ine and Q-nol, the maximum derivative values, which mean the maximum cure rates, increase with increasing amounts of Q-ine or Q-nol in the $1^{\text {st }}$ mixing step. In addition, the time at the maximum derivative value decreases, resulting in a faster cure rate in the presence of Q-ine or Q-nol. This is indicated by the NW-bound arrows in Figures 8.1(b). 

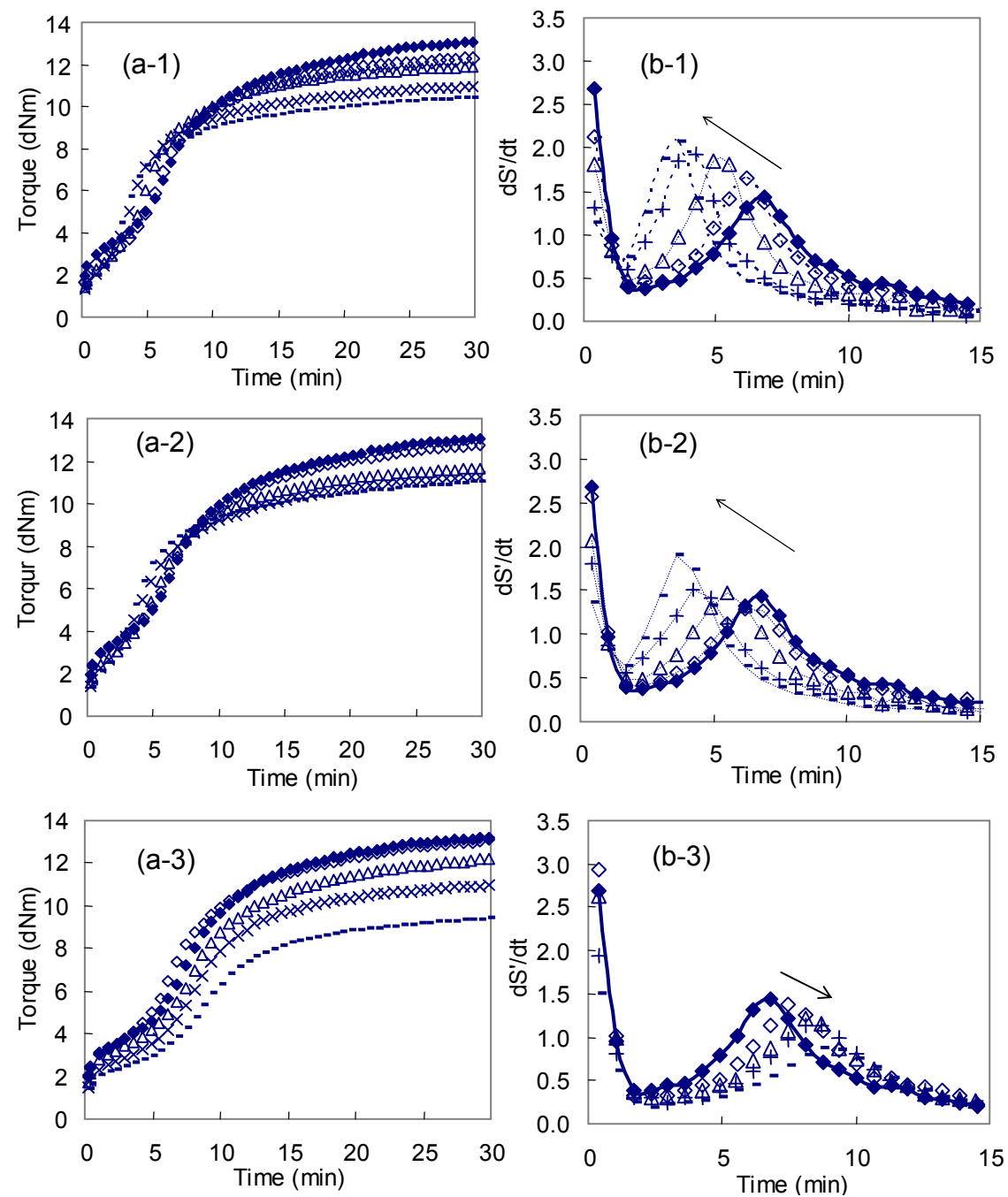

Figures 8.1 : Cure curves and differential curves: System 1

Cure curves : ( a-1 ) : Quinuclidine ; ( a- 2 ) : 3-Quinuclidinol ; ( a-3 ) : DPG Derivative curves : ( b-1 ) Quinuclidine ; ( b-2 ) 3-Quinuclidinol ; ( b-3 ) DPG Amount of amines at the first mixing step :

$(\diamond): 0 \mathrm{phr} ;(\diamond): 0.5 \mathrm{phr} ;(\Delta): 1.0 \mathrm{phr} ;(+): 1.5 \mathrm{phr} ;(-): 2.0 \mathrm{phr}$

For DPG the maximum torque decreases as well with increasing amount of DPG in the $1^{\text {st }}$ mixing step. A lower increase of torque at the very beginning of the vulcanization was observed as well. On the other hand, contrary to Q-ine and Qnol the maximum derivative values decrease with increasing amount of DPG in the $1^{\text {st }}$ mixing step. And the time at the maximum derivative value increases with increasing amount of DPG in the $1^{\text {st }}$ mixing step, even though equal amounts of amines are present in the rubber compounds after the $3^{\text {rd }}$ mixing step. This is indicated by the SE-bound arrow in Figure 8.1(b-3). DPG is capable of interacting 
not only with the silica surface but also with TESPT as described in Chapter $7 .^{[7]}$ Therefore, DPG can be consumed during rubber processing due to those interactions.

\subsubsection{Mooney scorch at $125^{\circ} \mathrm{C}$}

Figure 8.2 shows the Mooney scorch at $125^{\circ} \mathrm{C}$ as a function of the amount of each amine in the $1^{\text {st }}$ mixing step.

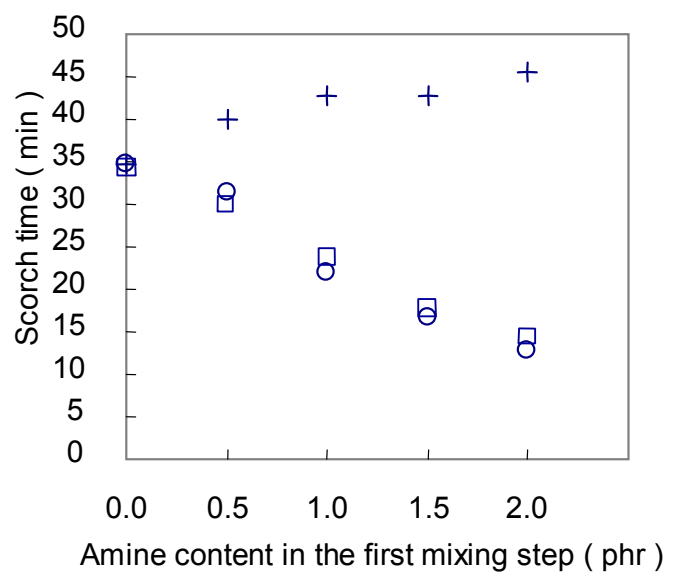

Figure 8.2 : Scorch time as a function of the amount of amines in the first mixing step

$(\circ)$ : Quinuclidine ; ( $)$ : 3-Quinuclidinol ; ( ) : DPG

In the presence of Q-ine or Q-nol, the scorch time sharply decreases. On the other hand, in the presence of DPG the scorch time increases with increasing amount of DPG in the $1^{\text {st }}$ mixing step. As mentioned above, DPG is capable of interacting with the silica surface as well as with TESPT. ${ }^{[7]}$ Therefore, for DPG this result also indicates that it is consumed during the $1^{\text {st }}$ mixing step. 


\subsubsection{Mooney viscosity}

Figure 8.3 shows the Mooney viscosity as a function of the amount of amines at the $1^{\text {st }}$ mixing step. The Mooney viscosity decreases somewhat, fast till $0.5 \mathrm{phr}$ and then remains unchanged, even if more amines are applied in the first mixing step.

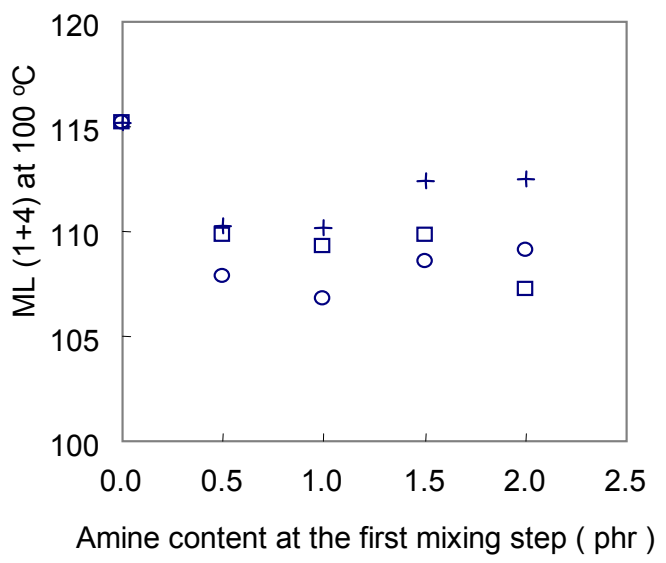

Figure 8.3 : Mooney viscosity as a function of the amount of amines in the first mixing step (०) : Quinuclidine ; ( $)$ ): 3-Quinuclidinol ; (+ ) : DPG

\subsubsection{Payne effect}

After the $3^{\text {rd }}$ mixing step the storage modulus at $0.56 \%$ strain was measured with the Rubber Process Analyzer RPA2000. Figure 8.4(a) shows the storage modulus at $0.56 \%$ strain as a function of the amount of amines for the non-vulcanized compounds.

In the presence of amines, the storage modulus at $0.56 \%$ strain decreases. As described in Chapter 6, the amines with higher pKa value are capable of promoting the silanization reaction. The decrease of the Payne effect in the presence of amines results from the promotion of silanization and consequent reduced fillerfiller interaction of the silica.

For the vulcanized rubber samples, the storage modulus at $0.56 \%$ strain was measured as well using the RPA2000. Figure 8.4(b) shows the storage modulus at $0.56 \%$ strain of the vulcanized rubber samples as a function of the amount of amines in the $1^{\text {st }}$ mixing step. 


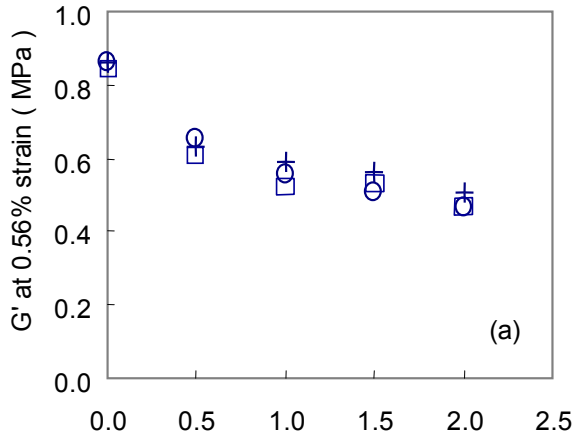

Amine content in the first mixing step ( $p h r$ )

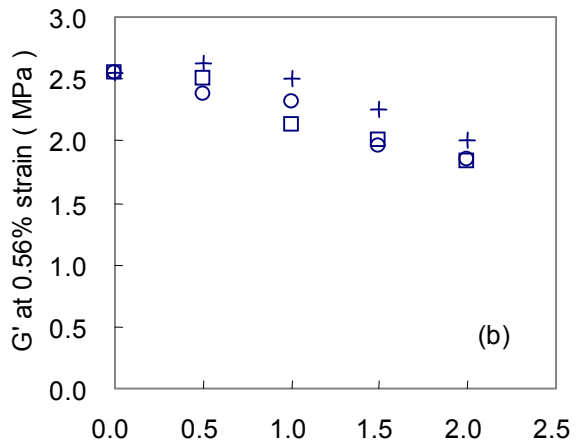

Amine content in the first mixing step ( phr)

Figure 8.4 : G' at $0.56 \%$ strain as a function of the amount of amines in the first mixing step

(a) : Unvulcanized rubber ; (b) : Vulcanized rubber

(०) : Quinuclidine ; ( $)$ ): 3-Quinuclidinol ; ( ) : DPG

As shown in Figure 8.4(b), a decrease of storage modulus can be seen, even after vulcanization. The effects of $Q$-ine and $Q$-nol are more or less comparable with DPG; in the vulcanized state Q-ine and Q-nol seem just a bit more effective in repressing the Payne-effect and corresponding filler-filler interaction.

\subsubsection{Bound rubber measurements}

Figure 8.5 shows the bound rubber contents after ammonia treatment as a function of the amount of amines at the $1^{\text {st }}$ mixing step.

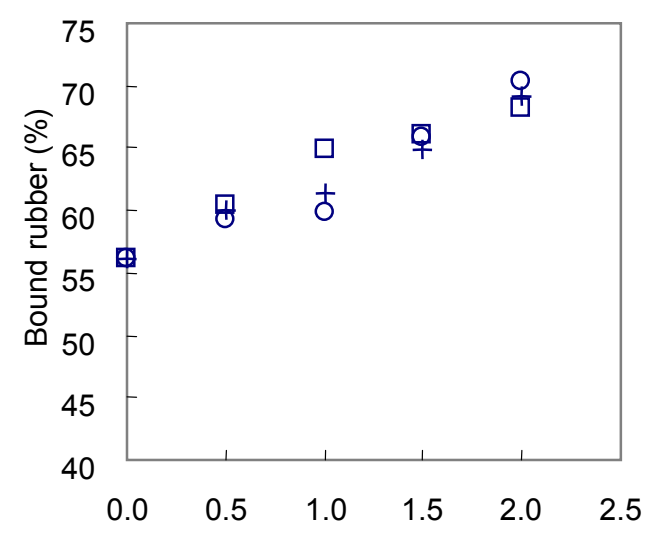

Amine content at the first mixing step (phr)

Figure 8.5 : Bound rubber content as a function of the amount of amines at the first mixing step

(०): Quinuclidine ; ( $\square$ ) : 3-Quinuclidinol ; ( + ) : DPG

In the presence of amines in the $1^{\text {st }}$ mixing step, the bound rubber content after ammonia treatment linearly increases with increasing amount of amines. This increasing bound rubber content results from accelerated silanization due to the 
presence of amines in the rubber compounds as already explained in Chapter 6. In addition, amines are capable of enhancing the sulfur donor effect of TESPT, resulting in an increase of cross-linked rubber on the silica surface.

\subsubsection{Flocculation kinetics}

Silica flocculation takes place during the heating process involved in vulcanization, even if silane coupling agents are applied. ${ }^{[12-17]}$ The flocculation rate and the activation energy are listed in Table 8.4.

Table 8.4 : Kinetic parameters of silica flocculation for different amounts of amines added during the $1^{\text {st }}$ mxing step

\begin{tabular}{|c|c|c|c|c|c|}
\hline \multirow{2}{*}{ Amine } & \multirow{2}{*}{ phr } & \multicolumn{3}{|c|}{ Flocculation rate $\left(\mathrm{min}^{-1}\right)$} & \multirow{2}{*}{$\begin{array}{l}\text { Activation energy } \\
(\mathrm{kJ} / \mathrm{mol})\end{array}$} \\
\hline & & $90^{\circ} \mathrm{C}$ & $100^{\circ} \mathrm{C}$ & $110^{\circ} \mathrm{C}$ & \\
\hline Amine free & 0 & 0.22 & 0.25 & 0.30 & 17.4 \\
\hline \multirow{4}{*}{$\begin{array}{l}\text { Quinuclidine } \\
\text { (Q-ine) }\end{array}$} & 0.5 & 0.22 & 0.24 & 0.27 & 14.4 \\
\hline & 1.0 & 0.21 & 0.24 & 0.27 & 14.4 \\
\hline & 1.5 & 0.21 & 0.24 & 0.25 & 8.8 \\
\hline & 2.0 & 0.19 & 0.20 & 0.22 & 7.1 \\
\hline \multirow{4}{*}{$\begin{array}{l}\text { 3-Quinuclidinol } \\
\text { (Q-nol) }\end{array}$} & 0.5 & 0.23 & 0.26 & 0.27 & 10.1 \\
\hline & 1.0 & 0.21 & 0.23 & 0.26 & 12.6 \\
\hline & 1.5 & 0.20 & 0.22 & 0.25 & 13.6 \\
\hline & 2.0 & 0.20 & 0.21 & 0.22 & 6.5 \\
\hline \multirow{4}{*}{$\begin{array}{l}\text { Diphenylguanidine } \\
\text { (DPG) }\end{array}$} & 0.5 & 0.24 & 0.26 & 0.28 & 8.8 \\
\hline & 1.0 & 0.21 & 0.25 & 0.26 & 10.5 \\
\hline & 1.5 & 0.20 & 0.22 & 0.25 & 12.1 \\
\hline & 2.0 & 0.20 & 0.21 & 0.22 & 6.5 \\
\hline
\end{tabular}

The flocculation rate and the activation energy both decrease in the presence of amines in the $1^{\text {st }}$ mixing step. As demonstrated in Chapter 4, due to an increase of the specific bound rubber, the flocculation rate of silica can decrease. In Figure 8.6 the flocculation rate at $110^{\circ} \mathrm{C}$ is plotted as a function of the bound rubber content after ammonia treatment. It shows a correlation with the bound rubber content. It is therefore inferred that the decreases of the flocculation rate in the presence of the amine compounds in $1^{\text {st }}$ mixing step result from the increasing interfacial layer between silica and rubber. However, the silica flocculation still takes place, even if the amines are applied. 


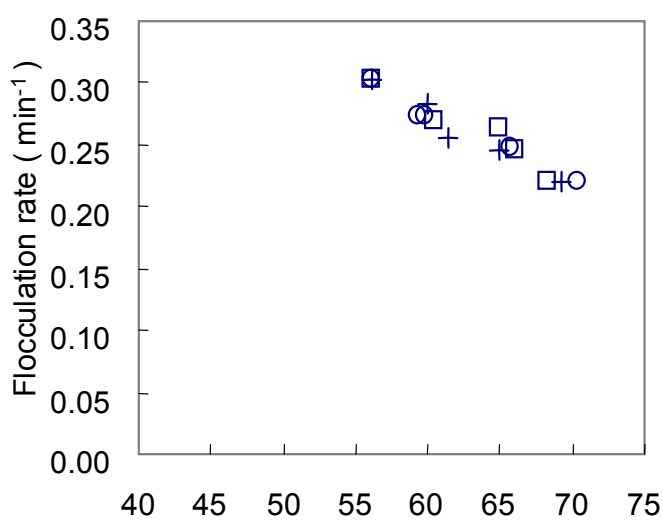

Bound rubber content after ammonia treatment ( \% )

Figure 8.6 : Flocculation rate as a function of the bound rubber content after ammonia treatment

$(\circ)$ : Quinuclidine ; ( $)$ : 3-Quinuclidinol ; (+ ) : DPG

\subsubsection{Mechanical properties}

The mechanical properties of the vulcanized samples are listed in Table 8.5.

Table 8.5 : Mechanical properties for the different amounts of added amines during the $1^{\text {st }}$ mixing step (System 1)

\begin{tabular}{|c|c|c|c|c|c|c|}
\hline & $\begin{array}{c}\text { Amine } \\
(\mathrm{phr})\end{array}$ & $\begin{array}{c}\text { E- } \\
\text { modulus } \\
(\mathrm{MPa})\end{array}$ & $\begin{array}{l}\text { M100 } \\
(\mathrm{MPa})\end{array}$ & $\begin{array}{l}\text { M300 } \\
(\mathrm{MPa})\end{array}$ & $\begin{array}{c}\text { TB } \\
(\mathrm{MPa})\end{array}$ & $\begin{array}{l}\text { EB } \\
(\%)\end{array}$ \\
\hline Control & - & 12.0 & 1.9 & 7.0 & 18.7 & 570 \\
\hline \multirow{4}{*}{ Quinuclidine } & 0.5 & 12.2 & 1.7 & 6.9 & 18.8 & 578 \\
\hline & 1.0 & 9.5 & 2.0 & 8.4 & 19.3 & 529 \\
\hline & 1.5 & 9.0 & 1.8 & 7.8 & 18.6 & 533 \\
\hline & 2.0 & 7.9 & 2.0 & 8.8 & 19.6 & 515 \\
\hline \multirow{4}{*}{ 3-Quinuclidinol } & 0.5 & 12.2 & 1.8 & 7.1 & 19.1 & 573 \\
\hline & 1.0 & 9.8 & 1.7 & 6.8 & 18.4 & 567 \\
\hline & 1.5 & 8.6 & 1.7 & 7.0 & 18.3 & 554 \\
\hline & 2.0 & 8.2 & 1.7 & 6.3 & 18.3 & 602 \\
\hline \multirow{4}{*}{$\begin{array}{l}\text { 1,3- } \\
\text { Diphenylguanidine }\end{array}$} & 0.5 & 13.3 & 1.7 & 6.8 & 18.6 & 582 \\
\hline & 1.0 & 12.4 & 1.7 & 7.1 & 19.3 & 585 \\
\hline & 1.5 & 9.5 & 1.7 & 7.0 & 18.8 & 572 \\
\hline & 2.0 & 9.0 & 1.9 & 8.0 & 18.5 & 521 \\
\hline
\end{tabular}

*Total amount of amine is adjusted to $2.0 \mathrm{phr}$.

The presence of the amines in the $1^{\text {st }}$ mixing step results in a lower elastic modulus, resulting from a higher degree of silanization and consequently reduced reinforcing power of the silica. ${ }^{[10]}$ For the other mechanical properties, no significant effect of amines can be seen. M300 increases with increasing amount of amines at the $1^{\text {st }}$ mixing step, except for Q-nol. No significant difference 
between these three amines can be seen in Tensile strength at Break TB. The Elongation at Break EB decreases with increasing amount of amines, except for Qnol.

\subsubsection{Reinforcement index (M300/M100)}

Figure 8.7 shows the reinforcement index M300/M100 as a function of the amount of amines in the $1^{\text {st }}$ mixing step.

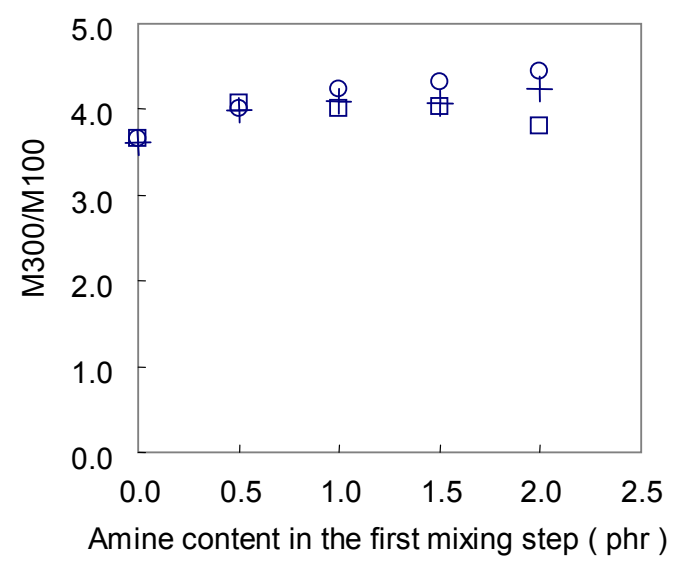

Figure 8.7 : Reinforcement index M300/M100 as a function of the amount of amines in the first mixing step

(०): Quinuclidine ; ( ) : 3-Quinuclidinol ; ( + ): DPG

For Q-ine and DPG, M300/M100 slightly increases with increasing amount of those two amines during the $1^{\text {st }}$ mixing step. On the other hand, for Q-nol M300/M100 shows some sort of maximum at around 1phr Q-nol. 
8.3.1.9 Visco-elasticity property: $\tan \delta$ at $60^{\circ} \mathrm{C}$

Figure 8.8 shows $\tan \delta$ at $60^{\circ} \mathrm{C}$ as a function of the amount of the amines added during the $1^{\text {st }}$ mixing step.

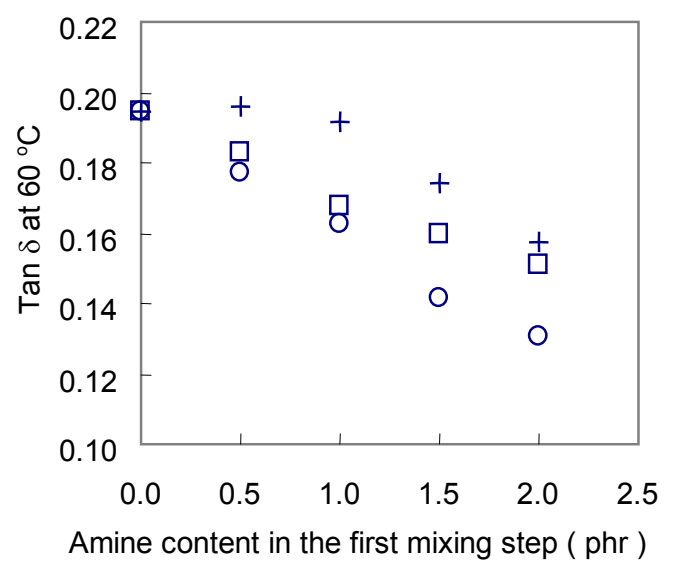

Figure 8.8 : $\operatorname{Tan} \delta$ at $60^{\circ} \mathrm{C}$ as a function of the amount of amines in the first mixing step

(०): Quinuclidine ; ( ૨ ): 3-Quinuclidinol ; ( + ): DPG

Tan $\delta$ at $60^{\circ} \mathrm{C}$ decreases with increasing the amount of the amines. Both new amines, Q-ine and Q-nol, show decreased values of $\tan \delta$ at $60^{\circ} \mathrm{C}$ as compared to DPG, which would indicate lower rolling resistance of tires made thereof.

Figure 8.9 shows the $\tan \delta$ at $60^{\circ} \mathrm{C}$ as a function of the bound rubber content.

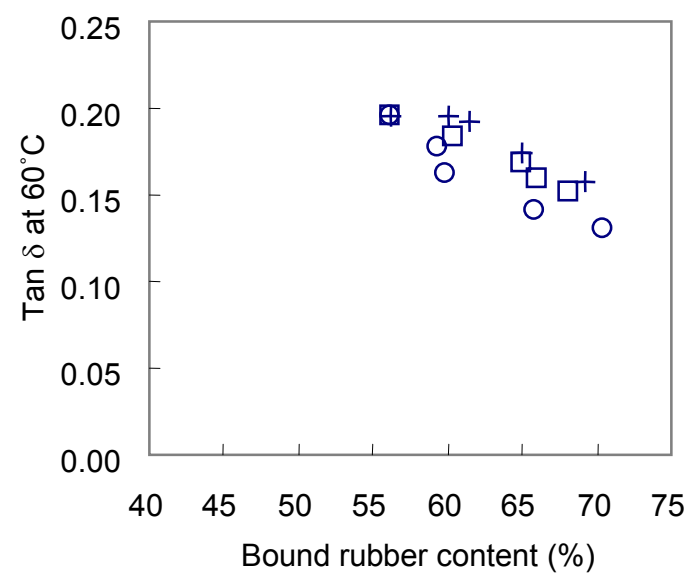

Figure 8.9 : Tan $\delta$ at $60^{\circ} \mathrm{C}$ as a function of the bound rubber content after ammonia treatment

(०): Quinuclidine ; ( $)$ : 3-Quinuclidinol ; (+) : DPG

As described before in Chapter 3 , the tan $\delta$ at $60^{\circ} \mathrm{C}$ shows a correlation with the chemically bound rubber content. It is well known that $\tan \delta$ at $60^{\circ} \mathrm{C}$ is related to the degree of filler-filler networking. An increase of chemically bound rubber on the silica surface leads to lower filler-filler networking in a rubber matrix. The fact that 
the points for the various amines are more or less superimposed indicates, that the correlation above is independent of the specific amine.

Another indication for rolling resistance of tires is the M300/M100 ratio, relating to the shape of the tensile curve. ${ }^{[18]}$ Therefore, the $\tan \delta$ at $60^{\circ} \mathrm{C}$ should show a correlation with the M300/M100 ratio.

Figure 8.10 shows the $\tan \delta$ at $60^{\circ} \mathrm{C}$ as a function of reinforcement index $\mathrm{M} 300 / \mathrm{M} 100$. Tan $\delta$ at $60^{\circ} \mathrm{C}$ does strongly correlate with the reinforcement index M300/M100, as anticipated.

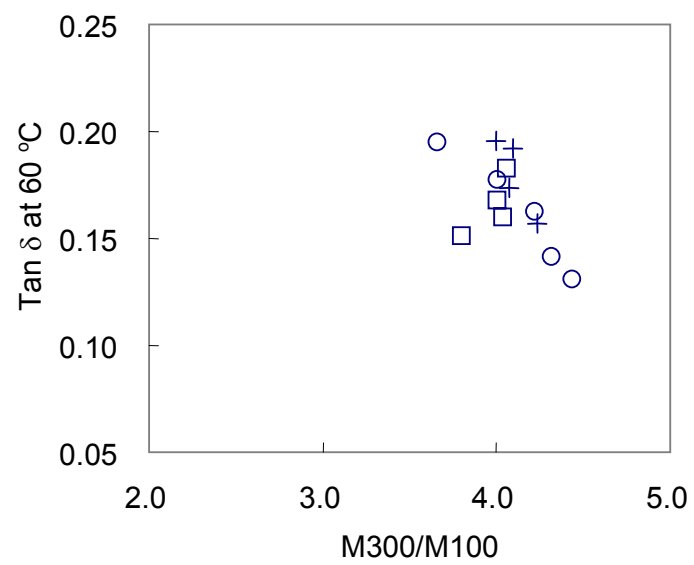

Figure 8.10: Tan $\delta$ at $60^{\circ} \mathrm{C}$ as a function of reinforcing index M300/M100

$(\circ)$ : Quinuclidine ; ( $\square$ ) : 3-Quinuclidinol ; ( + ) : DPG

Based on this part of the study, it will be interesting to explore if $Q$-ine or $Q$-nol can replace all DPG in the rubber compounds. In the next part, we investigate the total replacement of DPG according to System 2 (see experimental). 


\subsubsection{Effects of different total amounts of Q-ine and Q-nol (System 2)}

\subsubsection{Cure properties}

Rheogram of the compounds with different amounts of Q-ine and Q-nol in the absence of DPG are shown in Figures 8.11 (a-1) and (a-2), respectively.
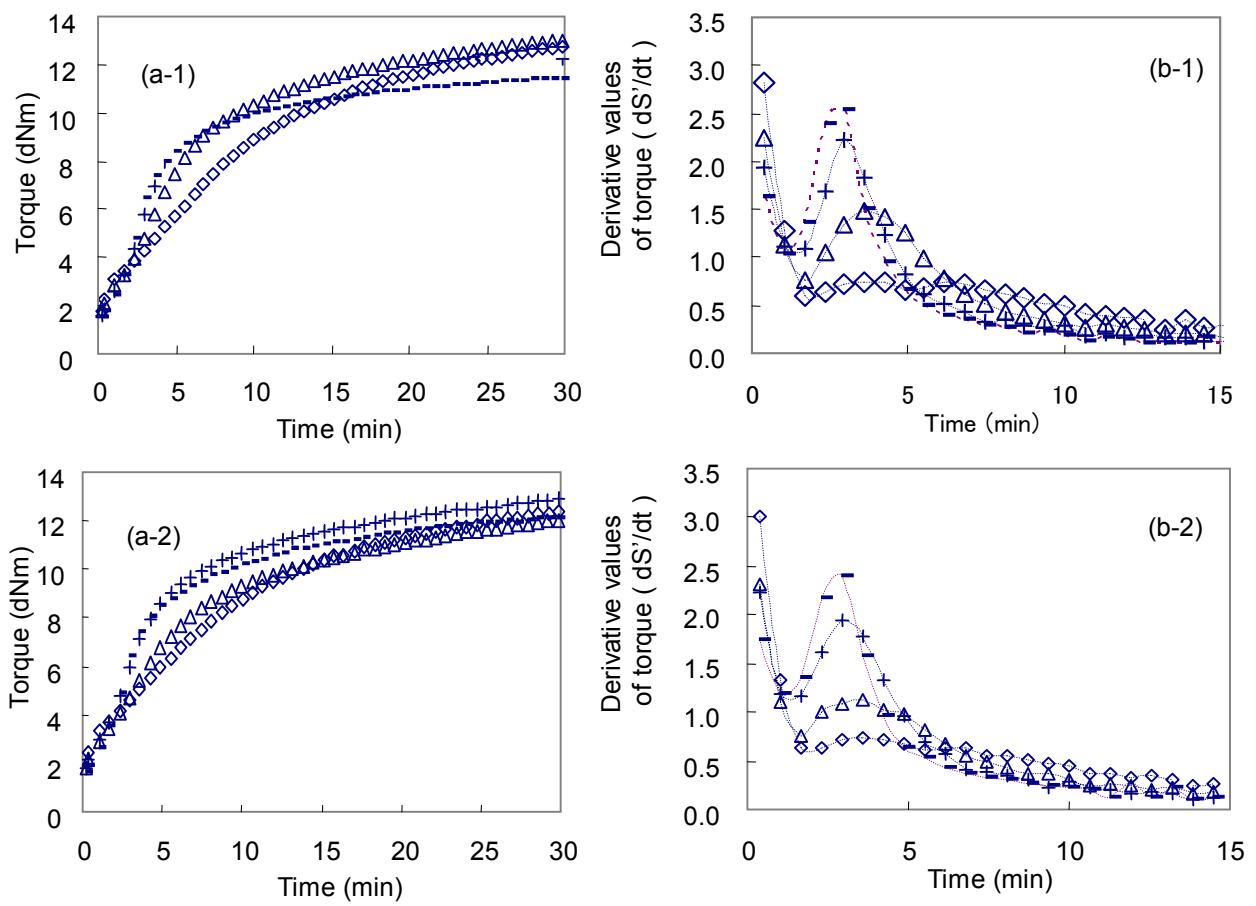

Figure 8.11 : Cure curves and differential curves: System 2

Cure curves : (a-1) : Quinuclidine ; (a-2) : 3-Quinyclidinol

Derivative curves : (b-1) : Quinuclidine ; (b-2) : 3-Quinuclidinol

Amount of DPG alternatives at the first mixing step :

$(\diamond): 0.5 \mathrm{phr} ;(\Delta): 1.0 \mathrm{phr} ;(+): 1.5 \mathrm{phr} ;(-): 2.0 \mathrm{phr}$

For both DPG alternatives it is clearly observed that fully developed vulcanization takes place, even if DPG was not applied in the system. Therefore, it is suggested that Q-ine and Q-nol act not only as silanization accelerator but also as cure accelerator. However, it is also found that a marching modulus effect strongly takes place at lower amounts of the Q-ine or Q-nol. In addition, the maximum torque decreases somewhat with increasing amount of $Q$-ine or $Q$-nol due to the high silanization reaction.

Figures $8.11(b-1)$ and (b-2) show the derivation curves for Q-ine and Q-nol, respectively. For both DPG alternatives an increase of the maximum derivative value can be seen corresponding with increased amounts of DPG alternatives. 
8.3.2.2 Mooney scorch at $125^{\circ} \mathrm{C}$

Figure 8.12 shows the Mooney scorch at $125^{\circ} \mathrm{C}$ of compounds containing Q-ine and Q-nol in the absence of DPG.

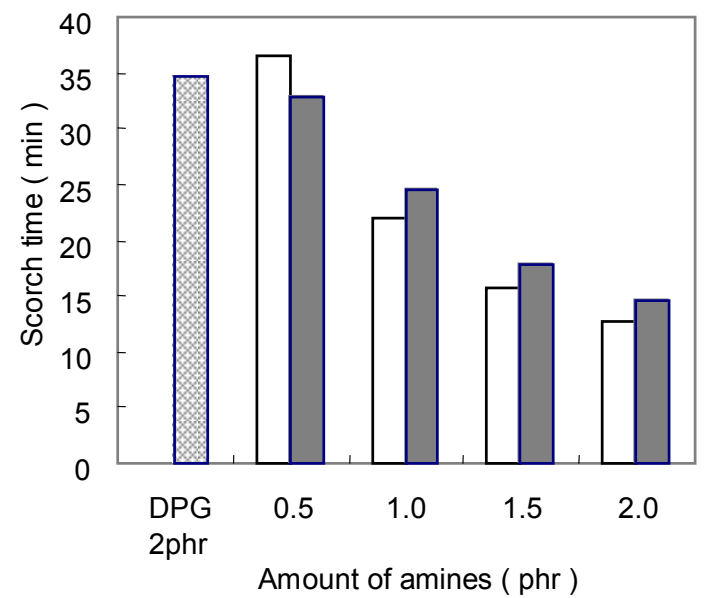

Figure 8.12 : Scorch time as a function of the amount of Q-ine and Q-nol

( ) : 2 phr DPG (Control) ; ( $\square$ ) : Quinuclidine ;

( ) : 3-Quinuclidinol

The scorch time decreases with increasing amounts of Q-ine or Q-nol, even in the absence of DPG. However, the scorch times of Q-ine and Q-nol are much shorter than that of the DPG-system. This corresponds with the observations already made with System 1: Figure 8.2. 


\subsubsection{Payne effect after vulcanization}

The effect of the Q-ine and Q-nol in the absence of DPG on the Payne effect was investigated after vulcanization. Figure 8.13 shows the storage modulus at $0.56 \%$ strain as a function of the amount of Q-ine or Q-nol.

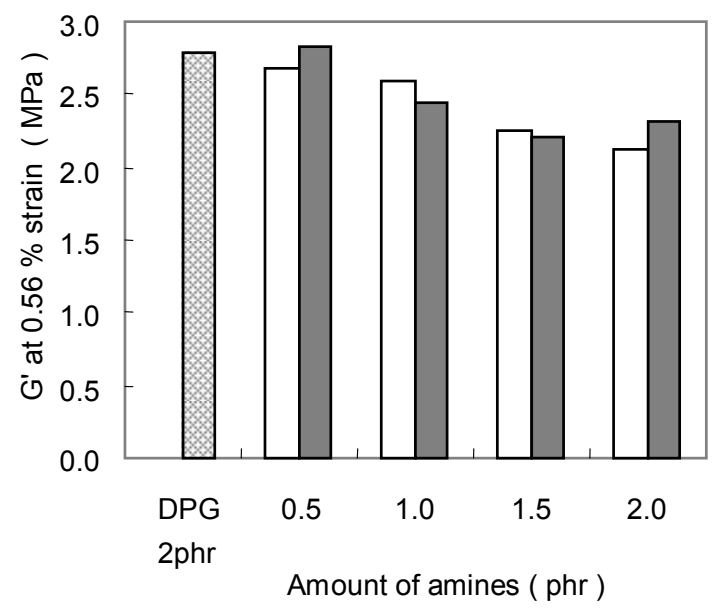

Figure 8.13: Payne effect of vulcanizates as a function of the amount of amines

( ) : 2 phr DPG (Control) ; ( $\square$ ): Quinuclidine ;

\section{( $)$ : 3-Quinuclidinol}

For both DPG alternatives the storage modulus at $0.56 \%$ strain after vulcanization is low compared to that of the 2 phr DPG system, in spite of lower total amount of amine. It demonstrates the strong effect of $Q$-ine and $Q$-nol in reducing filler-filler interaction, even at relatively low concentrations.

\subsubsection{Tensile properties}

The mechanical properties of the vulcanizates are summarized in Table 8.6.

Table 8.6 : Mechanical properties for the different amines

\begin{tabular}{|l|c|c|c|c|c|c|c|}
\hline & DPG & $\begin{array}{c}\text { DPG } \\
\text { alternatives }\end{array}$ & $\begin{array}{c}\text { E-modulus } \\
(\mathrm{MPa})\end{array}$ & $\begin{array}{c}\mathrm{M} 100 \\
(\mathrm{MPa})\end{array}$ & $\begin{array}{c}\mathrm{M} 300 \\
(\mathrm{MPa})\end{array}$ & $\begin{array}{c}\mathrm{TB} \\
(\mathrm{MPa})\end{array}$ & $\begin{array}{c}\mathrm{EB} \\
(\%)\end{array}$ \\
\hline Control & 2.0 & - & 12.0 & 1.9 & 7.0 & 18.7 & 570 \\
\hline \multirow{4}{*}{ Quinuclidine } & - & 0.5 & 10.0 & 1.6 & 6.0 & 18.6 & 603 \\
\cline { 2 - 8 } & - & 1.0 & 10.8 & 1.9 & 7.5 & 20.4 & 581 \\
\cline { 2 - 9 } & - & 1.5 & 11.6 & 2.0 & 8.6 & 20.9 & 547 \\
\cline { 2 - 9 } & - & 2.0 & 9.2 & 2.2 & 9.9 & 20.5 & 496 \\
\hline \multirow{3}{*}{$3-$-Quinuclidinol } & - & 0.5 & 11.7 & 1.8 & 6.0 & 18.0 & 596 \\
\cline { 2 - 9 } & - & 1.0 & 10.4 & 1.7 & 6.1 & 18.4 & 600 \\
\cline { 2 - 9 } & - & 1.5 & 11.8 & 1.9 & 7.5 & 19.6 & 567 \\
\cline { 2 - 9 } & - & 2.0 & 10.1 & 2.0 & 8.3 & 20.0 & 540 \\
\hline
\end{tabular}

*Total amount of amine is varied from 0 to $2.0 \mathrm{phr}$ range. 
For Quinuclidine, the M100 and M300 are relatively high for $1.0 \mathrm{phr}$ and more compared to the DPG-system. The tensile strength at break TB of Qinuclidine is also relatively higher than that of the DPG-system.

For 3-Quinuclidinol the M100, M300 and tensile strength at break show an increase with increasing amount of Q-nol. The tensile properties are still better, even if the amounts of Q-ine or Q-nol are reduced till half the amount of the DPGsystem. This is no surprise considering the molecular weight of these amines: $\mathrm{DPG}=211, \mathrm{Q}$-ine $=111, \mathrm{Q}-\mathrm{nol}=127$, from which almost the half quantities in phr would correlate with the same molar amounts.

\subsubsection{Reinforcement index: M300/M100}

The reinforcement index M300/M100 is plotted as a function of the amount of Qine or Q-nol in the absence of DPG in Figure 8.14.

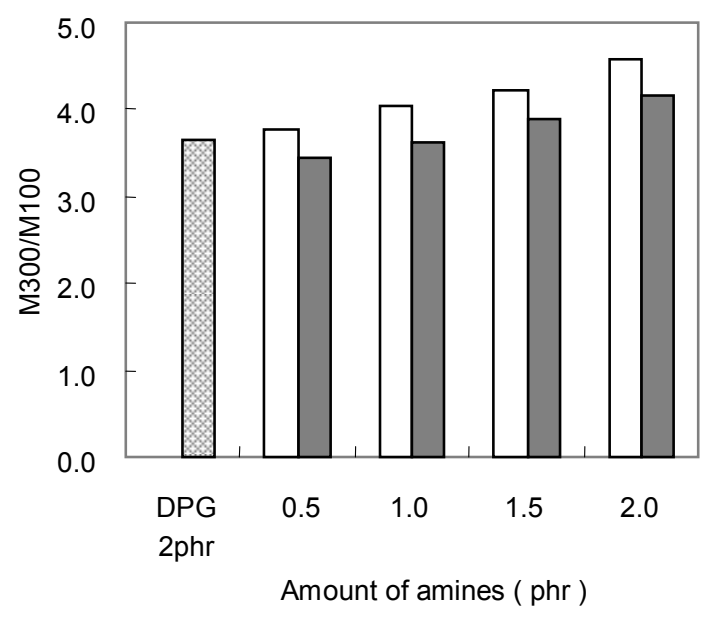

Figure 8.14 : Reinforcement index as a function of the amount of amines

( ) : 2 phr DPG (Control) ; ( $\square$ ): Quinuclidine ;

( ) : 3-Quinuclidinol

The reinforcement index M300/M100 of Q-ine and Q-nol are relatively high compared to that of the DPG system and show an increasing trend with increasing amounts of Q-ine or Q-nol. 
8.3.2. 6 Visco-elastic property: $\tan \delta$ at $60^{\circ} \mathrm{C}$

Figure 8.15 shows the tan $\delta$ at $60^{\circ} \mathrm{C}$ as a function of the amount of the Q-ine or Qnol.

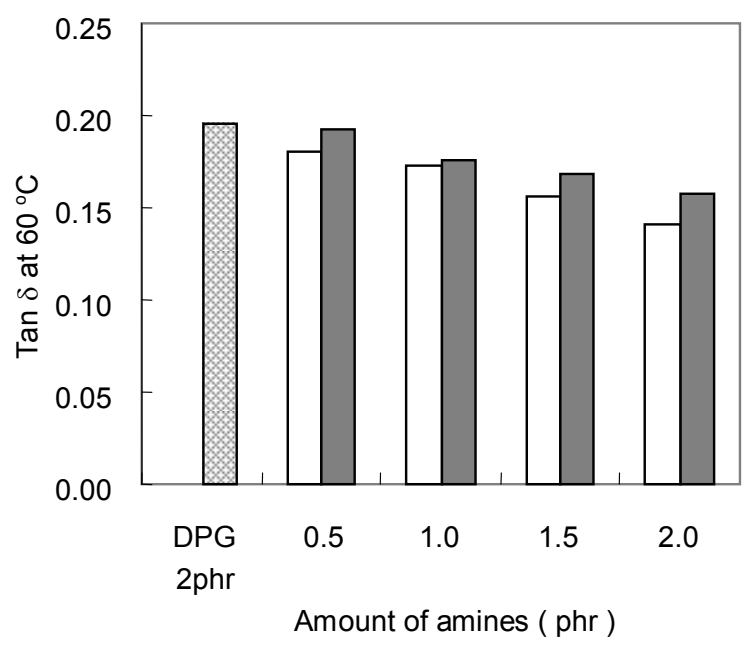

Figure 8.15: $\operatorname{Tan} \delta$ at $60^{\circ} \mathrm{C}$ as a function of the amount of amines

( ) : 2 phr DPG (Control) ; ( $\square$ ) : Quinuclidine ;

( ) : 3-Quinuclidinol

For both DPG alternatives the tan $\delta$ at $60^{\circ} \mathrm{C}$ is relatively low as compared to the DPG system and decreases slightly with increasing the amounts of the DPG alternatives. This also can be due to an increase of the bound rubber on the silica surface. Both figures 8.14 and 8.15 demonstrate the potential of Q-ine and Q-nol to replace DPG and result in lower rolling resistance of tires.

\subsection{Conclusions}

In the present chapter the DPG alternatives Q-ine and Q-nol, which have similar pKa values to DPG, were evaluated in silica rubber. Due to the presence of Q-ine or Q-nol in the $1^{\text {st }}$ mixing step, the silanization reaction is accelerated. In addtition, the bound rubber on the silica surface increase in the presence of Q-ine or Q-nol. Due to these factors, the physical properties of vulcanizates are improved. The Payne effect significantly decreases with increasing amounts of DPG alternatives. Also a decrease of silica flocculation can be seen. It is also possible to improve the physical properties related to rolling resistance of tires, such as M300/M100 and $\tan \delta$ at $60^{\circ} \mathrm{Cby}$ using the DPG alternatives Q-ine or Q-nol.

However, for the cure rate and scorch time, a different tendency between DPG and $\mathrm{Q}$-ine or Q-nol is found. In the case of Q-ine or Qnol, the cure rate increases with increasing amounts of these amines, but additionally the scorch time decreases fast. On the other hand, in case DPG is mixed in the $1^{\text {st }}$ mixing step, a decrease of 
cure rate and an increase in scorch time can be seen by increasing the amount of DPG. This indicates that DPG is consumed during rubber processing, wheras no consumption of Q-ine or Q-nol is noticed.

The effect of Q-ine or Q-nol in the absence of DPG was also investigated. Both DPG alternatives are capable of acting not only as silanization accelerator but also as cure accelerator. Considering all the properties, it is justified to conclude that Qine and Q-nol are capable of replacing DPG, whereas the shorter scorch-time relative to DPG needs to be corrected for. However, given the fact that the molecular weights of Q-ine and Q-nol are almost one half of that of DPG, only half amounts of Q-ine and Q-nol are needed on a phr-basis to replace DPG, for which the negative effect of reduced scorch-time remains limited. 


\subsection{References}

1. Ministry of Health, Labor \& Welfare, Japan (Ed): Toxicity Testing Reports of Environ. Chemicals, 8 (1) (2001).

2. Ministry of Labor, Japan: Mutagenicity Test Data of Exist. Chem. Subst.. JETOC (Ed.), pp. 111 (1996) (in Japanese).

3. W. David, U.S. Pat. 6.951.897, to Michelin Recherche et Technique S.A., (2307-2002).

4. S. Wolff, Kautsch. Gummi Kunstst, 34, 280 (1981).

5. A. Hasse, O. Klockmann, A. Wehmeier, Kautsch. Gummi Kunstst., 55, 236 (2002).

6. M.R. Kreja, J.L. Koenig, Rubber Chem. Technol., 66, 376 (1993).

7. M. Zaborski, J.B. Donnet, Macromol. Symp., 194, 87 (2003).

8. Aldrich MSDS 1 (2), CAS number: 100-76-5.

9. Aldrich MSDS 1 (2), CAS number: 1619-34-7.

10. L.A.E.M. Reuvekamp, "Reactive mixing of silica and rubber for tires and engine mounts", in Thesis: 2003, Dept. Rubber Technology, Univ. Twente: Enschede, the Netherlands

11. S. Wolff, Rubber Chem. Technol., 69, 325 (1996)

12. H.D. Luginsland, J. Frohlich, A. Wehmeier, Rubber Chem. Technol., 75, 563 (2002)

13. S. Mihara, R.N. Datta, W.K. Dierkes, J.W.M. Noordermeer, Paper No. 63 presented at the Fall 172th Technical Meeting of the Rubber Division, American Chemical Society, Cleveland, OH, 16-18 Oct. 2007

14. W.L. Hergenrother, Rubber Chem. Technol., 75, 215 (2002)

15. A. Coran, J. Donnet, Rubber Chem. Technol., 65, 1016 (1992)

16. G.A. George, A. Böhm, J. Appl. Polym. Sci., 55, 1041 (1995)

17. C.C. Lin, W.L. Hergenrother, ACS Technical Meeting of the Rubber Division, Fall, Cleveland, Ohio (2001).

18. J.W. Ten Brinke, : "Silica Reinforced Tyre Rubbers", in Thesis: 2002, Dept. Rubber Technology, Univ. of Twente: Enschede, the Netherlands 


\section{Chapter 9}

\section{CONCLUSIONS}

In recent years, silica has become one of the most important fillers used in tire tread compounds due to its contribution to a better environment. Silica is capable of not only reducing the rolling resistance but also improving the wet skid resistance of tires, compared to carbon black as a filler. However, silica-filled compounds provide many difficulties during rubber processing, because of the polarity difference between silica and polymer. To overcome these polarity differences a bi-functional silane coupling agent is generally used. A typical silane coupling agent is bis-(triethoxysilylpropyl)tetrasulfide (TESPT).

The silane chemistry during rubber processing is very complicated. Basically, from a processing point of view, two coupling reactions take place via TESPT. The first reaction is a coupling reaction between the TESPT molecule and the silica surface, the so-called silanization reaction. For this reaction hydrolysis of TESPT is required. The second reaction is silane-rubber coupling, supposed to happen only during the vulcanization stage. However, it is well known that TESPT acts as a sulfur donor during rubber processing. Therefore, premature crosslinking or scorch may take place at excess temperatures in the mixing stage already. All these reactions can take place simultaneously during silica rubber processing, and therefore the reinforcing mechanism of silica is much more complicated than that of carbon black.

Diphenylguanidine (DPG) greatly contributes to the physical properties of silica filled rubber. DPG acts as a secondary accelerator but also as silanization accelerator. In addition, DPG is capable of interacting with the silica surface. Therefore, DPG also affects the reinforcement effect of silica in rubber. DPG is subject to toxic concerns and has a negative influence on rubber-metal adhesion. Therefore, in the future DPG-alternatives will be required.

The first objective of the present thesis was to understand the reinforcing mechanism of different types of silica in rubber. Especially, the focus was on the bound rubber layer between silica and polymer, which significantly contributes to the physical properties of silica filled rubber. The second objective was to unravel the role of DPG played in silica-reinforced tire rubbers and the search for less toxic or environmentally friendly alternatives.

In the introduction Chapter 2 a general introduction was given regarding three elements playing an important role in silica-rubber technology: materials, methods and machinery. As to the materials aspect, the differences between highly dispersible (HD) and conventional (CV) silicas were described according to 
literature. Also newly developed silanes were introduced which can reduce the emission of volatile organic compounds during silica processing, in particular ethanol. For the various reactions of TESPT during rubber processing, the mechanism of the silanization reaction of silica by TESPT was reviewed. As to the methods and machine parameters regarding silica mixing, these two parameters are linked. The temperature development during mixing of the compounds is an important factor to control the silanization reaction. In addition, the type of mixer is important: with tangential rotor or intermeshing rotor geometry. It is well known that an intermeshing rotor mixer provides a better temperature control during mixing than a tangential rotor mixer, and consequently the silanization reaction is better controlled in the first one. In addition, several basic bound rubber models were introduced to understand the reinforcement mechanism of silica in rubber.

The effect of the bound rubber layer between silica and rubber polymer on the physical properties was studied in Chapter 3. The interfacial area between silica and polymer related to the filler-polymer interaction could be estimated by using the bound rubber measurement after ammonia treatment, to make sure that only the really chemically bound rubber was measured. The bound rubber content increased with higher mixing dump temperature due to a higher degree of silanization. Consequently, the Payne effect caused by filler-filler interaction was reduced. With increasing CTAB surface area of the silicas, the effective interfacial area of the silica surfaces accessible to the polymer $\left(\mathrm{V}_{\text {beff }} / \mathrm{CTAB}\right)$ becomes less, because of the strong filler-filler interaction caused by the polarity difference between silica and polymer. The bound rubber thickness was estimated using the Pliskin-Tokita equation. The bound rubber thickness increased relatively with lower CTAB surface area. This results again from the strong filler-filler interaction caused by the polarity difference between silica and polymer. The interfacial area between the silica and the polymer has a significant impact on the visco-elastic properties and the reinforcing power of silica in rubber. By increasing interfacial area between the silica surface and the rubber polymers by lower CTAB surface area, the Payne effect and $\tan \delta$ at $60^{\circ} \mathrm{C}$ are clearly reduced, because the increased interfacial area reduces the strong silica-silica interaction. The reinforcement parameter M300/M100, which is generally used in silica filled tire technology as an alternative measure for rolling resistance, also shows a good correlation with interfacial parameters such as the thickness ratio of bound rubber to the primary particle size of silica $\left(R_{g}+t\right) R_{g}$, and the specific bound rubber $\left(V_{\text {beff }} / C T A B\right)$. This means that the interfacial area on the silica surface plays a dominant role in determining the reinforcing properties for silica filled compounds.

Silica flocculation or demixing plays an important role in the reinforcement of silica filled compounds. It takes place at the very beginning of vulcanization. In Chapter 4 the flocculation process was monitored by following the change of the storage modulus at $0.56 \%$ strain, designated as the Payne effect value, using the RPA2000. The kinetic parameters, the rate constant and the activation energy of silica flocculation were calculated according to the Arrhenius equation. Considering the value of the activation energy, it was concluded that the flocculation of silica is a purely physical phenomenon. The flocculation rate of silica in the rubber matrix decreased with increasing interfacial bound rubber thickness on the silica surface. The flocculation process could be modeled according to Fick's law. In this chapter 
it was also suggested that the attractive flux due to the mutual forces between silica aggregates is the determining factor for silica flocculation.

An important aspect of silica reinforced rubber is how the silica can be properly dispersed in the rubber matrix. The sizes of the aggregates and of the agglomerates after mixing greatly impact the physical properties. As described in the previous chapter, silica flocculation takes place during the heating process involved in vulcanization. Therefore, the silica dispersion not only after mixing but also after vulcanization should be considered. In Chapter 5 the silica flocculation phenomenon during vulcanization was monitored using USAXS for two types of silica, which are a highly dispersible silica: Zeosil $1165 \mathrm{MP}$, and the conventional silica Ultrasil VN3. The cutoff length of the silica aggregates: $R_{s s}$, and the mass fractal dimension: $D_{m}$, were estimated according to the Unified Equation. For both silicas, $R_{s s}$ and $D_{m}$ increased during vulcanization. The $R_{s s}$ of VN3 was relatively high compared to that of $1165 \mathrm{MP}$. On the other hand, the $\mathrm{D}_{\mathrm{m}}$ of $\mathrm{VN} 3$ was relatively low compared to that of 1165MP. This means that VN3 has a lower tendency to silica flocculation in rubber. Silica-filled rubber without TESPT coupling agent showed a higher $R_{s s}$ and $D_{m}$ compared to the system with TESPT. This results from the shielding effect of the TESPT.

As demonstrated in the previous chapters, the interfacial area between silica and polymer plays an important role in the physical properties of silica reinforced rubber. Therefore, it is important to have a means to control the interfacial area. One of the possibilities is promotion of the silanization by using an amine compound. DPG is the preferred amine in silica filled rubber, capable of accelerating the silanization reaction. However, DPG is subject to toxic concerns, for which reason DPG-alternatives may be required in future. In Chapter 6 several amines were tested vs. DPG, differing in pKa values. The kinetic parameters, such as the reaction rate and the activation energy in model olefin experiments were estimated using the Arrhenius approach. The reaction rate of silanization remained more or less unchanged for amines with a pKa till 6.5, and then increased with further increasing pKa value. DPG showed the highest silanization rate, as well as Quinuclidine (Q-ine) and 3-Quinuclidinol (Q-nol), which have similar pKa values to DPG. The activation energy of silanization decreased in the presence of DPG or the DPG alternatives. The pKa values of amines is strongly related to their nucleophilicity, therefore the silanization reaction could be accelerated by the nucleophilic reaction. It means that hydrolysis of TESPT is the rate-determining factor. The three amines showed the lowest Payne effect values in the rubber system, indicative of the best degree of silanization. This corresponds to the results of the kinetic study with the model olefin system.

In Chapter 7, a further investigation regarding the role of amines during silica rubber processing was done by using LC-MS measurements. Model olefin compounds were used in this study as well. A sizable amount of cross-linked products was found even in the absence of elemental sulfur in the reaction mixture. As a matter of fact, TESPT is known to be able to act as a sulfur donor during the silanization reaction. Due to the presence of the amines DPG or its alternatives, the sulfur distribution of TESPT changes. The tri-sulfide significantly increases with increasing reaction time. As the starting TESPT is on average a tetra-sulfide, the 
decrease to on average the tri-sulfide means that active sulfur is indeed spent in the reaction mixture. Also a complex between the model olefin and TESPT was observed. This complex increased as well in the presence of the amines. Furthermore, a DPG-TESPT complex was observed. On the other hand, the DPGalternatives Q-ine and Q-nol did not show such a reaction product with TESPT.

The effects of DPG and the DPG alternatives on the physical properties of silicareinforced rubber were investigated in Chapter 8 . In the presence of these amines the bound rubber content increased with increasing amine content. As mentioned in the previous chapters, the bound rubber plays an important role in silica reinforced rubber. As a result the Payne effect decreased in the presence of DPG or the DPG- alternatives Q-ine and Q-nol. The reinforcement index M300/M100 increased with more of these amines added. Similarly, the $\tan \delta$ at $60^{\circ} \mathrm{C}$ decreased in the presence of these amines. Both parameters, the high M300/M100 and low $\tan \delta$ at $60^{\circ} \mathrm{C}$ are indicative of low rolling resistance tires. However, for scorch time and cure rate a different tendency was observed between DPG and its alternatives $\mathrm{Q}$-ine and Q-nol. In the latter cases the cure rate increased with the levels of Q-ine or Q-nol, and the scorch time decreased. On the other hand, in case DPG is mixed in the $1^{\text {st }}$ mixing step, a decrease of the cure rate and an increase of the scorch time can be seen with increasing amounts of DPG. Considering these results, it was suggested that DPG has the possibility to be consumed during the silanization reaction, and less so Q-ine and Q-nol. The effects of Q-ine and Q-nol in the full absence of DPG were also investigated. Both DPG alternatives are capable of acting as silanization accelerator as well as cure accelerator. Considering all the properties, it is possible to conclude that Q-ine and Q-nol are capable of replacing DPG at half quantities in phr (parts per hundred rubber) because of their half molecular weight relative to DPG. At these reduced quantities the decrease of scorch time in the presence of Q-ine or Q-nol can easily be taken care of in practice.

Silica greatly contributes to reduction of the rolling resistance of tires. This means that silica-reinforcement is of growing importance in tires because of reduced fuel consumption in automotive transport and consequent preservation of the environment. The present thesis provides insight into many aspects of silica reinforcement of rubber, as well as understanding of the reinforcing mechanism of silica. The results are expected to contribute to the future direction of silica technology worldwide, to provide lower energy consuming tires with otherwise the same or even better safety characteristics, for the benefit of mankind. 


\section{Conclusies}

Door zijn bijdrage aan een beter milieu is silica recentelijk een van de meest belangrijke vulstoffen geworden in loopvlak rubbermengsels van banden. Silica is niet alleen in staat de rolweerstand te verlagen maar ook om de grip bij nat wegdek te verbeteren, in vergelijking tot roet als vulstof. Echter, silica gevulde mengsels zorgen voor veel problemen tijdens het bewerken van rubber, door het polariteitsverschil tussen silica en polymeer. Om dit polariteitsverschil te overwinnen, wordt over het algemeen een bifunctioneel silane coupling agent toegevoegd. Een typische coupling agent is bis-(triethoxysilylpropyl)tetrasulfide (TESPT).

De silaan chemie tijdens rubber bewerking is erg gecompliceerd. Vanuit het proces perspectief vinden in principe twee reacties plaats via TESPT. De eerste reactie is een koppelingsreactie tussen het TESPT molecuul en het silica oppervlak, de zogenaamde silanisatie reactie. For deze reactie is hydrolyse van TESPT noodzakelijk. De tweede reactie is silane-rubber koppeling; deze wordt voorgesteld alleen plaats te vinden tijdens de vulkanisatie stap. Het is echter bekend dat TESPT zicht kan gedragen als een zwavel donor tijdens rubber bewerking. Daarom kan premature vernettingsreacties of scorch plaatsvinden bij hoge temperaturen al tijdens het mengproces. Al deze reacties kunnen gelijktijdig plaatsvinden tijdens silica rubber bewerking, en daarom is het versterkende mechanisme van silica veel gecompliceerder dan die van roet.

Diphenylguanidine (DPG) levert een grote bijdrage aan de eigenschappen van silica versterkt rubber. DPG fungeert als een secundaire versneller maar ook als een silanisatie versneller. Daarom beïnvloedt DPG ook het versterkende effect van silica in rubber. DPG wordt verdacht giftige eigenschappen te hebben en het heeft een negatieve invloed op rubber-metaal hechting. Daarom zijn in de toekomst alternatieven voor DPG nodig.

Het eerste doel van dit proefschrift was het begrijpen van het versterkende mechanisme van verschillende types silica in rubber. De focus was vooral op laag gebonden rubber tussen tussen silica en polymeer, die een significante bijdrage levert aan de fysische eigenschappen van silica gevuld rubber. Het tweede doel was de rol te ontrafelen die DPG speelt in silica gevuld banden rubbers en de zoektocht naar minder giftige of milieuvriendelijke alternatieven.

Hoofdstuk 2 geeft een algemene introductie over drie elementen die een belangrijke rol spelen in silica-rubber technologie: materialen, methoden en 
machines. Voor het aspect materialen, werde de verschillen tussen hoog dispergeerbare (HD) en conventionele (CV) silicas beschreven volgens de literatuur. Ook werden recentelijk ontwikkelde silanen geïntroduceerd die de emissie van vluchtige organische componenten die tijdens het silica proces ontstaan, in het bijzonder ethanol, kunnen verminderen. Van de verschillende reacties van TESPT tijdens het rubber proces, een overzicht is gegeven van het mechanisme van de silanisatie reactie van silica met TESPT. Voor de methoden en de machine parameters van het silica mengproces, deze twee parameters zijn verbonden. De temperatuur ontwikkeling tijden het mengen van de compounds is een belangrijke factor om de silanisatie reactie te controleren. Ook het type menger is belangrijk: met een tangentiële of intermeshing rotor geometrie. Het is bekend dat een menger met een intermeshing rotor een betere temperatuurscontrole heeft dan een tangentiële rotor menger, en daardoor de silanisatie reactie beter gecontroleerd wordt. Verder werden enkele elementaire gebonden rubber modellen geïntroduceerd om het versterkingsmechanisme te begrijpen van silica in rubber.

Het effect van de laag gebonden rubber tussen silica en het rubber polymeer op de fysische eigenschappen werd bestudeerd in Hoofdstuk 3. Het grensvlak gebied tussen silicaen polymeer gerelateerd aan de vulstof-polymeer interactie kon bepaald worden door gebruik te maken van de gebonden rubber meting na ammonia behandeling, om zeker te zijn dat alleen het chemisch gebonden rubber gemeten werd. De hoeveelheid gebonden rubber nam toe met toenemende dump temperatuur door een hoger silanisatie gehalte. Daardoor werd het Payna effect verminderd veroorzaakt foor vulstof-vulstof interactie. Met toenemende CTAB oppervlakte van de silicas, het effectieve grensvlak van het silica oppervlak toegankelijk voor het polymeer $\left(\mathrm{V}_{\text {beff }} / \mathrm{CTAB}\right)$ neemt af, door de sterke vulstof-vulstof interactie veroorzaakt door het polariteitsverschil tussen silica en polymeer. De dikte van de laag gebonden rubber werd bepaald door de Pliskin-Tokita vergelijking. De dikte van de laag gebonden rubber nam toe met afnemende CTAB oppervlakte. Ook dit wordt veroorzaakt door de sterke vulstof-vulstof interactie veroorzaakt door het polariteitsverschil tussen silica en polymeer. Het grensvlak tussen silica en polymeer heeft een significante invloed op de visco-elastische eigenschappen en de versterkende kracht van silica in rubber. Door het grensvlak te vergroten tussen het silica oppervlak en de rubber polymeren door het CTAB oppervlak te verlagen, het Payne effect en tan $\delta$ bij $60^{\circ} \mathrm{C}$ worden duidelijk verlaagd, omdat het toegenomen grensvlak de sterke silica-silica interactie verlaagd. De versterkingsparameter M300/M100, die over het algemeen gebruikt wordt in silica gevulde banden technologie als een alternatieve meting voor rolweerstand, laat ook een goede correlatie zien met grensvlakparameters zoals de ratio tussen de dikte van het gebonden rubber en de primaire deeltjesgrootte van silica $\left(R_{g}+t\right) R_{g}$, en het specifieke gebonden rubber $\left(V_{\text {beff }} / C T A B\right)$. Dit betekent dat het grensvlak van het silica oppervlak een dominante rol speelt voor het bepalen van de versterkende eigenschappen van silica gevulde compounds.

Silica flocculatie of ontmenging speelt een belangrijke rol in de versterking van silica gevulde compounds. Het gebeurt aan het begin van vulkanisatie. In Hoofdstuk 4 werd het flocculatieproces gevolgd door de verandering van de storage modulus bij $0.56 \%$ strain, ook wel de Payne effect waarde genoemd, te volgen met de RPA 2000. De kinetische parameters, de snelheidskonstante en de 
activeringsenergie van silica flocculatie ware berekend volgens de arrhenius vergelijking. Uit de waarde voor de activeringsenergie werd geconcludeerd dat de flocculatie van silica een puur fysisch fenomeen is. De flocculatie snelheid van silica in de rubber matrix nam af met toenemenede dikte van gebonden rubber op het silica oppervlak. Het flocculatie proces kon gemodelleerd worden volgend de wet van Fick. In dit hoofdstuk werd ook voorgesteld dat aantrekkende flux door de onderlinge krachten tussen silica aggregaten de bepalende factor is voor silica flocculatie.

Een belangrijk aspect van silica versterkt rubber is hoe de silica naar behoren gedispergeerd kan worden in de rubber matrix. De grootte van de aggregaten en de agglomeraten na het mengen heeft een grote invloed op de fysische eigenschappen. Zoals beschreven in het vorige hoofdstuk, vindt silica flocculatie plaats tijdens de verhitting bij vulkanisatie. Daarom moet de silica dispersie niet alleen na mengen maar ook na vulkanisatie bekeken worden. In Hoofdstuk 5 werd het silica flocculatie fenomeen tijdens vulkanisatie gevolgd met behulp van USAXS voor twee typen silica: de hoog dispersieve Zeosil 1165MP en de conventionele Ultrasil VN3. De cutoff lengte van de silica aggregaten: $R_{s s}$, en de massa fractie dimensie: $D_{m}$, waren bepaald volgens de 'Unified Equation'. Voor beide silicas namen $R_{s s}$ en $D_{m}$ toe tijdens vulkanisatie. De $R_{s s}$ van VN3 was relatief laag vergeleken met die van 1165MP. Aan de andere kant was de $D_{m}$ van VN3 relatief laag vergeleken met die van 1165MP. Dit betekent dat VN3 minder de neiging heeft tot flocculatie in rubber. Silica gevuld rubber zonder coupling agent TESPT liet een hogere $R_{s s}$ and $D_{m}$ zien vergeleken met het systeem met TESPT. De wordt veroorzaakt door het afschermend effect van TESPT.

Zoals gedemonstreerd in de vorige hoofdstukken speelt het grensvlak tussen silica en polymeer een belangrijke rol voor de fysische eigenschappen van silica versterkt rubber. Daarom is het belangrijk om middelen te hebben om het grensvlak te controlleren. Een van de mogelijkheden om silanisatie te promoten is het gebruik van een amine compound. DPG wordt bij voorkeur gebruikt in silica gevuld rubber omdat het in staat is de silanisatie reactie te versnellen. Echter, DPG wordt verdacht giftig te zijn; daarom zijn alternatieven nodig in de toekomst. In hoofdstuk 6 werden verscheidene amines, verschillend in pKa waarden, vergeleken met DPG. De kinetische parameters zoals de reactiesnelheid en de activeringsenergie in model olefin experimenten waren bepaald met behulp van de Arrhenius benadering. De silanisatie reactiesnelheid bleef min of meer onveranderd voor amines met een pKa tot 6.5, vervolgens nam deze toe met toenemende pKa waarde. DPG liet de hoogste silanisatie snelheid zien, samen met Quinuclidine (Q-ine) en 3-Quinuclidinol (Q-nol), deze hebben vergelijkbare pKa waarden. De activeringsenergie van silanisatie nam af in aanwezigheid van DPG of de DPG alternatieven. De pKa waarden van aminen is sterk gerelateerd aan hun nucleofiliciteit, daarom kan het zo zijn dat de silanisatiereactie versneld wordt door de nucleofiele reactie. Dit betekent dat de hydrolise van TESPT de snelheidsbepalende stap is. De drie amines lieten de laagste Payne effect waarden zien in het rubber systeem, wat kan duiden op de beste silanisatiegraad. Dit correspondeert met de resultaten van de kinetische studie met het model olefine systeem. 
In Hoofdstuk 7 is verder onderzoek gedaan naar de rol van de amines tijdens het bewerken van rubber met silica met behulp LC-MS metingen. Model olefine compounds werden ook in deze studie gebruikt. Een redelijke hoeveelheid vernette producten werd gevonden zelfs bij afwezigheid van elementair zwavel in het reactiemengsel. Het is bekend dat TESPT zich gedraagt als een zwavel donor tijdens de silanisatiereactie. Door de aanwezigheid van de amines DPG of zijn alternatieven verandert de zwavel verdeling van TESPT. De tri-sulfide neemt significant toe met toenemende reactietijd. De TESPT aan het begin is gemiddeld een tetra-sulfide, de afname naar gemiddeld een tri-sulfide betekent dat het actieve zwavel inderdaad afgegeven wordt in het reactiemengsel. Ook is een complex waargenomen tussen het model olefine en TESPT. Dit complex nam ook toe in de aanwezigheid van de amines. Verder werd ook een DPG-TESPT complex waargenomen. De DPG alternatieven $Q$-ine en $Q$-nol lieten niet een dergelijk reactieproduct zien.

De effecten van DPG en de DPG alternatieven op de fysische eigenschappen van silica versterkt rubber werden onderzocht in Hoofdstuk 8. In de aanwezigheid van deze amines nam de hoeveelheid gebonden rubber toe met toenemende amine gehalte. Zoals vermeld in de voorgaande hoofdstukken speelt gebonden rubber een belangrijke rol in silica versterkt rubber. Als gevolg daalde het Payne effect in de aanwezigheid van DPG of de DPG alternatieven Q-ine en Q-nol. De versterkingsindex M300/M100 nam toe wanneer meer van deze amines werden toegevoegd. Op gelijke wijze nam de tan $\delta$ af in de aanwezigheid van deze amines. Beide parameters, de hoge $\mathrm{M} 300 / \mathrm{M} 100$ en de lage tan $\delta$ bij $60^{\circ} \mathrm{C}$ zijn indicaties voor banden met een lage rolweerstand. Echter, voor de scorch tijd en vernettingssnelheid werd een andere tendens waargenomen tussen DPG en zijn alternatieven $Q$-ine en $Q$-nol. In de laatste gevallen nam de vernettingssnelheid toe met de hoeveelheid $Q$-ine of $Q$-nol, en de scorch tijd nam af. Voor het geval dat DPG in de eerste stap gemengd wordt kan een afname in vernettingssnelheid en een toename in scorch tijd worden waargenomen met toenemende hoeveelheid DPG. Deze resultaten in ogenschouw genomen werd gesuggereerd dat DPG de mogelijkheid heeft om geconsumeerd te worden tijden de silanisatiereactie; Q-ine en $Q$-nol hebben dit minder. De effecten van $Q$-ine en $Q$-nol in volledige afwezigheid van DPG werden ook onderzocht. Beide DPG alternatieven zijn in staat te fungeren als zowel silanisatie versneller en vernettingsversneller. Alle eigenschappen in ogenschouw genomen, kan geconcludeerd worden dat Q-ine en Q-nol in staat zijn DPG te vervangen met de helft van de hoeveelheid in phr (per honderd delen rubber) vanwege hun halve molekuulgewicht vergeleken met DPG. Bij deze lage hoeveelheden kan de afname in scorch tijd in de aanwezigheid van Q-ine en Q-nol eenvoudig te boven worden gekomen in de praktijk.

Silica levert een grote bijdrage aan de reductie van de rolweerstand van banden. Dit betekent dat silica versterking in toenemende mate belangrijk wordt in banden vanwege de afnemende brandstofverbruik in de auto transport en de milieuvriendelijkheid als gevolg daarvan. Dit proefschrift geeft inzicht in veel aspecten van silica versterking van rubber, als ook begrip van het versterkende mechanisme van silica. Verwacht wordt dat de resultaten bijdragen aan de toekomst van silica technologie wereldwijd, om minder energieverbruikende banden te leveren met dezelfde, of zelfs betere, veiligheidskarateristieken ten 
goede voor de mensheid. 


\section{Main symbols and abbreviations}

\begin{tabular}{|c|c|}
\hline$\delta:$ & phase angle \\
\hline$\phi:$ & volume fraction of filler \\
\hline$\phi_{\text {eff: }}$ & $\begin{array}{l}\text { effective volume fraction of silica which can form chemical bond } \\
\text { to polymer }\end{array}$ \\
\hline$\dot{\gamma}:$ & shear rate of measurement \\
\hline$\gamma(\mathrm{t}):$ & sinusoidal shear deformation \\
\hline$\gamma_{0}:$ & maximum strain \\
\hline$\gamma_{\mathrm{c}}:$ & strain half-width amplitude \\
\hline$\gamma_{\mathrm{s}}:$ & strain half-width amplitude \\
\hline $\begin{array}{l}\gamma_{S}: \\
\gamma_{S} \text { d: } \\
\gamma_{S}{ }^{s p}:\end{array}$ & $\begin{array}{l}\text { surface energy of a filler } \\
\text { dispersive component } \\
\text { polar component }\end{array}$ \\
\hline$\Gamma:$ & $\begin{array}{l}\text { fraction of gel which is insolubles naturally occurring in rubber } \\
\text { polymer }\end{array}$ \\
\hline & due to excessive branching or coming from production \\
\hline$\lambda:$ & wave length of the X-ray \\
\hline$\eta:$ & viscosity \\
\hline$\eta_{0}:$ & viscosity of pure liquid \\
\hline v: & concentration of elastically active chains per unit volume $\left[\mathrm{cm}^{3}\right]$ \\
\hline$\rho:$ & density of filler \\
\hline$\sigma(\mathrm{t}):$ & shear stress response \\
\hline ६:: & sample volume \\
\hline$\omega:$ & angular frequency \\
\hline a: & ratio of length/width of the particles \\
\hline A: & attractive force between the particles \\
\hline APCl: & atmospheric pressure chemical ionization \\
\hline BET: & Brunauer - Emmett - Teller specific surface area \\
\hline BR: & butadiene-rubber \\
\hline b: & bound rubber thiclness \\
\hline$b_{\text {eff: }}$ & effective bound rubber thickness \\
\hline C: & particle concentration \\
\hline$C(0):$ & summed amounts of unreacted TESPT isomers at time 0 \\
\hline$C(t):$ & summed amounts of unreacted TESPT isomers at time $t$ \\
\hline CBS: & N-cyclohexyl-2-benzothiazolesulphenamide \\
\hline $\begin{array}{l}\text { CTAB: } \\
\text { area }\end{array}$ & $\mathrm{N}$-cetyl-N,N,N'-trimethylammonium-bromide specific \\
\hline CV: & conventional silica \\
\hline & Euclidean dimension of the space \\
\hline
\end{tabular}




\begin{tabular}{|c|c|}
\hline D: & Diffusion coefficient \\
\hline DABCO: & 1,4-diazabicyclo[2,2,2]octane \\
\hline DAD: & diode array detector \\
\hline DBP: & Dibutyl phthalate \\
\hline $\mathrm{D}_{\mathrm{m}}:$ & mass-fractal dimension \\
\hline$D_{s}:$ & surface fractal dimension \\
\hline EPDM: & ethylene propylene diene rubber \\
\hline DPG: & 1,3-diphenylguanidine \\
\hline$D_{s}:$ & surface-fractal dimension \\
\hline $\mathrm{E}_{\mathrm{a}}:$ & activation energy \\
\hline $\mathrm{E}_{\mathrm{a} 1}$ : & activation energy of primary reaction of TESPT \\
\hline EB: & elongation at break \\
\hline $\begin{array}{l}\text { E-modulus: } \\
\text { f: }\end{array}$ & $\begin{array}{l}\text { Young's modulus for small strain of the stress-strain curve } \\
\text { fraction of filler surface exposed to the insoluble polymer in the } \\
\text { bound rubber measurement }\end{array}$ \\
\hline $\mathrm{F}:$ & fraction of filler which is chemically active \\
\hline G': & shear modulus \\
\hline $\mathrm{G}_{0}^{\prime}:$ & shear modulus of unfilled system \\
\hline$G^{\prime}(0):$ & shear modulus at zero strain amplitude \\
\hline$G^{\prime}(\infty):$ & shear modulus at the high strain amplitudes \\
\hline $\mathrm{G}^{\prime}(\mathrm{t}):$ & storage modulus at $0.56 \%$ strain amplitude after heating time $t$ \\
\hline G'(i): & storage modulus after preheating for 1 minute \\
\hline$G^{\prime}(f):$ & final storage modulus after heating for 12 minutes \\
\hline G”: & loss modulus \\
\hline G"(0): & loss modulus at zero strain amplitude \\
\hline G" $(\infty)$ & loss modulus at the high strain amplitudes \\
\hline HD: & highly dispersible silica \\
\hline HPLC: & high performance liquid chromatography \\
\hline I(q): & scattering intensity \\
\hline IIR: & isobutylene-isoprene rubber \\
\hline ISO: & international organization for standardization \\
\hline $\mathrm{J}_{\mathrm{f}}:$ & attractive flux \\
\hline k: & rate constant of reaction \\
\hline K: & Boltmann's constant \\
\hline $\mathrm{k}_{\mathrm{a}}:$ & rate constant of silica flocculation \\
\hline kagg: & rate constant of agglomeration \\
\hline kbre: & rate constant of breakage of agglomeration \\
\hline $\mathrm{k}_{\mathrm{e}}:$ & constant value for spherical particle \\
\hline $\mathrm{k}_{1}:$ & rate constant of primary reaction of TESPT \\
\hline $\mathrm{k}_{12}$ : & rate constant from primary particle to aggregate \\
\hline $\mathrm{k}_{2}:$ & rate constant of secondary reaction of TESPT \\
\hline $\mathrm{k}_{21}$ : & rate constant of breakage of aggregates into primary particles \\
\hline $\mathrm{k}_{23}$ : & rate constant from aggregate to agglomerate \\
\hline $\mathrm{k}_{32}:$ & rate constant of breakage of agglomerate into aggregates \\
\hline LC-MS: & liquid chromatography equipped with mass spectrometry \\
\hline $\mathrm{m}:$ & model fitting parameter \\
\hline M100: & stress at $100 \%$ strain \\
\hline M300: & stress at $300 \%$ strain \\
\hline M300/M100: & reinforcement index \\
\hline
\end{tabular}




\begin{tabular}{|c|c|}
\hline ML1+4: & Mooney viscosity \\
\hline 3-m-1-p: & 3-methyl-1-pentene \\
\hline $\mathrm{N}_{0}:$ & the number of elastically active filler contacts at zero deformation \\
\hline NBR: & nitrile rubber \\
\hline $\mathrm{N}_{\mathrm{c}}$ : & the number of remaining contacts at a given strain \\
\hline NR: & natural rubber \\
\hline p: & power law value in unified equation \\
\hline phr: & parts per hundred rubber \\
\hline PILATUS: & pixel apparatus for the statistic light scattering \\
\hline pKa: & acid dissociation constant \\
\hline q: & scattering angle \\
\hline Q-ine: & quinuclidine \\
\hline Q-nol: & 3-quinuclidinol \\
\hline R: & gas constant $\mathrm{R}$ \\
\hline RPA: & rubber process analyzer \\
\hline r: & hydrodynamic radius of particle \\
\hline$r_{\text {app }}:$ & apparent radius of the equivalent particle \\
\hline$r_{f}:$ & radius of filler particle \\
\hline $\mathrm{R}_{\mathrm{a}}$ : & radius of aggregate \\
\hline $\mathrm{R}_{\mathrm{i}}:$ & structural size of aggregates or agglomerates \\
\hline $\mathrm{R}_{\mathrm{gg}}$ : & upper (agglomerates) cut-off length of the mass-fractal structure \\
\hline $\mathrm{R}_{\mathrm{ss}}$ : & lower (aggregate) cut-off length of the mass-fractal structure \\
\hline$r_{\text {app: }}$ & apparent radius of filler particle \\
\hline $\mathrm{R}_{\text {agg: }}$ & rate of agglomelation \\
\hline $\mathrm{R}_{\text {break: }}$ & rate of breakage of agglomelation \\
\hline $\mathrm{R}_{\mathrm{gg}}:$ & upper cut-off length of the mass-fractal structure \\
\hline $\mathrm{R}_{\mathrm{i}}:$ & structure size of aggregates or agglomerates \\
\hline RPA2000: & rubber process analyzer \\
\hline $\mathrm{R}_{\mathrm{ss}}$ : & lower cut-off length of the mass-fractal structure \\
\hline S: & $\begin{array}{l}\text { specific surface area of silica obtained from the CTAB } \\
\text { measurement }\end{array}$ \\
\hline SAS: & small angle scattering \\
\hline S-SBR: & solution styrene-butadiene rubber \\
\hline $\mathrm{t}:$ & time \\
\hline $\mathrm{T}:$ & absolute temperature \\
\hline $\tan \delta$ : & loss angle \\
\hline TB: & tensile strength at break \\
\hline TEM: & transmission electron microscope \\
\hline TESPD: & Bis-(triethoxysilylpropyl)disulphide \\
\hline TESPT: & Bis-(triethoxysilylpropyl)tetrasulphide \\
\hline TME: & 2,3-dimethyl-2-butane \\
\hline T5: & Mooney scorch time \\
\hline USAS: & ultra small angle scattering \\
\hline USANS: & ultra small angle neutron scattering \\
\hline USAXS: & ultra small angle X-ray scattering \\
\hline UV: & Ulraviolet \\
\hline $\begin{array}{l}V_{\text {beff: }} \\
\text { silica }\end{array}$ & effective volume fraction of polymer chemically bound to the \\
\hline
\end{tabular}




$\begin{array}{ll}\mathrm{V}_{\mathrm{b}}: & \text { volume fraction of bound rubber in the polymer } \\ \mathrm{W}_{\mathrm{fg}}: & \text { weight of silica with the bound rubber attached to it after } \\ & \text { ammonia treatment } \\ \mathrm{W}_{\mathrm{f}}: & \text { weight of the silica in the specimen } \\ \mathrm{W}_{\mathrm{p}}: & \text { weight of the polymer in the specimen } \\ \mathrm{V}_{\mathrm{p}}: & \text { volume fraction of polymer in chemically bound rubber } \\ \mathrm{V}_{\mathrm{f}}: & \text { volume fraction of filler } \\ \mathrm{V}_{\mathrm{b}}: & \text { volume fraction of bound rubber in polymer } \\ \mathrm{v}_{\mathrm{pp}}: & \text { volume fraction of polymer which is detached by ammonia } \\ \mathrm{x}: & \text { treatment } \\ \mathrm{x}_{\mathrm{c}}: & \text { degree of distribution or dispersion. }\end{array}$




\section{Bibliography}

\section{JORNAL PAPERS}

1. Flocculation in silica reinforced rubber compounds

S. Mihara, R. N. Datta and J. W. M. Noordermeer,

Rubber Chem. Technol., accepted (2007)

2. Effect of DPG on silanization chemistry of silica in rubber processing

S. Mihara, R. N. Datta, A. G. Talma and J. W. M. Noordermeer,

Rubber Chem. Technol., submitted (2008)

3. Ultra small-angle $X$-ray scattering study of silica flocculation in filled rubber

S. Mihara, R. N. Datta, N. Amino, Y. Ishikawa, S. Nishitsuji and J. W. M. Noordermeer,

Macroolecules, to be submitted.

4. Determining factors of physical properties of silica reinforced rubber

S. Mihara, R. N. Datta and J. W. M. Noordermeer,

J. Appl. Polym. Sci., to be submitted.

5. Model compound study of DPG alternatives

S. Mihara, R. N. Datta, A. G. Talma and J. W. M. Noordermeer, Kautsch. Gummi Kunstst., to be submitted.

\section{CONFERENCE PROCEEDING}

1. Bound rubber study of silica filled rubber

S. Mihara, R. N. Datta and J. W. M. Noordermeer

Dutch Polymer Days, Lunteren, 5th Feb. 2007

2. Insight into the kinetics of flocculation in silica reinforced compounds

S. Mihara, R. N. Datta and J. W. M. Noordermeer

Proceeding of the $172^{\text {nd }}$ Technical Meeting, ACS Rubber Division, Cleveland, USA, Oct. 2007.

3. Effect of DPG on silanization chemistry of silica in rubber processing

S. Mihara, R. N. Datta, A. G. Talma and J. W. M. Noordermeer

Proceeding of the $173^{\text {rd }}$ Technical Meeting, ACS Rubber Division, Louisville, USA, Oct. 2008.

4. Effect of DPG on silanization chemistry of silica

S. Mihara, R. N. Datta, A. G. Talma and J. W. M. Noordermeer 
Proceeding of the Meeting, Verening van Kunststof en Rubber Technologen, Enschede, Dec. 2008.

5. Ultra small-angle $X$-ray scattering study of silica flocculation in filled rubber S. Mihara, R. N. Datta, N. Amino, Y. Ishikawa, S. Nishitsuji and J. W. M. Noordermeer

Proceeding of Eurofillers international conference, Alessandria, Italy, June 2009.

\section{PATENT APPLICATIONS}

1. S. Mihara, R. N. Datta, A. G. Talma, J. W. M. Noordermeer, Rubber compound. Filed in December 2006 


\section{Curriculum vitae}

Satoshi Mihara was born on $5^{\text {th }}$ March, 1973 in Kumamoto, Japan. He obtained his Bachelor of Science in 1995 and Master of Science in 1998 from Mie University. After graduation from the Mie University, he started to work in Yokohama Rubber Co., LTD. His research in Yokohama Rubber includes filler reinforcement with special focus to silica technology and compoundings.

In November 2005, he started his Ph.D under the supervision of Prof. Dr. Ir. J. W. M. Noordermeer and Dr. R. N. Datta at the University of Twente in the Netherlands. The main focus of his research was on "Reactive Processing of Silica-reinforced Tire Rubber". This research was financially supported by Yokohama Rubber Co. LTD. The results of this research are described in this thesis. 


\section{Acknowledgements}

The work described in this thesis is the results of work for three years at the University of Twente, the Netherlands and partly at the Yokohama Rubber Co., LTD. During this period as a Ph.D student, a lot of people helped me.

I would like to appreciate them and express my sincere gratitude to them.

First of all, I would like to thank my promoter, prof. dr. ir. Noordermeer, who gave me the opportunity to study at the Elastomer Technology and Engineering group. I have learned not only the scientific aspects regarding rubber technology but also the spirit as a researcher. I am sure that your teaching and coaching during this period will help me in my future. Again, thank you very much for all your support during this period.

Dear Rabin, with much sorrow I would like to express my sincere sympathies and acknowledgements. Even now I can not recognize your passing. You are not only my co-promoter but also a guide in this challenge. Without you, it would have been an impossible task. You have helped me a lot of things during this period. Although you were so busy during this project, we had a lot of discussion to find a good idea and the structure of my work. The way of your thinking to find new things will help me in my next career in Yokohama. Thanks for your teaching and advice, and I will miss you. Thanks are also due to Sumana-san for her generous support.

Dear Wilma, although we had limited scope for technical discussions, you also helped me a lot of things which made this thesis possible. I really appreciate all your support in this period. We will meet somewhere at rubber conference.

Dear, Auke, you really gave me good ideas and interpretations regarding my results. The time to discuss with you was a really fruitful. Your scientific imagination brought me the right way in my PhD work.

Dear Ishikawa, I really appreciate that you gave me an opportunity to study at the University of Twente as well as valuable advices. This project would not have been successful without all your support. I keep my promise to remain a bridge between Yokohama and European country regarding the rubber technology. Again, thank you for all your support before and during our project.

Dear Amino, Thank you for being my graduation committee, even though the delivery date of your first child might concur with my defense. I will continue to work with you in Yokohama.

Dear Mori, I appreciate all your support during this period. Although you left Yokohama, I hope we will see each other somewhere in the Rubber World.

Dear my colleagues in Yokohama, Kitamura: Thank you for all your help during this 
project. Kakubo: You also helped me a lot during this period. We will work together in the same group.

I would like to thank all member, personnel department and material testing division, for all your support.

I would like to appreciate to Yokohama Rubber Co., LTD for giving me a great opportunity to study in the University of Twente and financial support during this project.

Dear Laurant, thank for being committee member of my project. We had a good discussion in the rubber conference. We will continue to discuss the silica technology.

I would like to thank Prof. Eising, Prof. Prof. and Prof. for being my graduation committee.

I would like to thank the secretaries of RBT/ETE group. Gerda, Aleida, Hillie and Yvonne, thank you for all your support during my project.

Dear Jacob, I really appreciate all your support not only in lab. but also in the private.

Dear all my colleagues, Montse, Francesca, Hongmei, Rui, Agata, Kannika, Anoma, Kuno, Wilco, Murek, Tony, and Mukund, I had a great time with my colleagues at the RBT/ETE group during my project. The Japanese evening, borrels, drinking party and the other group activities, these were my treasure time. Thanks for your friendship and all your support during my project.

Wilco and Agata, I really appreciate for being my paranimffs. Wilco: We had a rubber friction test by using the table tennis racket during lunch. We have leaned a lot of things about the rubber friction with the ping-pong ball. Agata: We had not only discussion the research but also a lot of jokes in our office. Many thanks for your friendship and support.

I would like to thank Japanese ladies who organized Japanese community in Enschede. From the beginning of my project, all of you took care of my family very well. Due to this, my family has easily adjusted to the Dutch life.

I would like to express my sincere thanks to my parents and parents-in-law. During my project you took care of my family a lot. Thank you for all your support during my project. I thank my parent for all your support as well. We had a fun to travel in the Netherlands during the summer holiday.

Dear Yuzuka, I am really glad to come here again with you. It will definitely remind you the great time in Enschede when you grow up.

Finally, dear Sakiko: We have shared the great time in the Netherlands. Without 
you generous and loving support, I would not have managed to complete this project. This memory which we spent together in the Netherlands will remain an asset for the future. Many thanks for all your understanding and support.

\section{Satoshi}


